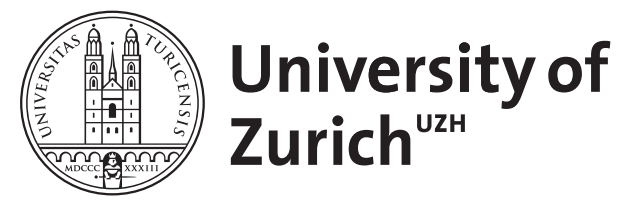

\title{
Kritik der Perspektive
}

Laleg, Dominique

\begin{abstract}
Die Linearperspektive ist in der künstlerischen Bildproduktion über Jahrhunderte ein wirkmächtiges Paradigma, bis sie in eine Krise gerät. Denn die ästhetische Moderne attackiert das hegemoniale Modell der perspektivischen Formgebung und macht die Perspektive zu einem Objekt der Kritik, von der angenommen wurde, dass sie Perspektivität überwinde. Anhand philosophischer Schlüsseltexte und mit Blick auf ausgewählte Werke von Rebecca H. Quaytman, Walid Raad, Bruce Nauman, Alberto Giacometti und Marcel Duchamp, entwickelt Dominique Laleg einen Begriff der Perspektive, welcher dem modernen Narrativ von deren Ende widerspricht. Denn gerade in der Kritik der Perspektive zeigt sich ihre Konjunktur als Modell, das sowohl in der modernen Theoriebildung als auch in der künstlerischen Praxis zum Tragen kommt. Laleg zeigt, wie die moderne Geschichte der Perspektive in den wirksamen Transformationen ihrer Form sowie der damit konstituierten Subjektivität besteht. Die moderne Kritik der Perspektive muss als Kritik mit den Mitteln der Perspektive selbst begriffen werden, denn Selbstkritik bildet den Knotenpunkt von Perspektive und Moderne.
\end{abstract}

DOI: https://doi.org/10.4472/9783035803884

Posted at the Zurich Open Repository and Archive, University of Zurich ZORA URL: https://doi.org/10.5167/uzh-205266

Monograph

Published Version

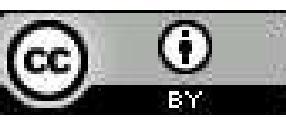

The following work is licensed under a Creative Commons: Attribution 3.0 Unported (CC BY 3.0) License.

Originally published at:

Laleg, Dominique (2021). Kritik der Perspektive. Zürich/Berlin: Diaphanes.

DOI: https://doi.org/10.4472/9783035803884 


\section{Dominique Laleg}

$$
\begin{aligned}
& \text { Kritik der } \\
& \text { Perspektive }
\end{aligned}
$$

DIAPHANES 
Dominique Laleg

Kritik der Perspektive

DIAPHANES 


\section{Publiziert mit Unterstützung von}

\section{FNDNF}

SCHWEIZERISCHER NATIONALFONDS

ZUR FÖRDERUNG DER WISSENSCHAFTLICHEN FORSCHUNG

ISBN 978-3-0358-0388-4

DOI $10.4472 / 9783035803884$

Dieses Werk ist lizenziert unter einer Creative Commons Namensnennung 3.0 Schweiz Lizenz.

Coverabbildung: Rebecca H. Quaytman, The Sun, Chapter 1, 2001, $50,8 \times 81,2 \mathrm{~cm}$, Siebdruck, Gesso auf Holz.

Layout, Satz: 2edit, Zürich

www.diaphanes.net 


\section{Inhalt}

$\begin{array}{ll}\text { Vorwort } & 7\end{array}$

Einleitung $\quad 9$

I Was (wenn überhaupt etwas) ist falsch an der Perspektive? 19

Die Perspektive relativieren 19

Modernistische Selbstkritik $\quad 24$

Anamorphotische Grenzgänge $\quad 29$

Die Perspektive wieder entdecken 36

II Dispositionen des Subjekts $\quad 47$

$\begin{array}{ll}\text { Die Perspektive neu verhandeln } & 47\end{array}$

Jenseits der Autonomie $\quad 49$

Eine Syntax für die Malerei $\quad 58$

Die Reflexivität des Dispositvs 63

$\begin{array}{ll}\text { Die Krisen des Subjekts } & 71\end{array}$

III Die Implosion der Perspektive $\quad 75$

Phänomenologie und Perspektive $\quad 75$

Was ist (k)ein Bild? $\quad 77$

Perspektive und Weltbild $\quad 93$

"malin dispositif« $\quad 97$

Von der Nichtung des Bildes $\quad 107$

Neutralität 115

IV Die Perspektive auf den Kopf stellen $\quad 119$

Perspektivische Depression 119

Augenrollen 133

$\begin{array}{ll}\text { Topologien der Projektion } & 137\end{array}$

V Inversionen der Kritik $\quad 151$

View from Inner to Outer Compartment 151

Bedroom Ensemble $\quad 161$

Die Dialektik der Autonomie 167 
VI Perspektive und Bewusstsein $\quad 179$

"Bis jemand kommt und mir sagt, wer ich bin« $\quad 179$

$\begin{array}{ll}\text { Der blinde Fleck } & 188\end{array}$

Bewusstseinskritik 193

VII Appositionen der Perspektive $\quad 203$

Die Perspektive als... 203

Das Modell »Perspektive« 206

Zur Geschichtlichkeit der Perspektive $\quad 224$

$\begin{array}{ll}\text { Schluss } & 235\end{array}$

$\begin{array}{ll}\text { Anhang } & 249\end{array}$

Abbildungsverzeichnis $\quad 249$

Literaturverzeichnis 255 


\section{Vorwort}

Die vorliegende Publikation wurde an der Philosophisch-Historischen Fakultät der Universität Basel als Dissertation vorgelegt. Ich danke Prof. Dr. Ralph Ubl und Prof. Dr. Claudia Blümle für die Betreuung und die Unterstützung während der gesamten Entstehungszeit dieses Textes. Mein Dank gilt auch den Mitarbeitenden des Nationalen Forschungsschwerpunktes Bildkritik - eikones der Universität Basel und vor allem meinen Kolleginnen und Kollegen des Moduls "Form und Bild in der Moderne«. Besonders bedanke ich mich bei Dr. Rahel Villinger, Dr. Fabian Grütter, Christoph Haffter, Gaudenz Metzger, Dr. Arno Schubbach, Martina Venanzoni sowie den Mitarbeitenden des Exzellenzclusters "Bild Wissen Gestaltung" der Humboldt Universität zu Berlin. Ebenfalls bedanke ich mich bei Prof. Dr. Sebastian Egenhofer und Lea Pelosi für die Unterstützung und das Interesse. Grundlegende Anregungen für das Projekt verdanke ich Prof. em. Dr. Gottfried Boehm, Prof. Dr. Emmanuel Alloa, Prof. em. Dr. Friedrich Teja Bach, Dr. Wolfram Pichler und Dr. Caroline Lillian Schopp. Anya Perse und Eliza Lips danke ich für ihre hilfreichen Lektüren und Martin Walti für die zahlreichen Lektionen im linearperspektivischen Zeichnen.

Die Realisierung und Publikation der vorliegende Dissertation wurden ermöglicht durch den Schweizerischen Nationalfonds (SNF), die Freiwillige Akademische Gesellschaft Basel (FAG), die Josef und Olga Tomcsik-Stiftung, den Dissertationenfonds der Universität Basel sowie durch die Basler Studienstiftung. 



\section{Einleitung}

Die Perspektive ist ein Gegenstand anhaltender sowie weitreichender Debatten. Seit ihrer Entstehung in der frühen Neuzeit als sogenannte Zentral-, Linear- oder Fluchtpunktperspektive beschäftigt sie nicht nur die bildenden Künstler und andere gestalterische Bildproduzenten, sondern ist ebenso ein Objekt der Theorie und insbesondere des philosophischen Denkens geworden. Die Persistenz, mit der sich die Perspektive bis heute als ein Objekt ästhetischer und philosophischer Diskussionen behauptet, steht dabei in starkem Kontrast zur verbreiteten antiperspektivischen Rhetorik der Moderne. Nicht nur wird in der modernen Malerei die perspektivische Konstruktion in Frage gestellt und ihre Weise der Raumbildung durch andere Mittel wie etwa die Farbe ersetzt, auch aus wissenschaftlicher Sicht gerät die Perspektive unter Druck. Moderne Theorien zum nicht-euklidischen Raum, physiologische Erkenntnisse zur menschlichen Sinneswahrnehmung und nicht zuletzt philosophische Theorien zur Wahrnehmung und Bildlichkeit stellen die Voraussetzungen der perspektivischen Darstellungs- und Wahrnehmungsweise auf vielfältige Weise in Frage. So hat sich ein Narrativ vom Ende der Perspektive etabliert, was beispielhaft in Fritz Novotnys Befund aus dem Jahr 1938 zum Ausdruck kommt, wenn er im Hinblick auf Cézannes Malerei schreibt: "Das Leben der Perspektive ist geschwunden, die Perspektive im alten Sinn ist tot. ${ }^{1}$

Die vorliegende Untersuchung hat ihrZiel darin, diese Geschichte vom modernen Untergang der Perspektive in Zweifel zu ziehen bzw. neu zu interpretieren. Was passiert mit der Perspektive im zwanzigsten Jahrhundert? Sie als tot zu beschreiben, scheint angesichts ihrer Präsenz nicht überzeugend. Paradoxerweise geht die moderne Nekropsie der Perspektive mit einer Nobilitierung einher, einer Nobilitierung, die ihr neuen Ruhm verleiht. Kaum je erhält die Perspektive mehr Aufmerksamkeit als in der Theorie des zwanzigsten Jahrhunderts, wo sie etwa für die Kunstgeschichte, die Philosophie, die Psychoanalyse, die Filmtheorie oder die Visual

1 Novotny, Cézanne und das Ende der wissenschaftichen Perspektive, 1938, S. 102. 
Studies, um nur einige zu nennen, zu einem bedeutenden Gegenstand wird. Diese Bedeutung der Perspektive als theoretisches Objekt $^{2}$ macht sich auch in der künstlerischen Praxis und ihren Produkten bemerkbar. Zwar tritt ihre normative Funktion als bildnerisches Mittel in den Hintergrund, jedoch wird sie von Künstlern als Modell in Anspruch genommen, mit dem unterschiedliche Anliegen im Hinblick auf Räumlichkeit, Darstellung und Situation des Betrachters bearbeitet werden.

Es scheint mir daher auch problematisch, von einem »Nachleben $\aleph^{3}$ der Perspektive in der Moderne zu sprechen, denn dies setzt die Prämisse voraus, dass die Moderne einhergeht mit dem Ableben der Perspektive. Entgegen dieser Annahme gehe ich in der vorliegenden Studie der Frage nach, inwiefern die Perspektive ein virulentes Objekt für die Moderne sowie die Gegenwart bleibt. Denn die Beziehung der Moderne zur Perspektive - so lautet meine These - ist nicht bloß als negative Ablehnung, sondern als kritische Auseinandersetzung zu verstehen. Der Terminus der Kritik ist deshalb geeignet, um diese besondere Weise der Auseinandersetzung mit der Perspektive zu beschreiben, weil er deren produktive Effekte zu benennen vermag und zugleich ein Paradigma der ästhetischen und philosophischen Moderne bildet. Weder meint Kritik die Verabschiedung der Perspektive, noch erschöpft sie sich in der Frage nach deren Richtigkeit. Kritik bezeichnet vielmehr einen so vielseitigen wie vielgestaltigen Prozess, mit dem eine engagierte Befragung der Perspektive, ihrer Voraussetzungen, Probleme und Möglichkeiten stattfindet.

Eine analytische Definition des Begriffs Kritik muss zwischen einer nicht-anspruchsvollen Kritik auf der einen Seite und einer anspruchsvollen Kritik auf der anderen Seite unterscheiden. Eine nicht-anspruchsvolle Kritik ist eine Tätigkeit, die zunächst darauf abzielt, Unterscheidungen zu treffen. Dabei können vermeintlich identische Entitäten unterschieden werden, was in einem weiteren Schritt ihre differenzierte Bewertung ermöglicht. Anspruchsvolle Kritik dagegen erschöpft sich nicht in der Unterscheidung

2 Damisch, Der Ursprung der Perspektive, 2010.

3 "A good deal has been written about the 'overthrow of perspective from the impressionists onward, but we still know little of the afterlife of perspective, which remains a ghostly presence throughout modernism." Elkins, Poetics of Perspective, 1994, S. 259. 
und Bewertung des Unterschiedenen, sondern wendet sich den eigenen Voraussetzungen zu, unter denen Kritik betrieben wird. Anspruchsvolle Kritik ist in diesem Sinn reflexive Kritik und sie ist daher immer Selbstkritik. In der vorliegenden Untersuchung gehe ich der Frage nach, inwiefern die Perspektive in der Moderne als Objekt einer nicht-anspruchsvollen bzw. einer anspruchsvollen Kritik im erläuterten Sinn auftritt. Es geht mir darum, an ausgewählten Beispielen der Kunst und Theorie zu zeigen, dass die moderne Kritik der Perspektive sich nicht in einer unterscheidenden und bewertenden Kritik erschöpft - einer Kritik an der Perspektive -, sondern dass sie auch eine reflexive Kritik ist - eine Kritik mit der Perspektive. Die dabei zentrale Frage lautete: Wie wird die moderne Kritik der Perspektive mit den Mitteln der Perspektive selbst geleistet?

Eine Schwierigkeit dieser Frage liegt darin, dass die Kritik der Perspektive nicht innerhalb eines begrenzten Gegenstandsbereichs stattfindet. Bei der Kritik der Perspektive handelt es sich vielmehr um einen Prozess, der weder einer einzelnen Disziplin noch einer gesicherten Methode verpflichtet ist. Zu ihrer Prozessualität gehört vielmehr, dass sie sich über die Grenzen von Gegenstandsbereichen hinausbewegt. In der vorliegenden Studie thematisiere ich drei dieser Gegenstandsbereiche: die visuelle Wahrnehmung, deren Bedingungen die Perspektive zu erklären bemüht ist, die bildliche Formgenese, die durch die Perspektive ermöglicht wird, und schließlich das philosophische Denken, das von der Perspektive und ihren Bedingungen in vielseitiger Weise angeregt wird. Dass diese drei Gegenstandsbereiche gemeinsam den Entstehungs- und Diskussionsherd der Perspektive ausmachen, ist evident. Es wird zu klären sein, wie die Perspektive diese drei Pole miteinander in Beziehung setzt und welche Bedeutung diese Inbeziehungssetzung für die moderne Kritik der Perspektive hat.

Als derartiger Prozess findet die Kritik der Perspektive - sei es nun im nicht-anspruchsvollen oder im anspruchsvollen Sinn innerhalb eines sie mitbestimmenden historisch-intellektuellen Rahmens statt. Wie eine Vielzahl von Kritiken erlebt sie in der Moderne ihre historisch wichtigste Entwicklungsperiode. Es ist kein Geheimnis, dass reflexive Kritik seit Ende des achtzehnten Jahrhunderts zu einer theoretischen und ästhetischen Leitfigur 
in der europäischen Geistesgeschichte geworden ist. ${ }^{4}$ Innerhalb dieses kulturellen, historischen und intellektuellen Biotops formt sich moderne Kritik an diversen Gegenständen und auf unterschiedliche Weisen. Etwa als Machtkritik, als Vernunftkritik, als Religionskritik, als Ideologiekritik, als Metaphysikkritik, als Universalismuskritik, als Subjektkritik, als Medienkritik, Repräsentationskritik, Kapitalismuskritik usw. Es geht mir u.a. darum, über die Verknüpfungen zwischen der Kritik der Perspektive und diesen anderen Ausformungen der modernen Kritik nachzudenken. Es sind die Kreuzungspunkte innerhalb dieser Verflechtungen moderner Kritiken, die meine historische Logik bilden und die ich als einzelne Momente der Geschichte der Kritik der Perspektive gezielt aufgreife und untersuche. Dass diese untersuchten Momente jeweils unter spezifischen historischen, künstlerischen und intellektuellen Voraussetzungen stattfinden, versteht sich von selbst. Diese Voraussetzungen sollen so weit wie nötig rekonstruiert und bedacht werden.

Der Umstand, dass die Kritik der Perspektive nicht auf einen eingegrenzten Gegenstandsbereich beschränkt ist, dass die untersuchten Momente vielmehr immer Knotenpunkte sind, in denen künstlerische Praxis und Theorie auf bisweilen untrennbare Weise miteinander verbunden sind, schließt eine einseitige Hinwendung der Untersuchung zu einer dieser beiden Seiten aus. Die Bedeutung der Perspektive in der Moderne kann weder ausschließlich im Hinblick auf künstlerische Phänomene oder deren praxiologische Untersuchung ermessen werden noch mittels einer rein theoretischen Rekonstruktion philosophischer Thesen. Vielmehr ist es nötig, beide in ihrem Wechselspiel zu analysieren und dieses Wechselspiel systematisch zu rekonstruieren. Die Kritik der Perspektive erzeugt Effekte, die sich sowohl in der Theorie, als auch in konkreten Werken bemerkbar machen. Dabei können weder die gestalterischen Praktiken und Produkte unabhängig von den sie hervorbringenden Diskursen der Theorie untersucht werden, noch können die theoretischen Diskurse losgelöst von den singulären Objekten analysiert werden, an denen sie sich formen, schärfen und etablieren. In diesem Sinn wäre es ein anderes Unternehmen,

4 Vgl. dazu: Villinger, "Form und Mimesis. Elemente frühromantischer Kunsttheorie bei Husserl, Benjamin und Adorno«, 2015, S. 277-298. 
wollte man die Bedeutung des Perspektivismus in der Philosophiegeschichte nachzeichnen ${ }^{5}$ oder etwa eine Geschichte des Bildraums in der Malerei erzählen. ${ }^{6}$ Mein Anliegen besteht im Grunde gar nicht darin, eine Geschichte zu erzählen, sondern vielmehr durch die Untersuchung exemplarischer Inanspruchnahmen der Perspektive das Zusammenspiel zwischen Werken und Theorien zu rekonstruieren. Damit wird es möglich sein, bestehende Narrative zu hinterfragen und das besondere Schicksal der Perspektive in der Moderne zu interpretieren.

Der gewählte Zeitraum, der sich vom Beginn des zwanzigsten Jahrhunderts bis ins frühe einundzwanzigste Jahrhundert erstreckt, ist dabei weniger als eine historische Linie gedacht, sondern mehr als ein geschichtlich-intellektuelles Gefäß, in dem das Arbeiten über und mit der Perspektive stattfindet. Dieses Arbeiten, von dem man behaupten könnte, es sei im Kern vor allem ein Denken, ist weder linear oder teleologisch ausgerichtet, noch lässt es sich mit den Mitteln einer historischen Chronologie angemessen beschreiben. Wie ich zeigen werde, basiert die kritische Arbeit an der Perspektive u. a. auf überraschenden Rückgriffen, Umkehrungen, Umstülpungen und Transformationen, die zwar einerseits mit ihrem jeweiligen historischen Kontext zusammenhängen, zugleich aber an Fragen und Problemen arbeiten, die über die historische Faktizität des Phänomens hinausführen. Es kann daher möglich sein, dass die eine oder andere Beziehung von Werken aus Kunst und Philosophie auf den ersten Blick historisch disparat erscheinen mag, was nichts anderem als meinem systematischen Interesse verpflichtet ist.

Wie kann man das populäre Narrativ des Untergangs der Perspektive widerlegen? Indem man nachweist, dass die kritischen Ambitionen der Moderne im Zusammenhang mit der Perspektive zahlreiche produktive Effekte erzeugt haben. Dabei werde ich selbst Kritik üben, nämlich dort, wo die moderne Kritik an der Perspektive es verpasst, deren kritisch-reflexives Potential zu erkennen und zwecks eigenen Interessen einzusetzen - sprich dort, wo sie in einer nicht-anspruchsvollen Kritik an der Perspektive verhaftet bleibt. Ich werde zeigen, dass die Moderne gelegentlich 
unnötigerweise die Perspektive aus dem Register ihrer kritischen Mittel ausschließt. Ebenso geht es mir darum, das populäre Bild der Perspektive als eines starren und unbeweglichen Objekts zu revidieren. Die Perspektive ist ein Gegenstand, dessen Wirkungsweisen und Möglichkeiten nicht endgültig bestimmt und fixiert sind. Ich werde demonstrieren, wie gerade im Prozess der Kritik die orthodoxen Grenzen der Perspektive überwunden werden, von denen man sie determiniert geglaubt hat. Die Bedeutung der Kritik der Perspektive, so schlage ich vor, sollte am Gehalt ihrer Möglichkeiten ermessen werden.

Selbstverständlich erhebe ich nicht den Anspruch, die weitreichenden Bedeutungen der Perspektive, ihre epistemologischen, historischen und bildnerischen Implikationen vollständig aufzuzeigen, geschweige denn abschließend zu klären. Mein Projekt verfolgt vielmehr das Anliegen, auf der Basis einzelner Werk- und Textanalysen eine Konzeption der Perspektive zu erarbeiten, die es erlaubt, das Fortleben der Perspektive in der Kunst der Moderne und bis zur Gegenwart so zu begreifen, dass ihre zahlreichen Variationen und Wirkungsweisen in und zwischen den oben erwähnten Gegenstandsbereichen bedacht und besser verstanden werden. Dabei ist die Auswahl der behandelten Positionen naturgemäß selektiv, da es angesichts der ausufernden Thematik unmöglich ist, alle relevanten Thesen, Theorien und Kunstwerke zu berücksichtigen, die sich im zwanzigsten Jahrhundert mit der Perspektive beschäftigen. Was die Theorie betrifft, habe ich mich entschlossen, einer weitgehend phänomenologischen Tradition der Perspektivkritik zu folgen, was mir einerseits dazu dient, den sonst schier unendlichen Umfang der Thematik zu begrenzen und andererseits prägnante Positionen der phänomenologisch geprägten Kunstgeschichte gründlich zu durchleuchten. Den Preis, den ich für diesen Schwerpunkt entrichte, ist die Ausklammerung gewisser Diskurse - etwa Jacques Lacans Beschäftigung mit der Anamorphose $^{7}$-, die zwar gewichtige Beiträge zum Thema bilden, hier jedoch zugunsten anderer Protagonisten der Diskussion nicht behandelt werden.

7 Zu einer kritischen Darstellung der Wahrnehmungstheorien Lacans siehe: Jay, Downcast Eyes. The Denigration of Vision in Twentieth-Century French Thought, 1994, S. $329 \mathrm{ff}$. 
Einen weiteren Akzent setze ich auf die Untersuchung der Wirkungsweise der Perspektive in und zwischen den unterschiedlichen Gegenstandsbereichen von Wahrnehmung, Kunst und Philosophie. Zu diesem Zweck werde ich Hubert Damischs Vorschlag,

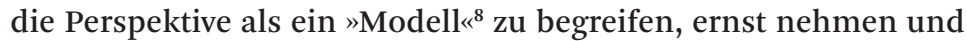
ihren Modellcharakter systematisch untersuchen. Welche Konsequenzen ergeben sich für die Bedeutung der Perspektive in der Moderne, wenn man sie als ein Modell begreift, das in der bildenden Kunst sowie in der Theoriebildung auf kritische Weise in Anspruch genommen wird? Was bedeutet es, künstlerische Arbeit an der Perspektive als Arbeit an einem Modell für das Denken zu verstehen?

Das Konzept des Modells, das in Damischs Perspektiv-Buch stellenweise dunkel bleibt, erhelle ich u.a. mit Hilfe der systematischen Überlegungen Bernd Mahrs, der kurz vor seinem frühen Tod in Berlin, überzeugende Ansätze einer Modelltheorie entworfen hat. ${ }^{9}$ Wenn ich den Fokus auf den - wie zu zeigen sein wird - vielfältigen Modellcharakter der Perspektive richte, dann vor allem, um der faktischen Bedeutung und Wirkung der Perspektive in Kunst und Theorie gerecht zu werden. In diesem Sinn muss die Frage, ob die Perspektive, wie Ernst Gombrich meint, den Bedingungen der natürlichen Wahrnehmung entspricht, oder ob es sich bei ihr um eine Konvention handelt, wie Nelson Goodman behauptet, anders gestellt werden:10 Was macht die Perspektive zu jenem wirkmächtigen Objekt, das auch nach über einem halben Jahrtausend nach seiner Entstehung scharfsinnige Denker des zwanzigsten Jahrhunderts zu regen Debatten, elaborierter Theoriebildung und künstlerischer Arbeit anregt?

Um diesen Fragen nachzugehen, ist es dringend notwendig, die Perspektive als wirkmächtiges Objekt in der ästhetischen Moderne ernst zu nehmen. Wenn ich von ihrer Wirkungsmacht spreche,

8 Damisch, Der Ursprung der Perspektive, 2010, S. 19.

9 Mahr, Ein Modell des Modellseins, 2008.

10 Gombrich, Art and Illusion, 1984, dort Kapitel VIII, S. 194-232. Goodman, Sprachen der Kunst. Entwurf einer Symboltheorie, 1997, S. 21-30. Lambert Wiesing hat diese Diskussion vor kurzen wiederaufgenommen, um eine pragmatistische Theorie der Perspektive zu umreißen: Wiesing, Sehen lassen. Die Praxis des Zeigens, 2013, S. 141-179. 


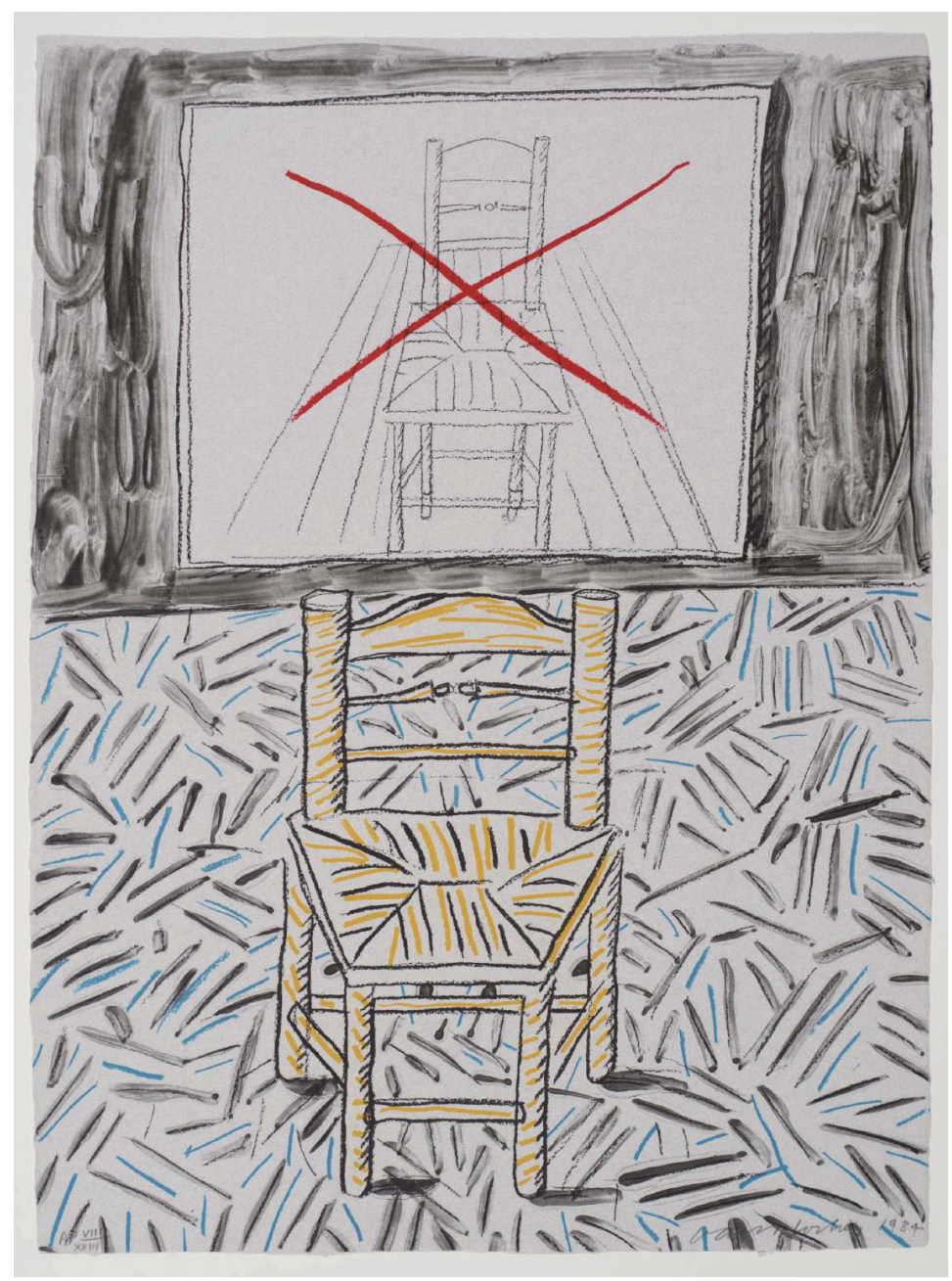

Abb. 1: David Hockney, The Perspective Lesson, 1984, Lithographie auf Papier.

dann meine ich damit nicht ihre gleichsam emblematische Funktion innerhalb einer bisweilen polemischen Rhetorik (Abb. 1). Derartige nicht-ernsthafte Kommentare verfehlen die eigentliche Tragweite der Perspektive in der Moderne, die sich nicht darin erschöpft, mittels systematisch konvergierender Linien einen Raum darzustellen, auch wenn darin ihr pragmatischer Ursprung 


\section{Think of this-as a Winclow..}

Abb. 2: Cerith Wyn Evans, Think of this as a Window, 2005, Neonschrift.

liegt. Die Bedeutung der Perspektive in der Moderne zeigt sich oftmals dort, wo sie nicht in buchstäblicher Weise in Erscheinung tritt (Abb. 2). Man kann diese Wirkungsweise, wie etwa Goodman, als Effekt einer bloßen Konditionierung behandeln, oder man kann nach den Gründen und Bedingungen des Fortlebens der Perspektive fragen. 



\section{Was (wenn überhaupt etwas) ist falsch an der Perspektive?}

\section{Die Perspektive relativieren}

Die Physiologie des neunzehnten Jahrhunderts bildet die erste gravierende Wende in der modernen Bedeutungsgeschichte der Perspektive. Ihre Erkenntnisse und nicht zuletzt die auf der Basis dieser Erkenntnisse entwickelten Apparate verändern das Verständnis der menschlichen Wahrnehmung maßgebend. Diese Veränderung wird in der Wissenschaftsgeschichte der foucaultschen Tradition prominent als Bruch besprochen und markiert so gesehen auch eine Zäsur in der westlichen Bildgeschichte. ${ }^{1}$ Die zunehmenden Erkenntnisse und die Bedeutung der Physiologie als Bruch mit den Modellen der klassischen Repräsentation der Wirklichkeit zu besprechen heißt auch, die Physiologie als Kritik an der Perspektive zu verstehen. Diese Kritik beruht dann wesentlich in der Falsifizierung der perspektivischen Darstellungsweise und zwar durch kritische Vergleiche mit biologischen Bedingungen des menschlichen Sehapparates. Ein zentraler Kritikpunkt, den die Physiologie dabei gegen die Perspektive richtet, lautet: Das perspektivisch konstruierte Bild ist ungenügend bzw. ungenau, weil es sich bei seinem angeblichen Vorbild und Analogon, dem sogenannten Netzhaut- oder auch Retinabild, um eine Projektion auf eine konkave Fläche handelt und nicht, wie es in der üblichen perspektivischen Konstruktion der Fall ist, um eine plane Fläche. Daraus folgt, dass das sogenannte Netzhautbild Kurvaturen aufweist, die das perspektivisch konstruierte Bild ignoriert. Eine viel rezipierte Studie zu diesem Problem bieten die Untersuchungen Guido Haucks, der mit dem Konzept der kurvilinearen Perspektive ein Mittel entwickelt hat, das die adäquate Übertragung biologischer Sehbedingungen auf die Formgebung des Bildes verspricht

1 Dazu Crary, Techniken des Betrachters, 1996; sowie Brain, The Pulse of Modernism, 2015. 

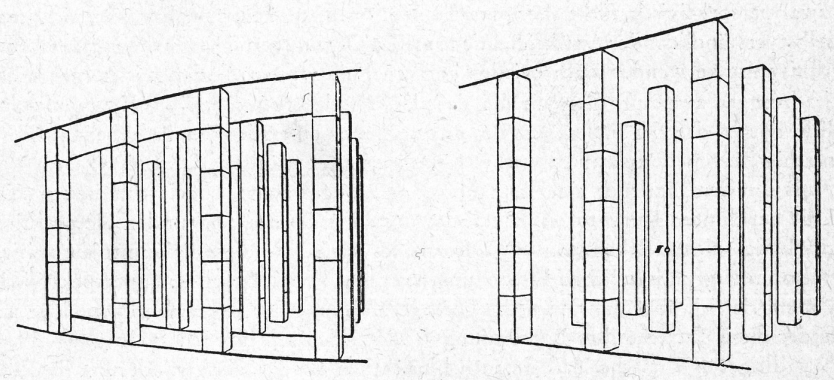

Abb. 1: Guido Hauck nach Panofsky, Pfeilerhalle, konstruiert gemä $\beta$ der subjektiven (Kurven-)Perspektive (links) und der schematischen (Plan-) Perspektive (rechts), 1927.

(Abb. 1). ${ }^{2}$ Obschon die Netzhautbild-Kritik des perspektivischen Bildes eine lange Geschichte besitzt, die bis zu den Ursprüngen der Perspektive zurückführt, ${ }^{3}$ ist für unser Interesse vor allem entscheidend, dass sie noch in jenen Überlegungen eine zentrale Rolle spielt, die bis heute das Fundament dessen bilden, was man als moderne Perspektivkritik bezeichnen kann.

Erwin Panofsky wird in seinem ursprünglich als Vortrag konzipierten Text Die Perspektive als symbolische Form ‘ die physiologische Argumentation Haucks aufnehmen, fortschreiben und damit eine theoretische Grundlage der modernen Perspektivtheorie formulieren. ${ }^{4}$ Panofskys Ergänzungen der Netzhautbild-Kritik sind untrennbar mit seinem Ort in der Geschichte des Denkens verbunden, der sich als psychologistisch, historisierend und zugleich als neukantianisch beschreiben lässt. Auch Panofsky gilt ein vermeintlich natürliches Sehen als absolute Referenz, mit der sich die perspektivische Darstellungsform messen muss. Doch obschon sich Panofsky explizit auf Hauck beruft, spielt für ihn nicht einzig die Anatomie des Auges, sondern auch die psychologische Interpretation der bewussten Wahrnehmung eine zentrale Rolle bei

2 Hauck, Die subjektive Perspektive und die horizontalen Curvaturen des dorischen Styls, 1879.

3 Siehe etwa Chastel, Leonardo Da Vinci. Sämtliche Gemälde und die Schriften zur Malerei, 1990, S. 241f.

4 Panofsky, »Die Perspektive als `symbolische Form«, 1974. 
der Entstehung des subjektiven Seheindrucks. Die Zusammensetzung dieser beiden Bedingungen führt dazu, dass Panofsky vom "psychophysiologischen Raum" der Wahrnehmung spricht. ${ }^{5}$ Diese symptomatischen Begrifflichkeiten verweisen nicht nur auf die hegemonialen Modelle der Wahrnehmung des ausgehenden neunzehnten und frühen zwanzigsten Jahrhunderts, sondern auch auf jenen Parameter, an dem sich die historische Bedeutung der Renaissanceperspektive für Panofsky ermessen lässt: der Raum. Panofsky skizziert entlang mehrerer Epochen eine dialektische Geschichte des Bildraums, in welcher er zugleich die abendländische Geistesgeschichte erkennen will. Eine Raumanschauung, so seine Hypothese, hängt stets mit einer Weltanschauung zusammen. Die Problematik und Undeutlichkeit dieses Zusammenhangs, den Panofsky mit einem Hinweis auf Ernst Cassirers Philosophie der symbolischen Formen zu klären glaubt - ihn damit aber eher verunklärt -, können hier nicht genauer behandelt werden. ${ }^{6}$ Festgehalten werden soll aber, dass die Perspektive als Moment einer dialektischen Ideengeschichte begriffen wird, die unter dem Einfluss physiologischer sowie psychologischer Bedingungen zum Gegenstand einer relativierenden und mitunter historisierenden Kritik wird. Demnach ist die perspektivische Bildform nicht nur dahingehend zu kritisieren, dass sie der erlebten visuellen Wahrnehmung nicht gerecht wird, sie ist zudem bloß eine historisch bedingte Weise der Darstellung unter vielen.

Die physiologische sowie die historisierende Kritik an der perspektivischen Form, die sich in Panofskys Aufsatz verbinden, teilen die Gemeinsamkeit, dass sie die Perspektive zum bloßen Objekt der Kritik reduzieren. Die physiologische Position formuliert ihre Kritik scheinbar im Ausgang von einem der Perspektive prinzipiell externen Standpunkt, dem der Physiologie. Sie scheint insofern legitim, als sie diesen Standpunkt deutlich macht und aus der damit erzeugten Distanz Kritik übt. Ob sie diese Distanz tatsächlich einhält, wird jedoch fraglich, wenn man ihre Prämissen genauer analysiert, die möglicherweise ihrerseits mit der Perspektive verquickt sind; bedenkt man, dass die Argumentation der Netzhautbild-Kritik wesentlich darauf beruht, dass das Perspektivbild dem

6 Dazu Alloa, »Ist die Perspektive eine symbolische Form?«, 2010, S. 13-27. 
Netzhautbild nicht in korrekter Weise entspricht. Dies setzt voraus, dass es sich bei der Ansammlung gebündelten Lichts auf der Netzhaut überhaupt um so etwas wie ein Bild handelt, was wiederum nicht nur den Gegenstandsbereich der Physiologie und Optik übersteigt - denn diese kennen überhaupt keine Bilder im engeren Sinn -, sondern zudem voraussetzt, dass der Sehvorgang des Auges ein Vorgang von bzw. mit Bildern ist. Nun fällt die früheste bildtheoretische Konzeption des Sehvorgangs als einem quasi-piktoralen Prozess und die damit überhaupt ermöglichte Idee einer Äquivalenz zwischen Sehbild und artifiziellem Bild aber nicht zufällig mit dem theoretischen Gründungsakt der Perspektive im 15. Jahrhundert zusammen. Albertis De pictura (1535/36) ist eines der ersten uns bekannten Dokumente, das die Vorstellung formuliert, das Auge sehe in Bildern, und zwar in unmittelbarem und explizitem Zusammenhang mit der perspektivischen Konstruktion. ${ }^{7}$ Dagegen sind die für Alberti zugrunde liegenden Traktate der Optik (allen voran Euklid, Ptolemäus und Alhazen) keine expliziten Theorien des Bildes, sondern Theorien der visuellen Wahrnehmung. Diese antiken bzw. mittelalterlichen Sehtheorien begreifen das finale Gelingen des Sehvorgangs und damit die Bedingung der Bildwerdung stets in Abhängigkeit von der vielschichtigen, ambivalenten und aktiven Imagination als einem Vermögen, das in der Subjektphilosophie als Einbildungskraft bezeichnet wird und die anatomischen Bedingungen des Auges bei weitem überschreitet. ${ }^{8}$ Wenn aber Albertis Theorie der Perspektive zu den ersten gehört, die überhaupt so etwas wie ein Sehbild konzipiert - um dann das perspektivisch konstruierte Bild als dessen Äquivalent zu bestimmen -, so dreht sich die Argumentation der modernen Netzhautbild-Kritik im Kreis. Denn in diesem Fall formuliert sie ihren zentralen Kritikpunkt an der Perspektive ausgerechnet in Berufung auf das Paradigma der Perspektive - eine seltsame Sachlage, die für die Beziehung von Kritik und Perspektive möglicherweise symptomatisch ist.

Mit Panofskys Kritik scheint sich die Sache zu verkomplizieren, denn er erkennt jene in seiner Deutung ’psychologischen $>$ Prozesse

7 Alberti, "De pictura «, 2000.

8 Dazu auch Simon, Archéologie de la vision, 2003; sowie Simon, Le regard, l'être et l'apparance dans l'Optique de l'Antiquité, 1988. 
und Voraussetzungen an, die sich zwischen den affizierenden Lichtstrahlen auf der Netzhaut und der bewussten Wahrnehmung abspielen. Die für unsere Fragestellung relevanten Überlegungen liegen daher auch nicht in Panofskys Konzept der psychophysiologischen Wahrnehmung, sondern in der Makrostruktur seiner Argumentation. Panofskys Schlussüberlegungen, die er im vierten und letzten Teil seines Textes formuliert, zeigen, dass er die Renaissanceperspektive als systematische Verschränkung des Objektiven mit dem Subjektiven begreift und in ihr daher ein homologes Äquivalent der Transzendentalphilosophie erkennt. Der perspektivisch konstruierte Bildraum wird hier als eine symmetrische Synthese von rationalem und empirischem Raum verstanden, eine Art systematisches Konglomerat von theoretischem Idealraum und subjektiv erschlossenem Wahrnehmungsraum.

So gesehen besitzt die Perspektive für Panofsky im doppelten Sinn Modellcharakter. Denn perspektivische Bilder sind modellhafte Darstellungen der Wahrnehmungsbilder und -räume, insofern sie diese in abstrahierter Weise wiedergeben. Die Perspektive ist aber auch ein epistemologisches Modell, da der durch sie erzeugte Bildraum als Analogon der subjektiven Erscheinungswelt begriffen wird. Diese zweite Analogie fußt auf der kantianischen Prämisse, dass die phänomenale Welt ’bloße Vorstellung eines Subjekts ist und dennoch der kategorialen Regelhaftigkeit des Verstandes folgt, mithin in ihrer Erscheinungsweise berechenbar ist. Dieses transzendentalphilosophische Prinzip einer Quasiverschränkung von Subjektivität und Objektivität sieht Panofsky in der Renaissanceperspektive vorweggenommen.

Blickt man von hier auf die Argumentation des gesamten Texts zurück, stellt sich die Frage, ob Panofskys ideengeschichtlicher Begriff der 'Weltanschauung`, mit dem er die Perspektive einer historisierenden und damit relativierenden Kritik unterwirft, nicht eben diesem epistemologischen Modell des Kantianismus verpflichtet ist - ob die Idee von so etwas wie -Weltanschauung erst auf der Basis jener spezifischen Subjekt-Objekt-Konstellation sowie einer damit einhergehenden epistemologischen Rehabilitation der Anschauung durch Rationalisierung möglich wird. Dies würde jedoch bedeuten, dass der gesamte konzeptuelle Überbau des Textes, der eine wechselseitige Beziehung zwischen bildlicher Darstellung und (Welt)Anschauung postuliert - eine Beziehung, 
die Panofsky als bildgeschichtliche Konstante voraussetzt -, letztlich in der Perspektive als einem epistemologischen Modell gründet. Die historisierende Kritik der Perspektive, die auf einer radikalen Relativierung derselben beruht, verliert jedoch ihre Kraft, um nicht zu sagen: ihren Sinn, wenn deutlich wird, dass man für das vorperspektivische Zeitalter keine dialektische Geschichte der Perspektive schreiben kann, ohne sich auf die Perspektive als quasiüberhistorischen Referenzpunkt zu beziehen.

Es wird deutlich, dass sowohl die physiologische als auch die historisierende Kritik an der perspektivischen Formgebung einer Problematik aufsitzt, die mit der Perspektive und ihrer komplexen Bedeutung unmittelbar zusammenhängt - und zwar nicht bloß für die Form piktoraler Darstellung, sondern ebenso für die Form des Denkens. Denn die wissenschaftliche Kritik der Perspektive scheint hier selbst mit den Mitteln der Perspektive zu denken, indem sie ihre Prämissen voraussetzt, ohne dies zu merken. So gesehen ist dieses Denken von der Perspektive selbst informiert, was letztlich darauf hinweist, dass Kritisiertes und Kritisierendes miteinander verwoben sind. Doch worauf verweist diese Verwicklung und damit die Problematik, dass die Kritik der Perspektive dieser selbst nicht entkommt? Deutet der Umstand, dass ausgerechnet die prominentesten Perspektivkritiker der Moderne ihre Kritik an der Perspektive zugleich mit der Perspektive formulieren, möglicherweise auf ein der perspektivischen Form innewohnendes kritisches Vermögen?

\section{Modernistische Selbstkritik}

Will man die schwierige Beziehung der Moderne zur Perspektive besser verstehen, kommt man nicht umhin, diese Beziehung im Hinblick auf die Bedeutung von 'Kritik zu befragen. Im Zusammenhang mit der Entwicklung der bildenden Künste im zwanzigsten Jahrhunderts bildet die Kunsttheorie Clement Greenbergs dabei ein besonders geeignetes Objekt der Analyse, denn sie verbindet drei Elemente, die für die hier vorliegende Fragestellung relevant sind: Erstens formiert Greenbergs Theorie, die in der Mitte des zwanzigsten Jahrhunderts entsteht, die malereigeschichtlichen Entwicklungen des neunzehnten und frühen zwanzigsten 
Jahrhunderts zu einem einflussreichen Narrativ, das vor allem für die spätmodernistische Malereiproduktion und -rezeption maßgebend sein wird; zweitens erlaubt der formalistische Charakter seiner Theorie, die Rolle der Perspektive zu bestimmen; drittens sind diese historisch bedeutende Narrativbildung und ihre formalistischen Kriterien auf dezidierte Weise mit einer Konzeption von Kritik verknüpft - einer Kritik, die auch ausdrücklich eine Kritik der perspektivischen Formgebung ist und das moderne Verständnis der Perspektive entscheidend prägen wird.

Greenberg entwickelt ab Mitte des zwanzigsten Jahrhunderts eine Gruppe von Kriterien, die für den Fortgang modernistischer Formparadigmen so bedeutsam wie problematisch sein werden. ${ }^{9}$ Diese Kriterien lassen sich auf drei grundlegende Momente reduzieren, die sich als drei zusammenhängende Hypothesen erweisen.

Erstens das Kriterium kritischer Reflexion, das Greenberg unter anderem im Rekurs auf Kants kritische Philosophie entwickelt. Das Wesen des Modernismus liegt demnach in seinem kritischen Selbstbezug, wobei die Methode eines bestimmten Gegenstandsbereichs in kritischer Weise auf sie selbst angewendet wird, um ihre eigene Legitimität zu prüfen bzw. zu stärken. Für den Gegenstandsbereich der Kunst bedeute dies zunächst, dass die künstlerischen Verfahrensweisen selbst zum Gegenstand der Kunst avancieren. ${ }^{10}$

Von dieser zunächst systematischen These geht Greenberg zu seinem zweiten und dabei formalistischen Kriterium über, nämlich der Bestimmung dessen, was künstlerische Verfahrensweisen sind. Denn diese, so wird im Text "Avantgarde und Kitsch" erläutert, ${ }^{11}$ sind nichts anderes als die gestalterischen Verfahrensweisen des jeweiligen "Mediums", d.h. im Fall der bildenden Künste das »Finden und Ordnen von Räumen, Flächen, Formen, Farben etc. ${ }^{12}$ Kritische Selbstreflexion kommt in der Praxis der bildenden Kunst also dadurch zum Tragen, dass diese ein "Nachahmen

9 Greenberg, "Zu einem neuen Laokoon«, 2009.

10 Ebd., S. 267.

11 Greenberg, "Avantgarde und Kitsch«, 2009.

12 Ebd., S. 35. 
des Nachahmens« vollzieht und damit ihre eigenen Mittel, die als Gestaltungsmittel bestimmt werden, befragt und exponiert. ${ }^{13}$

Bis zu diesem Punkt müsste die Perspektive kein prinzipielles Problem für die avantgardistische Praxis werden, denn es ist nicht einsichtig, weshalb ein kritischer Selbstbezug sowie eine Reflexion ihrer gestalterischen Verfahrensweisen prinzipiell nicht möglich sein sollen. Mit Greenbergs dritter und materialistischer Hypothese ändert sich dies jedoch, und zwar indem er seine Bestimmung des Mediums weiter zuspitzt. Dieses wird nicht mehr bloß mit den gestalterischen Verfahrensweisen im weitesten Sinne in Verbindung gebracht, sondern zunehmend an die materiellen Eigenschaften der jeweiligen Gattung gebunden. Für die Malerei bedeutet das schließlich, dass die Materialität des Bildträgers zum virulenten Bestandteil kritischer Reflexivität des Modernismus wird. Greenberg glaubt jene Virulenz in einer "neue[n] Flächigkeit « zu erkennen, die seit Gustave Courbet Einzug in die Malerei gehalten habe und seither eine zunehmende Anerkennung innerhalb der Disziplin gewinne. ${ }^{14}$ Diese historisch zunehmende Anerkennung und Betonung hat gleichsam teleologischen Charakter und erfährt für Greenberg in der abstrakten Malerei und insbesondere in jener der amerikanischen Nachkriegszeit eine Art Höhepunkt.

Dieses dritte Kriterium ist von besonderer Tragweite im Hinblick auf die Perspektive. Denn das malerische Medium wird nicht mehr bloß als Dispositiv bestimmt, bestehend aus den unterschiedlichsten gestalterischen Verfahren, die in ihrer Art und Anzahl prinzipiell unbegrenzt und beliebig sind, sondern es wird nun mit dem materiellen Substrat des Bildes identifiziert. Die Avantgarde zeichnet sich folglich dadurch aus, dass sie die »Undurchdringlichkeit der Bildoberfläche" anerkennt und dieser dezidiert "materiellen Flächigkeit" Ausdruck verleiht. ${ }^{15}$ Unter dieser Prämisse kommt Greenberg schließlich dazu, die künstlerische Praxis der Avantgarde als Antithese der perspektivischen Formgebung und den durch sie erzeugten illusionistischen Raum folgendermaßen zu beschreiben:

14 Greenberg, "Zu einem neuen Laokoon«, 2009, S. 66.

15 Ebd., S. 76. 
"Die Geschichte der Avantgarde-Malerei ist die Geschichte ihrer schrittweisen Anerkennung der Widerständigkeit ihres Mediums, welche hauptsächlich darin besteht, dass die plane Bildfläche den Versuchen widersteht, sie zu einem realistischen perspektivischen Raum hin zu durchstoßen «. ${ }^{16}$

Ohne Greenbergs Konzeption bzw. Narrativ der modernistischen Repräsentationskritik sowie dessen Folgen und Probleme für die Praxis und Theorie der Malerei weiter zu erörtern, lässt sich festhalten, dass auf der Basis der drei geschilderten Hypothesen eine explizite Kritik der Perspektive artikuliert wird. Diese wird für Greenberg zum grundsätzlichen Gegenspieler reflexiver Kritik und damit des Modernismus schlechthin. Dabei unterscheidet sich Greenbergs Kritik der Perspektive vor allem dahingehend von Panofskys Kritik, dass sie ihre Kriterien nicht auf der Basis einer gelingenden Äquivalenzbeziehung zwischen Perspektivbild und einem vermeintlich natürlichen bzw. erlebten Wahrnehmungsbild entwickelt. Im Gegensatz zu dieser an Richtigkeit interessierten Kritik baut Greenberg auf einer Logik auf, die man als selbstreflexiven Kritizismus beschreiben könnte, und den er als formtheoretisches Paradigma für die Moderne Malerei einsetzt. Dieser Unterschied markiert eine wichtige Entwicklung der späten ästhetischen Moderne, die sich und ihre Paradigmen zunehmend vom Bereich der Wissenschaft abtrennen will. Dabei wird die Perspektive nicht deshalb zum Objekt der Kritik, weil ihre Ergebnisse ungenügende Äquivalente des wissenschaftlich untersuchten Sehvorgangs sind, sondern weil scheint, als sei das perspektivische Bild nicht mit einem bestimmten Paradigma der Selbstkritik vereinbar. Genau diese Schlussfolgerung aber möchte ich anzweifeln, indem ich die Frage aufwerfe, ob Greenbergs Paradigmen die perspektivische Bildform möglicherweise zu Unrecht als Antithese einer reflexiven Kritik in seinem Sinn beurteilt. Natürlich hängt das Schicksal der Perspektive in der Moderne nicht einzig von dieser Beurteilung ab, jedoch hat die Tragweite von Greenbergs Modernismus-Konzeption das historische sowie theoretische Verständnis der Perspektive bis in die Gegenwart geprägt. Die Notwendigkeit dieser 
Beurteilung in Zweifel zu ziehen bedeutet daher auch über die Konstruktion eines größeren Narrativs nachzudenken, das unser Bild der Moderne mitbestimmt.

Ich möchte an dieser Stelle die Problemlage, die Greenbergs selbstreflexiver Kritizismus mit sich bringt, verdeutlichen: Ich folge Greenberg zunächst darin, dass der Modernismus als ein wesentlich kritisches, mithin emanzipatorisches Projekt zu verstehen ist, und erkläre mich insoweit einverstanden damit, als die Kritik, um die es geht, prinzipiell Selbstkritik ist. Ein starker Begriff von Selbstkritik setzt voraus, dass diese (selbst-)reflexiv verfasst ist. Dazu schreibt Greenberg: "[D]er Modernismus kritisiert von innen heraus und bedient sich dabei der Verfahren eben dessen, was er kritisiert. «17 $>$ Kritik` beschreibt hier nicht einfach die wahllose Beziehung zwischen einem kritisierenden Subjekt und einem kritisierten Objekt. Gemeint ist vielmehr eine selbstreflexive Kritik im engen Sinn: "von innen heraus« bedeutet, im Gegensatz zu einer Kritik von außen, dass das Subjekt und das Objekt der Kritik sich wechselseitig konstituieren. Diese intrinsische, wechselseitige Abhängigkeitsbeziehung führt zur schwierigen Frage, ob und wie eine derartige, dem Kunstwerk immanente Kritik, deren Ziel, mit Fried gesprochen, in der »überzeugenden Selbstbehauptung" des Werks liegen würde, gelingen kann. ${ }^{18}$ Es handelt sich hier im Grunde um ein logisches Problem, das sich Greenbergs Modernismus mit der Aneignung des metaphysischen Reflexionsparadigmas einhandelt. Dieses Problem liegt darin, eine Erklärung vorzulegen, wie die ernst zu nehmende Kritik eines Systems gelingen soll, wenn die Operatoren der Kritik aus dem zu kritisierenden System selbst stammen. Anders gefragt: Wie soll Kritik möglich sein ohne kritische Distanz, d.h. ohne externen Standpunkt des kritisierenden Subjekts, von dem her sich dieses überhaupt erst kritisch auf ein Objekt beziehen kann?

Wie bereits erläutert wurde, versuchen die Netzhautbild-Kritik und die historiographische Kritik der Perspektive, aus einer derart transzendenten Position heraus Kritik zu üben. Beide stellen die Legitimität der Perspektive von außen, d.h. von einem jeweils sys- 
temexternen Ort, etwa dem der Physiologie, infrage. Sie verstehen die Perspektive dabei nolens volens als bloßes Objekt der Kritik. Wenn das Paradigma des Modernismus jedoch als Reflexion im engeren Sinne konzipiert ist, stellt sich die Frage, wie es um die Perspektive als Subjekt der Kritik steht. Der modernistische Diskurs des zwanzigsten Jahrhunderts hat diese Frage in einem gewissen Sinn übergangen, indem er den Begriff der Perspektive in Stellung gebracht hat, um gewisse Anliegen zu verfolgen. Dabei hat der Konnex zwischen den Begriffen 'Selbstreflexion` und ‘Flächigkeit‘ dazu geführt, dass die Perspektive als raumbildendes Mittel vom modernistischen Reflexionsparadigma dissoziiert wurde. Die Dichotomie von Fläche und Raum scheint in diesem Zusammenhang einen Scheideweg eröffnet zu haben, der dazu beigetragen hat, dass die Perspektive nicht als ein potentiell selbstreflexives und damit kritisches bildnerisches Mittel wahrgenommen werden kann.

\section{Anamorphotische Grenzgänge}

Die Perspektive wird im Licht der wissenschaftlichen sowie der ästhetischen Moderne also zur Zielscheibe der Kritik. Es scheint mir nicht unwichtig zu betonen, dass diese Kritik zugleich definitorischen Charakter für die ästhetische Moderne selbst besitzt. Die bis ins neunzehnte Jahrhundert und teilweise länger andauernde hegemoniale Bedeutung der Perspektive und der durch sie gestalteten Bildräumlichkeit bietet einen hervorragenden Schauplatz, auf dem die künstlerische Moderne ihren kritischen und revolutionären Charakter unter Beweis stellen kann, indem sie die perspektivische Logik außer Kraft setzt. Im weiteren wird es darum gehen, dieses populäre Verständnis der Perspektive als bloßes Objekt der Kritik in Zweifel zu ziehen. Die zentrale Frage lautet dabei: Ist die Perspektive als Modell der bildlichen Formgenese in der Lage, den kritisch-reflexiven Ansprüchen der Moderne gerecht zu werden? Dazu werde ich zunächst einige Überlegungen zur Anamorphose anstellen, die sich mit der Frage beschäftigen, ob und wie in den anamorphotischen Projektionen bereits in der frühen Geschichte der Perspektive eine Kritik angelegt ist und wie man diese Kritik mit dem modernistischen Reflexionsparadigma in Beziehung setzen kann. 
Die Anamorphose ist kein Phänomen der Moderne im engeren Sinn, denn wie die Schriften Leonardos beweisen, liegen ihre Ursprünge gerade in der Blütezeit des toskanischen Perspektivismus. Nach einer steilen Karriere als delikates Konstruktionsverfahren, vor allem im 17. Jahrhundert, nimmt sie in der Geschichte der Kunst bald nur noch eine Nebenrolle ein und wird im zwanzigsten Jahrhundert zu einem eher exotischen Kuriosum. ${ }^{19}$ Für ein adäquates Verständnis der Perspektive und ihrer Kritik ist eine Beschäftigung mit der Anamorphose jedoch unabdingbar, nicht nur weil ihre Phänomene belegen, dass die Perspektive schon früh in mannigfaltiger Weise eingesetzt wird, sondern auch weil sie die Bedeutung des modernen Begriffs der `Kritik` im Hinblick auf die perspektivische Sichtbarkeit schärfen kann.

Ich möchte zunächst die Phänomene eingrenzen, um die es hier geht. Denn von Interesse sind hier nicht beliebige anamorphotische Phänomene, zu denen etwa auch die Spiegelanamorphose gehört, sondern lediglich solche, die als linearperspektivische Projektionen konstruiert sind. Es handelt sich in den meisten Fällen um lateral bzw. vertikal verzerrte Bilder, wie sie etwa Jean-François Niceron in seinem Standardwerk »La perspective curieuse « aus dem Jahr 1638 vorstellt. Er zeigt darin, wie der virtuose Perspektivist ein Bild derart konstruiert, dass dieses für den Betrachter lediglich aus einem seitlichen Blickwinkel wahrnehmbar wird, aus der üblichen frontalen Position vor der Bildfläche jedoch bis zur Unkenntlichkeit deformiert erscheint (Abb. 2). Der Reiz solcher anamorphotischer Bilder besteht genau aus diesem Wechselspiel zwischen Formation und Deformation des Sichtbaren, die mit dem Eintreten bzw. Verlassen des korrekten Blickpunktes verbunden sind. Mit dieser perspektivischen Praxis gehen zwei entscheidende Prinzipien einher: Erstens ist der Betrachter relativ zur materiellen Bildfläche als mobiler Betrachter konzipiert. Zweitens ist mit dieser Mobilität die

19 Neben Marcel Duchamp ist etwa Jurgis Baltrušaitis’ Buch zu erwähnen, Baltrušaitis, Les perspectives depravées - anamorphoses ou thaumaturgus, 1955. Jacques Lacans Kapitel zur Anamorphose im Buch XI seiner Grundbegriffe ist wohl u. a. dem Einfluss von Baltrušaitis' zuvor erschienenem Text zu verdanken. In der Literaturwissenschaft hat Inka Mülder-Bach darauf hingewiesen, dass Henry James' Roman The Ambassadors (1903) strukturelle Parallelen zum gleichnamigen Gemälde von Hans Holbein und dessen anamorphotischer Konstruktion aufweist, Mülder-Bach, »The point where the death comes in. Perspektivik und Blendung in James’ The Ambassadors«, 1997, S. 249 f. 


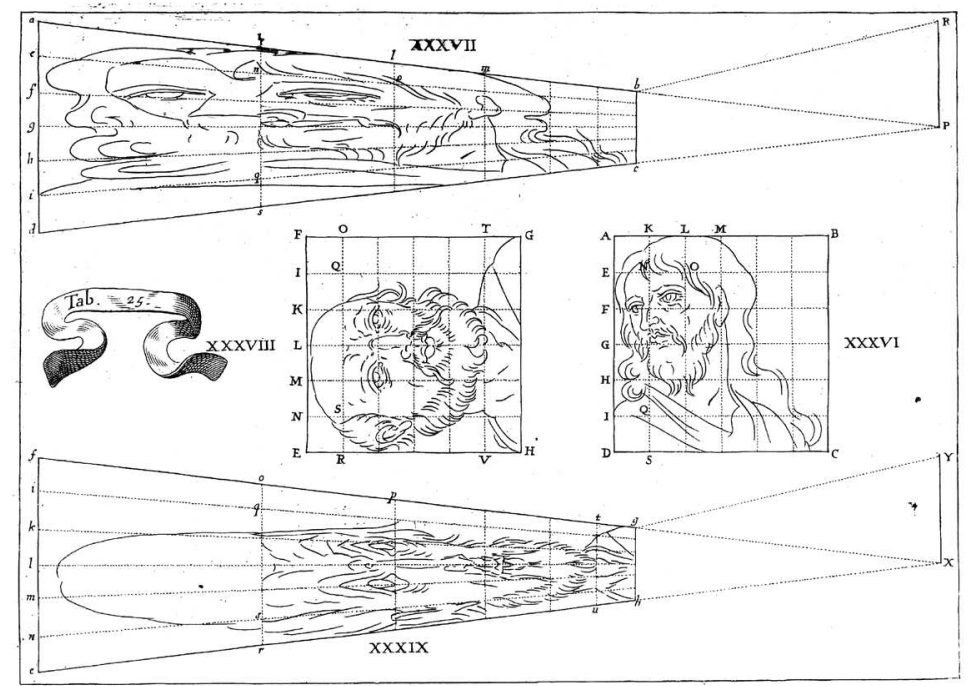

Abb. 2: Jean François Niceron, Bildtafel aus La perspective curieuse ou magie artificielle des effets merveilleux, 1638.

zum Teil kryptische Verzerrung des Bildes prinzipiell auflösbar. Um diesen Umstand besser zu verstehen, muss man sich die Grundsätze der perspektivischen Formgebung in Erinnerung rufen.

Das übliche perspektivische Darstellungsverfahren basiert auf der Idee, dass sich die Projektionsebene der perspektivischen Konstruktion parallel zur empirischen (und zumeist planaren) Bildfläche und dabei im $90^{\circ}$-Winkel zur zentralen Blickachse befindet (Abb. 3, links). Als Projektionsebene bezeichne ich jene Ebene, die sich im Gesichtsfeld des Betrachters als Fenster zum Bildraum hin öffnet und in diesem Sinn eine Ebene mit rein optischem Charakter ist. Im perspektivischen System ist diese Ebene spätestens seit Alberti als Grundfläche einer Pyramide bestimmt, welche prinzipiell auf jede materielle Fläche mit beliebiger Oberflächenbeschaffenheit projiziert werden kann. Die Projektionsebene ist in diesem Sinn eine rein systemische Ebene, die zwar nicht in Erscheinung tritt, jedoch für die Konstruktion perspektivischer Sichtbarkeit eine implizite Rolle spielt, da sie gewissermaßen das optische Lot eines Bildes bestimmt. 

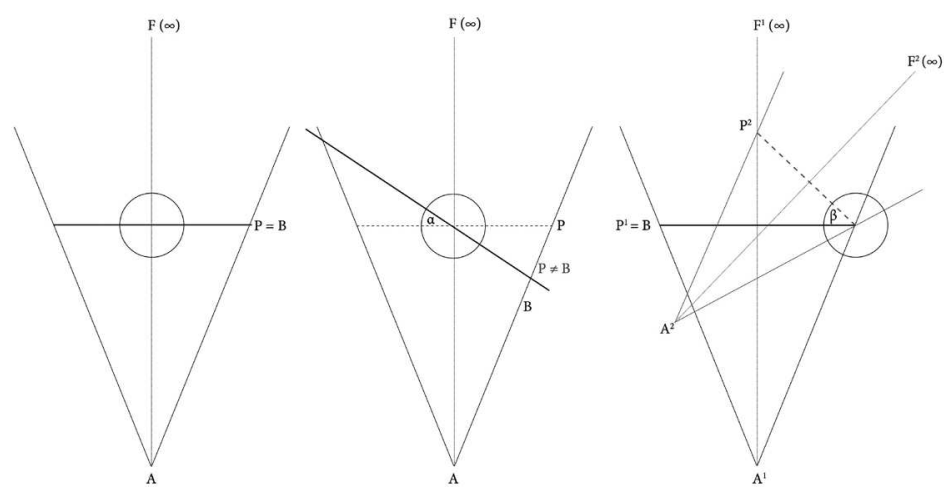

Abb. 3: Grundrissschemata perspektivischer Darstellungen (Dominique Laleg). A entspricht dem Augpunkt der Projektion, F entspricht der linearen Richtung des Fluchtpunkts, die Gerade AF bildet die zentrale Blickachse, P bildet die systemische Projektionsfläche, B die materielle Bildfläche. Die Winkeldifferenz $\alpha$ ergibt sich aus der Rotation der Projektionsfläche relativ zur Bildfläche (WP-WB), während sich die Winkeldifferenz $\beta$ aus der Rotation der zweiten Projektionsfläche relativ zur ersten Projektionsfläche ergibt (WP1-WP2).

Das anamorphotische Darstellungsverfahren beruht nun darin, eine Rotation einzuführen, mit der eine Winkeldifferenz zwischen der Projektionsebene und der empirischen Bildfläche entsteht (Abb. 3, Mitte). Der Schnitt durch die Sehpyramide ist hier also nicht rektangulär realisiert, weshalb die Proportionen des Dargestellten aus der frontalen Sicht derart verzerrt erscheinen, dass das Dargestellte nicht mehr als solches erkennbar ist. Vielmehr zeigt sich die Bildfläche dann als kryptisch pigmentierte Fläche, und erst wenn der Betrachter die geometrisch korrekte und seitliche Position vor dem Gemälde einnimmt, fügt sich das sichtbare Material zu einem Bild. Bei der Anamorphose handelt es sich so gesehen um ein kalkuliertes Spiel zwischen Deformation und Formation der Sichtbarkeit, die mit dem Eintreten bzw. Verlassen des korrekten Blickpunktes verbunden sind und die auf der misslingenden bzw. gelingenden Wahrnehmung einer perspektivisch generierten Darstellung basiert. 
Die Anamorphose führt damit zunächst vor Augen, worin die gestalterische Funktion der Perspektive eigentlich liegt: Sie regelt zunächst die Beziehung zwischen einem materiellen Bildträger und einer räumlich dargestellten Bilderscheinung und setzt diese Beziehung wiederum in Beziehung zu einem situierten Blickpunkt - ein Verfahren, das Ralph Ubl und Wolfram Pichler als »Formatierung « bezeichnen. Anamorphotische Darstellungen sind ein Beispiel dafür, wie diese Relationalität von Beziehungen eingesetzt werden können. Das Phänomen der Anamorphose belegt weiter, dass es bereits in der frühen Geschichte der Perspektive ein Bewusstsein für die systematische Unterscheidung von Projektionsebene und Bildfläche gibt und dass mithin die Suggestion der Identität des Bildes mit dem Schnitt durch die Sehpyramide, die in Albertis berühmter Fenstermetapher zum Ausdruck kommt, keineswegs zwingend ist, sondern nur eine unter vielen möglichen Verwendungsweisen der Perspektive. ${ }^{20}$ Es mag sein, dass die Perspektivisten des 15. und 16. Jahrhunderts es vorzogen, die Projektionseben möglichst bruch- und nahtlos mit dem Träger zu verbinden, doch wie die Perspektivtraktate des 17. Jahrhundert belegen, ist schon bald eine Vielzahl raffinierter Varianten perspektivischer Konstruktion entstanden, mit denen die Differenz von Projektionsebene und Bildfläche gezielt eingesetzt wird. Weiter zeigt die Anamorphose, dass die rechtwinklige Frontalität zwischen Betrachter und Bild, d.h. genauer gesagt zwischen der Sichtachse als zentralem Sehstrahl und der materiellen Bildfläche, keine notwendige Voraussetzung perspektivischer Sichtbarkeit ist. Die räumliche Diagonalität der materiellen Bildfläche führt, bei entsprechendem Blickwinkel, sogar dazu, dass ein Teil derselben sich vor der eigentlichen Projektionsfläche befindet (Abb. 3, Mitte). Dieser Umstand und sein visueller Effekt hat Niceron zur Behauptung verführt, das sichtbargemachte Objekt befinde sich dann, anders als bei der üblichen perspektivischen Darstellung, nicht hinter der Bildfläche, sondern zwischen der Bildfläche und dem Auge. ${ }^{21}$

20 Vgl. dazu auch Maynard, Drawing Distinctions, 2005, S. $28 f$.

21 "Or nous avons seulement considéré jusqu'à présent le plan situé entre l'œil \& l'objet, mais nous le considérons désormais indifféremment, soit que l'objet ait sa place entre l'œil \& le plan, ou derriere le plan«. Nicéron, La perspective curieuse ou magie artificielle des effets merveilleux, 1638, S. 90. 
Die perspektivische Formatierung eines Bildträgers ermöglicht damit eine Vielzahl von Möglichkeiten, mit denen das Dargestellte und sein Bildraum auf den Betrachter im Realraum bezogen werden können. Ihre Verwendung erlaubt Modifikationen und folgt nicht, wie vielfach angenommen, einem komplett regulierten oder statischen Verfahren. Damit zeigt sich auch, dass die perspektivisch organisierte Beziehung von Bildträger und Bilderscheinung nicht zwingend jenen antinomischen Charakter besitzt, den ihr etwa die phänomenologisch-hermeneutische Bildtheorie attestiert. ${ }^{22}$ Denn wenn die Grundlage der Anamorphose gerade im spannungsvollen Zusammenspiel zwischen projizierter Sichtbarkeit und ihren materiellen Voraussetzungen liegt, zeigt sich damit auch, dass die materielle Bildfläche ein zentraler Bestandteil perspektivischer Sichtbarkeit ist, deren Modifikation (etwa durch Rotation) das Sichtbare empfindlich verändert. Die bildliche Sichtbarkeit siegt also nicht auf Kosten des Bildträgers und durchstößt nicht bloß seine Fläche, sondern tritt mit ihm in ein Wechselspiel, das die Grundlage ikonischer Sichtbarkeit bildet. Die materielle Bildfläche und ihre jeweils spezifische Beziehung zur projizierten Sichtbarkeit muss folglich als integratives Element der perspektivischen Disposition begriffen werden.

In der Anamorphose kommen also die komplexen Beziehungen zwischen projizierter Sichtbarkeit, materiellem Träger und Betrachterstandpunkt zum Ausdruck. Inwiefern handelt es sich dabei aber um eine Kritik? Welche Bedeutung hätte der Begriff der 'Kritik` in diesem Zusammenhang überhaupt und wie kann man diesen mit dem modernistischen Paradigma selbstreflexiver Kritik und damit einem Diskurs in Beziehung setzen, der die Perspektive als Problem bestimmt?

Wie beschrieben liegt der primäre Effekt der anamorphotischen Darstellung im dynamischen Wechselspiel zwischen Formierung und Deformation des Sichtbaren. Dieses Wechselspiel zwischen Formierung und Deformation perspektivischer Sichtbarkeit kann nun verschieden interpretiert werden. Man könnte entweder zu dem Schluss kommen, dass es sich letztlich um eine Affirmation der Perspektive handelt, da unter bestimmten Voraus- 
setzungen das Gelingen des perspektivischen Bildmodells erlebbar gemacht wird, womit die Theorie perspektivischen Sehen verifiziert ist. Oder aber man kann die anamorphotische Deformation zum Anlass nehmen, um den Trugcharakter der Perspektive hervorzuheben, oder gar, wie es Descartes zugeschrieben wird, um die sinnliche Wahrnehmung schlechthin in Frage zu stellen. ${ }^{23}$

Mir scheint, dass beide Positionen, die man verkürzt als Realismus bzw. Skeptizismus bezeichnen könnte, der eigentlichen Leistung der Anamorphose nicht gerecht werden, denn die Anamorphose stellt weder die perspektivische Theorie unter Beweis, noch ist sie eine Falsifizierung derselben. Vielmehr scheint es mir angemessen, von einer Explikation der notwendigen Bedingungen zu sprechen, unter denen perspektivisch konstruierte Sichtbarkeit stattfinden kann. Der Betrachter einer anamorphotischen Darstellung in unserem Sinne erlebt vor allem das vorausgesetzte Verhältnis zwischen dem bildlich Dargestellten und dem Bildträger sowie dem Verhältnis dieses Verhältnisses zu seinem eigenen Standpunkt. Es sind also gerade die konstitutiven Beziehungen, bzw. Beziehungen von Beziehungen zwischen den am Sichtbarmachungsprozess beteiligten Elementen - mit anderen Worten das Dispositiv und seine Grenzen -, die als solche bemerkbar werden.

Für die Frage nach der Kritik spielt das skeptische Moment der Anamorphose jedoch eine entscheidende Rolle: Die Verzerrung des Sichtbaren, die Descartes möglicherweise zum Anlass nimmt, um die Gewissheit der sinnlichen Wahrnehmung zu problematisieren, beruht buchstäblich auf dem Austritt aus einem perspektivischem System. Was von einem Blickpunkt aus sichtbar ist, deformiert sich zur Unkenntlichkeit, wenn es von einem anderen Blickpunkt aus gesehen wird, der nicht systematischer Teil des perspektivischen Dispositivs ist. ${ }^{24}$ Der mit diesem Austritt gleich-

23 Jurgis Baltrušaitis argumentiert für einen unmittelbaren Zusammenhang zwischen der Anamorphose und René Descartes Skeptizismus, der von Nicerons Traktat von 1638 beeinflusst worden sei. Ob die von Baltrušaitis zitierten Stellen des Discours de la Méthode - oder überhaupt etwas an Descartes' Text auf die Anamorphose verweist, scheint mir jedoch nicht ohne weiteres klar.

24 Zwar kann man dafür argumentieren, dass das Verlassen des perspektivischen Standpunktes kalkuliert ist und daher zum System der Anamorphose gehört, dieses Kalkül ist aber nicht Teil der Perspektive als solcher, wie Dieter Mersch annimmt. Mersch, »Abbild und Zerrbild. Zur Konstruktion von Rationalität und Irrationalität in frühneuzeitlichen Darstellungsweisen«, 2006. 
sam empirisch gewordene Blick auf eine nunmehr bloß kryptisch pigmentierte Fläche ist nicht mehr in der Lage, einen Bildraum oder ein Dargestelltes, ja überhaupt ein Bild wahrzunehmen. Wenn man also die Anamorphose als Kritik der Perspektive verstehen möchte, muss man verstehen, dass die Anamorphose diese Kritik immer nur auf Kosten der Sichtbarkeit des Bildes formulieren kann, denn ihr zentraler Effekt beruht buchstäblich auf dem Austritt aus dem perspektivischen System. Die anamorphotische Kritik der Perspektive ist demnach wesentlich transzendent, sie ist Kritik von außen, denn sie zwingt den Betrachter dazu, einen systemexternen Standpunkt einzunehmen, der die perspektivische Sichtbarkeit negiert. Die anamorphotische Kritik der Perspektive operiert demnach an den Grenzen des perspektivischen Dispositivs, dessen Bedingungen nur freigelegt werden, indem sie überschritten werden.

\section{Die Perspektive wieder entdecken}

Gemessen an der greenbergschen Konzeption einer kritischen Moderne, lässt die Anamorphose also eine selbstreflexive Kritik im eigentlichen Sinn vermissen. Ich erinnere nochmals daran, dass Greenberg die Perspektive auf der Basis seines kunsttheoretischen Programms in Frage stellt, ein Programm, das nicht an einer Äquivalenzbeziehung zwischen Perspektivbild und einem vermeintlichen Wahrnehmungsbild interessiert ist, sondern auf einer Logik aufbaut, die ich selbstreflexiven Kritizismus nenne. Im weiteren werde ich der Frage nachgehen, ob und wie die perspektivische Form diesem selbstreflexiven Kritizismus gerecht werden kann, denn wie die Rekonstruktion von Panofskys Argumentation gezeigt hat, ist die Perspektive als epistemologisches Modell, mit der Kritik der Perspektive selbst verwoben. Mit anderen Worten bedeutet das, dass die in diesem Fall theoretischen Mittel der Perspektive zur Kritik derselben eingesetzt werden können. Im Folgenden werde ich nach der künstlerischen Tragweite dieses selbstkritischen Potentials fragen.

In der jüngeren Kunstproduktion lässt sich ein ernsthaftes Interesse an Verfahren der perspektivischen Bildgebung nachweisen, welche sich jene kritische Kapazität perspektivischer Form 


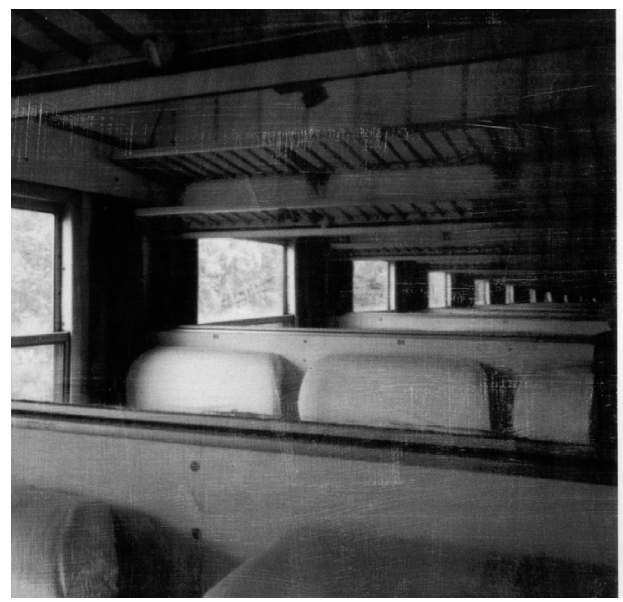

Abb. 4: Rebecca H. Quaytman, The Sun, Chapter 1, 2001, Siebdruck, Gesso auf Holz.

zu eigen macht, die in der Netzhautbild-Kritik sowie in Panofskys historiographischer Kritik der Perspektive latent bemerkbar wird. Dass heute eine künstlerische Arbeit mit der Perspektive gerade im Zusammenhang mit einer kritischen Lektüre des modernistischen Erbes besonders produktiv sein kann, zeigt die Malerei der US-Amerikanerin Rebecca H. Quaytman. Sie leistet eine so komplexe wie intelligente Rehabilitierung der perspektivischen Darstellungsform, und zwar unter Berücksichtigung jener historischen Diskurse, mit denen die Perspektive im zwanzigsten Jahrhundert verunglimpft wurde. ${ }^{25}$ Die zwei Gemälde aus der Serie The Sun (2001) bestehen, wie alle ihre Gemälde, aus mehreren Zentimeter dicken Sperrholzplatten, deren Oberflächen auffällig glatt und im Siebdruckverfahren bearbeitet wurden (Abb. 4 und 5). Der Vergleich der beiden Gemälde zeigt deutlich, wie die fotografische Vorlage nicht bloß bildinterne perspektivische Verkürzungen aufweist, sondern in einem Gemälde abermals einer Perspektivierung unterworfen ist. Die fotografische Darstellung des Inneren eines

25 Zum Zusammenhang von Perspektive und Modernismus im Werk von Quaytman siehe etwa, Quaytman, Allegorical Decoys, 2008, S. 13ff; sowie das Gespräch mit Steel Stillman, "Interview with Rebecca H. Quaytman«, 2010, S. 3ff. 


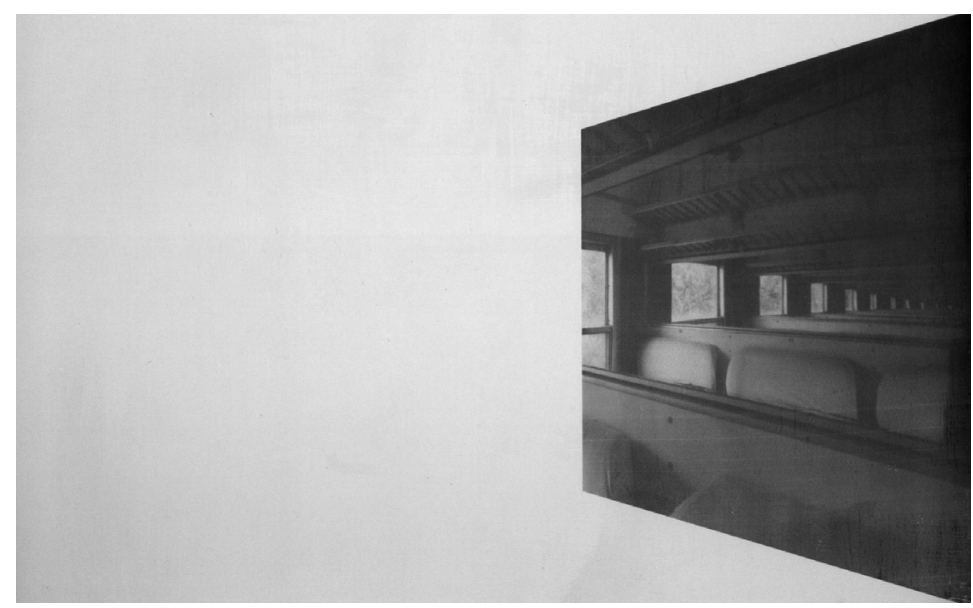

Abb. 5: Rebecca H. Quaytman, The Sun, Chapter 1, 2001, Siebdruck, Gesso auf Holz.

Zugwaggons wirkt, als wäre sie scharnierartig ins Gemäldeinnere geklappt. Sie fluchtet in eine leere monochrome Farbfläche, die zugleich den Malgrund für den Siebdruck bildet. Die Verzahnung dieses perspektivischen Effekts führt in Zusammenhang mit dem dargestellten Innenraum des Zuges zur Suggestion einer Bewegung, mit der sich der Zugwaggon sowie die fotografische Darstellung zugleich in Gang zu setzen scheinen. Die im Bild nicht definierte Fahrtrichtung - sie könnte vorwärts oder rückwärts gerichtet sein - könnte im Rahmen von Quaytmans Erzählung zum besagten Werk nicht nur als eine Reise durch einen Raum, sondern möglicherweise auch durch Zeit gedeutet werden. Denn die Fotografie ist bei einer Zugfahrt von Quaytman nach Lodz entstanden, von wo der Großvater der Künstlerin einst in die USA emigrierte. ${ }^{26}$

Im Folgenden konzentriere ich mich jedoch auf die formalperspektivische Konfiguration des Gemäldes, die auf Seiten des Betrachters sowie des Gemäldes frappante Konsequenzen mit sich bringt. Einerseits ist die resultierende Gesamtform im Hinblick auf den sie tragenden und dabei distanzierten Blickpunkt zu verstehen. Unabhängig von der Frage, ob dieser Blickpunkt 
möglicherweise Kennzeichen neuzeitlicher Subjektivität aufweist und wie man eine Verbindung zwischen Perspektivismus und Subjektivismus plausibel machen kann, muss festgehalten werden, dass die im Bild implizite Adressierung des Betrachters von ganz bestimmter Art ist. Denn in einem sind sich alle Theoretiker einig: Die perspektivische Form ist wesentlich eine standpunktbezogene Form, ganz ungeachtet dessen, wie dieser Standpunkt begriffen bzw. besetzt wird. Dieser implizite Standpunkt ist in seiner Qualität also zunächst indifferent, es handelt sich um einen geometrisch formalisierten Punkt. ${ }^{27}$ Nun hat diese reduktionistische Formalisierung des Betrachters wiederum jene Kritiker auf den Plan gerufen, die betonen, dass die Perspektive die sinnliche Leiblichkeit zuungunsten des Bildes sowie zuungunsten des Betrachters übergehe. Indem die Perspektive die Anlage des Bildes konsequent geometrisch systematisiere und auf einen formalisierten sowie fixierten Blickpunkt hin ausrichte, sei sie, wie Maurice MerleauPonty sagt, ein »bösartiges Dispositiv« ${ }^{28}$ Unklar bleibt, weshalb diese Abschwächung der affektiven Koppelung des Leibes zum Bild unbedingt schlecht sein muss. Zeigt Quaytmans Verwendung der Perspektive nicht, dass man eben jene Eigenschaften der perspektivischen Form, die unter phänomenologischen Vorzeichen als problematisch eingestuft werden, gezielt nutzen und damit künstlerisch fruchtbar machen kann? Nicht zufällig entspricht der Entaffizierung des formalisierten Blickpunktes die anonyme fotomechanische Bildproduktion sowie der Verzicht auf Farbe, was schließlich zu einer derart distanzierten Adressierung des Betrachters führt, dass man mit Martin Jay geradezu von einer "De-Erotisierung « sprechen kann. ${ }^{29}$ Ihre Verwendung der Perspektive lässt sich in diesem Sinn als eine Strategie begreifen, die sich einen von der modernen Bildtheorie immer wieder kritisierten Aspekt der perspektivischen Formgebung zu eigen macht, um damit unter veränderten historischen Bedingungen bestimmte Ziele zu verfolgen.

27 Der formale Charakter dieses Punktes hat dazu veranlasst, diesen in unterschiedlicher Weise zu besetzen. Dazu etwa: Rotman, Die Null und das Nichts. Eine Semiotik des Nullpunkts, 2000.

28 Der von Merleau-Ponty verwendete Wortlaut ist "malin dispositif«, MerleauPonty, "L'œil et l'esprit", 1964, S. 20.

29 Jay, "Scopic Regimes of Modernity“, 1988, S. 8. 
Die Konsequenzen der perspektivischen Konfiguration zeigen sich aber auch auf der gegenüberliegenden Seite des Blickpunktes. Denn die distanzierte Beziehung des Betrachters zum Gemälde bedeutet nicht, dass die Materialisierung des Bildes zu einem vernachlässigbaren Faktor wird. Vielmehr liegt die bemerkenswerte Leistung des Gemäldes gerade im besonderen Verhältnis zwischen Bildraumorganisation und Flächenorganisation, d.h. der spezifischen Inbeziehungssetzung der beiden. Bedenkt man zunächst, dass die Perspektive als raumgebendes Mittel funktioniert, indem sie die Bildelemente formal so anordnet, dass die systematisch nachvollziehbare Illusion einer dreidimensionalen Bildtiefe entsteht. Diesen Raum, seine kontinuierliche Tiefe und die damit generierte Disposition des Blickpunkts, setzt sie zugleich in explizite Beziehung zu einer materiellen Fläche. Diese letzte Beziehung wird in aller Regel wenig bedacht, was auch daran liegt, dass die gängige Verwendung der perspektivischen Bildproduktion darum bemüht ist, sie unsichtbar zu machen, indem sie eine Identität zwischen systemischer Projektionsfläche und materieller Bildfläche suggeriert. Die verwendete Perspektivierung unterbricht nun diese nahtlose Überblendung des Bildträgers durch die Projektion von drei Bildrändern, wodurch nicht nur die drohende infinite Regression der Selbstdarstellung unterbunden wird, sondern auch das materielle Substrat des Bildes, sein Format und seine Flächigkeit thematisch werden. ${ }^{30}$ Die vorliegende Perspektivierung verweist so auf die allzu oft vergessene Gegebenheit, dass das opake Element der materiellen Bildfläche ein fundamentaler Bestandteil der perspektivischen Form ist, dass mithin die Perspektive nicht bloß die vielfach betonte Beziehung zwischen Blickpunkt und Fluchtpunkt herstellt, sondern diese Beziehung abermals mit einer materiellen Ebene in Beziehung setzt. Indem die im Gemälde hergestellte Metaperspektive die Illusion einer kontinuierlichen Identität von perspektivischer Projektion und Bildfläche unterbricht, artikuliert sie also eine Differenz, die dem perspektivischen Bildmodell wesentlich ist, jedoch kaum je sichtbar gemacht wird. Die perspektivische Form ist hier als jenes »Medium« begriffen, das, wie

30 Jüngst hat Johannes Grave darauf aufmerksam gemacht, dass bereits die Malerei des Quattrocento die Randzonen perspektivischer Bilder als produktive Irritationsmomente einsetzt. Grave, Architekturen des Sehens, 2015. 
Michael Fried sagt, eine Wechselbeziehung herstellt zwischen dem materiellen Träger und demjenigen, was in und mit diesem Träger erscheint. ${ }^{31}$

Die Arbeit Quaytmans macht in diesem Sinne deutlich, dass die Bildfläche ein Teilelement der perspektivischen Disposition ist und dass man ihrer Rolle nicht gerecht wird, wenn man sie als zu negierende Materialität, als bloß transitorische Größe denkt. Vielmehr ist sie Teil einer Ordnung, deren Funktion gerade darin besteht, mit einer materiellen Ebene eine räumliche Erscheinung zu generieren und diese mit der Betrachterposition auf eine jeweils bestimmte Weise in Beziehung zu setzen, um unter gewissen Bedingungen abermals bestimmte Absichten zu verfolgen. Begreift man die Perspektive in diesem Sinn als ein Instrument, das zu bestimmten Zielen eingesetzt werden kann, verdeutlicht sich auch ihre mögliche Rolle in der Kunst der Gegenwart. Denn im Hinblick auf die Perspektive und ihrer modernen Geschichte sehen sich die Künstler der Gegenwart einigen Problemen ausgesetzt, die ihr die modernistische Malereitradition zumutet. Quaytman, deren Vater Maler der New Yorker Nachkriegsavantgarde war, ist mit diesen Diskursen überaus vertraut. Ihre Entscheidung, Malerei zu betreiben, ist auch eine bewusste Entscheidung, sich in ein historisch komplexes, um nicht zu sagen belastetes Feld einzuschreiben. Die Perspektive spielt dabei eine entscheidende Rolle, bildet sie als illusionistisches Gestaltungsmittel doch gerade eine Zielscheibe des modernistischen Ikonoklasmus. Die historische Kritik der Perspektive bildet für die Generation junger Malerinnen und Maler wie Quaytman also eine schwierige und zugleich delikate Ausgangslage. Denn einerseits erbt Quaytman das modernistische Misstrauen gegenüber der projektiven Geometrie: »The evacuation of that system left me as a young painter with an intense suspicion and immediate distrust of perspective. ${ }^{32}$ Andererseits schwebt ihr die Möglichkeit einer dialektischen Aussöhnung vor:

31 "... shape as a medium within which choices about both literal and depicted shapes are made, and made mutually responsive«. Fried, "Shape as Form. Frank Stella's Irregular Polygons«, 1998, S. 77.

32 Email-Konversation zwischen Apsara Di Quinzo und Rebecca Quaytman, publiziert anlässlich der Ausstellung New Work 22.10. bis 16.01.2011 im San Francisco Museum of Modern Art. 
»The edges, the picture plane, and the object of the painting could still be experienced in tandem with the illusionistic space of the picture. $«^{33}$

Ich argumentiere dafür, dass diese Wiederentdeckung der Perspektive eine Konfiguration des Gemäldes vollzieht, die vor dem Hintergrund der modernistischen Malereitradition als Kritik und letztlich als Emanzipation von einem historischen Paradigma der Malerei begriffen werden muss. Ich kann diese Kritik anhand dreier Aspekte beschreiben. Da ist zunächst der rationale Charakter der perspektivischen Konstruktion, der einer originellen, inspirierten oder anderweitig auratisierten Einschreibung des Malersubjekts auf der Bildfläche widerspricht. Die anonyme geometrische Konstruktion und ihre prinzipielle Reproduzierbarkeit stehen in scharfem Gegensatz zur Idee einer authentischen Autorschaft und findet in der ebenso anonymen fotomechanischen Produktion des Gemäldes ihre Entsprechung. Zweitens findet eine Umdeutung der Bildfläche statt, die durch das projektivgeometrische Verfahren mehr als neutrale Projektionsfläche denn als signifikante Materialität bestimmt wird. Dieser Umstand wird besonders durch die Beschaffenheit der Bildfläche unterstrichen, deren Glätte und Homogenität der modernen Idee des Gemäldes als einer fakturierten Einschreibungsfläche entgegensteht und damit mit der intensivierten Beziehung des Trägermaterials zur Bilderscheinung bricht. Drittens ist der radikale Verzicht auf Farbe auffällig, der im Sinn eines rational operierenden disegno als Loslösung vom modernen Kolorismus interpretiert werden kann.

Die Rationalität und Anonymität, die durch die perspektivgeometrische und mechanische Entkörperlichung des Gemäldes erzeugt wird, hängt wesentlich mit der vom Werk explizierten Autorschaft zusammen, was etwa auch durch Quaytmans konsequente Reduktion aller Bildanschriften und -legenden auf die bloßen Initialen der Künstlerin betont wird. Quaytmans Projekt nutzt also die Perspektive, um sich gegen eine von der Moderne tradierte Konzeption von Malerei zu wenden, die das Bild primär als stofflich signifikantes Produkt eines körperlich agierenden 
Künstlersubjekts und die Bildfläche als Ort der Oberflächeneinschreibung begreift. Die Perspektive, ihre Eigenschaften und bildtheoretischen Implikationen werden so gesehen reaktiviert, um Kritik an einem seinerseits historischen Bildmodell zu üben. Die Perspektive zeigt sich damit als eine Art Vehikel der Kritik, einer Kritik, die man am besten als diskursiv beschreibt, denn sie operiert wesentlich mit einer dialektischen Wende, die ein Modell des Bildes durch ein anderes Modell ersetzt. Unter bestimmten historischen Voraussetzungen auf ein besonderes historisches Modell der Sichtbarkeitserzeugung zurückzugreifen, kann demnach kritische Effekte erzeugen. Es stellt sich aber die Frage, ob sich das kritische Potential der Perspektive in dieser diskursiven Kritik erschöpft. Wie steht es um die Selbstkritik im engeren Sinn? Gibt es eine genuin perspektivische Kritik, die sich mit den Maßstäben des modernistischen Reflexionsparadigmas messen kann, einem Paradigma, das die Kritik eines Systems als Effekt desselben Systems festlegt?

Man könnte zum naheliegenden Fehlurteil gelangen, es handle sich bei der seltsam verzerrten Sichtbarkeit in Quaytmans Gemälde um eine anamorphotische Darstellung. Ich habe jedoch bereits erläutert, wie die Anamorphose das Eintreten bzw. Verlassen des korrekten Blickpunktes vor dem Bild einsetzt, um damit die Formierung bzw. Deformation des perspektivisch Dargestellten zu bewirken. Mit anderen Worten, der Betrachter tritt aus dem perspektivischen System aus, was die anamorphotische Kritik der Perspektive als eine Kritik von außen kennzeichnet. Quaytmans Verwendung der Perspektive unterscheidet sich nun maßgeblich von dieser anamorphotischen Verwendung, was etwa daran erkennbar wird, dass die perspektivische Verzerrung der fotografischen Darstellung sich in keinem Fall - und erst recht nicht durch Bewegung vor dem Gemälde - auflösen lässt. Dies liegt an der spezifischen räumlichen Konstruktion von Quaytmans Darstellung, welche eine eigentümliche Verdoppelung der Perspektive herbeiführt. Wie die schematische Rekonstruktion des Grundrisses (Abb. 3, rechts) zeigt, ist die perspektivische Formierung des fotografisch Dargestellten einer weiteren Perspektivierung unterworfen, indem ein zweites Perspektivsystem mit einem zweiten Augpunkt, einem zweiten Fluchtpunkt und einer zweiten 
Projektionsebene eingeführt wird. Die hier vorliegende Rotation ist also keine zwischen Projektionsebene und empirischer Bildfläche, wie bei der Anamorphose, sondern eine zwischen einer ersten und einer zweiten Projektionsebene, die dabei eine gemeinsame Horizonthöhe teilen. Anstelle einer Deformation der perspektivischen Darstellung findet so eine Perspektivierung der perspektivischen Form statt, wodurch ebendiese Form nicht dieselbe bleibt. Die damit erzeugte Metaperspektive macht nicht etwa als Negation, Bruch oder Störung auf die perspektivische Form und deren Konstitution aufmerksam, vielmehr ermöglicht sie die Explikation perspektivischer Formkonstitution mit deren eigenen Mitteln.

Der aus perspektivtheoretischer sowie modernistischer Sicht interessante Aspekt dieser Metaperspektive liegt denn auch genau in dieser Möglichkeit, die Kritik der Perspektive nicht auf Kosten der perspektivischen Sichtbarkeit zu formulieren. Es ist hier die Perspektive selbst, die ihre Kritik ermöglicht. Ihr Formgesetz wird gerade nicht durch Negation desselben expliziert, sondern mit seinen eigenen Mitteln. Folglich handelt es sich bei der hier zum Tragen kommenden Kritik erstens um eine Reflexion im engeren Sinne, d.h. eine Bewegung der Immanenz, in der das Subjekt der Reflexion mit dem Objekt der Reflexion identisch ist. Und sie ist zweitens in der Lage, die für eine Kritik nötige Distanz von eben jenem System, das sie selbst ist, zu erzeugen. Die perspektivische Form ist in der Lage, von sich selbst zu differieren, um zugleich zu sich zurückzukehren. Erst diese Selbstdifferenz, in welcher Transzendenz und Immanenz zusammengehen, macht es möglich, dass sich Form zugleich kritisch und reflexiv auf sich selbst beziehen kann.

Es scheint, als sei das populäre modernistische Narrativ, das die perspektivische Transparenz gegen kritische Selbstreflexion ausspielt, weitgehend blind für das kritische Vermögen der Perspektive. Dies liegt vor allem daran, dass sich sein Reflexionsparadigma ab einem gewissen Zeitpunkt einseitig auf die materielle Fundierung des Bildes und ein damit verbundenes Paradigma von Malerei verengt hat. Dieser Materialismus ist deswegen besonders bedauerlich, weil es ihm nicht gelingt, die perspektivischen Reflexionsleistungen geometrisch-räumlicher Konstruktionen $\mathrm{zu}$ ver- 
Die Perspektive wieder entdecken

stehen. Die genaue Rekonstruktion dieser Leistungen hilft nicht nur unser Verständnis von Reflexion und Kritik zu präzisieren, sondern eröffnet auch neue Perspektiven auf den Modernismus. 



\section{Dispositionen des Subjekts}

\section{Die Perspektive neu verhandeln}

Ein großer Teil der modernen Perspektivkritik nimmt die Perspektive und ihre Produkte zum Anlass einer Kritik des Subjekts. Unabhängig von der jeweiligen Argumentation wird das Problem der Perspektive dabei wesentlich als ein Problem der Subjektivität bzw. deren jeweiliger Verfasstheit diskutiert, die mit der Art und Weise der Adressierung des Betrachters durch das Bild zusammenhängt. Die Korrelation von Bild und Subjekt basiert dabei auf Bedingungen, die vom Bild gestellt werden und auf dessen formaler Anlage basieren. Weil der Betrachter nicht umhinkommt, bei der Wahrnehmung des Bildes dessen spezifisch formalen Charakter, d.h. vor allem die punktzentrierte Systematik des Raums einzulösen, richtet er sich zwangsläufig an eine vom Bild vorgeschriebene Weise des Sehens. Die Kritik perspektivischer Subjektivität geht davon aus, dass diese Beziehung von Bild und Betrachter Konsequenzen für die Verfassung des Betrachters mit sich bringen. Die Neomarxisten haben diese Effekte teilweise unter dem Begriff der Appellation diskutiert, ${ }^{1}$ wobei bereits Karl Marx die Produktion von Subjektivität als zentrale Funktion des Kunstwerks begriffen hat:

»Der Kunstgegenstand [...] schafft ein kunstsinniges und für die

Künste aufnahmefähiges Publikum. Die Produktion produziert daher nicht nur einen Gegenstand für ein Subjekt, sondern auch ein Subjekt für einen Gegenstand. «²

Subjektivität wird in diesem Sinn als Effekt eines Dispositivs gedacht, das den Betrachter implementiert. Da die Besonderheit der Perspektive darin liegt, diese Implementierung durch die formale

1 Siehe etwa Baudry, "Ideologische Effekte erzeugt vom Basisapparat «, 1993, S. 38 .

2 Marx, »Einleitung zur Kritik der politischen Ökonomie«, 1974, S. 624. 
Anlage zu bewirken, zieht die Form des Bildes also eine bestimmte Form der Subjektivität nach sich.

Wenn die Perspektive als appellierendes Dispositiv nicht nur das Verhältnis von Betrachter und Bild organisiert, sondern auch das Selbstverhältnis des Betrachters beeinflusst oder gar bestimmt, stellt sich die Frage, welcher Art dieses Selbstverhältnis sein kann. Die französische Traditionslinie der modernen Perspektivkritik hat dazu tendiert, die Perspektive als Unterschlagung der Kardinalität des Leibes zu begreifen. ${ }^{3}$ Eine nicht präjudizierende Untersuchung perspektivischer Subjektivität sieht sich jedoch gezwungen, ein allzu starres Körperparadigma hinter sich zu lassen. Ein ontologischer Begriff der Leiblichkeit, der alle anderen, nicht leiblichen Voraussetzungen menschlicher Wahrnehmungs- und Reflexionsformen unberücksichtigt lässt sowie Konzepte eines Körperschemas, das dem Leib eine somatische Ordnung zusprechen, die für das Welt- und Selbstverhältnis von Subjekten eine allgemeine strukturierende Funktion besitzt, tendieren dazu, andere, die Subjektivität strukturierende Effekte zu vernachlässigen. Der Leib sollte nicht nur als Instanz begriffen werden, durch die ein Individuum auf sich und die Welt vermittelt ist, der Leib ist auch ein Ort der Einschreibungen historischer Realitäten, die sein Selbstverhältnis auf entscheidende Weise mitformen. Der Körper ist, mit anderen Worten, nicht nur konstituierend, sondern zugleich auch konstituiert durch historische Dispositive, an die er verwiesen und in die er implementiert ist. ${ }^{4}$

Die Perspektive als ein solches historisches Dispositiv zu verstehen, bedingt weiter, die singulären Bedingungen seines Gebrauchs zu beachten, denn selbst wenn das formale Dispositiv in seinen systematischen Grundfunktionen seit dem fünfzehnten Jahrhundert dasselbe geblieben ist, wäre es doch absurd, seine Bedeutung und subjektivierenden Effekte als über die Jahrhunderte gleichbleibend zu interpretieren. Den historischen Bedeutungswandel der Perspektive seit der Moderne kann man dabei besonders gut an Beispielen der aktuellen Malerei ermessen. Sie macht klar, dass

3 Prominent ist dafür etwa die Philosophie Maurice Merleau-Pontys (siehe Kapitel III, » "malin dispositif«). Dazu hat etwa Jean-François Lyotard kritisch bemerkt, dass Merleau-Ponty eine "philosophie de la chair savante" betreibe. Lyotard, Discours, figure, 1974, S. 22.

4 Vgl. dazu auch Bourdieu, Die männliche Herrschaft, 2012, S. $19 \mathrm{ff}$. 
die Verwendung eines Dispositivs wie der Perspektive im 21. Jahrhundert mit veränderten Fragen und Zielen zusammenhängt, die sich zwar nicht von ihrer Geschichte ablöst, die Perspektive sowie die perspektivische Subjektivität jedoch neu verhandeln.

\section{Jenseits der Autonomie}

Im Folgenden nehme ich abermals die Malerei von Rebecca Quaytman zum Anlass, die Neuverhandlung der Perspektive exemplarisch zu untersuchen. Ihre Auseinandersetzung mit Perspektive ist nicht nur von besonderer Aktualität, sondern zudem künstlerisch und theoretisch außergewöhnlich fundiert, was ihre Schlüsselrolle für die vorliegende Untersuchung begründet. Die im Jahr 2011 in der Kölner Galerie Buchholz gezeigte Ausstellung mit dem Titel Cherchez Holopherne ist hinsichtlich der Frage nach der Perspektivierung von besonderem Interesse. Die Ausstellungsansicht in Abbildung 1 zeigt eine Gruppe von drei Gemälden, deren linkes die perspektivisch verkürzte Ansicht einer Bildtafel samt hölzernem Tafelprofil zeigt, wie sie die Malerin nahezu in ihrem ganzen Werk einsetzt. Die perspektivisch verkürzte Darstellung fluchtet in die Tiefe einer unbestimmten weißen Leere. Das gemalte Bildprofil, das die Schichtholzstruktur des Bildträgers maßstabsgetreu wiederholt, ${ }^{5}$ erscheint als Bild im Bild und berührt dabei den rechten Rand des tatsächlichen Bildfeldes, womit es mit dem realen Bildträger in Beziehung tritt. Dadurch entsteht ein eigentümlicher Scharniereffekt zwischen der übereck dargestellten Bildtafel und dem realen Gemälde. Das kompositorische Ungleichgewicht und die einseitig perspektivische Verzerrung der Übereckdarstellung erzeugen eine ausgeprägte Asymmetrie im gesamten Bildaufbau.

Dies hat Auswirkungen auf die Betrachterposition vor dem Gemälde, denn die Asymmetrie destabilisiert nicht nur den üblicherweise frontalen Standpunkt vor einem Gemälde dieser Größe, die innerbildliche Perspektivierung führt auch dazu, dass der Blickpunkt der Darstellung mit der suggestiven Scharnierbewegung zur Seite kippt. Der lateral verschobene Fluchtpunkt löst nicht nur die

5 Quaytman verwendet den Begriff des »Trompe l'œil« selbst. Siehe dazu Quaytman, »Allegorical Decoys«, 2008, S. 18. 


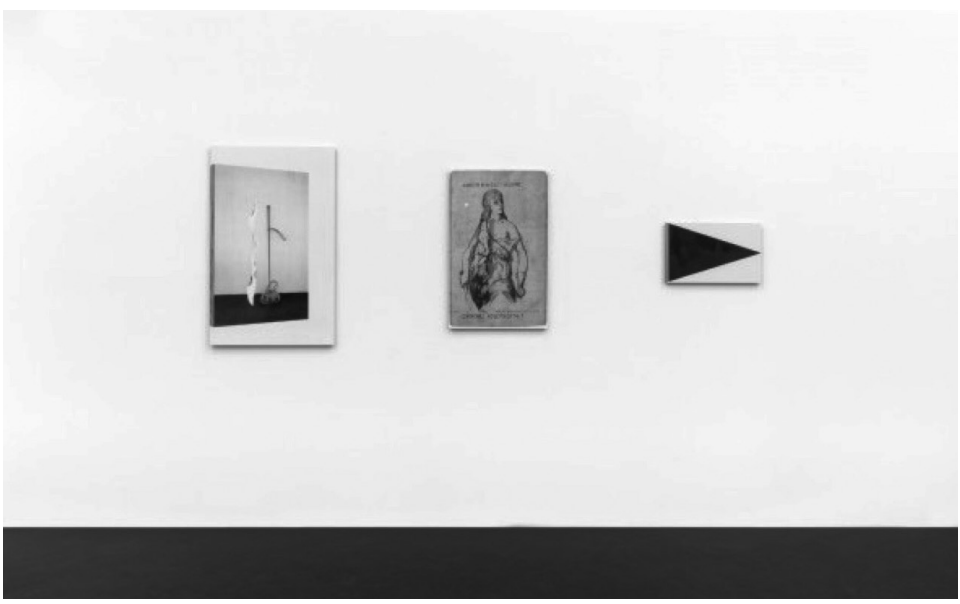

Abb. 1: Rebecca H. Quaytman, Ausstellungsansicht Cherchez Holopherne Chapter 21, 2011.

statisch anmutende Zentralprojektion auf, sondern projiziert den Betrachter auch an einen seitlich versetzten Ort.

Diese laterale Erweiterung der perspektivischen Blickregie zeigt zunächst, dass Quaytman gezielt mit den perspektivischen Darstellungsformen operiert. Sie setzt die perspektivische Adressierung nicht in tradierter Weise als frontale und unbewegte Seherfahrung ein, viel eher dient ihr die Perspektive als Instrument zur Dezentrierung des Verhältnisses von Betrachter und Gemälde sowie zur Lateralisierung der Aufmerksamkeit. ${ }^{6}$ Diese Lateralisierung zielt dann auch nicht auf eine immersive Präsenz des einzelnen Gemäldes und seiner Repräsentation, sondern rückt diese in Zusammenhang mit seiner unmittelbaren Umgebung und seinen Nachbargemälden, mit denen es in Korrespondenz gesetzt wird. Die nach rechts führende Flucht der Übereckdarstellung, die weit über die Bildgrenzen hinausführt, korrespondiert formal mit dem seitlich zugespitzten Dreieck des rechten Gemäldes, als würde

6 Der Begriff der Lateralität spielt in Quaytmans Aussagen eine entscheidende Rolle: "The transference of the pictured image onto a painted presence/present that laterally, instead of frontally, directs attention." Quaytman, Spine, 2011, Umschlagtext. 

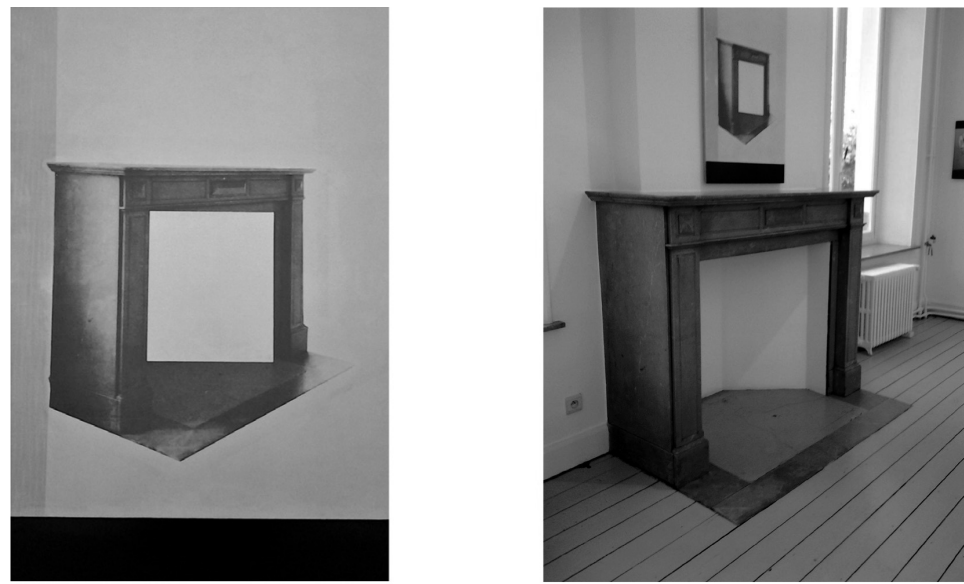

Abb. 2: Rebecca H. Quaytman, Point de Gaze-Chapter 23, 2012, Öl, Siebdruck, Gesso auf Holz.

Abb. 3: Ausstellungsansicht.

dieses die Fluchtlinien und den Fluchtpunkt der Konstruktion markieren (Abb. 1).

Die damit erwirkte Öffnung des einzelnen Gemäldes und seine Inbeziehungssetzung zum Kontext unterstreicht die Malerin mitunter auch durch die motivischen Bezüge der perspektivischen Darstellung. Beispielhaft dafür ist ein Gemälde aus der Ausstellung Point de Gaze in der Gladstone Gallery in Brüssel aus dem Jahr 2012 (Abb. 2). Das Gemälde zeigt eine mittels Siebdrucktechnik erzeugte Ansicht eines Kamins, der zu den Räumlichkeiten der Galerie gehört und über dem das Gemälde für die Ausstellung angebracht wurde. Die im Gemälde perspektivisch leicht seitlich erfasste Ansicht des Kamins kontrastiert dabei die zentrierte Ansicht, des realen Kamins, welche sich aus der frontalen Position vor dem Gemälde ergibt.

Diese Kontrastierung ist nicht daran interessiert, das Richtigkeitsproblem der perspektivischen Bildkonstruktion zu illustrieren - etwa als kritischer Vergleich von Perspektivbild und Wahrnehmungsbild. Vielmehr dient die perspektivische Inkongruenz zwischen abgebildetem Raum und Realraum auch hier einer Dezentrierung und lateralen Verschiebung des Blickpunkts. Die Quasi-Polyfokalität, die sich aus der Simultanität der 
verschiedenen Ansichten ergibt, ist eine dynamische, d.h. die Beziehung zwischen den perspektivischen Ansichten verändert sich mit der Bewegung des Betrachters vor dem Bild. ${ }^{7}$ Da die perspektivisch fixierte Ansicht innerhalb des Bildes in aller Deutlichkeit auf einen Blickpunkt linksseitig der zentralen Mittelachse des Kamins hindeutet, wird der Betrachter dazu gebracht, sich seitlich so lange zu bewegen, bis sich sein Blickwinkel jenem der Fotografie angleicht (wiedergegeben in Abb. 3). Die damit erzeugte Aufmerksamkeit und Bewegung führen auch hier dazu, dass die Umgebung und die Nachbargemälde thematisch werden. (Die kleinere quadratische Tafel in Abb. 4, die an der Seitenwand des Kaminzimmers angebracht ist, steht mit dem Kamin-Gemälde in Beziehung, denn das sichtbare weiße Viereck im Innenbereich des dargestellten Kamins ist in ihm als Formelement wiederholt.)

Es wird deutlich, dass die Perspektive auch hier als Katalysator einer lateralen Aufmerksamkeit eingesetzt wird, die sich sowohl auf den Ausstellungsraum als auch auf die weiteren Gemälde richtet, und es zeigt sich darin, dass diese Praxis fundamentale Paradigmen des Tafelbildes in Frage stellt, die wiederum unmittelbar mit der Frage nach Subjektivität zusammenhängen. ${ }^{8}$ Will man die Tragweite dieser Infragestellung angemessen begreifen, muss man zunächst die Bedeutung des Fluchtpunktes ermessen. Denn seine Verwendung, Setzung und Besetzung ist keine bloß formale Entscheidung, sondern impliziert eine subjekttheoretische und bildkonstitutive Dimension. Im frühneuzeitlichen Bildsystem der Perspektive ist der Fluchtpunkt kein beliebiger Ort im Bild, noch ist er ein bloßes Zeichen oder Symbol unter anderen, er ist vielmehr der maßgebliche Punkt, aus dem sich alle anderen Orte im Raum, ihre räumlichen Beziehungen sowie der Ort des Betrachtersubjekts ergeben. Es handelt sich bei ihm also um ein konstituierendes Element im mehrfachen Sinn: Er ist tragende Bezugsgröße eines orga-

7 In dieser peripatetischen Dynamik liegt wohl der entscheidende Unterschied zur Polyfokalität, die Kahnweiler im Kubismus erkennt, Kahnweiler, "Der Kubismus«, 1916, S. 219.

8 Dazu Quaytman: "The relation of one painting to the next was always thought through«. Quaytman, Allegorical Decoys, 2008, S. 14. - Der Kurator und Autor Galvez hat im Rahmen der von ihm kuratierten Ausstellung Arrythmia in der Galerie Nathalie Obadia in Paris 2013 die Regelhaftigkeit von Quaytmans Hängung im Begleittext zur Ausstellung als Diagramm abgedruckt. Wiedergegeben in Bois, »Of Wasps and Orchids and Books and Paintings", 2016, S. 68. 


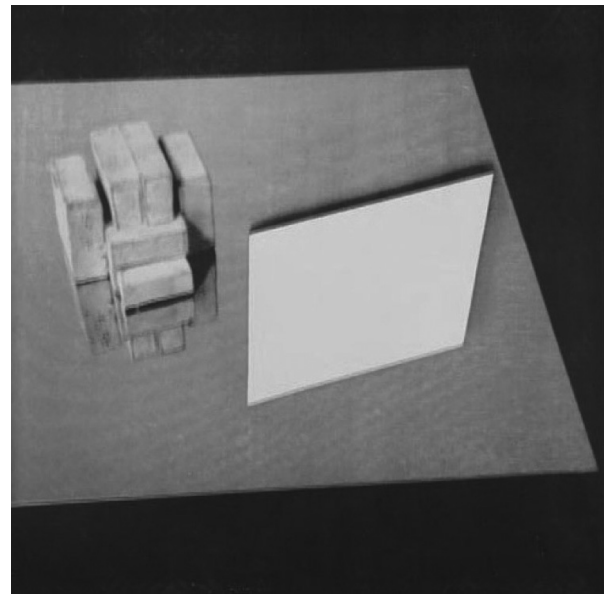

Abb. 4: Rebecca H. Quaytman, Point de Gaze-Chapter 23, 2012, Öl, Siebdruck, Gesso auf Holz.

nisierten Bildraumes sowie eines damit korrelierenden Subjekts, das ebendiesen Raum phänomenal erschließt. Die Wahrnehmung dieses Raumes ist aber an eine weitere Funktion des Fluchtpunktes gekoppelt, die Panofsky in seinem wegweisenden Aufsatz nur en passant beschreibt: "Die Entdeckung des Fluchtpunktes [...] ist gleichsam das konkrete Symbol für die Entdeckung des Unendlichen selbst... «9 Die konstituierende Bedeutung des Fluchtpunktes nimmt damit maximale Dimensionen an. Wenn er keine eigentliche Darstellung des Unendlichen leistet, sondern lediglich auf sie verweist - Panofsky spricht von einem "Symbol« -, wird er zu einem Signum der Unendlichkeit, das sich jedoch innerhalb des subjektiv Endlichen zeigt. Der Fluchtpunkt ist damit ein quasitranszendentales Element, das nicht nur dem Betrachter seinen Ort im Gefüge eines Bildraumes zuspricht, sondern auch auf die absolute Grenze des Raumes und damit die Grenze der subjektiven Sichtbarkeit schlechthin verweist. So gesehen gehört es zu seinen Besonderheiten, dass er die Konstitution des Bildraums und dessen Korrelation mit der Betrachterin mit einer Vernunftidee im kantischen Sinn verbindet, nämlich jener der Unendlichkeit. 
Vor diesem Hintergrund lässt sich nun die Tragweite von Quaytmans Verwendung der Perspektive und die damit verbundene Neuverhandlung von Subjektivität interpretieren. Die gezielte Verkoppelung des Fluchtpunktes mit der Umgebung des Gemäldes (wie in Abb. 1) ersetzt die Idee der Unendlichkeit, als deren Signum der Fluchtpunkt einst fungierte, durch den unmittelbaren Kontext des Bildes. Der Fluchtpunkt als konstituierendes Element von Raum und Subjekt bezieht Letzteres nicht mehr auf eine spekulative Idee, sondern auf eine faktisch reale Umgebung. Einst Signum einer Transzendenz zur Unendlichkeit, wird er zum Wegweiser einer Transzendenz des ästhetischen Raumes hin zu anderen Bildern sowie zur sozialen und historischen Realität des Werks.

Diese Neuverhandlung der Perspektive bringt weiter die Infragestellung ästhetischer Paradigmen mit sich, die sowohl die Selbstgesetzlichkeit des ästhetischen Objekts als auch die Integrität des Subjekts betreffen. Ästhetische Autonomie kann nicht anders denn als in Abhängigkeit von ästhetischer Qualität gedacht werden, wobei ich mit Qualität die spezifische Organisation und Formung sinnlichen Materials bezeichne. Die traditionelle Ästhetik behandelt denn auch die ästhetische Qualität als Problem der Form. Kants Kritik der Urteilskraft arbeitet in Folge des $§ 11$ eine Theorie der "Zweckmäßigkeit der Form« aus, die er für das reine Geschmacksurteil verantwortlich macht. ${ }^{10}$,Form $<$ meint dann die Eigenschaften eines wahrgenommenen Gegenstands, die sich nicht in der sinnlichen Affektion des Körpers erschöpfen und die außerdem den Gegenstand innerhalb des Wahrnehmungsfeldes begrenzt erscheinen lassen. Für die vorliegenden Fragen ist Letzteres von besonderer Bedeutung. Genauer erläutert wird es am Anfang der Analytik des Erhabenen im Zusammenhang mit ästhetischer Qualität. Kant schreibt, dass im Unterschied zur Erfahrung des Erhabenen, die sich am "formlosen Gegenstande" entzündet, die Erfahrung des Schönen die »Form des Gegenstandes« betreffe, und er formuliert pointiert, dass eben diese Form »in der Begrenzung besteht « ${ }^{11}$ Wenn also Begrenzung und Immanenz das zentrale Element ästhetischer Qualität und damit das Konstituens von

10 Kant, Kritik der Urteilskraft, 2006, в 38.

11 Ebd., B 75. 
Autonomie sind, dann müssen Quaytmans perspektivische Dezentrierungen und laterale Öffnungen der Gemälde als Kritik dieser ästhetischen Autonomie begriffen werden. ${ }^{12}$ Die Geschlossenheit der einzelnen Darstellung, von welcher das Ideal ihrer Selbstbehauptung abhängt, wird transzendiert zugunsten einer Kontextualisierung des Bildes in der realen Welt und jenseits des ästhetischen Bereichs.

Unter diesem Gesichtspunkt stellt sich die Frage nach den Konsequenzen für das Subjekt eben dieser Transzendenz, ein Subjekt, das zwar als Korrelat eines etablierten Dispositivs in Erscheinung tritt, dessen subjektivierende Funktionen jedoch im Zeichen einer Veränderung stehen. Es reicht nicht aus, sich auf den populären Topos zu berufen, der die Perspektive schlechthin mit Subjektivität verbindet, wenn man es dann versäumt zu klären, welche Konsequenzen für das Subjekt einer jeweiligen perspektivischen Praxis erwachsen.

Die perspektivische Form - wenigstens darin sind sich alle Theoretiker einig - ist wesentlich eine standpunktbezogene Form, ganz ungeachtet dessen, wie dieser Standpunkt interpretiert oder symbolisch besetzt wird. Der perspektivische Standpunkt ist seiner Qualität nach indifferent, denn er tritt lediglich als punktförmige und daher qualitäts- und ausdehnungslose Markierung auf. Diese Indifferenz wurde von prominenter Seite problematisiert, weil sie gewisse Bedingungen der Wahrnehmung unterschlage. ${ }^{13}$ Weshalb aber, so wird man fragen müssen, soll die Indifferenz des perspektivischen Standpunkts unter allen Umständen ein Problem darstellen? Wäre es denkbar, dass die angeblichen Defizite dieser Subjektivierungsweise, die unter bestimmten Voraussetzungen der Moderne stets unterstrichen wurde, unter anderen Bedingungen eine andere Bedeutung gewinnen?

Quaytmans Malerei vollzieht in diesem Sinn eine Wende in der Geschichte der perspektivischen Malerei, denn wie ich bereits

12 "I began to reconsider perspective due to my anxiety about abstraction's vulnerability to cliché, arbitrariness, and irrelevance, along with my desire to break target gravitational force of painting's ego - its arrogance."Quaytman, Allegorical Decoys, 2008, S. 13f.

13 Panofsky bemerkte dazu bereits, dass die perspektivische Konstruktion von der Tatsache absehe, »daß wir nicht mit einem fixierten, sondern mit zwei beständig bewegten Augen sehen“. Panofsky, "Die Perspektive als `symbolische Form«", 1974, S. 101. 
gezeigt habe, setzt sie die Perspektive mit einem Interesse ein, das an der Dezentrierung von Singularität der Gemälde, an der Lateralisierung der Aufmerksamkeit sowie einer Kritik ihrer ästhetischen Autonomie arbeitet. Der Begriff der Subjektivität scheint dabei zunächst fragwürdig, denn bereits auf Seiten der Autorschaft erscheint das Werk weitgehend frei von subjektiven Kennzeichen. Die mechanisch erzeugte Faktur der Bildoberfläche, die reduzierte Farbigkeit, die antikompositionelle und meist geometrische Organisation der Bildfelder, das rationale System, mit dem die Bildformate generiert werden, ${ }^{14}$ aber auch die Reduzierung des Vornamens der Künstlerin auf die Initialen R.H. zeigen, wie Quaytmans Projekt an einer Entsubjektivierung der Autorschaft arbeitet und sich damit gegen eine Konzeption von Malerei wendet, die das Bild als singuläres Produkt einer authentischen Künstlerperson versteht.

Bei dieser Anonymisierung spielt das Bildmodell der Perspektive eine entscheidende Rolle: Die geometrischen Operatoren der Perspektive sind als solche frei von subjektiven Entscheidungen und ermöglichen eine formale Gestaltung, die festgelegten Regeln folgt; weiter neutralisiert die perspektivische Konfiguration des Bildes dessen Fläche, die als Projektionsfläche nicht mehr den Ort einer expressiven Oberflächeneinschreibung bildet; und schließlich erzeugt die Perspektive eine Formalisierung und Distanzierung des Betrachters, die seine räumliche und körperliche Beziehung zur Darstellung abschwächt.

Ich vertrete die Ansicht, dass die Reaktivierung der Perspektive hier dem Ziel dient, die Verbindung von Subjekt und Malerei auf kalkulierte und distanzierende Weise zu organisieren. Die im Werk immer wieder verwendete Scharnierbewegung (Abb. 5), mit der die Entkoppelung der bildlichen Darstellung von der Flächenfaktur ihres Trägers vorgeführt wird, steht in diesem Sinn quasi emblematisch für das Projekt Quaytmans, die sich auf Seiten der Produktion sowie der Rezeption gegen eine verklärte und körperlich fetischisierte Beziehung von Malerei und Subjekt ausspricht. Ich meine, dass die in der Moderne vielfach kritisierten Aspekte der perspektivischen Bildform hier eingesetzt werden, um der 


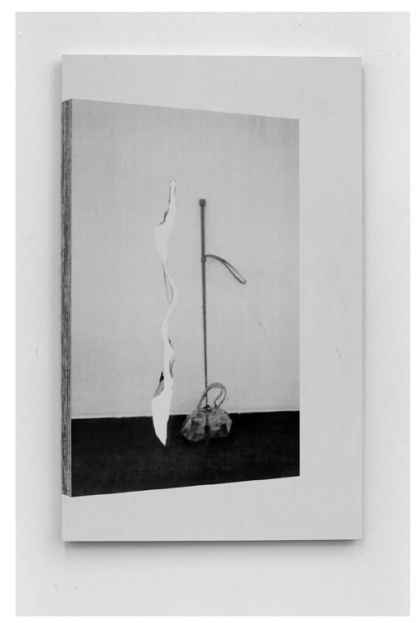

Abb. 5: Rebecca H. Quaytman, Cherchez Holopherne - Chapter 21, 2011, Siebdruck, Gesso auf Holz.

Betrachterin einen Raum und eine Distanz zurückzugeben, die der modernen Malerei weitgehend fremd ist und lange Zeit als überaus suspekt galt. Nicht dass ich der Auffassung wäre, es handle sich hierbei um eine Rückkehr zu einem frühneuzeitlichen Perspektivismus, vielmehr gewinnt die Perspektive eine kritische Funktion gerade dadurch, dass sie in einem historischen Moment zum Einsatz kommt, in dem die malereigeschichtliche Entwicklung einer modernistischen Reflexion im Element der Fläche, der Faktur oder des Trägermaterials zum wiederholten Mal an ein Ende gekommen ist.

Dass Quaytman diese historischen Diskurse der Malerei nicht ignoriert, dass sie vielmehr Teil ihrer Arbeit sind, zeigt sich symptomatisch in der unbestimmten weißen Leere, die sich hinter den perspektivischen Fluchten ihrer Darstellungen abzeichnet. Sie erzeugen eine Tiefenwirkung, die nicht dem Systemraum gleichkommt, von dem Panofsky im Hinblick auf die Renaissancekunst spricht. Denn ihre Illusionsräumlichkeit ist paradoxerweise zugleich flächig, handelt es sich beim monochromen Weiß doch auch um die sichtbare Grundierung, die den Bildträger für das serigrafische Druckverfahren vorbereitet. Der gespenstische Charakter, der dieser eigentümlichen Raum-Fläche anhaftet, resultiert 
mitunter aus der Unmöglichkeit, deren bildräumliche Modalität in der vereinfachenden Dichotomie von Transparenz und Opazität einzuordnen. Diese Raum-Fläche steht aber auch im Zusammenhang mit einer Krise der Subjektivität, auf die ich noch zu sprechen komme.

\section{Eine Syntax für die Malerei}

Ein künstlerisches Projekt, das mittels der Perspektive die Beziehung zwischen Malerei und Betrachter als kalkulierte Distanz organisiert, könnte Gefahr laufen, als Rückkehr zu einer metaphysischen Raum-, Bild- und Subjektkonzeption interpretiert zu werden. Dass es Quaytman nicht darum geht, den Perspektivismus der Renaissance zu rehabilitieren, habe ich anhand meiner Beobachtungen zur Dezentrierung, Lateralisierung und Kontextualisierung im Werk verdeutlicht. Ich habe gezeigt, dass die metaphysischen Kennzeichen der Renaissanceperspektive gleichsam umgebaut werden zugunsten einer Transzendenz der ästhetischen Autonomie, die eine Verabschiedung des Immanenzcharakters des Gemäldes bedeutet. Es wird im Folgenden darum gehen, die Bedeutung und Konsequenzen dieser Transformation besser zu verstehen. Wie bereits gezeigt, verfolgt Quaytmans Programm der Lateralisierung eine Öffnung und Verbindung des einzelnen Gemäldes mit seinem Kontext. Die "Hauptachse der Lesbarkeit", wie sie sagt, wird "umgelenkt vom individuellen Gemälde hin zur Sequenz und Nachbarschaft in der jeweiligen Ausstellung: ${ }^{15}$ Anhand der Ausstellung Distracting Distance im Rahmen der Whitney Biennial 2010 werde ich herausarbeiten, wie diese Sequenzierung erzeugt wird, wie sie funktioniert und schließlich, was sie für die Frage der mit dem Werk korrespondierenden Subjektivität bedeutet.

Die Ausstellungsansicht in Abbildung 6 zeigt, wie ein Ausstellungsraum des Whitney Museum of American Art mit einer Serie von Gemälden bespielt ist, in welcher eine Variation von formal unterschiedlichen Bildsprachen vorkommen. Auf der rechten Seite der Abbildung ist ein größeres Gemälde zu sehen, das eine

15 Quaytman im Interview mit Jenny Schlenzka. Schlenzka, »Augen auf«, 2011, S. 61. 


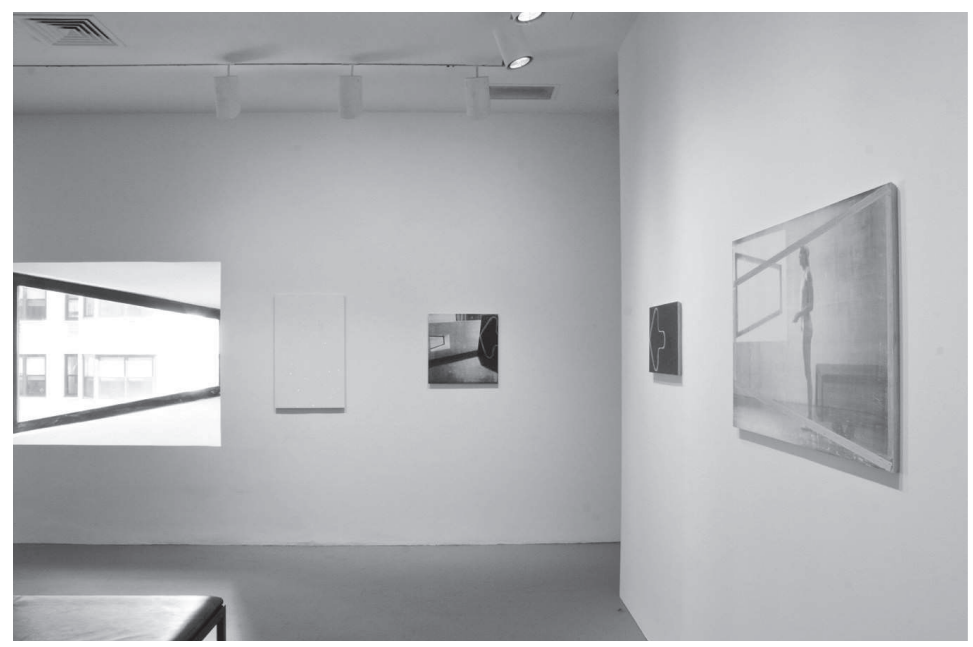

Abb. 6: Rebecca H. Quaytman, Ausstellungsansicht, Distracting Distance Chapter 16, 2010.

fotografische Darstellung zeigt, die mit trapezförmigen braunen Linien übermalt ist. Die Darstellung (Abb. 7) zeigt eine nackte, stehende Figur in Profilansicht, die von der Bildmitte her leicht nach rechts versetzt ist. ${ }^{16}$ Im Hintergrund ist eines der charakteristischen Fenster von Marcel Breuers Museumsbau zu sehen, dessen ungewöhnliche Fensterform von den braunen trapezförmig fluchtenden Linien im Gemälde wiederholt wird. Diese in die entgegengesetzte Richtung verlaufende Wiederholung erzeugt eine eigentümliche Bewegung zwischen dem Inneren des Bildraums und der Bildoberfläche. Sie beginnt mit dem Blick der Aktfigur, führt über die Ober- und Unterseiten des dargestellten Fensters zum linken Bildrand, wo sie, gleichsam in einer Scharnierbewegung auf die Oberflächenbemalung umgelenkt wird und so aus der Bildraumtiefe auf die Bildoberfläche gelangt. Von dort führt sie über die braunen Linien weiter bis an den rechten Bildrand, wo dessen

16 Das Gemälde rekurriert auf Edward Hoppers Women in the Sun aus der Sammlung des Whitney Museum of American Art. Quaytman hat gemeinsam mit der befreundeten Künstlerin K8 Hardy das Sujet Hoppers in den Räumen des Museums neu inszeniert. Dazu: Quaytman, Spine, 2011, S. 279. 


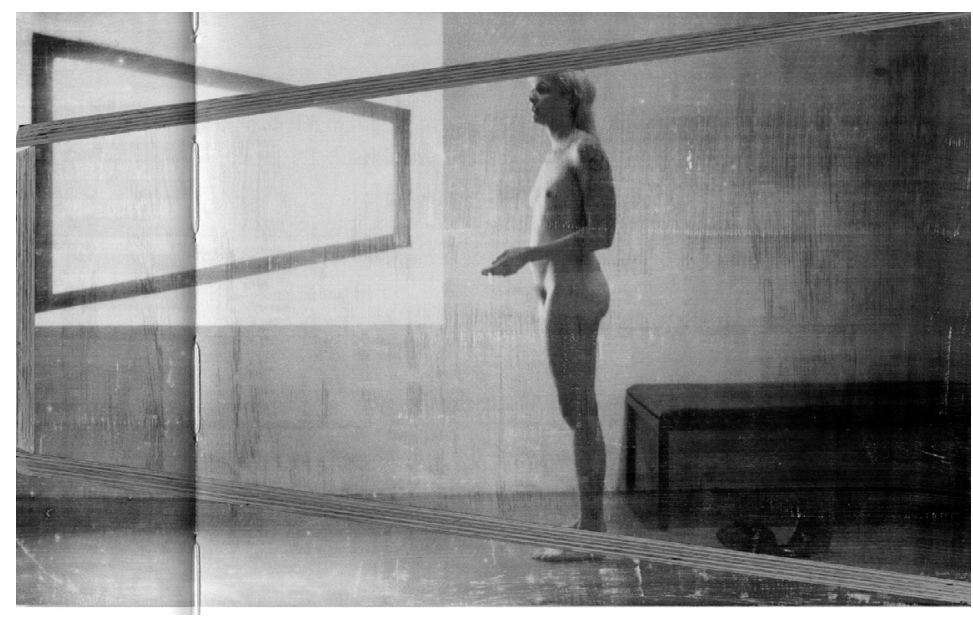

Abb. 7: Rebecca H. Quaytman, Distracting Distance - Chapter 16, 2010, Öl, Siebdruck, Gesso auf Holz.

Sperrholzprofil sie wiederholt und damit die Aufmerksamkeit von der Bildfläche zum Bildrand übergeht.

Diese Bewegung vom Bildraum zur Bildfläche und weiter zum Bildrand, führt schließlich zu jener lateralen Aufmerksamkeit, wie sie in der Ausstellungsansicht (Abb. 6) ungefähr wiedergegeben ist. Das Blickfeld ist sogleich auf die Nachbargemälde sowie den Ausstellungsraum erweitert und von hier aus wird deutlich, wie die Fluchten der Trapezform des besprochenen Gemäldes auf die kleinere benachbarte Tafel zulaufen (Abb. 8). Dieses kleinformatige, schwarzgrundierte Gemälde zeigt eine nach links führende Pfeilform, die den linken Bildrand berührt. ${ }^{17}$ Eine frontale Aufnahme des Bildpaares zeigt, dass sich die Fortsetzungen der Ober- und Unterseiten der Trapezform - also quasi ihr Fluchtpunkt - exakt in der Pfeilspitze am linken Rand des kleineren Nachbargemäldes treffen (Abb. 9). Der Pfeil wird damit zu einem lateralen Richtungsvektor, mit dem der Blick weiter nach links durch den Ausstellungsraum gelenkt wird, wo er an der benachbarten Wand auf

17 Die Darstellung bezieht sich formal auf die Zeichnungen Wladyslaw Strzeminskis, dessen Werk Quaytman vermutlich durch die Texte Yve-Alain Bois' kennenlernte. Vgl.: Quaytman, Allegorical Decoys, 2008, S. 21. 


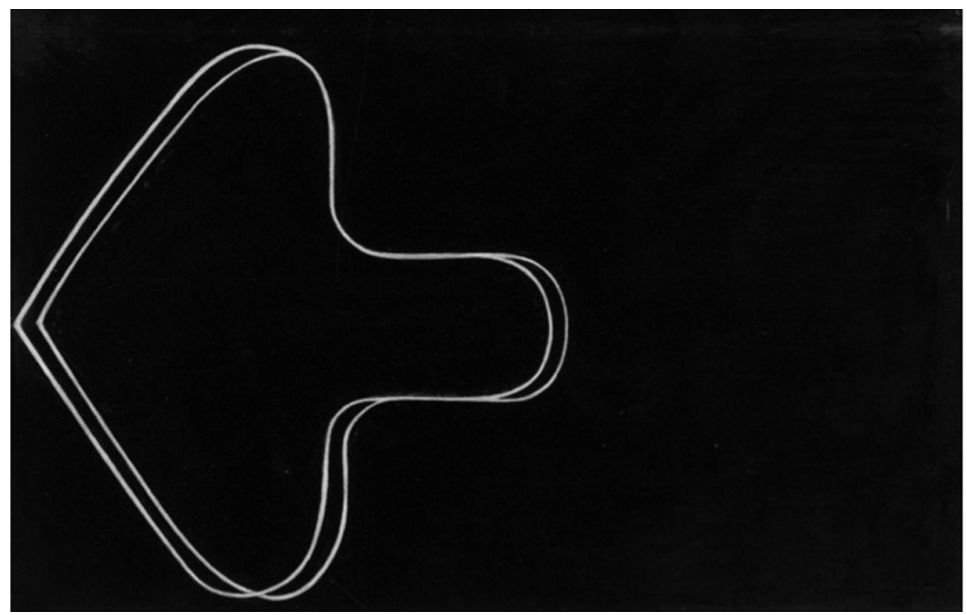

Abb. 8: Rebecca H. Quaytman, Distracting Distance-Chapter 16, 2010, Öl auf Holz.

eine quadratische Bildtafel trifft (Abb. 10). Dieses quadratische Gemälde bildet gleichsam den Treffpunkt für die von rechts und links kommenden Richtungstendenzen, denn in ihm wiederholt sich einerseits der erwähnte Richtungsvektor, aber auch die charakteristische Form des Fensters von Breuers Gebäude, dessen Fluchten ebenfalls direkt auf die quadratische Tafel zulaufen und sich in dieser treffen. Es bildet demnach einen Kulminationspunkt, in dem sich die von links und rechts kommenden Bewegungs- und Richtungstendenzen treffen, ohne dabei zu einem Schlusspunkt zu kommen. Anstelle einer finalen Pointe findet im Bild eine Überkreuzung statt, in der die Fluchten, Richtungsvektoren und Motive der Nachbargemälde sowie der Ausstellungsarchitektur einem Echo gleich widerhallen.

Die damit erzeugte Verkettung von Bildern ist dabei durchsetzt von disjunkten Brüchen, die vor allem durch die formalen Unterschiede der Darstellungen erzeugt werden. Die von Hand gemalte Pfeil-Tafel mit ihrem abstrakten, flächenhaften und nahezu emblematischen Charakter bildet formal einen starken Kontrast zum fotobasierten Nachbargemälde mit seiner mechanischen Faktur, den fein abgestuften Tonwerten und der illusionsräumlichen Tiefe. Aber auch das hochformatige Gemälde neben dem Fenster 


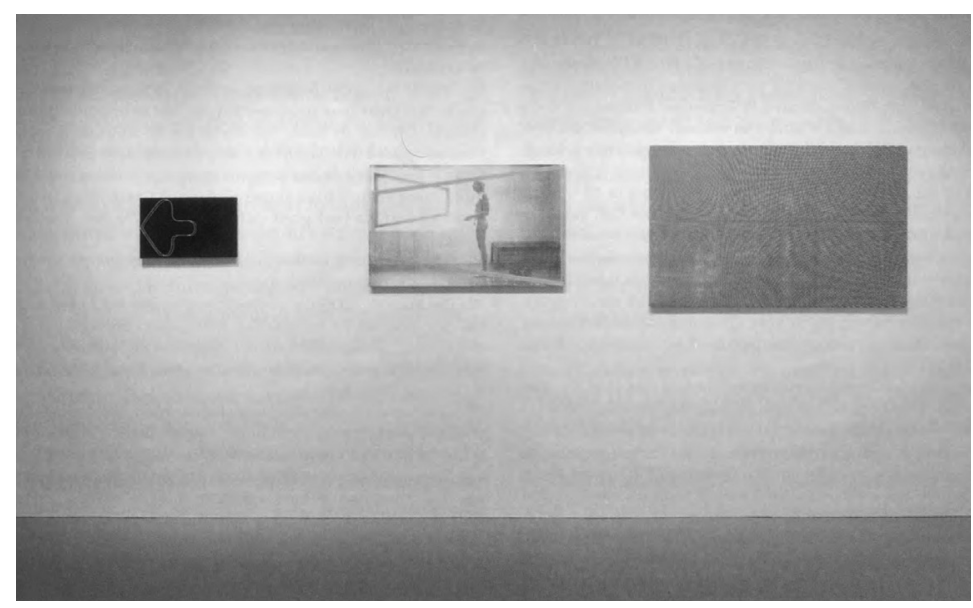

Abb. 9: Rebecca H. Quaytman, Ausstellungsansicht, Distracting Distance Chapter 16, 2010.

(Abb. 6) unterscheidet sich mit seiner oszillierenden Oberfläche auf frappante Weise von seinen Nachbarbildern. Dessen pulsierende, optische Oszillation löst eine starke, um nicht zu sagen schmerzhafte visuelle Irritation aus und hängt unmittelbar mit der Bewegung der Betrachterin vor dem Bild zusammen, womit die laterale Aufmerksamkeit an Dynamik gewinnt.

Die Dezentrierung der einzelnen Gemälde, die mit einer Verkettung derselben einhergehen, ist also zugleich verbunden mit distinkten Bildsprachen, durch die sich die Bilder deutlich unterscheiden. Diese bilden eine zusammenhängende Reihe sichtbarer Entitäten, die gleichsam von visuellen Konjunktionen sowie Disjunktionen durchsetzt ist. In den Disjunktionen artikulieren sich Differenzen, die ihre Wirkung in einem bestimmten Zusammenhang entfalten. Es wird deutlich, dass die ästhetische Selbstbehauptung einzelner Bilder einer Verkettung weicht, die gleichsam sprachförmigen Charakter besitzt. Die paradigmatische Form des Werks ist hier offensichtlich nicht begrenzend und endogen, sondern muss als offen und exogen verstanden werden. Die formale Gestaltung der einzelnen Gemälde ist auf ein sie übergreifendes System hin orientiert, das Bedeutsamkeit aus differenziellen Beziehungen erzeugt. 


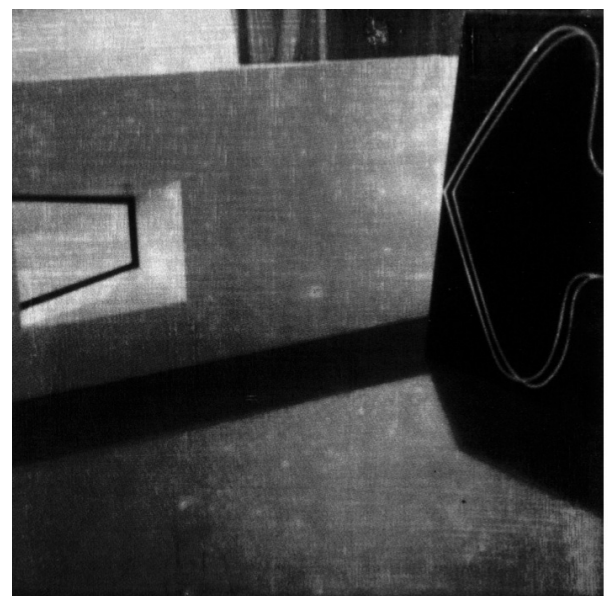

Abb. 10: Rebecca H. Quaytman, Distracting Distance - Chapter 16, 2010, Siebdruck, Gesso auf Holz.

\section{Die Reflexivität des Dispositvs}

Im Werk Quaytmans ist die Sichtbarkeit also mit diskursiven Strukturen durchsetzt, die das visuelle Feld nach semiotischen Prinzipien organisieren. Es geht mir nun darum zu zeigen, dass die Perspektive in diesem Zusammenhang nicht bloß ein formales Instrument bildet, das bei der Organisation dieser Strukturen zum Tragen kommt, sondern dass sie eine grundlegendere Rolle im Unternehmen der Künstlerin spielt. Da diese Rolle wesentlich mit einer theoretischen Dimension verbunden ist, muss ich an dieser Stelle eine bestimmte Tradition der Perspektivtheorie erläutern, um die hier relevante Tragweite der Perspektive zu verdeutlichen.

In der zweiten Hälfte des zwanzigsten Jahrhunderts haben verschiedene Voraussetzungen dazu geführt, dass die strukturalistisch informierte Bildtheorie sich der Perspektive gewidmet hat. Zunächst wirft die moderne Malereitradition mit ihrer profunden Kritik der punktzentrierten Raumkonstruktion, ein negatives Schlaglicht auf die Perspektive, womit diese zum Objekt eines bildgeschichtlichen Bruchs wird, der grundlegende ideengeschichtli- 
che Fragen mit sich bringt. ${ }^{18}$ Weiter ist die Perspektive als formales und systematisches Repräsentationssystem für strukturalistisch orientierte Bildtheoretiker besonders attraktiv, da ihre besonderen Funktionsweisen empfänglich sind für ein Denken, das sich in der Auseinandersetzung mit Sprachsystemen gebildet hat. So kommt es, dass die Perspektive in der zweiten Hälfte des zwanzigsten Jahrhunderts zu einem delikaten Objekt der semiotischen Bildtheorie wird.

Zwei Studien aus Frankreich stechen in der zweiten Hälfte des zwanzigsten Jahrhunderts besonders hervor. In den frühen Siebzigerjahren arbeitet Jean-François Lyotard im Rahmen seiner Studie Discours, figure eine strukturalistische Theorie der Perspektive aus, ${ }^{19}$ und in den Achtzigerjahren entsteht eine umfassende Studie von Hubert Damisch, mit dem Titel: L'origine de la perspective. Letztere ist für die vorliegende Fragestellung von besonderer Bedeutung, denn Damisch formuliert darin nicht nur eine geschichtsphilosophische These zur Perspektive, ${ }^{20}$ er verbindet die Perspektive dabei auch mit Fragen nach der sprachlichen Organisation sowie mit Problemen der Subjektivität.

Ausgangslage und Zentrum seiner Überlegungen ist ein Experiment Brunelleschis, das durch die Schriften Antonio Manettis überliefert ist. ${ }^{21}$ Es bildet den theoretischen sowie historischen Nukleus von Damischs Studie, welchen er als experimentellen Gründungsakt der Perspektive behandelt. Manettis Überlieferung zufolge verwendet Brunelleschi eine im handlichen Format angefertigte perspektivische Darstellung des Baptisteriums in Florenz, in welche an der Stelle des zentralen Fluchtpunkts ein kleines Loch gebohrt ist. Brunelleschi hält sein Auge an die Rückseite der Bildtafel, um durch die lochförmige Öffnung hindurch auf einen gegenüberliegenden Spiegel zu blicken, in dem sich das gemalte Bild widerspiegelt. Das Experiment findet laut Manetti auf dem Florentiner Domplatz statt, wo Brunelleschi den Darstellungseffekt Kubismus in Kahnweiler, »Der Kubismus«, 1916.

19 Lyotard, Discours, figure, 1974. Vgl. dazu das VI. Kapitel der vorliegenden Studie.

20 Damisch, Der Ursprung der Perspektive, 2010. Zu dessen geschichtsphilosophischer These vgl. das VIII. Kapitel der vorliegenden Studie.

21 Manetti, The Life of Brunelleschi, 1970. 
seines Apparates in der unmittelbaren Umgebung seines Motivs prüfen kann.

Das Zusammenspiel von Guckloch, Spiegel und Bild schafft für Damisch die Grundlage dessen, was er als perspektivisches Dispositiv bezeichnet. Es handelt sich um einen Apparat, an den der Blick des Betrachters gleichsam überantwortet ist und wodurch dieser innerhalb einer spezifischen Anordnung organisiert wird. Entscheidend ist dabei für Damisch, dass dasjenige, was sich im Bild, oder genauer gesagt, in dessen sichtbarer Spiegelung zeigt, nicht identisch ist mit demjenigen, dem dieses Bild erscheint. Das im Reflex des Spiegels Erblickte ist Malerei, deren Schein vom zentralen Fluchtpunkt konstituiert wird, der mit dem blickenden Auge des Betrachters auf besondere Weise koinzidiert. In dieser Koinzidenz erkennt Damisch eine doppelte und dabei paradoxe Verfassung des Subjekts: Es sei im sichtbaren Bild impliziert und zugleich exkludiert, will heißen, es ist in der reflexiven Beziehung von Bild und Spiegel anwesend, im selben Moment aber aus diesem »Spiegelkreislauf «22 auch ausgeschlossen. Damisch beschreibt diese Anwesenheit von Abwesenheit in linguistischer Manier als Elision und er versteht den Fluchtpunkt als deren visuelle Chiffre, deren linguistisches Äquivalent die Apostrophierung sei. ${ }^{23}$ Die Perspektive ermögliche damit zum einen die regulative Disposition des Sichtbaren in Beziehung zu einem formalisierten Subjekt, dessen reduzierte Punktförmigkeit die reine Immanenz von Descartes' Cogito quasi vorwegnehme, zum anderen - und das ist für Damisch weitaus wichtiger - reflektiert sie diese Funktion für die Betrachterin.

Die Wirkung des Dispositivs ist so gesehen eine zweifache: Es konstituiert ein Wahrnehmungssubjekt, das an eine außerhalb seiner selbst befindliche Ordnung, d.h. an bestimmte Verhältnisse

22 Damisch, Der Ursprung der Perspektive, 2010, S. 437.

23 Brian Rotman formuliert in einer zeitgleich zu Damischs entstandenen Studie eine ähnliche These, die allerdings auf der mathematischen Semiotik basiert. Rotman begreift die doppelte Bestimmung des Fluchtpunkts als bildinternes Zeichen und zugleich als Metazeichen, das seinerseits auf ein Metasubjekt verweist, analog zur mathematischen Null. Rotman, Die Null und das Nichts. Eine Semiotik des Nullpunkts, 2000.

Albrecht Koschorke wird die These einer Semiotik des Fluchtpunktes zum Thema des Horizonts formulieren. Koschorke, Die Geschichte des Horizonts. Grenze und Grenzüberschreitung in literarischen Landschaftsbildern, 1990. 
einer organisierten Sichtbarkeit verwiesen ist, aus denen es sein Selbstverhältnis und damit seine Subjektivität bildet, deren Bedingungen im selben Moment thematisch gemacht werden. Aus dieser Verfassung des Subjekts folgert Damisch zwei für seine Theorie zentrale Pointen: Er nimmt sie (erstens) zum Anlass einer Analogie von Perspektive und Sprache, welche er mit Hilfe linguistischer Überlegungen aufzeigt. Die frontale Korrelation von Augpunkt und Fluchtpunkt gilt ihm dabei als Äquivalenz der Ortsadverbien (hier-dort) oder der Personalpronomina (ich-du). Zugleich begreift er die Ordnung der Tiefenfluchten der Darstellung, die auf den Fluchtpunkt zulaufen, als Deklinationen, insofern sie eine formale Flexion bedeuten und damit der grammatischen Beugung entsprechen. Die Figuren des perspektivisch konstruierten Bildes seien aber nicht nur auf die Tiefe des Horizonts bezogen, sondern zugleich auf die Ebene, wo sich ihr Zusammenspiel als Konjugation beschreiben lasse. Für Damisch bietet die Perspektive der Malerei einen der Sprache analogen »formalen Apparat«, der paradigmatische sowie syntagmatische Funktionen im Feld des Sichtbaren ermöglicht. Für Damisch bedeuten diese Funktionen keine vollständige Überführung des Bildes in Sprache, jedoch mache sich in den perspektivischen Bildern ein Wille zur Sprache bemerkbar: "Die Perspektive tendiert zum Diskurs «. ${ }^{24}$

Mit diesem theoretischen Programm nimmt Damisch nicht nur Cassirers Interesse an einer Grammatik der symbolischen Formen wörtlich und arbeitet diese mit strukturalistischen Mitteln aus, er möchte in gewissem Sinn auch Cassirers kulturphilosophischen Entwurf einer Subjektivität einlösen, die sich nicht durch Vernunft, sondern an Gegenständen ihrer Entäußerung, d.h. im "Prozess der Gestaltung und `Bildung"« realisiert, wie es bei Cassirer heißt. ${ }^{25}$ Damit komme ich zu Damischs zweiter Pointe, die der Frage nach Subjektivität verpflichtet ist: Die reziproke Beziehung

24 Damisch, Der Ursprung der Perspektive, 2010, S. 442.

25 Cassirer, Philosophie der symbolischen Formen, 1964, S. 50. Damisch bezieht sich im Grunde auf Cassirers Interesse an einer Transformation der Formen des Denkens zu den sinnlichen Formen der Repräsentation, und er möchte damit auch jene Frage beantworten, die Panofsky mit seinem kurzen Hinweis auf Cassirer im Grunde schuldig bleibt. Die Perspektive, so Damisch, sei eine symbolische Form, weil sie paradigmatisch für die »Eroberung der Welt als Repräsentation" stehe und damit ins philosophische Programm des Neukantianers passe. Damisch, Der Ursprung der Perspektive, 2010, S. 29. 
zwischen Betrachter und perspektivischem Dispositiv sei dahingehend zu verstehen, dass das Subjekt, so Damisch, zugleich als Effekt und Träger des Dispositivs auftritt. In der korrelativen Beziehung von Betrachter und perspektivischem Bild ist das Subjekt sowohl durch den Apparat konstituiert als auch konstitutiv für dessen Gelingen. Die Genese dieser Subjektivität kommt also durch eine Selbsterfahrung zustande, die wesentlich von einem Apparat und dessen Wirkung abhängig ist und umgekehrt.

In dieser These verdichtet Damisch zwei Theorietraditionen der Subjektivierung. Zum einen spielt die Psychoanalyse eine zentrale Rolle, deren Beziehung zur Perspektive über das populäre Schema Lacans hinausgeht und eine eigene Studie wert wäre. Damisch rekurriert zunächst auf Sigmund Freuds Vorstellung einer Konstitution des Ichs als `Projektion einer Oberfläche‘, bevor er, wenig überraschend, auf Lacans Überlegungen zum Spiegelstadium als Bildner der Ichfunktion zu sprechen kommt. Er kann damit das Moment des Spiegelbilds in Brunelleschis Experiment mit dem imaginären Charakter des Selbstbewusstseins im Sinne Lacans verbinden und weiter seine eigene strukturalistische Interpretation der perspektivischen Form als einer Grammatik mit der symbolischen Ordnung des Unterbewusstseins assoziieren.

Auf der anderen Seite bezieht sich Damisch auf Michel Foucault, dem er vor allem dann folgt, wenn er die Konstitution der Subjektivität als Effekt eines historischen Dispositivs begreift. Er übernimmt damit die von Foucault beschriebene Ambivalenz zwischen der Fremd- und der Selbstbeherrschung des Subjekts. "Das Wort Subjekt«, so schreibt Foucault, »hat einen zweifachen Sinn: vermittels Kontrolle und Abhängigkeit jemandem unterworfen sein und durch Bewusstsein und Selbsterkenntnis seiner eigenen Identität verhaftet sein. «26

Ist man zunächst etwas erstaunt, dass Damisch sich auf die machtkritische Theorie seines französischen Kollegen bezieht, wo es ihm sonst ein ausgesprochenes Anliegen ist, die Perspektive gegenüber ideologiekritischen Verunglimpfungen zu rehabilitieren, versteht man bald, dass Damisch die Bedeutung des Begriffs "Dispositiv« nicht auf Probleme und Fragen der Unterwerfung 
verengt. Er betont weniger den limitierenden Charakter des Dispositivs, sondern vielmehr dessen Möglichkeiten. Die Befähigung des Subjekts hängt paradoxerweise von seiner Disziplinierung ab. Das Subjekt ist zwar vom Dispositiv abhängig, diese Abhängigkeit ist jedoch nicht nur negativ, denn das Dispositiv bildet zugleich auch den Horizont von Möglichkeiten des jeweiligen Subjekts und seines Selbstentwurfs. Unter diesem Gesichtspunkt betont Damisch vor allem den reflexiven Aspekt des perspektivischen Dispositivs und seines Effekts. Die perspektivische Subjektivität wird zwar in Abhängigkeit eines sie konstituierenden Apparates begriffen, doch was für Damisch zählt, ist der Umstand, dass sich in der Wirkung des Apparats die Genese des Subjekts diesem selbst darbietet. Das Subjekt ist nicht bloß der Effekt des perspektivischen Dispositivs, es kann durch das Dispositiv den Prozess der Subjektwerdung auch erleben. Der Betrachterin, die im perspektivischen Bild elidiert ist und deren Blick sich zwar spiegelt, jedoch nur, um als formales Moment im Horizont eines nach Regeln organisierten Diskurses zu ihm zurückzukehren, vermag ihre Abhängigkeit als Subjekt selbst zu erleben. Für Damisch ist die Perspektive nicht nur das Paradigma subjektgenetischer Diskurse und Repräsentationen, sondern zugleich ein Dispositiv der Reflexion und Enthüllung der Operatoren dieses Paradigmas.

Erst vor dem Hintergrund dieser Theorie der Perspektive als einem reflexiven Dispositiv, das Diskurs und Subjekt konstituiert, lässt sich Quaytmans Reaktivierung der Perspektive angemessen verstehen. Ich habe in den obigen Werkanalysen gezeigt, wie die Perspektive als Instrument der Formalisierung und Distanzierung des Betrachters eingesetzt wird und dass diese Distanzierung mit einer Dezentrierung der einzelnen Gemälde und ihrer ästhetischen Autonomie einhergeht. Ich argumentiere dafür, dass diese Distanzierung und Dezentrierung in Quaytmans Werk, auf programmatische Weise an Damischs Konzeption der Perspektive orientiert ist. Die syntagmatischen Strukturen des Werks - die Rede war von visuellen Konjunktionen und Disjunktionen - sind bestimmt von der Idee einer »Syntax für die Malerei«, wie sie Damisch in seiner Auseinandersetzung mit der Perspektive formuliert. ${ }^{27}$ Als syntaktisches

27 Die syntagmatischen Ausstellungssituationen entwickelt Quaytman nach eigenen Aussagen in Folge ihrer Auseinandersetzung mit Perspektivtheorie 
Malerei-Dispositiv ist die Perspektive also nicht bloß ein Formelement innerhalb der Reihen piktoraler Syntagmen, sie bilden vielmehr das zugrunde liegende Modell dieses Werks und seiner übergreifenden Ordnung. Quaytmans Arbeit zeigt sich in diesem Sinn als Aussage-Dispositiv, das einen Diskurs ebenso grammatisch wie visuell, ebenso subjektbezogen wie reflektiert organisiert.

Diese modellhafte Aneignung von Theorie in der künstlerischen Praxis vollzieht selbstverständlich auch Modifikationen und Verschiebungen an der Perspektive, welche besonders am Ort des Subjekts deutlich werden. Zwar weist Quaytman ganz im Sinne Damischs dem Subjekt einen Ort zu und organisiert die Verhältnisse um diesen Ort mit systematischer Akribie. Während Damisch im Hinblick auf Brunelleschis Experiment diesen Ort jedoch als statisch und fixiert beschreibt, zielt Quaytmans Programm aber auf eine Dynamisierung, ja man könnte sagen Destabilisierung dieses Ortes. Die laterale Orientierung ihres Malereidispositivs setzt das Betrachtersubjekt in Bewegung, eine reale Bewegung seines Körpers im Ausstellungsraum. Das tut der Tatsache jedoch keinen Abbruch, dass Damischs Perspektivtheorie modellhafte Bedeutung für Quaytmans Werk besitzt, sondern zeigt lediglich, dass ihr Werk eine unter historischen Bedingungen zu begreifende Transformation und nicht etwa eine Restauration der Perspektive leistet. Der geschlossene Spiegelkreislauf von Brunelleschis Experiment, durch den das Subjekt mit dem Dispositiv korreliert, wird zwar lateral erweitert, jedoch bleibt das Subjekt an eine kalkulierte Gesamtdisposition verwiesen, aus der es nicht entkommen kann, die es zugleich aber seine Abhängigkeit erleben lässt.

Der Begriff der Abhängigkeit bringt mich zu einem nächsten wichtigen Punkt. Denn die reflexive Dimension des Malereidispositivs erschöpft sich nicht in der formalen Adressierung des

und besonders mit Hubert Damischs Studie: "After doing painstaking perspectival studies, I decided instead to build a white box and place a mirror in it in various positions and take photographs. I also placed a small model of a painting across from the mirror. The photographs would both show me what was in the mirror and act as a mirror to the shallow box of the painting's picture plane. [...] During this time I was reading Hubert Damisch's The Origin of Perspective and Erwin Panofsky's Perspective as Symbolic Form. Following my experimentation with the mirror in a box, I began making models of the actual spaces the paintings were meant for from the perspective of where the viewer would look at the painting." Quaytman, Allegorical Decoys, 2008, S. 14. 
Subjekts. Es gehört zur Perspektive als repräsentationalem Dispositiv, dass sie nicht nur einen formalen Apparat bildet, der an ein Subjekt appelliert, vielmehr ist diese formale Organisation immer auch mit einer Repräsentationsleistung verbunden, mit der die Form innerhalb des Horizonts einer Darstellung zum Tragen kommt. Das ikonografische Programm von Quaytmans Werk spricht denn auch eine eindeutige Sprache. Ob die Gemälde nun die Architekturen des Ausstellungsraumes zeigen, auf die Sammlungsgeschichte der Institution verweisen, oder einfach ihre Nachbargemälde darstellen, in jedem Fall handelt es sich um die Voraussetzung der Sichtbarkeit und Existenz des Werks selbst. Dem Betrachter werden auf Schritt und Tritt die kulturellen, institutionellen und historischen Bedingungen vor Augen geführt, die seiner Wahrnehmung von Malerei zugrunde liegen. Dieses Werk ist über alle Maßen einer Idee von Reflexion verpflichtet, die dem Subjekt seine Implementierung in den Diskurs der Malerei und deren Geschichte aufzeigt. Auch wenn die laterale Dynamik das Subjekt im realen Raum in Bewegung setzt, ist dieser Raum letztlich genauso hermetisch wie der Spiegelkreislauf von Brunelleschis Experiment.

An dieser Stelle wird erneut deutlich, was die oben erläuterte Kritik der ästhetischen Autonomie des Gemäldes bedeutet: Sie ersetzt die moderne Idee einer inneren Gesetzlichkeit des Bildes durch die äußere Gesetzlichkeit des Diskurses. Die Perspektive und ihre formgenetischen Funktionen sind zu diesem Zweck besonders geeignet. Als mathematischer Regelsatz durchkreuzt sie gleichsam die moderne Eigengesetzlichkeit des Werks, allerdings - das ist entscheidend - nicht, um das Sichtbare auf eine metaphysische Idealität zu berufen, sondern um sie als Manifestation eines historischen Diskurses namens Malerei auszuweisen und so mit den Anliegen der Institutionskritik im Sinne einer »kritisch-reflexive[n] Ortsspezifik« zu verbinden. ${ }^{28}$ 


\section{Die Krisen des Subjekts}

Wie ich bereits thematisiert habe, muss Quaytmans Aneignung der Perspektive als Reflexions-Dispositiv nicht nur als Kritik der modernen Werkautonomie begriffen werden; sie muss im selben Zug auch als Kritik einer Subjektivität verstanden werden, deren Autonomie ebenfalls in Frage steht. Die Krise der Subjektivität ist keineswegs neu, bildet Subjektivität doch den prekären Brennpunkt einer Ideengeschichte, die das Problem des 'Ichs seit langem umkreist und unter wechselnden Bedingungen diskutiert. Unter den Vorzeichen neuzeitlicher Rationalität war die Krise des Subjekts erstmals als Krise der metaphysischen Idealität in Erscheinung getreten, eine Idealität, die in der Immanenz von Descartes' Cogito seine reinste Form gefunden hatte. Die Krise äußerte sich u. a. darin, dass diese denkende Immanenz sich selbst fremd bleiben musste, denn unter Einhaltung der deduktiven Methode konnte sie nicht mehr über sich in Erfahrung bringen, als ihre radikal unterbestimmte Existenz - ergo sum. Wenn das perspektivische Dispositiv die Formalisierung des Subjekts zu einem Punkt verantwortet, findet dies also im Horizont einer Geschichte der Subjektivität als Krise statt. Ich möchte zum Schluss dieses Kapitels die perspektivische Subjektivierungsweise in Quaytmans Werk besprechen und dafür argumentieren, dass ihre Aneignung der Perspektive als reflexives Dispositiv eine profunde Krise der Subjektivität mit sich bringt, welche die Abgründigkeit des Cogito unter veränderten ideengeschichtlichen Bedingungen reformuliert.

Die Weise der Subjektivität, um die es sich handelt, ist weder als reine Immanenz noch als Korrelat einer integralen und selbstgenügsamen Form des Werks konzipiert. Im Gegenteil führt die subjektive Reflexion der radikalen Abhängigkeit von den sie tragenden Diskursen, auf die das Werk "transitiv" geworden ist, wie David Joselit es im Hinblick auf Quaytmans Werk formuliert, eine ganz andere Konzeption des Subjekts ins Spiel. ${ }^{29}$ Was aber bedeutet es für ein Subjekt, eine Reflexion zu vollziehen, die weder der Effekt einer im tradierten Sinn ästhetischen Erfahrung ist - einer reflek- 
tierenden Urteilskraft, die seine subjektiven Erkenntnisvermögen und deren Beziehung zur Welt affirmiert - noch die Reflexion der inneren Regeln eines autonomen Werks? Ich folge Damisch, wenn ich behaupte, dass dieses Subjekt nichts 'Humanistisches an sich hat, dass es mittels des Dispositivs vielmehr eine Erfahrung macht, mit der es nicht, wie eine kantische Interpretation nahelegen würde, seine Mündigkeit, sondern vielmehr seine Abhängigkeit erkennt. ${ }^{30}$ Ich erinnere daran, dass die Funktion der Perspektive u. a. darin liegt, das Subjekt in geregelte Beziehungen zu setzen und diese Inbeziehungssetzungen dem Subjekt gleichsam vorzuführen. ${ }^{31}$ Was aber sind die Konsequenzen dieser Erfahrung, die ja wesentlich eine Erfahrung einer sonst weitgehend verborgenen Abhängigkeit ist?

Zur Debatte stehen also die kritischen oder möglicherweise emanzipatorischen Effekte einer Reflexion der eigenen Abhängigkeit. Ich argumentiere dafür, dass das Ergebnis von Quaytmans künstlerischer Praxis einen Effekt erzeugt, der darin liegt, das Subjekt an einem äußerst wunden Punkt zu treffen. Denn wenn Subjektivität der Effekt eines Dispositivs und seiner Diskurse ist und man sich dazu entschließt, dem Subjekt seine Konstitution und seine Abhängigkeit von diesen Diskursen schonungslos vor Augen zu führen, dann droht die subjektive Reflexion zu einer Erschütterung zu werden. Inwiefern kann ein Subjekt die Konstitution seiner selbst wahrnehmen? Gehört es möglicherweise zu den notwendigen Bedingungen einer intakten subjektiven Existenzweise, dass sie ihre Abhängigkeit von einem Diskurs gerade nicht sehen kann bzw. sehen will? Damisch, der die Prekarität des Subjekts in keiner Weise leugnet, ist überzeugt davon, dass die profunde Abhängigkeit des Subjekts vom Dispositiv der Perspektive deren Reflexion

30 Kant kommt in der Analytik des Erhabenen zu dem Schluss, dass ästhetische Erfahrung unsere Subjektivität in ihrer Autonomie affirmiert, indem sie uns erfahren lässt, »dass wir eine selbständige Vernunft haben«. Kant, Kritik der Urteilskraft, 2006, B 99.

31 Patrick Maynard betont, dass die Perspektive im Unterschied zur Parallelprojektion nicht bloß Verhältnisse von Teilen zueinander regelt, sondern diese Verhältnisse relativ zu anderen Verhältnissen, nämlich jenen des Betrachterstandpunktes organisiert. Die Perspektive regelt also die Verhältnisse von Verhältnissen. Maynard, Drawing Distinctions. The Varieties of Graphic Expression, 2005, S. 29. 
und damit ein Wahrheitsmoment nicht ausschließt. ${ }^{32}$ Worin aber liegt der Preis, den ein Subjekt für eine derartige Wahrheit entrichten muss? Kann es sich eine derart profunde Reflexion überhaupt leisten, ohne Gefahr zu laufen, in seiner Selbstverfassung tiefgreifend erschüttert zu werden? Mit Erschütterung meine ich nicht eine Erfahrung, die in letzter Instanz den gelingenden Weltbezug der subjektiven Vermögen affirmiert und nach Kant anzeigt »dass der Mensch in die Welt passe «, ${ }^{33}$ aber auch nicht eine negative Lust, die das Scheitern der Einbildungskraft zum Anlass nimmt, die übersinnliche Bestimmung des Vernunftsubjekts zu entdecken. Ich meine, dass das Werk Quaytmans Gefahr läuft, die subjektkritische Erschütterung ihrer ästhetischen Form gleichsam zu entkleiden und damit das uneinlösbare Versprechen ablegt, das noch Adorno als Wahrheitsmoment der Kunst ausmacht. Jenseits des Ästhetischen bleiben dem Subjekt aber kaum Möglichkeiten, die Kontingenz seiner eigenen Genese zu erfahren. Wenn Damisch Freud zitiert, um vom 'Ich` als einer Projektion der Körperoberfläche zu sprechen, ${ }^{34}$ deutet sich damit auch an, dass die projektive Genese des Subjekts mit der Verdrängung realer Abhängigkeitsverhältnisse verbunden ist. Die illusionistische Projektion ist dann eine geeignete Metapher für Subjektivität, insofern eine Illusion ihre Konstruktion erfolgreich von sich abspalten muss, weil sie sonst ihre Überzeugungskraft verliert. Die für die Subjektgenese konstitutiven Abhängigkeitsverhältnisse, die Quaytman konsequent ausstellt, sind so gesehen die notwendigerweise abgespaltenen und verdrängten Ahnungen des Subjekts. Das Werk leistet in diesem Sinne keine emanzipative Reflexion im humanistischen Sinn, also keine das Subjekt und seine Freiheit affirmierende Erfahrung. Vielmehr ist die erfahrbare Subjektivierung konsequent auf ihre historische und institutionelle Genese verwiesen. Es ist denkbar, dass diese Dekonstruktion ästhetischer Autonomie dennoch eine Form der Emanzipation mit sich bringt, die etwa in der Exposition der Antinomien des modernen Subjekts liegt. Mir scheint jedoch, dass dem Subjekt in seiner Reflexion Grenzen gesetzt sind, Grenzen, die es möglicherweise nur 
um den Preis seiner eigenen Schädigung überwinden kann. Das Subjekt der Perspektive - Damisch sagt es zu Recht - ist immer schon ein gespaltenes und es ist durch diese Spaltung von einem abgründigen Unbehagen verfolgt. Der phantasmagorische Charakter, der Quaytmans Gemälden anhaftet, ist nichts anderes als der Ausdruck dieses Unbehagens. Der gespenstische Charakter des unbestimmbaren weißen Raumes, der sich hinter den Bildfluchten abzeichnet, markiert die nihilistische Krise, die diesem Projekt innewohnt. Das Unheimliche, das aus der kalten Leere dieser Bilder spricht, ist eine abgründige, mit Foucault gesprochen, eine »essentielle Leere ${ }^{35}$

35 Foucault spricht davon, wie sich in Velasquez' Meninas eine "essentielle Leere gebieterisch von allen Seiten anzeigt«. Foucault, Die Ordnung der Dinge, 1974, S. 45 . 


\section{Die Implosion der Perspektive}

\section{Phänomenologie und Perspektive}

Die Beziehung der Philosophie zur modernen Kunst ist nicht selten eine enge und teilweise leidenschaftliche. Es ist bekannt, dass Martin Heidegger über van Gogh und Chillida geschrieben hat, Merleau-Ponty über Cézanne, Jean-François Lyotard über Newman und Gilles Deleuze über Bacon. Die philosophische Auseinandersetzung mit der Kunst der Moderne ist dabei unter so verschiedenen Voraussetzungen betrieben worden, dass es unsinnig erscheint, diese in einer gemeinsamen Geschichte - sei es nun eine Geschichte des Denkens oder der Kunst - zu verorten. Wenn ich die Frage nach der Bedeutung von Philosophie für die moderne Kritik der Perspektive aufwerfe, kann dies also nur für eine ausgewählte und für den systematischen Zusammenhang sinnvolle Gruppe von Autoren und Texten gelten. Eine Denktradition, die in dieser Hinsicht besonders heraussticht, ist jene der Phänomenologie. Nicht nur machen ihre vielfachen Verquickungen mit der modernen Kunst sie zu einem relevanten Feld in der Auseinandersetzung mit der modernen Perspektivkritik, ihre Argumentationen haben auch Eingang in den perspektivkritischen Diskurs des 20. Jahrhunderts gefunden. Sie sollen nun Gegenstand des folgenden Kapitels sein.

Die Beziehung zwischen der phänomenologischen Bildtheorie und der modernen Kunst ist eine komplexe und die Perspektive ist ein Objekt, an dem sich diese Komplexität sozusagen herauskristallisiert. Ein problematischer Aspekt dieser Beziehung liegt in der Suggestion einer Unmittelbarkeit. Denn die phänomenologische Kunstrezeption vermittelt gelegentlich den Eindruck, als machten die Theoretiker an den Werken der Moderne Erfahrungen, aus denen sie Schlüsse über den menschlichen Weltbezug ziehen, welche dann wiederum ihre Beurteilung der Perspektive bestimmen. Diese Konzeption einer phänomenologischen Kunstrezeption unterschlägt, dass die dabei vollzogenen Erfahrungen bereits unter bestimmten intellektuellen Voraussetzungen gemacht werden, die auf die jeweilige Erfahrung gleichsam präfigurierend wirken. 
Daher scheint es mir angemessen, davon zu sprechen, dass die jeweiligen Erfahrungen an wiederum ausgesuchten modernen Werken auf bereits vorhandene Vorstellungen treffen und diesen mehr oder weniger entgegenkommen. Eine andere, nicht weniger problematische Beschreibung der Beziehung zwischen phänomenologischer Philosophie und moderner Kunst könnte diese als bloß diskursive Allianz gegen die Perspektive verstehen, die nach dem Motto operiert: ‘Der Feind meines Feindes ist mein Freund. Ich gehe davon aus, dass derartige Allianzen in der modernen Kritik der Perspektive tatsächlich eine Rolle spielen, denn die Perspektive fungiert öfters auch als Feindbild eines modernen Denkens, in welchem sich eine ganze Reihe von Problemen kumuliert (metaphysischer Intellektualismus, Formalisierung der Wissenschaften, Verlust der Lebenswelt, Ignorierung der Körperlichkeit usw.). Eine Rekonstruktion dieser Allianzen ohne Berücksichtigung der philosophischen Argumentationen kann aber nicht aussagekräftig sein.

Man wird mir die Bildarmut dieses Kapitels verzeihen müssen. Diese hängt jedoch mit dem programmatischen Anspruch zusammen, gerade nicht die Arbeit am Bild zu untersuchen, sondern die intellektuellen Voraussetzungen hervorzuheben, die eben jener Arbeit und ihren historiografischen Konsequenzen zugrunde liegen. Dazu werde ich eine kurze Reihe phänomenologischer Bildtheorien auf ihren Standpunkt hinsichtlich perspektivischer Bildformen befragen. Diese voraussetzungsreiche Kritik, in der sich eine Denktradition kumuliert, die ich `phänomenologisch`nenne, gibt mir Anlass, das Feld der so gearteten Bildtheorie gleichsam von vorne aufzurollen. Dabei werde ich Überlegungen von Gottfried Boehm, Hans-Georg Gadamer, Martin Heidegger, Maurice Merleau-Ponty und Edmund Husserl heranziehen, um nach den Gründen für die phänomenologische Skepsis gegenüber perspektivischer Bildlichkeit zu fragen. Der philosophiegeschichtliche Fluchtpunkt dieser Befragung liegt schließlich in der Phänomenologie Edmund Husserls und seinen frühen Überlegungen zum Bildbewusstsein, welche er in seinen Göttinger Vorlesungen aus den Jahren 1904 bis 1905 formuliert. An diesen Ursprungsdokumenten der phänomenologischen Bildtheorie möchte ich ein grundsätzliches Problem der phänomenologischen Bildanalyse aufzeigen, das 
für die moderne Interpretation des Perspektivbildes von zentraler Bedeutung ist.

Die Grundlage dieses Durchgangs ist das ausgeprägte Interesse an bildlichen Phänomenen, das sich durch die Geschichte des phänomenologischen Denkens bis zurück zu dessen Anfängen in der Philosophie Edmund Husserls nachzeichnen lässt. Da ich keine Geschichte der phänomenologischen Bildtheorie verfassen möchte, habe ich mich entschlossen, diesen Durchgang gleich einer archäologischen Arbeit zu vollziehen. Es geht mir darum, die theoretischen Schichten, die sich zwischen der spätmodernen Ausformung und dem Anfang phänomenologischen Denkens über Bilder abgelagert haben, schrittweise abzutragen. Dieser Durchgang durch die phänomenologische Bildtheorie ist weder vollständig noch lässt er sich insgesamt auf einen gemeinsamen Nenner bringen, da die Fragen und Interessen der jeweiligen Denker doch sehr unterschiedlich ausgeprägt sind. In diesem Sinn verstehe ich 'Phänomenologie` weniger als philosophische Disziplin oder Programm denn als eine Methode. Ist also die Rede von phänomenologischer Bildtheorie, ist damit nicht eine einheitliche Theorie gemeint, sondern ein philosophischer Gegenstandsbereich, der unter gewissen methodischen Bedingungen bearbeitet wird, für die sich bildliche Phänomene als ausgezeichnete Objekte erwiesen haben. Trotz dieser Empfänglichkeit der Phänomenologie für Fragen und Probleme der Bildlichkeit ist die Beziehung dieser beiden aber auch geprägt von tiefgreifenden intellektuellen Problemen, die - wie ich zeigen werde - vor allem ontologischer Natur sind.

\section{Was ist (k)ein Bild?}

Die Kunstgeschichte Gottfried Boehms eröffnet gleich mehrere Wege in die Phänomenologie des Bildes, die hier - so weit als möglich - als Phänomenologie der Perspektive behandelt wird. Perspektivische Bilder spielen in den Überlegungen Boehms immer wieder eine prägnante und zugleich spannungsvolle Rolle, die ich hier im Hinblick auf ihre theoretischen Grundlagen rekonstruiere. Boehm verfasste bereits in den sechziger Jahren seine Dissertation an der Universität Heidelberg zur Perspektive, ein äußerst akademischer Text, der in aller Deutlichkeit den Einfluss seines dama- 
ligen Mentors Hans-Georg Gadamer und dessen Denktradition bezeugt. ${ }^{1}$ So sachkundig diese frühen Überlegungen Boehms zur Perspektive auch sind, so deutlich ist aus heutiger Sicht die fehlende Distanz zu den meisten der im Text behandelten Autoren, was vermutlich dazu geführt hat, dass es nie zu einer Neuauflage dieser 1969 erschienen Studie gekommen ist. In diesem Sinn kann sein Dissertationsprojekt als eine Art intellektuelle Vorarbeit für seine später in der Kunstgeschichte entwickelte Bildtheorie begriffen werden, auf die ich mich im Folgenden konzentriere. Entscheidend für die Frage nach der Kritik der Perspektive ist dabei die Bedeutung, die der Perspektive in Boehms elaborierter Bildtheorie zukommt. In seinem Aufsatz "Vom Medium zum Bild « unterscheidet er den Begriff der ’Perspektive`, der ein »Verfahren und Medium « bezeichne, in präziser Weise von seiner adjektivischen Verwendung, wenn vom "perspektivischen Bild « die Rede ist. ${ }^{2}$ Trotz der langen und engen Beziehung zwischen der Geschichte der Perspektive und der Geschichte der Malerei konstatiert Boehm für die Perspektive den Status eines "Verfahren[s], das Bilder ermöglicht, ohne selbst Bild zu sein «. ${ }^{3}$ Denn das perspektivische Darstellungsverfahren basiere nicht auf der Formung eines konkreten, d.h. sinnlichen Materials, sondern bestehe lediglich aus einem "Satz mathematischer Regeln ${ }^{4}{ }^{4}$ In dieser zunächst analytischen Feststellung ist zugleich eine ontologische Bestimmung der Perspektive angelegt: Es handelt sich bei ihr weder um ein Bild noch um eine stabile visuelle Entität. Daraus folgt auch, dass die Perspektive als Verfahren immer nur mit bzw. an etwas sichtbar wird, das sie selbst nicht ist - sie impliziert mithin einen Objektbezug.

Für die Bildtheorie Boehms ist dieser ontologische Status der Perspektive insofern von Bedeutung, als sie einem geometrischen Prinzip folgt, das gegenüber seiner singulären gestalterischen Konkretion indifferent ist. "Die mathematische Idealität ihrer Vorgehensweise muss sich nicht darum kümmern, ob dies mit Farbe, Kreide oder Grabstichel geschieht, auf Papier, Leinwand oder auch auf einer Kupferplatte etc. ${ }^{5}$ Die Perspektive als solche favorisiert

1 Boehm, Studien zur Perspektivität, 1969.

2 Boehm, »Vom Medium zum Bild«, 1999, S. 171.

3 Ebd.

4 Ebd.

5 Ebd., S. 172. 
demnach keine bestimmte Weise ihrer materiellen Ausgestaltung, genauso wenig wie der Geometer an den spezifisch ästhetischen oder materiellen Qualitäten seiner Beweisführung interessiert ist, solange sie das Verfahren nicht stören. Um diesen idealen Charakter der perspektivischen Konstruktion zu verdeutlichen, verwendet Boehm den von Heidegger geprägten Terminus der "Richtigkeit « ${ }^{6}$ Die richtige Konstruktion erzeuge eine adäquate Repräsentation eines beliebigen visuellen Sachverhalts und zwar regelgemäß, d. h. nach logischen Regeln nachvollziehbar. Boehm verweist in diesem Zusammenhang auch auf den "apparativen" Charakter der Perspektive, denn die logische Richtigkeit der Konstruktion erlaube auch die prinzipielle Reproduzierbarkeit des Konstruierten. ${ }^{7}$

Durch die Bestimmung der Perspektive als mathematisch-logisches Verfahren bringt Boehm dann ihre systemische Idealität als Gegensatz der sinnlichen Partikularität des jeweiligen Trägermaterials in Stellung. Das rrichtige Gelingen der perspektivisch konstruierten Sichtbarkeit sei gerade auf die völlige Transparenz der materiellen Bildfläche angewiesen. Als »reine Projektionsschicht" sollte diese idealerweise totale Durchsichtigkeit ermöglichen und jede »Opazität« vermeiden, die als Störung des Durchblicks in den illusionistischen Raum auftrete. ${ }^{8}$ Entscheidend ist hier die Beobachtung, dass die materielle Fläche als sinnliches Substrat des Bildes von Boehm nicht als Teilelement des systemischen Zusammenhangs perspektivischer Konstruktion begriffen wird, sondern als dessen Konterkarierung. Als genuin sinnliches Element stehe sie der idealen und universellen Konstruktion fundamental entgegen. Boehm unterscheidet und polarisiert also zwei Modalitäten der Sichtbarkeit des Bildes: einerseits die perspektivische als ideale und dabei transparente und andererseits die konkret sinnliche als partikulare und dabei opake.

Für die bildtheoretische Arbeit bietet diese dialektische Polarisierung eine durchaus produktive Ausgangslage, mit der sich über die eigentümliche Sichtbarkeit ikonischer und insbesondere perspektivischer Phänomene nachdenken lässt. Denn es stellt sich nicht nur die Frage nach der genauen Unterscheidung dieser 
beiden Weisen der Sichtbarkeit, sondern auch nach deren jeweiliger Beziehung, Abhängigkeit und Interaktion. Auf der Basis von Boehms ontologischer Bestimmung der Perspektive muss man zu dem Schluss kommen, dass jede perspektivische Darstellung zwingend einer Weise der materiellen Konkretisierung bedarf, um überhaupt sichtbar zu sein, d.h. die perspektivische Konstruktionen muss sich einem wie auch immer beschaffenen opaken Träger einschreiben, womit ihre ideale Sichtbarkeit auf eigentümliche Weise immer schon durchquert ist von der opaken Phänomenalität eines partikularen Materials. ${ }^{9}$

Boehm selbst schenkt dieser Polarität der perspektivischen Bildgebung kein ausgeprägtes Interesse, was daran liegt, dass er dazu tendiert, die Kategorie des Bildes grundlegend auf der Seite des opaken Trägers zu verordnen. Das Bild wird dabei freilich nicht in den Status eines Materials gestellt, die Seinsweise des Bildes ist also keineswegs positivistisch, d.h. als bloßes Objekt bestimmt. Vielmehr begreift Boehm die Erscheinung des Bildes grundsätzlich als ein Differenzphänomen, das sich im Wahrnehmungsvollzug zwischen einem »kontinuierenden Moment" und darin sichtbaren »diskreten Elementen ereignet. ${ }^{10}$ Diese Weise der Differenz ist aber wesentlich in der opaken Materialität des Bildes verortet, ein Umstand, der etwa dann verdeutlicht wird, wenn Boehm im besagten Text von der "eigene(n) Wirklichkeit des Bildes « spricht. ${ }^{11}$

Diese Prämissen lassen nur den Schluss zu, dass das perspektivische Bildgebungsverfahren der eigentlichen Bildlichkeit radikal entgegengesetzt ist. Denn die perspektivisch erzeugte Sichtbarkeit, so Boehm, führe »überhaupt nicht zu einem wirklichen Bild« ${ }^{12}$ Das bereits erwähnte bildtheoretisch potente Zusammenspiel von perspektivischer Transparenz und materieller Opazität zählt Boehm denn auch nicht zum genuin ikonischen Differenz-

9 Jean-François Lyotard hat die zweifache Bedeutung des Trägers des perspektivischen Bildes aus strukturalistischer Sicht beschrieben, "Die Malerei der Repräsentation behandelt den Träger sowohl als Transparenz, die das Sehen, als auch als Opazität, die das Lesen ermöglicht." Lyotard, "Veduta auf ein Fragment der Geschichte des Begehrens«, 2011, S. 186.

10 Boehm, "Ikonische Differenz«, 2011, S. 172. Zum Element des Kontinuums vgl. auch Boehms Begriff des »Grundes« in Boehm, »Der Grund. Über das ikonische Kontinuum«, 2012.

11 Boehm, "Vom Medium zum Bild«, 1999, S. $173 \mathrm{f}$.

12 Ebd. 
phänomen. Etwa am Beispiel der Malerei von Piero della Francesca macht er deutlich, dass er dieses Zusammenspiel als ein Gegenspiel zwischen "perspektivischem Medium" auf der einen Seite und "Malerei« auf der anderen Seite begreift: "Der Künstler stiftet eine Balance zwischen den Ansprüchen der Projektionslogik und jenen anderen, die sich aus der Logik des Bildes ergeben, fallweise schlichtet er, was an Widersprüchen, was im 'versus $`$ aufkommt. ${ }^{13}$ Die Polarität ist also weniger als produktive Beziehung zweier bildlicher Modalitäten gedacht, deren Zusammenspiel die bildliche Darstellung ausmache, sondern als antagonistisches Verhältnis einer ikonischen, d.h. bildkonstituierenden Bewegung und einer gleichsam anti-ikonischen, das Bild negierenden Gegenbewegung. ${ }^{14}$ So gesehen arbeitet die perspektivisch generierte Sichtbarkeit und ihre Logik gegen das Wesen des Bildes, was Boehm an anderer Stelle dazu veranlasst, die Perspektive als eine Weise des bildimmanenten Ikonoklasmus zu beschreiben: "Das illusionistische Bild ist aber auf paradoxe Weise selbstzerstörerisch. ${ }^{15}$

Man könnte zu der Annahme kommen, dass Boehms Beschreibung der perspektivischen Sichtbarkeit als Autoikonoklasmus wesentlich ein Problem des Raumes ist, da die Begrifflichkeiten wie "Opazität« oder »Projektionsschicht" sich scheinbar auf die räumlichen Modalitäten des Bildes beziehen. Es ist umso überraschender, dass ein zentraler Aspekt von Boehms Kritik der

13 Ebd.

14 In seinem Aufsatz »Die Bilderfrage « erwähnt Boehm zwar die bildtheoretische Notwendigkeit einer Verbindung zwischen einer Transparenz- und Opazitätstheorie des Bildes, um jedoch sogleich die Transparenztheorie als »Überschreitung des Bildes" abzuhandeln und die antiperspektivische Malerei der Moderne als Neuentdeckung der »Urrealität aller Malerei« darzustellen. Boehm, »Die Bilderfrage«, 1994, S. 338ff.

15 Ebd. An anderer Stelle formuliert Boehm die These von der Perspektive als einem bildinternen Ikonoklasmus mit den Worten des Paul Graf Yorck von Wartenburg, wenn er schreibt, dass die perspektivische Malerei danach strebe, »die Bildlichkeit mittels des Bildes aufzuheben«. Boehm, »Die Wiedergewinnung der ikonischen Zeit«, 2007, S. 104. Boehm dazu: »Wäre es darum, um ein illusionsstiftendes Bild gegangen, das sich idealenfalls von der Realität, die es darstellte, gar nicht mehr unterscheiden ließe, das Bild würde sich mit der Erreichung dieses Ziels selbst aufheben. Man müsste sagen, Bild soll nicht sein, Realität soll sein, genauer, das Bild soll Realität werden. Denkt man diesen Gedanken zu Ende, stellt man überrascht fest, dass die vollendete Abbildlichkeit, d.h. der Illusionismus, mit der perfekten Ikonoklastik konvergiert. Mitten im gelungenen Abbild nistet eine bildaufhebende Kraft." Boehm, »Die Bilderfrage«, 1994, S. 336. 
Perspektive auf die Temporalität des perspektivischen Bildes zielt. Formuliert wird dies in konziser Weise im Text "Die Wiedergewinnung der ikonischen Zeit «. ${ }^{16}$ Im Vordergrund steht dabei Boehms Beobachtung, dass perspektivisch konstruierte Darstellungen eine prinzipielle Scheidung von Raum und Zeit aufweisen. Auf der Basis des bereits skizzierten ersten Arguments, der Negation opaker Valenzen durch die perspektivische Raumkonfiguration, unterstreicht Boehm weiter den zeitlosen Charakter des linearperspektivischen Bildraums. Die geometrische Idealität dieses Raums führe zu einem zeitlichen Stillstand, mit dem die dem Bild eigene Zeitlichkeit untergraben werde. Die temporalen Artikulationsmöglichkeiten perspektivischer Malerei liege einzig in den dargestellten Szenen, d.h. in den "agierenden Figuren«, die im selbst zeitlosen Bildraum zu sehen sind und vermittels der dargestellten Handlungen eine nachvollziehbare Narration bewirken. ${ }^{17}$ Eine solche narratologisch begriffene Temporalität ist für Boehm jedoch problematisch, weil sie auf Kosten einer genuin ikonischen Zeitlichkeit entstehe, deren Wiederkehr er in der modernen Malerei erkennt.

Bevor ich Boehms malereigeschichtliches Narrativ der Wiedergewinnung der ikonischen Zeit beschreibe, soll zunächst die Temporalitätskritik der Perspektive genauer analysiert werden. Deren Grundlage liegt in der fundamentalen Unterscheidung zweier Weisen der Zeitlichkeit: Die anhand einer abgebildeten Szene artikulierte Zeit muss als eine dargestellte Zeit verstanden werden und ist von der Zeit der Darstellung selbst zu unterscheiden. Diese Zeit der Darstellung ist nichts anderes als die Zeitlichkeit der bereits erwähnten ikonischen Differenz. Die Differenz opaker Elemente, die in einem materiellen Träger fundiert sind, wird von Boehm auch als eine zeitlich prozessuale Differenz gedacht. Da er in der perspektivischen Konfiguration des Bildes eine Aufhebung der ikonischen Differenz erkennt, folgt daraus, dass auch ihre Zeitlichkeit verändert wird: "Das Perspektivbild transferiert Temporalität aus dem Bereich der Fläche und des Grundes in denjenigen der diskreten Figuren, des exemplarischen Körpers. «18 Die Zeit der 
Darstellung, d.h. die temporale Ereignishaftigkeit der Bilderscheinung, werde zugunsten der dargestellten Ereignisse aufgegeben, was nicht weniger bedeutet, als dass perspektivische Bilder, ganz im Sinne Lessings, lediglich in der Lage sind, Zeit "auf indirekte Weise zugänglich" zu machen. ${ }^{19}$

Diese elaborierte Kritik der Perspektive muss schließlich in dem größeren historischen Zusammenhang begriffen werden, in dem Boehm die Perspektive verortet. Entscheidend ist dabei das malereigeschichtliche Narrativ, das im Text "Die Wiedergewinnung der ikonischen Zeit" auf exemplarische Weise formuliert wird. Denn die perspektivische Bildform wird nicht einfach als Verlust einer eigentlichen Bildlichkeit und genuin ikonischen Temporalität des Bildes gedeutet, sondern bildet die Prämisse weiterer Analysen ausgesuchter Werke vom achtzehnten bis zum zwanzigsten Jahrhundert. Anhand einer Reihe von Beispielen der modernen Malerei - unter ihnen sind William Turner, Edouard Manet und Claude Monet (Abb. 1 bis 3) - zeigt Boehm, wie eine schrittweise Emanzipation der Malerei von der perspektivischen Darstellungskonvention stattgefunden hat, und beschreibt damit jene Wiedergewinnung der ikonischen Zeit, die dem Text seinen programmatischen Titel gibt. Die durchschlagende Überwindung der Perspektive skizziert er mittels ausgesuchter Werke der impressionistischen Malerei, die er am Beispiel Claude Monets als endgültige »Auflösung" der perspektivischen Scheidung von Raum und Zeit begreift. ${ }^{20}$

Es sind denn auch die Werke Monets, an denen Boehm exemplarisch jene Weise der bildlichen Temporalität herausarbeitet, die den Gegenpol zur bloß darstellbaren Zeit durch perspektivische Bildmittel darstellt. Dabei geht es um die bereits erwähnte Zeitlichkeit einer Erfahrung, die sich nicht auf das im Bild Repräsentierte bezieht, sondern auf das Erscheinen des Bildes selbst, also den Umstand, dass auf der bemalten Fläche des Gemäldes etwas sichtbar wird, das dessen faktische Materialität in sinnstiftender Weise übersteigt. Dieser sinnvolle Mehrwert, durch den ein Stück bemalte Leinwand überhaupt als Bild zu erscheinen vermag, liegt für Boehm gerade nicht in der restlosen Transzendenz

19 Ebd.

20 Ebd., S. 115. 


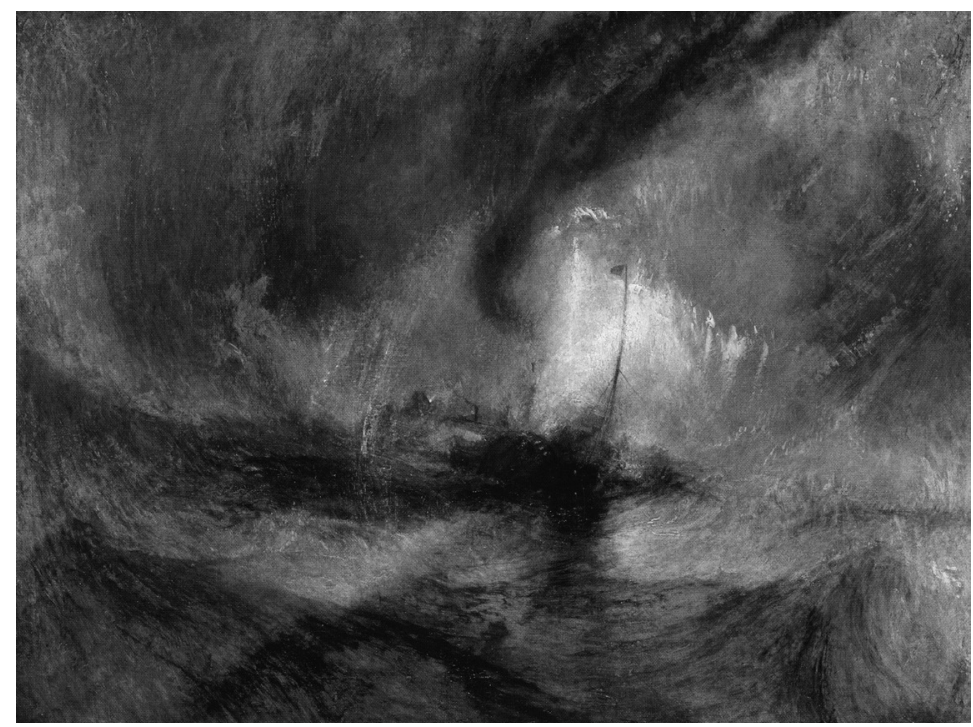

Abb. 1 : William Turner, Schneesturm, 1842, Öl auf Leinwand.

seiner bloßen Materialität, sondern in einem besonderen Wahrnehmungsvollzug, in dem sich diese Materialität gleichsam dynamisiert. Monets spezifische Verwendung der malerischen Faktur, des Farbspektrums und seiner additiven Farbmischung bildet die gestalterische Grundlage dieser Dynamisierung. Die unzähligen farbigen Pinselspuren, von denen die Bildfläche gleichmäßig bedeckt ist, lassen sich weder restlos mit dem Dargestellten identifizieren noch in ihrer chromatischen Qualität als einzelne Farbflecken isolieren. Vielmehr schließen sie sich zu einer präsenten Ganzheit zusammen, deren Erfahrung Boehm als »Oszillation des Sehens « beschreibt, eine Erfahrung, in der die Dimensionen Raum und Zeit untrennbar miteinander verbunden seien. ${ }^{21}$ Die Raumtiefe sei hier "aus der materiellen Realität der Fläche« hergeleitet und diese Herleitung hat pulsierenden und damit zeitlichen Charakter: "Der Puls der Oszillation begründet die Erfahrung von Zeit, er ist der Herzschlag des Sichtbaren selbst. ${ }^{22}$ Es geht hier also 


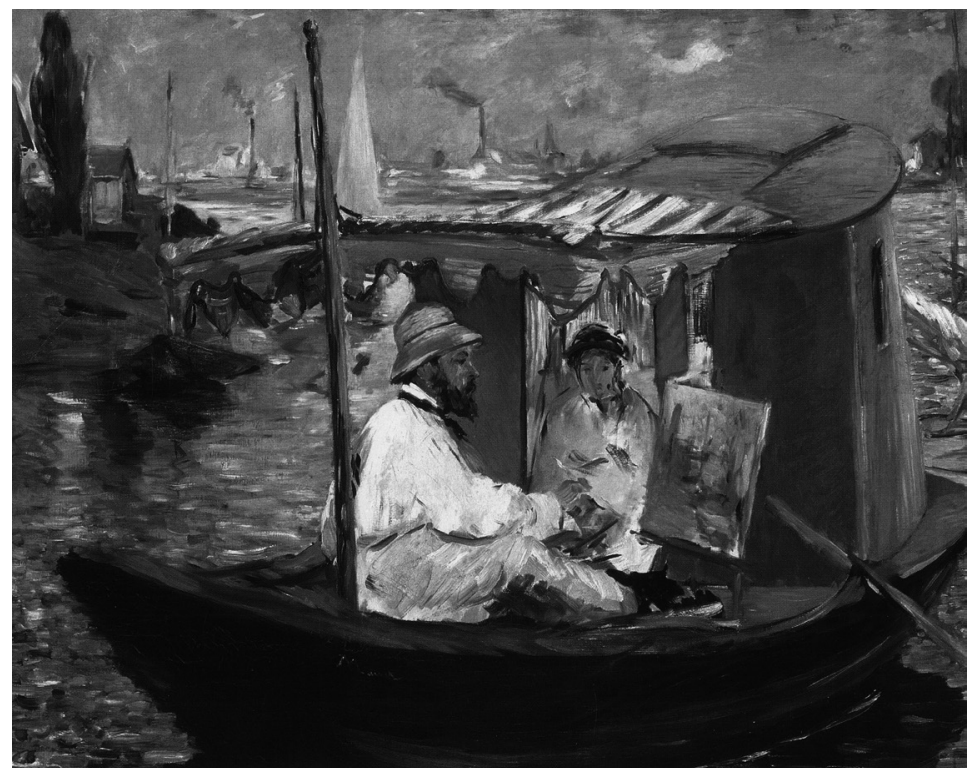

Abb. 2 : Edouard Manet, Die Barke, 1874, Öl auf Leinwand.

um eine besondere Weise der Bildgestaltung, die eine besondere Weise der Bildwahrnehmung zur Folge hat, in der die Erfahrung von Räumlichkeit radikal von der Zeit derselben Erfahrung durchdrungen ist.

Es sei an dieser Stelle nur angedeutet, dass Boehm kaum über die wissensgeschichtlichen Bedingungen, wie etwa die Physiologie spricht, die der Malerei der klassischen Moderne und ihren Weisen der Sichtbarmachung zugrunde liegen. ${ }^{23}$ Sein Narrativ behandelt dagegen die Wiederentdeckung der ikonischen Zeit "als Bildereignis«, d.h. als ein bildgeschichtlicher Prozess, der scheinbar ausschließlich in der autonomen Sphäre der Kunst stattfindet. ${ }^{24}$ Obschon Boehm dabei eine ganze Reihe von Argumenten ins Feld führt, mit der die Perspektive problematisiert wird, bleibt sie für sein malereigeschichtliches Narrativ doch fundamental. Bedenkt man, dass der bildgeschichtliche Prozess der Wiedergewinnung

23 Eine in dieser Hinsicht aufschlussreiche Gegenlektüre bietet etwa Brain, The Pulse of Modernism. 2015.

24 Boehm, »Die Wiedergewinnung der ikonischen Zeit«, 2007, S. 117. 


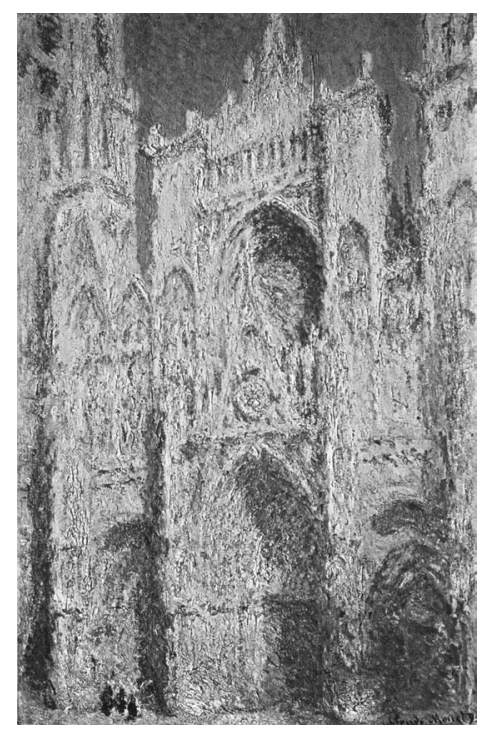

Abb. 3 : Claude Oscar Monet, Kathedrale von Rouen, 1894, Öl auf Leinwand.

wesentlich im Hinblick auf das Bildmodell der Perspektive geschildert wird, wird klar, dass der Perspektive in diesem Narrativ auch eine diskursive und rhetorische Rolle zukommt. Diese macht sich zunächst in den Begrifflichkeiten der "Wiederentdeckung" und "Wiedergewinnung" bemerkbar, denn das Adverb 'wieder antizipiert, dass die Errungenschaften der modernen Malerei letztlich einer Rückbesinnung auf eine ursprüngliche und eigentliche Leistung des Ikonischen gleichkommen..$^{25}$ Die perspektivische Malerei und ihre historische Wirksamkeit werden in diesem Zusammenhang als Verlust jener Ursprünglichkeit veranschlagt, die in der Moderne wiedergefunden wird. Dies vermittelt mitunter den Eindruck, als arbeite die moderne Malerei scheinbar nicht unter spezifisch historischen Bedingungen, d. h. unter Voraussetzungen der künstlerischen Produktion, welche mit Interessen und Problemen der modernen Lebenswelt, Wissenschaft und Machtverhältnissen konfrontiert ist. Vielmehr wird dafür argumentiert, dass die 
moderne Malerei an der Überwindung der hegemonialen Konventionen perspektivischer Darstellung interessiert sei. Deutlich wird dies an jenen Stellen, an denen Boehm die besonderen Qualitäten der modernen Malerei explizit im Gegensatz zur Perspektive herausarbeitet. Er spricht etwa von der "Ganzheit« und "Intensität der Wahrnehmung « impressionistischer Bilder, um im selben Zug zu betonen: "Ein bildbeherrschender Fluchtpunkt hat ausgedient. ${ }^{26}$ Dieselbe Dialektik kehrt wieder, wenn es ebenfalls hinsichtlich Monets Malerei heißt: "Deren Disparität und Dynamik sprengte das feste Gefüge des Perspektivbildes. ${ }^{27}$ Und im Hinblick auf ein Werk aus Monets Serie der Nymphéas: "Ein Zeit-Raum mit Betonung auf dem ersten Wort: temps. Damit ist die im Perspektivbild enthaltene Unterordnung definitiv umgekehrt. Zeitliche Impulse tragen die von Räumlichkeit, die bei Bedarf aufgehen, um fluidale Tiefen zu schaffen, nirgendwo verfestigen. Nichts vom linearen Schematismus der Perspektive. ${ }^{28}$

Diese Dialektik, die sich als wirksames rhetorisches Mittel erweist, um Fragen nach der Zeitlichkeit von Bildern auszuformulieren, ist ein hervorragendes Beispiel dafür, wie der moderne Diskurs Konzepte, Differenzen und Narrative mit Hilfe der Perspektive produziert. Besonders kennzeichnend ist dabei die eigentümliche Beziehung zwischen theoretischen Überlegungen und historischen Phänomenen der Malerei. Denn die Thesen zu den unterschiedlichen Temporalitätsstrukturen, die perspektivische Bilder etwa von impressionistischen unterscheiden, zeigen sich als Teil einer größeren Geschichte, die von Befreiung und errungener Autonomie der modernen Malerei handelt. Dabei ist unklar, ob diese Geschichte mehr den historischen Entwicklungen oder aber den theoretischen Überlegungen gerecht wird. Die folgende Textstelle aus Boehms Aufsatz verdeutlicht dieses Problem: "Es geht ihm [Claude Monet] um die Verschärfung der Augenblicklichkeit, darum, die in Auflösung befindliche Raum-Zeit-Verzweigung des Perspektivbildes durch integrale Bildformen zu ersetzen. ${ }^{29}$ Der Text schreibt der Perspektive demnach die Rolle eines 
unmittelbaren Objekts der künstlerischen Kritik zu, wobei ihre Rolle als Objekt der Kritik des Autors selbst ausgeblendet ist.

Diese doppelte Rolle der Perspektive macht sich auch im Umstand bemerkbar, dass sie einerseits das zentrale, wenn auch negative Referenzobjekt der theoretischen und historischen Argumentation bildet. Andererseits wird ihre Bedeutung aber auch einem Relativismus unterworfen. Boehm betont, dass die Perspektive bloß eines von vielen Modellen des Bildes sei: "Es [das Perspektivmodell] ist nicht richtiger oder falscher als andere. ${ }^{30}$ Dieser Relativismus überrascht, denn er steht nicht nur in Kontrast zum Unbehagen gegenüber der Perspektive, welches im Text zum Ausdruck kommt, auch muss man aus einer derartigen Aussage schließen, dass grundsätzlich eine Pluralität gleichberechtigter Bildmodelle besteht, zu denen dann konsequenterweise auch jene der Moderne zählen müssten. Boehms Überlegungen vermitteln jedoch weitgehend den Eindruck, dass die moderne Malerei das Bildmodell der Perspektive nicht zugunsten alternativer Darstellungsweisen verabschiedet, die ihrerseits historischen, normativen, kurzum kontingenten Charakter haben, sondern dass die Bildmodelle der modernen Malerei im Modus einer nicht relativierbaren Freiheit operieren. Die "Norm des Perspektivbildes" wird demnach nicht durch eine andere historische Norm abgelöst, sondern von Normen befreit, was schließlich »den Blick frei« gibt. ${ }^{31}$ Die moderne Malerei als Verneinung tradierter Normen darzustellen, um im selben Zug die historischen und paradigmatischen Voraussetzungen der modernen künstlerischen Bildproduktion unerwähnt zu lassen, zeigt eine verbreitete Funktion der Perspektive innerhalb der modernen Diskurse zur Malerei.

Die diskursive Funktion der Perspektive als ein negatives und zugleich konstituierendes Moment ist für deren Schicksal in der Moderne entscheidend. Adorno hat diese Entwicklung treffend beschrieben, wenn er schreibt: "Wo immer Kunstwerke, auf der Bahn ihrer Konkretion Allgemeines: eine Gattung, einen Typus, ein Idiom, eine Formel polemisch eliminieren, bleibt das Ausgeschiedene durch seine Negation in ihnen enthalten; dieser Sachverhalt 
ist konstitutiv für die Moderne. ${ }^{32}$ Die Perspektive ist aber nicht nur das Objekt dieser diskursiven Negation, sondern zugleich ein theoretisches Objekt, das als solches Gegenstand philosophischer Debatten ist. Boehms Denken über Bilder steht in einer post-nietzscheanischen Tradition, die zu einem verstärkten Interesse an sinnlicher Erfahrung geführt hat, Erfahrung, die nicht im traditionell epistemologischen Sinn prädikativ sind, sich aber auch nicht mit der vom Idealismus geprägten Disziplin der Ästhetik fassen lassen. Die Kunst der Moderne bietet dabei in mehrfacher Hinsicht ein Register von Erfahrungsmöglichkeiten, mit denen die Philosophen operieren können. Bilder nehmen dabei eine entscheidende Rolle ein, werfen bildliche Darstellungsweisen doch fundamentale Fragen auf, die etwa unter ästhetischen, wahrnehmungstheoretischen oder semiotischen Vorzeichen diskutiert werden können.

Für Gottfried Boehms Kunstgeschichte spielt zunächst HansGeorg Gadamers Hermeneutik eine zentrale Rolle. Abgesehen von biografischen Umständen bestehen enge intellektuelle Beziehungen zwischen den Überlegungen der beiden Autoren zum Bild, die ich im Folgenden kurz skizziere. Boehm und Gadamer ist gemeinsam, dass sie das Bild aus dem Schatten einer traditionell logozentrischen Wissenschaftskultur lösen wollen, um es als autonome Sinnquelle zu begreifen. In dieser Hinsicht hat Hans-Georg Gadamer entscheidende Vorarbeit geleistet, die besonders in Boehms Perspektivtheorie zum Tragen kommt. Ich diskutiere hier Gadamer, der als Denker der philosophischen Hermeneutik gilt, im Kontext einer phänomenologischen Kritik der Perspektive, nicht nur wegen seiner biografischen Nähe zur phänomenologischen Tradition, sondern weil seine Argumentation hinsichtlich des Bildes methodisch der Phänomenologie verpflichtet bleibt. ${ }^{33}$

Gadamer siedelt bildliche Phänomene innerhalb seines hermeneutisch begriffenen Horizonts von Sprache an, den er im weitesten Sinn als den Horizont des Verstehbaren definiert. ${ }^{34}$ Innerhalb

32 Adorno, Ästhetische Theorie, 1973, S. 522.

33 Gadamer hatte seit den frühen 1920er Jahren intensive und nachhaltige Beziehungen zu Edmund Husserl und vor allem auch zu Martin Heidegger. Vgl. dazu Gadamers intellektuelle Autobiografie, Gadamer, Philosophische Lehrjahre, 1995.

34 Der Begriff "Sprache« bezeichnet in diesem Sinn den gesamten Bereich jeder epistemologischen, historischen und ästhetischen Sinngenese. So 
dieses Horizonts schenkt Gadamer dem Bild viel Aufmerksamkeit, deren Ausgang zunächst eine romantische Konzeption der ästhetischen Erfahrung ist. Gadamer erweitert die Konzeption ästhetischer Erfahrung jedoch an entscheidenden Punkten, indem er sie mit ontologischen Fragen ergänzt. Diese Ontologisierung der ästhetischen Erfahrung scheint mir von entscheidender Bedeutung für die Fragen nach der modernen Perspektivkritik, denn wie schon die Rekonstruktion von Boehms Argumentationen gezeigt hat, ist die ontologische Unterscheidung und Bestimmung des Bildes maßgebend für die Urteile über perspektivische Bilder.

Diese Ontologisierung macht sich in Gadamers Überlegungen zur ästhetischen Erfahrung dann bemerkbar, wenn er das Moment der unauflöslichen Verbundenheit zwischen Dargestelltem und Darstellung betont. Denn in seiner Konzeption ästhetischer Erfahrung hebt Gadamer nicht die formalen Qualitäten des ästhetischen Gegenstands hervor, sondern betont die Integrität von Form und dem affektiven Element des Objekts bzw. des Inhalts. ${ }^{35}$ Wer Schönheit erfährt, wird nicht in der Lage sein, am Objekt seiner Erfahrung eine klare Unterscheidung etwa zwischen den philosophisch tradierten Kategorien Form und Stoff zu treffen oder zwischen der Form der Darstellung und ihrem Inhalt zu unterscheiden. Beide Dichotomien müssen nach Gadamer als analytische Unterscheidungen begriffen werden, die im Rahmen der ästhetischen Erfahrung obsolet sind, da sich die scheinbar dichotomen Kategorien in der Erfahrung immer als unauflösliche Einheit zeigen. Gadamer beschreibt diese Einheit mit dem Begriff der "ästhetischen Nichtunterscheidung ${ }^{36}$ und zielt damit in letzter Instanz auf die Ununterscheidbarkeit von Darstellung und Dargestelltem.

Diese Auslegung der Erfahrung des Schönen ist für die Frage nach der Perspektive daher von Interesse, weil sie auf jene Dimension des Bildes abzielt, die für Boehms Problematisierung perspektivischer Bilder entscheidend ist. Dies wird besonders klar gemacht, wenn Gadamer die besonderen Valenzen der bildlichen

schreibt Gadamer in Wahrheit und Methode: "Was verstanden werden kann ist Sprache«. Gadamer, Wahrheit und Methode, 1999, S. 479.

Zur traditionellen Konzeption der ästhetischen Erfahrung, wo die affektive Dimension der sinnlichen Erfahrung nicht virulent ist, siehe vor allem die Analytik des Schönen, in: Kant, Kritik der Urteilskraft, 2006, S. 47-104.

Gadamer, Wahrheit und Methode, 1999, S. $122 \mathrm{ff}$. 
Darstellung gegenüber dem schriftlichen Text verdeutlicht. Anders als im Medium des Wortes seien beim Bild die sinnlichen Qualitäten der Darstellung für das Dargestellte absolut virulent. Während etwa die »sinnlosen Striche ${ }^{37}$ eines Texts bloß funktional dienlich seien und als "reines Verweisen ${ }^{38}$ funktionieren, partizipiere beim Bild dessen ganze Existenz am Dargestellten. Die bildliche Darstellung verhält sich zum Dargestellten demnach nicht als ein transitives Medium, sondern hat in seiner sinnlichen Existenz und Partikularität wesentlich Teil an ihm. Gadamer ist der Auffassung, „dass die primäre Intention dem Bild gegenüber zwischen Dargestelltem und Darstellung nicht unterscheidet. « ${ }^{39}$

Entscheidend an Gadamers Konzeption einer Indifferenz zwischen Darstellung und Dargestelltem ist schließlich deren Bestimmung, die letztlich weder ästhetisch noch medial ist, sondern ontologisch. Er macht unmissverständlich klar, dass es ihm um das Sein der Darstellung geht: "das Bild [macht] sein eigenes Sein geltend, um das Abgebildete sein zu lassen. ${ }^{40}$ Diese ontologische Deutung der genuin bildlichen Darstellungsweise fasst Gadamer dann im Begriff der 'Seinsvalenz` zusammen, einem Begriff, der die ontologischen Prämissen der phänomenologischen Perspektivkritik anzeigt.

Wie ich bereits gezeigt habe, argumentiert Boehm dafür, dass die perspektivische Bildform dasselbe ontologische Moment aushebelt, dessen Valenz Gadamer betont. Wenn die Perspektive aber ein Verfahren ist, dass der genuin bildlichen Darstellungsweise, unter den erläuterten Voraussetzungen, nicht gerecht wird, dann stellt sich die Frage, wie man die Artefakte der perspektivischen Gestaltungsverfahren begreift. Denn wenn sie die Seinsvalenz des Bildes untergraben, kann es sich bei ihnen nicht um Bilder im eigentlichen Sinn handeln. Boehm schlägt seine Lösung für dieses Problem in direkter Auseinandersetzung mit Gadamer vor, und zwar indem er eine zweite, defizitäre Klasse von Bildern einführt. Er entwickelt diese Klasse auf der Basis von Gadamers Begriff des "Abbildes« in Wahrheit und Methode. Im Aufsatz mit dem pointierten Titel 
"Zuwachs an Sein. Hermeneutische Reflexion und bildende Kunst" betont Boehm, dass ein Abbild im Gegensatz zum Bild stets nach "Selbstverleugnung" strebe. $^{41}$ »Es [das Abbild] vollendet seine Intention dann am besten, wenn es keinerlei Eigenwillen ins Spiel bringt, gar nicht auf sich verweist, sondern sich ganz transparent macht auf die Sache. $«^{42}$ An dieser Stelle wird etwa deutlich, wie Boehm die ontologische Argumentation Gadamers mit einer Semantik anreichert, die bereits am Modell der Perspektive orientiert ist, denn er erkennt die Heteronomie des defizitären Abbilds ausdrücklich in dessen Transparenz. Ergänzt wird diese semantische Assoziation schließlich durch eine historische Argumentation, denn die Geschichte der Abbilder wird dabei kurzerhand mit der Geschichte der Perspektive identifiziert, die in jenem Moment beginne, »als es in der Renaissance möglich wurde, Bilder nach rationalen, nämlich geometrischen Regeln zu konstruieren. «33

Die Identifikation des Perspektivbildes mit dem Abbild muss als ein Postulat von Boehms Bildtheorie begriffen werden, denn in Gadamers eigener Konzeption des Abbildes finden sich keine Überlegungen, die das Abbild mit dem perspektivischen Bild in Verbindung. Für Gadamer ist weder die jeweilige Herstellungstechnik des Bildes noch dessen formale Anlage für den Abbildcharakter verantwortlich, sondern einzig das, was er die »Intention «4 des Bildes nennt. Es geht ihm zunächst um die Bezugnahme der bloß abbildenden Darstellung auf das Dargestellte, welche er als 'wiedergebend bezeichnet. Das Abbild beziehe sich auf etwas von ihm Verschiedenes, auf eine bildexterne Referenz, und erfülle damit eine Funktion, die man als Vermittlung von Information bezeichnen kann. Dem gegenüber behaupte sich das Bild als Sinneinheit, die gerade nicht in einem bloß wiedergebenden Verhältnis zu einer anderweitigen Sache stehe, sondern selbst an der dargestellten Sache teilhabe. Durch diese Teilhabe gewinne das Bild einen Mehrwert, den Abbilder grundsätzlich vermissen lassen und den Gadamer in ontologischen Begriffen als "Zuwachs an Sein»

41 Boehm, "Zuwachs an Sein. Hermeneutische Reflexion und bildende Kunst«, 1996, S. 100.

42 Ebd., S. 101.

43 Ebd.

44 Gadamer, Wahrheit und Methode, 1999, S. 144. 
bezeichnet. ${ }^{45}$ In den Schriften Gadamers gibt es keine hinreichenden Anhaltspunkte dafür, dass perspektivische Darstellungen diesen ontologischen Überschuss nicht leisten können. Im Gegenteil betont Gadamer sogar, dass selbst mechanische Verfahren der Bildproduktion, wie etwa die Fotografie, in der Lage seien, Bilder im engeren Sinn zu generieren. ${ }^{46}$ Gadamers nicht unproblematische Unterscheidung zwischen Bild und Abbild ist daher unabhängig von formalen, medialen oder technischen Aspekten und bietet so gesehen eine heuristische Unterscheidung, die auf eine Vielfalt von Bildern angewendet werden kann - so schwierig eine Unterscheidung im Einzelfall auch zu treffen wäre.

\section{Perspektive und Weltbild}

Die Rekonstruktion von Boehms Perspektivkritik zeigt, wie stark die moderne Kunstgeschichte von theoretischen Voraussetzungen durchdrungen ist, eine Durchdringung, die sich auf ihre historiografische Arbeit auswirkt - was die Kunstgeschichte selbst aber nicht ohne weiteres zu reflektieren in der Lage ist. Die Geschichte der ästhetischen Moderne ist zugleich auch eine Geschichte der Theorie und zwar einer modernen Theorie, die ihrerseits in der Kunst ihrer Zeit eine Entsprechung und Legitimierung sucht. Denn ihre Modernität liegt auch darin, dass sie die moderne Welt sowie deren Denk- und Lebensformen radikal in Frage stellt. In dieser Hinsicht bietet die moderne Kunst ein Depot an vermeintlicher Authentizität, Intensität und Unmittelbarkeit. Diese Suggestionen gewinnen ihre Macht auch aus der Negation des tradierten perspektivischen Repräsentationssystems, dessen Implosion als Überwindung einer Distanz zwischen Subjekt und Welt begriffen wird. Die Philosophie Martin Heideggers gehört zu den wichtigsten Momenten dieser Implosion, betreibt sie ihre profunde Kulturkritik der Moderne doch auf der Basis einer kritischen Relektüre

45 Ebd., S. 145.

46 "Selbst die mechanischen Bildtechniken der Gegenwart können insoweit künstlerisch gebraucht werden, als sie aus dem Abgebildeten etwas herausholen, das in seinem bloßen Anblick als solchem so nicht liegt. Ein solches Bild ist kein Abbild, denn es stellt etwas dar, was ohne es sich nicht so darstellte. Es sagt über das Urbild etwas aus. (Z. B. ein gutes Porträtfoto)«. Ebd., S. $144 f$. 
der Philosophiegeschichte, in der die Perspektive eine bestimmte Rolle einnimmt.

Im Aufsatz "Die Zeit des Weltbildes« kritisiert Heidegger den Begriff des »Weltbildes«, der für ihn Ausdruck und Brennpunkt einer defizitären Weise der Welterschließung ist. ${ }^{47}$ Wohlgemerkt kommt der Begriff des Bildes hier unter sehr spezifischen Voraussetzungen ins Spiel und meint nicht ausschließlich Bilder im engeren Sinn also visuelle Artefakte -, sondern vielmehr 'Bild als epistemologisches Paradigma. Die Genese dieses Paradigmas verortete Heidegger in der Neuzeit und interpretiert sie ontologisch als Geschichte des Seins. Heidegger erkennt in den wissenschaftlichen Entwicklungen der Neuzeit eine veränderte Beziehung des Menschen zur Welt, welche er als fortschreitende Berechnung und Beherrschung alles Seienden beschreibt. Die Totalität einer jeweiligen Welt werde zunehmend als eine Ansammlung von Objekten gedacht, die von einem vorentwerfenden System vorgezeichnet und bestimmt wird. Der maßgebliche Träger dieses Systems sei der Mensch, der in der Rolle des Subjekts den fundierenden Bezugspunkt alles Seienden bildet: "Der Mensch wird zu jenem Seienden, auf das sich alles Seiende in der Art seines Seins und seiner Wahrheit gründet. Der Mensch wird zur Bezugsmitte des Seienden als solchen. ${ }^{48}$ Diese subjektivistische Weise der Welterschließung gilt Heidegger nicht bloß als wissensgeschichtliches Symptom der neuzeitlichen Epistemologie und Kultur, sondern als ontologische Voraussetzung, die den Wesenszug des neuzeitlichen Welt- und Selbstverständnisses des Menschen bestimmt. Der Begriff des Bildes spielt dabei eine zentrale Rolle, die ich hier über einen Umweg erschließe.

Um die ontologische Defizienz der neuzeitlichen Welterschließung zu veranschaulichen, bringt Heidegger zunächst den Begriff des naturwissenschaftlichen Experiments ins Spiel. Die experimentelle Versuchsanordnung vollziehe genau jene Bewährungsprobe, die an das Seiende die Forderung stellt, den Gesetzen eines vorgreifenden Systems zu gehorchen. Heidegger versteht in diesem Sinn das Experiment weniger als eine Befragung von Natur mit offenem Ausgang, sondern vielmehr als deren Beherrschung. Denn es sei dem Experiment wesentlich, das es zunächst die 
"Zugrundelegung des Gesetzes" vollziehe, das vom Subjekt selbst vorgestellt wird. Den Begriff der »Vorstellung« begreift Heidegger nicht nur wörtlich, sondern ontologisch, denn im experimentellen Erschließungsvollzug des Seienden sei das Gesetz vor-gestellt, d. h. es handelt sich um eine Weise der Welterschließung, in der das Seiende bereits vom Subjekt präfiguriert ist, insofern es den subjektiven Vorstellungen und deren Bedingungen unterworfen ist. ${ }^{49}$

Diese philosophiegeschichtliche Dekonstruktion des Subjektivismus impliziert auch eine Kritik an der Distanz, die sich zwischen dem Subjekt und seiner objektivierten Welt auftut, denn diese distanzierte Beziehung verunmöglicht einen ursprünglichen Weltbezug des Menschen. Eine derartige Weltlichkeit besteht dort, wo der Mensch - existentialontologisch von Heidegger als 'Dasein bestimmt - einen unmittelbaren Zusammenhang zwischen Herstellung und Gebrauch seiner Artefakte und seiner Existenz erfährt. Die dingliche Welt erscheint im Rahmen dieses Zusammenhangs nicht als objektiv, sondern als handhabbar, was Heidegger in Sein und Zeit noch mit dem Begriff der "Zuhandenheit" ausdrückt. ${ }^{50}$ So ist etwa der Hammer zuhanden, um das Dach zu befestigen, das Dach ist zuhanden, um Schutz vor dem Unwetter zu haben, der Schutz gilt dem Sein des Daseins (dem Menschen). Dagegen ist der Horizont der modernen Wissenschaft ein Horizont der Vergegenständlichung, den Heidegger von der Zuhandenheit unterscheidet und dem defizitären Modus der »Vorhandenheit« zuordnet. ${ }^{51}$ Das Präfix im Begriff `Vorhandenheit`zeigt denn auch dieselbe ontologische Defizienz an, die im subjektiven Vorgestellt-sein der Welt zum Tragen kommt. ${ }^{52}$ Letzterer ist schließlich entscheidend für den im Weltbildaufsatz geprägten Begriff des Bildes, denn das subjektiv fundierte `Vor-stellen` der Welt bezieht sich

49 In seinen Überlegungen zur Technik bespricht Heidegger dieselbe Problematik und entwickelt dazu den Begriff »Ge-stell«. Heidegger, »Die Frage nach der Technik«, 2004, S. 23ff.

50 Heidegger, Sein und Zeit, 2006, S. 69ff. Mir scheint die Rekonstruktion und Bestimmung des Welt-Begriffs auf der Basis von Sein und Zeit trotz Heideggers sogenannter Kehre in den dreißiger Jahren eine hilfreiche Orientierung, um die grundlegenden Dimensionen seiner Subjekt- und Metaphysikkritik zu skizzieren.

51 Heidegger, Sein und Zeit, 2006., S. $72 \mathrm{ff}$.

52 Merleau-Ponty wird unter anderen Voraussetzungen dieselbe Problematik thematisieren: "Schließlich ist die Welt um mich herum, nicht vor mir«. Merleau-Ponty, »Das Auge und der Geist«, 1984, S. 300. 
zwar auf Seiendes, ist aber nicht mehr in der Lage, dieses anders denn als subjektive Vorstellung zu verstehen. Für Heidegger folgt daraus, dass die auf diesem Weg erschlossene Welt den Charakter eines Bildes besitzt, nicht nur weil sie als Produkt gewisser subjektiver Vermögen erscheint - sie ist im transzendentalen Sinn "ästhetisch« -, sondern weil die ontologische Verfassung einer solchen Welt es nicht mehr ermöglicht, diese als ein an sich Seiendes zu denken, sondern bloß noch als für ein Subjekt Erscheinendes. Kurzum: Was dem Subjekt erscheint, ist nicht mehr die Welt, sondern ein Bild von der Welt. Unter der Voraussetzung, dass es jenseits subjektiver Vor-stellungen nichts gibt, was sich dem Subjekt erschließen könnte, erschöpft sich die jeweils phänomenale Welt im Status des Bildes, dessen Totalität vom Horizont als Grenze des Seienden schlechthin markiert wird.

Heidegger verwendet den Begriff des Bildes nicht einfach als Metapher, sondern als ontologische Figur, mit der seine Bedeutung auf ein Maximum ausgedehnt wird. Seine Kritik gilt der subjektivistischen Epistemologie und damit einer Disposition, die sich zur formalen Disposition der Linearperspektive homolog verhält. Die Bildförmigkeit der erscheinenden Welt, ihre subjektive Konstitution, ihre distanzierte Objektivierung und Präfiguration durch Gesetze sind allesamt Aspekte, die auch dem Perspektivsystem zugeschrieben werden können. Mit gutem Grund geht Gottfried Boehm davon aus, dass das neuzeitliche Perspektivbild eine Grundlage für Heideggers These des Weltbildes darstellt und er verweist auf Panofskys Aufsatz »Perspektive als symbolische Form«, den Heidegger zwischen dessen Publikation im Jahr 1927 und der Veröffentlichung seines Weltbildaufsatzes im Jahr 1938 mit hoher Wahrscheinlichkeit zur Kenntnis genommen hat. ${ }^{53}$ Es scheint überzeugend, dass Panofskys transzendentalphilosophische Interpretation der Perspektive als einem Modell der modernen Subjekt-Objekt-Beziehung sowie sein Begriff der epochalen 'Weltanschauung die Ausgangslage von Heideggers Kritik darstellt. ${ }^{54}$ Dafür spricht etwa, dass Heidegger explizit die Vorstellung eines antiken bzw. mittelalterlichen Weltbildes kritisiert:

$54 \mathrm{Zu}$ Panofskys subjektphilosophischer Interpretation der Perspektive vgl. auch das Kapitel I der vorliegenden Studie. 
"Die Redewendung 'Weltbild der Neuzeit und 'neuzeitliches Weltbild sagen zweimal dasselbe und unterstellen etwas, was es nie zuvor geben konnte, nämlich ein mittelalterliches und ein antikes Weltbild. Das Weltbild wird nicht von einem vormals mittelalterlichen zu einem neuzeitlichen, sondern dies, dass überhaupt die Welt zum Bild wird, zeichnet das Wesen der Neuzeit aus. $\ll^{55}$

Interpretiert man Heideggers Weltbildaufsatz als Engführung von Weltbild und Perspektivbild, kommt man zu Schluss, dass die Perspektive gleichsam die Rolle eines weit gefassten Emblems zukommt. Sie steht für transzendentale Epistemologie, für subjektivistische Ontologie, für rationalistische Metaphysik, für naturwissenschaftliche Methodik, für historiographischen Relativismus und letztlich auch für den kulturphilosophischen Neukantianismus, mit dem Panofsky in seinem Aufsatz liebäugelt. Kurzum: die Perspektive steht für alles, was der post-nietzscheanischen Philosophie zuwider ist. ${ }^{56}$

\section{"malin dispositif»}

Wie bisher deutlich wurde, kommt der Perspektive im Kontext phänomenologischer Denkansätze eine gleichsam schillernde Rolle zu. Denn als Gegenstand der Kritik bietet die Perspektive auch die nötige Reibungsfläche für philosophische Gegenentwürfe und ist damit ein Objekt, an dem sich eine genuin moderne bildtheoretische Tradition konturieren kann. Ein Höhepunkt dieser Theoriebildung durch Perspektivkritik bildet die Phänomenologie Maurice Merleau-Pontys. Seine Auseinandersetzung mit der Perspektive bietet nicht nur die Möglichkeit, weitere Dimensionen der modernen Perspektivkritik aufzuzeigen, sondern auch die

55 Heidegger, »Die Zeit des Weltbildes«, 2003, S. 90.

56 Wenn man Heideggers Weltbildaufsatz in diesem Sinn als Reaktion auf Panofskys Perspektiv-Aufsatz liest, muss man ihn auch im Kontext einer philosophischen Debatte zwischen und Heidegger und dem Neukantianismus verorten, wofür etwa die Dokumente der Davoser Disputationen von 1929 ein skurriles Zeugnis abgeben, "Davoser Disputationen zwischen Ernst Cassirer und Martin Heidegger«, 1998. 
Allianz zwischen Phänomenologie und moderner Malerei genauer ins Auge zu fassen.

Dass im Feld der phänomenologischen Bildtheorie ontologische Fragen eine entscheidende Rolle spielen, hat sich bereits in der Auseinandersetzung mit Gottfried Boehm, Hans-Georg Gadamer und Martin Heidegger gezeigt. Doch gibt es einen wichtigen Aspekt der modernen Ontologie, der bisher noch nicht explizit behandelt wurde. Der menschliche Körper hat bereits durch die Physiologie des 19. Jahrhunderts eine veränderte Rolle eingenommen, die auf die Bedeutung der perspektivischen Darstellungsform Einfluss nimmt. Doch während das physiologische Interesse am Körper zumeist zu einer Problematisierung der Richtigkeit piktoraler Darstellung führt, zielt die leibphänomenologische Kritik der Perspektive auf andere Aspekte. Das phänomenologische Interesse am Leib muss dabei im Zusammenhang mit einem zentralen Anliegen begriffen werden, das vor allem darin besteht, den lebensweltlichen Boden der Erfahrung in Anschlag zu bringen. Diesen lebensweltlichen Boden als einen Ort zu begreifen, der vom Leib bewohnt wird, ist eine frühe Einsicht der Phänomenologie, die sich schon in den Prozessen der eidetischen Reduktion bei Husserl vorzeichnet. ${ }^{57}$

Der Topos der 'Leibes` meint unter phänomenologischen Vorzeichen eine integrale Entität, die nicht als Erfahrungsfundament der kognitiven Akten begriffen wird, sondern die Basis des menschlichen Welt- und Selbstverhältnisses schlechthin bildet. Der Begriff des Leibes meint dann natürlich nicht einfach den menschlichen Körper als biologische Funktionseinheit, sondern als koordinative Grundlage der durch ihn erschlossenen und bewohnten Lebenswelt einerseits sowie als selbstreflexives Moment andererseits. Diese Basis bildet der Leib wesentlich durch seine Wahrnehmung. Diese wird in der phänomenologischen Tradition seit Husserl nicht etwa als durch subjektive Erkenntnisvermögen geleistete Synthesis begriffen, die den Übergang eines hyletischen Datums zur begrifflichen Einheit erbringt. Der die Lebenswelt bewohnende Leib nimmt jene vielmehr in einem vorprädikativen Erfah-

57 Die einschlägigsten Stellen zum Leib als "Nullpunkt" der Orientierung im Raum findet sich etwa in Husserl, Ideen zu einer reinen Phänomenologie und phänomenologischen Philosophie, 1952, S. $158 \mathrm{ff}$. 
rungsvollzug wahr, einem prozessualen Vollzug, mit dem sich der Leib einerseits und die Welt andererseits laufend konstituieren. Durch Wahrnehmung gewonnene Erscheinungen sind in diesem Sinn keine Resultate apprehensiver Vermögen, die ihrerseits über transzendentale Formen bzw. Kategorien verfügen, von denen sie präfiguriert werden. Vielmehr bewohnt der wahrnehmende Leib selbst schon immer das Feld der Erscheinung, ist mithin ein Teil von diesem und nicht ein ihm Entgegentretendes.

Bereits hier zeichnen sich die Konfliktzonen zwischen der phänomenologischen Bildtheorie und dem Bildmodell der Perspektive ab. Denn dessen Disposition setzt eine Betrachterin voraus, die dem betrachteten Objekt distanziert gegenübersteht, und verbindet diese Distanz mit einer systemischen Konstruktion des Sichtbaren, also einem formgenetischen Konzept durch rationale und apriorische Regeln. Und hier setzt die leibphänomenologische Kritik Merleau-Pontys an, welche ich im Folgenden anhand zweier zentraler Momente kurz umreißen werde. Erstens möchte ich Merleau-Pontys leibphänomenologischen Reflexionsbegriff thematisieren und zweitens den damit verbundenen Bildbegriff erläutern. Beide Begriffe erlauben es, die Kernanliegen von Merleau-Pontys Perspektivkritik nachzuvollziehen.

Der französische Phänomenologe entwickelt seinen emphatischen Begriff des Leibes in kritischer Differenz zu den Paradigmen neuzeitlicher Epistemologien. In seinem Text "Das Auge und der Geist « dient ihm in dieser Hinsicht die Philosophie René Descartes' als Ausgangslage seiner Kritik. Merleau-Ponty rekonstruiert fragmentarisch, wie Descartes in seiner Dioptrique eine Theorie der Wahrnehmung entwickelt, die inspiriert sei "von den Techniken der Perspektive in der Renaissance ${ }^{58}$ Er kritisiert den französischen Rationalisten darin, dass er Bilder der Malerei als formgleiche Substitute begreift, die in der Lage sind, die äußeren Hüllen der Dinge nach Regeln für das Auge abzubilden. Die Grundlage für diese systematisch konstruierten Abbilder sei ein Raumbegriff, den Merleau-Ponty folgendermaßen beschreibt: "Zunächst galt es, den Raum zu idealisieren; es ging darum, jenes auf seine 
Art vollkommene, klare, handliche und homogene Wesen zu konzipieren, welches ein standpunktloses Denken überfliegt« ${ }^{59}$

Der Satz zeigt zwei wesentliche Kritikpunkte auf, die sich zugleich an Descartes und an die Perspektive richten: zum einen das Konzept eines abstrakten, homogenen und transparenten Raumes; zum anderen die Vorstellung eines im topologischen Sinn ortlosen Bewusstseins, das sich diesen abstrakten Raum zu eigen macht. Was mich an dieser Stelle beschäftigt, ist Merleau-Pontys Gegenentwurf zum rationalistischen Modell des 'standpunktlosen Denkens` sowie dessen geistige Reflexionsform. Merleau-Ponty ersetzt gewissermaßen die intellektualistische Konzeption eines abstrakten und von der Lebenswelt losgelösten Bewusstseins durch den immer schon in der Lebenswelt situierten Leib: »Das Rätsel liegt darin, dass mein Leib zugleich sehend und sichtbar ist. Er, der alle Dinge betrachtet, kann sich zugleich auch selbst betrachten ${ }^{60}{ }^{60}$ Und an anderer Stelle: "Es ist ein Selbst, das nicht vermittels einer Transparenz wie das Denken alles erdenkliche in sich selbst aufnimmt [...] sondern ein Selbst durch Betroffenheit, einen Narzissmus, eine Verknüpfung von dem, der sieht mit dem was er sieht, und von dem der berührt mit dem, was er berührt «. ${ }^{61}$ Es ist diese eigentümliche Übertragung, mit der Merleau-Ponty die Figur der selbstreflexiven Bewegung der res cogitans gleichsam auf den Leib umschreibt und die es ihm ermöglicht, von einer "metaphysische[n] Struktur unseres Leibes « zu sprechen. ${ }^{62}$

Hier zeigt sich, wie die emphatisch betonte Bedeutung des Leibes zu einem radikalen Paradigmenwechsel des philosophischen Reflexionsmodells führt. Die Selbsttransparenz des Cogito ist unter den Voraussetzungen der metaphysikkritischen Phänomenologie und deren profunder Verankerung im menschlichen Leib nicht länger tragbar. Das sich selbst transparente Reflexionssubjekt (das Cogito) wird im Zuge seiner Verleiblichung quasi selbst opak, findet die Reflexion doch im Vollzug des sich selbst wahrnehmenden Leibes und dessen Affektion und Undurchdringlichkeit statt. Merleau-Ponty spricht daher von einer »Reflexivität des 
Sinnlichen « und diese hat für die Frage nach dem Bild und insbesondere der Perspektive unmittelbare Auswirkungen. ${ }^{63}$ Die Transparenz des perspektivisch konstruierten Raumes kann für den französischen Phänomenologen in keiner Weise als Moment einer sinnlichen Leiblichkeit und deren Reflexivität fungieren, denn sie involviere den sich selbst empfindenden Leib in keiner Weise. Die perspektivisch generierte Sichtbarkeit unterbinde gar die wahre Reflexivität des Leibes:

"Wenn unsere Augen so beschaffen wären, dass unser Blick keinen Teil unseres Körpers träfe, oder wenn irgendeine bösartige Vorrichtung uns zwar erlaubte, unsere Hände über die Dinge gleiten zu lassen, uns aber daran hinderte, unseren Körper zu berühren ... dann wäre dieser Körper, der sich nicht reflektierte, sich nicht fühlte, dieser fast diamantene Körper, der ganz und gar nicht Leib wäre, auch kein Körper der Menschen mehr und es gäbe kein Menschsein.« ${ }^{64}$

Es bedarf keines Spekulationswillens, um in Merleau-Pontys Szenario der »bösartigen Vorrichtung« eine Karikatur der Perspektive zu erkennen. Als geometrisch konstruierte Sichtbarkeit für einen frontalausgerichteten und unbeweglichen Blick, kann die Perspektive für Merleau-Ponty lediglich ein »malin dispositif« sein, wie es im französischen Originaltext heißt. Dass Merleau-Ponty nachweislich vertraut war mit dem Experiment Brunelleschis, welches den Leib des Betrachters vom Raum der Repräsentation abtrennt und den Blick statisch und monokular organisiert, untermauert die Assoziation von "malin dispositif « und Perspektive. ${ }^{65}$

Doch dabei werden stillschweigend fundamentale Voraussetzungen über den visuellen Wahrnehmungssinn gemacht, die gerade auch aus phänomenologischer Sicht problematisch sind. Die Konstitution des eigenen Leibs im Erfahrungsvollzug der Selbstberührung, die von Merleau-Ponty emphatisch als "Das Rätsel« ${ }^{66}$ beschrieben wird, orientiert sich wesentlich an den Bedingungen

63 Ebd.

64 Ebd., S. $280 \mathrm{f}$.

65 Merleau-Ponty beschreibt Brunelleschis "merkwürdigen Apparat « recht ausführlich in: Merleau-Ponty, "Das indirekte Sprechen und die Stimmen des Schweigens«, 1984, S. 113f.

66 Merleau-Ponty, "Das Auge und der Geist«, 1984, S. 279. 
des Tastsinns, wobei nicht klar wird, weshalb dessen Voraussetzungen auch für die visuelle Wahrnehmung gelten soll. So schreibt Merleau-Ponty: "Er [der Leib] sieht sich sehend, er betastet sich tastend, er ist für sich selbst sichtbar und spürbar. « ${ }^{67}$ So überzeugend seine Argumente sind, dass die Selbstberührung des Körpers eine Weise der Reflexion impliziert, in der Berührendes und Berührtes sich gegenseitig und reversibel differenzieren und zugleich konstituieren, so unklar bleibt, inwiefern sich diese Figur auf die visuelle Wahrnehmung übertragen lässt. Schließlich kann das Auge zwar andere Körperteile sehen, niemals aber unmittelbar sich selbst als sehendes Auge. Wenn das Auge also einen Arm erblickt, ist dieser zwar Teil des Leibes, dem es angehört, es ist aber kein Sehendes, das da erblickt wird. Anders formuliert: der Körper sieht sich eben gerade nicht als sehender Körper in der unmittelbaren Weise wie er sich selbst tastend erfährt. Edmund Husserl, aus dessen Ideen zu einer reinen Phänomenologie und phänomenologischen Philosophie die Gedankenfigur der Selbstberührung stammt, hat diese Andersartigkeit zwischen Tast- und Sehsinn früh erkannt:

"Ich sehe mich selbst, meinen Leib, nicht, wie ich mich selbst taste.

Das, was ich gesehenen Leib nenne, ist nicht gesehenes Sehendes, wie mein Leib als getasteter Leib getastetes Tastendes ist. Eine visuelle Erscheinung eines Objektes, das sieht, d.h. in dem die Lichtempfindung angeschaut wird als in ihm seiend, fehlt. Es fehlt also das Analogon zur Tastempfindung, die wirklich mit der tastenden Hand erfasst wird. Die Rolle der Gesichtsempfindungen bei der korrelativen Konstitution von Leib und Außendingen ist also eine andere als die der Tastempfindungen.«68

Man könnte an dieser Stelle darüber spekulieren, was unter diesen Bedingungen des Sehsinns eine Spiegelung des Auges bedeutet. Man wird zu dem Schluss kommen müssen, dass das Auge selbst dort, wo es sich im Spiegel erblickt, nicht in der Lage ist, sich als sehendes zu sehen - in der Weise, wie die rechte Hand in der Lage ist, die linke Hand zu ertasten. Die Reflexion des Blicks im Spiegel sophie, 1952, S. 148. 
scheint von anderer Art zu sein, als die direkte Selbstwahrnehmung des Tastsinns, und so bleibt sich der Blick im Spiegel auf eigentümliche Weise fremd - der Blick in den Spiegel kann, wie Husserl in einer Fußnote schreibt, nur »indirekt « darauf schließen, dass dieses im Spiegel sichtbare Ding dasjenige ist, mit dem man sieht. ${ }^{69}$ (Möglicherweise ist diese im Spiegelbild sich vollziehende Selbstentfremdung des Blicks mitunter ein Grund dafür, dass es den Perspektivisten des fünfzehnten Jahrhunderts und allen voran Brunelleschi leicht fällt, das Auge mit einem geometrischen Punkt zu identifizieren.)

Ich bleibe an dieser Stelle bei Merleau-Ponty, der die Andersartigkeit von Seh- und Tastsinn im besagten Text unterschlägt und auf der Basis einer integralen Leiblichkeit seinen Bildbegriff formuliert. Dieser Bildbegriff orientiert sich explizit an der Malerei, die für Merleau-Ponty die Rolle eines Dispositivs für den Leib spielt. Denn der Leib und sein ontologisch reflexiv begriffener Wahrnehmungsprozess schlägt sich im Gemälde nieder und manifestiert sich dort, um schließlich für andere erneut erlebbar zu sein. Das ist möglich, weil Merleau-Ponty die besondere Tätigkeit des modernen Malers als volle Hingabe an die Wahrnehmung bestimmt und damit jenes Moment zelebriert, aus dem sich die Welt und sein Selbst auf chiastische Weise konstituieren.

"Das Sehen des Malers ist nicht mehr ein Blick auf Äußeres, eine bloß 'physisch-optische Beziehung zur Welt. [...] Vielmehr ist es der Maler, der in den Dingen geboren wird wie durch eine Konzentration und ein Zu-sich-Kommen des Sichtbaren; und das Gemälde bezieht sich schließlich nur dann auf irgendetwas unter den empirischen Dingen, wenn es zunächst autofigurativ ist; es ist nur insofern ein Schauspiel von irgendetwas, als es 'Schauspiel von nichts‘ ist, indem es die schale der Dinge aufsprengt, um zu zeigen, wie Dinge zu Dingen und die Welt zur Welt werden. «70

Werke der Malerei sind also zunächst autofigurativ, d.h. sie sind selbstreferentiell, weil ihre eigentliche Leistung nicht in ihrer Repräsentationsfunktion liegt, sondern im Sichtbarmachen schlecht-

69 Ebd.

70 Merleau-Ponty, "Das Auge und der Geist«, 1984, S. 305. 
hin. Gemälde sind exponierte Orte, an denen Sichtbares zu-sichkommt, und zwar auf eine Weise, die in besonderer Beziehung zur Leiblichkeit steht. Die im Leib zentrierte Wahrnehmung, gedacht als chiastische Verschränkung von Selbst und Welt, und der dadurch realisierte Prozess, der Sehendes und Gesehenes hervorbringt, wird vom modernen Maler geradezu zelebriert, und zwar derart, dass er diese Erfahrung unmittelbar in eine malerische Struktur übersetzen kann. Möglich wird dies, weil das Malen selbst ein Akt des Leibes und nicht etwa des Denkens. So ist es ihm möglich, innerhalb der ursprünglichen Integrität von Leib und Welt zu arbeiten. Dabei ist der Leib für die Malerin im doppelten Sinn das Hauptorgan ihrer Arbeit: Denn Sehen und Malen kann nur der Leib:

"Indem der Maler der Welt seinen Leib leiht, verwandelt er die Welt in Malerei. Um diese Verwandlung [transsubstantation] zu verstehen, muss man den fungierenden und gegenwärtigen Leib wiederfinden ${ }^{71}$

Indem der Maler sein leibbasiertes Sehen zur abermals leiblichen Geste macht, entsteht auf dem materiellen Grund der Welt eine sichtbare Objektivation, die eine Art Äquivalent des Wahrnehmungsaktes bildet. Das Bild ist ausgezeichnet durch seine Kraft, mittels der es eine Erscheinung erzeugt, die anderer Art ist als alles, was uns vermittels der normalen Weltwahrnehmung erscheint. Das Gemälde verfügt als solches über einen Mehrwert, denn seine Sichtbarkeit geht über die bloße Materialität seines Trägers hinaus. Um eine autonome Lesbarkeit einzufordern, muss es eine offensichtliche Distinktion vollziehen, mit der es sich von der Welt, die es trägt, unterscheidet, allerdings - dies ist die zentrale Pointe - ohne in einen Illusionismus zu verfallen, der die Seinsart des Bildes vergessen macht, sondern vielmehr indem diese mitsichtbar gemacht wird. Das autofigurative< Bild impliziert eine Reflexivität, die darin liegt, dass das Bild nicht nur etwas sichtbar macht, sondern dabei immer auch auf sich selbst verweist, mithin auf das Stück Welt, auf dem das Bild erscheint. Diese visuelle Ver- 
dichtung bezeichnet Bernhard Waldenfels in Bezug auf MerleauPonty auch als Sichtbarkeit, die "sich potenziert $"{ }^{72}$

Diese im ontologischen Sinn potenzierte Sichtbarkeit des malerischen Bildes ist wesentlich mit dem Paradigma der Leiblichkeit verbunden, denn in ihr manifestiert sich ein doppelter Leibbezug, da das Gemälde einerseits Resultat der leiblichen Wahrnehmung und Arbeit des Künstlers ist, andererseits im Akt der leiblichen Wahrnehmung des Betrachters stets neu aktualisiert wird. Das Hauptelement, in dem sich dieser doppelte Leibbezug manifestiert, ist für Merleau-Ponty die Farbe. Sie ermöglicht »jene andere und tiefere Offenheit zu den Dingen«, die Descartes entgehe, weil er sich ganz am Modell der Perspektive und deren Linearismus orientiert. ${ }^{73}$ Farbe ist das berührende Element zwischen Leib und Bild und stellt damit für Merleau-Ponty ein Moment der Wahrheit dar. Der Farbe wird eine Valenz zugesprochen, die ein Verhältnis zwischen Bild und den "wahren Eigenschaften der Dinge« ermögliche $^{74}$ - ein Verhältnis, dass sich niemals systematisch regeln lässt, so wie die Perspektive es fälschlicherweise suggeriert.

Zusammenfassend kann man sagen, dass sich für Merleau-Ponty in der Perspektive eine ganze Reihe von Problemen verdichtet: Die Perspektive formuliert einen falschen Bildbegriff (jenen der geregelten Repräsentation), einen falschen Raumbegriff (jenen des abstrakten, homogenen Raumes) und eine falsche Bewusstseinsweise (einer standpunktlosen denkenden Immanenz). Diese radikale Kritik, die es ihm ermöglicht, sein Konzept einer 'Reflexivität des Sinnlichen`als Gegenentwurf zur Perspektive zu formulieren, wird an einigen Stellen aber auch relativiert. So wirft er Descartes vor, dass er die Perspektive nicht als ein bestimmtes Modell der Wahrnehmung begreife, die es in einer übergreifenden Theorie der Wahrnehmung zu verorten gelte: »Und er [Descartes] hätte vielleicht die Perspektive als einen Einzelfall in ein umfassenderes ontologisches Vermögen integrieren müssen. « ${ }^{75}$

72 Waldenfels, »Das Rätsel der Sichtbarkeit. Kunstphänomenologische Betrachtungen im Hinblick auf den Status moderner Malerei«, 1990, S. 211.

73 Merleau-Ponty, "Das Auge und der Geist«, 1984, S. 292.

74 Ebd.

75 Ebd. 
Aus derartigen Textstellen kann man schließen, dass es Merleau-Ponty nicht darum geht, das Bildmodell der Perspektive als solches zu entwerten. Eher scheint es, als wolle er ihre Deutung, also die Art und Weise der Bezugnahme auf die Perspektive, kritisieren und schließlich auch historisch differenzieren:

»Er [Descartes] hatte auch darin Recht, sich von den Techniken der Perspektive in der Renaissance inspirieren zu lassen: Sie haben die Malerei ermutigt, in freier Weise Tiefenexperimente durchzuführen und allgemein Darstellungen des Seins hervorzubringen. Sie täuschte sich nur dort, wo sie vorgab, Forschung und Geschichte der Malerei zum Ende gebracht und eine exakte und unfehlbare Malerei begründet zu haben. ${ }^{76}$

Das eigentliche Problem der Perspektive liegt für Merleau-Ponty offenbar nicht in der von ihr geleisteten Genese von Bild, Raum und Bewusstsein, sondern lediglich in einem angeblich absoluten Anspruch. In Berufung auf Panofsky schreibt Merleau-Ponty deshalb:

"Die Perspektive der Renaissance ist kein unfehlbarer `Trick : Sie ist nur ein Einzelfall, ein Datum, ein Augenblick in einer poetischen Ausformung der Welt, die nach ihr fortwirkt. «" ${ }^{77}$

Diese relativistische Kritik der Perspektive ist überzeugend, doch sie steht im krassen Gegensatz zu Merleau-Pontys eigenem Bildbegriff. Denn dieser ist zwar selbst an historischen Malweisen der koloristischen Moderne orientiert - bekanntlich etwa an Cézanne -, der ontologische Jargon und die Rede von 'Wahrheit markieren jedoch den Anspruch auf überhistorische Geltung. Als sinnliches Reflexionsdispositiv steht das malerische Bild in Merleau-Pontys Konzeption in unmittelbarer Beziehung zu einem ontologischen Vermögen, was etwa dann deutlich wird, wenn er davon spricht, dass die Malerei »die ‘Schale der Dinge aufsprengt, um zu zeigen, wie die Dinge zu Dingen und die Welt zur Welt 
wird ${ }^{78}{ }^{78}$ Es wird auf frappante Weise deutlich, dass Merleau-Ponty das Modell der Perspektive als historisches Paradigma behandelt, die Bildmodelle der modernen Malerei dagegen als Quasiwissenschaft einer prädikativ unerreichbaren Wahrheit einstuft. Vielleicht liegt man nicht falsch, wenn man diesen Widerspruch als Kennzeichen der paradox verfassten Moderne begreift. Wenn Merleau-Ponty einerseits die Perspektive als kontingentes Moment der Geschichte beschreibt, scheint dieser Relativismus zugleich den Wunsch nach einer nicht relativierbaren Wahrheit und Authentizität zu provozieren. Dieser Wunsch scheint so groß zu sein, dass in Vergessenheit geriet, dass die moderne Überwindung der angeblich dogmatischen Perspektive zu nichts anderem führen kann als zu weiteren Einzelfällen der Geschichte.

\section{Von der Nichtung des Bildes}

Es hat sich gezeigt, dass es vor allem ontologische Gründe sind, die in der phänomenologischen Kritik der Perspektive zum Tragen kommen. Diese können wie bei Gadamer und Boehm bildontologischer Art sein, insofern sie das Sein des Bildes angehen, sie können aber auch, wie bei Heidegger, existentialontologischer Natur sein, wenn sie die seinsgeschichtliche Verfassung des Menschen und seiner Welt betreffen, oder aber sie können, wie bei Merleau-Ponty, leibontologisch sein, wenn sie den sinnlichen Wahrnehmungsvollzug des Leibes angehen. Ich möchte im Folgenden zeigen, dass diese ontologische Problematisierung der Perspektive mit einem phänomenologischen Grundproblem in der Auseinandersetzung mit Bildern zu tun hat. Dies werde ich an Edmund Husserls Überlegungen zum Bild aufzeigen, welche sozusagen die Wurzel der Tradition phänomenologischer Bildtheorie darstellen und damit eine philosophiegeschichtliche Perspektivierung der bisher besprochenen Positionen erlauben. Aus systematischen Gründen konzentriere ich mich dabei auf Husserls bildtheoretische Anliegen und nicht auf phänomenologische Probleme der Perspektivität schlechthin. Denn obschon 
Husserl sich dem Problem perspektivischer Wahrnehmung im Zusammenhang mit der Konstitution von Raum und Kinästhese befasst, sind diese wahrnehmungstheoretischen Untersuchungen für die vorliegende Fragestellung von vernachlässigbarer Bedeutung. ${ }^{79}$ Da es mir darum geht, Husserls Phänomenologie im Hinblick auf die phänomenologische Kritik der perspektivischen Bilder zu befragen, konzentriere ich mich im Wesentlichen auf Husserls frühe Überlegungen, d.h. auf das, was er in den Göttinger Vorlesungen von 1904 bis 1905 »das Bildbewusstsein «nennt. ${ }^{80}$ Diese frühen bildtheoretischen Gedanken, so die These, bereiten die ontologische Problematisierung der Perspektive in der zweiten Hälfte des zwanzigsten Jahrhunderts vor. Meine Analyse dieser Texte muss dabei ein Versuch bleiben, denn Husserls Konzeption des Bildbewusstseins ist keineswegs eine fertige Theorie, sondern stellt vielmehr eine heuristische Befragung des Phänomens Bild dar. Die Göttinger Vorlesungen lesen sich in diesem Sinn als ein Fragment von Husserls Denken, dessen Fortgang sich gleichsam mäandernd an den Problemen bildlicher Darstellungen abarbeitet, ohne ein festgesetztes Ziel erreichen zu wollen, und in diesem Sinn ganz der phänomenologischen Methodik verpflichtet ist.

Zunächst gilt es Husserls Interesse und Kritik am Bild zu differenzieren, denn bereits in seinen Logischen Untersuchungen spricht

79 Etwa Husserls Konzeption der »Abschattung« zeigt, dass Perspektivität im phänomenologisch begriffenen Objektbezug gewissermaßen bereits mitgedacht ist. "Abschattung" beschreibt den Umstand, dass ein Objekt der Wahrnehmung perspektivisch erscheint und dennoch wird die einzelne Abschattung transzendiert, da sie eine prinzipiell unendliche Reihe anderer potentieller Abschattungen impliziert. Aus der Abschattung öffnet sich so ein protentionaler und retentionaler Horizont, der temporal begriffen werden muss. Unklar bleibt, wie die Synthese der Abschattungen im Zusammenhang der Perspektivität zu verstehen ist. Denn es müsste geklärt werden, was diese temporale Synthese (Husserl nennt sie auch "passive Synthesis«), mit der die Identität des gegebenen Objekts, aber auch die Kontinuität des Wahrnehmungsfilmes ermöglicht wird, mit der räumlichen Perspektivierung einer Erscheinung zu tun hat. Denn passive Synthesis ist wesentlich temporal, sie synthetisiert den zeitlichen Ablauf des Bewusstseinsstromes, dessen identischer Pol die Noesis als das beharrende Ich ist. Wie dieses noetische Ich mit dem Blickpunkt einer perspektivischen Ansicht zusammenhängt, ist aus phänomenologischer Sicht nicht ohne weiteres klar und wäre Gegenstand einer anderen Untersuchung. Siehe dazu vor allem Husserl, Ideen zu einer reinen Phänomenologie und phänomenologischen Philosophie, 1952, S. $73 \mathrm{ff}$. 
er explizit vom »Irrtum einer Bildertheorie « ${ }^{81}$ und wendet sich damit gegen eine repräsentationalistische Konzeption des Bildes im erkenntnistheoretischen Sinn - eine Konzeption also, die ein inneres Bild als Abbild eines außerhalb vorhandenen Dinges versteht. Dabei steht nicht weniger als der Bildbegriff auf dem Spiel, denn für Husserl meint 'Bild gerade nicht eine bewusstseinsimmanente Repräsentation eines davon zu unterscheidenden Dinges in der Welt. Diese Kritik der cartesianischen Repräsentationstheorie findet sich etwa in den Beilagen zu den $\S 11$ und 12 der Logischen Untersuchungen, wo Husserl die verfehlte Vorstellung eines Bewusstseins als "Schachtel« kritisiert. ${ }^{82}$ Im Zeichen der husserlschen Epoché, als radikale Infragestellung empirischer Voraussetzung und zugunsten einer eidetischen Wesensschau, arbeiten die Göttinger Vorlesungen daran, den Begriff des Bildes vom neuzeitlichen Modell der Repräsentation abzulösen. Husserl begreift hier das Bild nicht mehr als eine Repräsentation, d.h. als Darstellung, die auf ein außerbildlich Gegebenes referiert, sondern als Phänomen, mit dem "eine wesentlich neue Weise der Intention Erlebnis wird $\ll^{83}$

Eine solche Theorie des Bildes ist nur schwer zu begreifen, ohne eine ansatzweise Vorstellung des zugrunde liegenden phänomenologischen Anschauungsbegriffs. So basiert Husserls Konzeption der Anschauung eben nicht auf dem Prinzip, dass die sinnliche Affektion eines äußerlich vorhandenen Gegenstands mit einem abstrakten Vermögen der Begriffe verbunden wird. Denn für Husserl ist Anschauung als solche das Ergebnis eines intentionalen Aktes und als akthafte Präsentation von einem entgegentretenden Objekt befreit. Diese Beziehung des Bewusstseins zur Welt, die als noetisch-noematische Korrelation gedacht ist, steht bereits in spannungsvoller Beziehung zur Perspektive. Denn die gegenseitige Abhängigkeit von Noema und Noesis schließt die von der perspektivischen Konstruktion vorgesehene Distanz zwischen Subjekt und Objekt aus. Das Bewusstsein wird nicht als eine Entität gedacht, die der Welt aus sicherer Entfernung entgegentritt, um

81 Husserl, Logische Untersuchungen. Untersuchungen zur Phänomenologie und Theorie der Erkenntnis, 1980, S. 421.

82 Ebd., S. 165.

83 Ebd., S. 385. 
Repräsentationen eines wahren Gegenstandes in sich aufzunehmen, sondern ist mit der Welt immer schon verbunden. Das Modell der Zentralperspektive, dessen Logik in einer regelhaft konstruierten visuellen Repräsentation zwischen einem distanzierten Subjekt und seinem Objekt besteht und dabei die subjektive Erscheinungsweise des Objekts vom an-sich-seienden Objekt trennt, scheint mit dieser phänomenologischen Konzeption des Erlebens schwer vereinbar zu sein. Zwar könnte man dafür argumentieren, dass die Perspektive einen immanenten Objektbezug aufweist, insofern jede perspektivische Darstellung auf einen Gegenstand angewiesen ist, an dem sich Perspektivität als solche überhaupt erst manifestiert. Ein solcher Objektbezug der Perspektive scheint dann strukturelle Ähnlichkeit mit der noetisch-noematischen Verflechtung intentionaler Gegenstandsbezugnahme aufzuweisen, und Husserls Leitsatz, dass Bewusstsein immer 'Bewusstsein von Etwas ist, ließe sich in diesem Sinn auf die Perspektive übertragen, die immer ’Perspektive von Etwas` ist. Doch bleibt dann völlig unklar, was diese strukturelle Ähnlichkeit bedeuten soll. Begreift man die perspektivische Konstruktion etwa als Analogon der eidetischen Variation, also quasi als phänomenologische Untersuchungsmethode, stellt sich das Problem, dass ihre geometrischen Voraussetzungen einer vorurteilsfreien Untersuchung im Sinn der Epoché radikal entgegenstehen. Die Perspektive beschreibt zwar die Welt, aber sie tut es mit Mitteln, die der phänomenologischen Idee der Zurückhaltung nicht gerecht werden können. Das will selbstverständlich nicht heißen, dass andere Weisen der Bildproduktion in der Lage wären, eine derartige Wesensschau zu leisten. Dieser Schluss, zu dem etwa Maurice Merleau-Ponty kommt, ${ }^{84}$ unterschlägt, dass jede Bildproduktion auf historische und epistemologische Voraussetzungen angewiesen ist, die an der Konstitution des Gegenstandes und seiner Darstellung teilhaben. Daraus folgt, dass Bildpraxis im phänomenologischen Sinn nie eine Wesensschau im ursprünglichen Sinn leisten kann. Da aber das phänomenologische Programm Husserls an einer radikalen analytischen Rückführung auf das Bewusstsein interessiert ist und dieses Bewusstsein als konstituierend konzipiert, sind die 
Möglichkeiten seiner Phänomenologie begrenzt. Mit anderen Worten: Husserl nutzt Bilder, um aus ihnen Aufschluss über das sie konstituierende Bewusstsein zu gewinnen, nicht aber als historische Dispositive, die auf das Bewusstsein einwirken oder es gar konstituieren. Das Bewusstsein ist mit seinen Phänomenen zwar auf Gedeih und Verderb verbunden, diese Verbindung ist jedoch nicht symmetrisch, da die Konstitution des Gegenstandes durch den intentionalen Akt des Bewusstseins geschieht und sich nicht ohne weiteres umkehren lässt. Die jeweilige Setzung des Erlebnisses durch das Bewusstsein bestimmt die Geltungsweise des Phänomens, also ob ein Gegenstand etwa als leibhaftig gegenwärtig gilt, wie in der Modalität des Wahrnehmungsbewusstseins, oder etwa als Erinnerung, in der Modalität des Erinnerungsbewusstsein.

Für den vorliegenden Zusammenhang ist von Bedeutung, dass Husserl für das Phänomen des Bildes schließlich eine eigene Bewusstseinsmodalität verantwortlich macht, die er in den Göttinger Vorlesungen bekanntlich 'Bildbewusstsein` nennt. Zunächst behandeln die Vorlesungen die inneren Bilder der Phantasie und die äußeren physischen Bilder so weit als möglich gleich. Doch im Laufe seiner Überlegungen kommt Husserl dazu, die "Phantasievorstellung « und die "physische« - oder, wie er auch sagt, "gewöhnliche« - Bildvorstellung immer stärker zu unterscheiden, um im $\S 21$ schließlich zur Auffassung zu gelangen, es sei "auf Seiten der physischen Bildvorstellung [...], wie es scheint, komplizierter wie auf Seiten der Phantasievorstellung ${ }{ }^{85} \mathrm{Zu}$ dieser Feststellung gelangt Husserl, weil er bemerkt, dass es sich bei der physischen Bildvorstellung um ein Phänomen von seltsam ambivalenter Art handelt. Zum einen erscheint das "physische Bild«, d. h. der materielle Bildträger, zum anderen aber auch das "geistige Bild«, oder, wie er auch sagt, das »Bildobjekt", mit dem er die innerbildliche Erscheinung meint, also dasjenige, was im physischen Bild sichtbar wird. ${ }^{86}$ Im Unterschied zur Phantasievorstellung ist das Bildobjekt also einer materiellen Fundierung unterworfen. Dagegen kann die Phantasievorstellung eine nicht anwesende Sache vergegenwärtigen, ohne auf einen materiellen Träger angewiesen zu sein.

85 Husserl, Phantasie und Bildbewusstsein, 2006, S. 43.

86 Ebd., S. 21. 
So kommt Husserl zu der Einschätzung, dass das Bild (erstens) aus einem »Bildding", d.h. einem materiellen Träger besteht, der im Modus der leibhaftigen Gegenwart erlebt wird, sich also im wirklichen Raum befindet und dem somit "Wirklichkeitscharakter" zukommt. Dem gegenüber unterscheidet er (zweitens) dasjenige, das in diesem Bildding erscheint und das er bereits in den Logischen Untersuchungen als "Bildobjekt « bezeichnet. ${ }^{87}$ Dabei handelt es sich um das Erscheinen eines vom intentionalen Bewusstsein konstituierten innerbildlichen Objekts, das im Bildraum sichtbar wird. ${ }^{88}$

Die charakteristische Produktivität der husserlschen Bildtheorie liegt also darin, dass sie auf die divergenten Momente des Bildes zielt, welche den prekären Status bildlicher Erscheinung ausmachen. Ich übergehe an dieser Stelle, dass Husserl in der Strukturierung des bildlichen Phänomens eine weitere dritte Ebene erkennt, die er als "Bildsujet ${ }^{89}$ bezeichnet, und komme direkt zum entscheidenden Problem. Dieses liegt im eigentümlichen Spannungsverhältnis zwischen Bildobjekt und Bildding, das aus dem scheiternden Versuch resultiert, den Bildraum und die darin befindlichen Objekte in das Kontinuum des realen Wahrnehmungsraums einzuordnen. Es liege, so Husserl, ein "Widerstreit « zwischen physischer Bildwirklichkeit und dem Bildobjekt vor.90 Die Wahrnehmung des Bildobjekts im Bildraum eines Gemäldes stellt eine Irritation der kontinuierlichen Erfahrungswelt, d.h. der Erfahrung des leibhaftigen Raumes, dar.

Nicht nur die Tatsache, dass Husserl die Problematik des Bildes als Problematik der Räumlichkeit diskutiert, zeigt, dass seine Überlegungen Konsequenzen haben für das phänomenologische Verständnis der Perspektive als dem Modell illusionistischer Raumbildung par excellence. Im unmittelbaren Zusammenhang mit der geschilderten Problematik der Räumlichkeit wird deutlich, dass sich Husserls Analyse am Modell des perspektivischen

Husserl, Logische Untersuchungen. Untersuchungen zur Phänomenologie und Theorie derErkenntnis, 1980, S. 422.

88 Ebd., S. 423.

89 Anders als Lambert Wiesing betont Emmanuel Alloa gerade die dreiteilige Struktur von Husserls Bildbegriff. Alloa, Das durchscheinende Bild. Konturen einer medialen Phänomenologie, 2011, S. 197.

90 Husserl, Phantasie und Bildbewusstsein, 2006, S. 34. 
Bildes orientiert, wenn er seine Erfahrung mit Albertis Fenstermetapher beschreibt: "Wir blicken durch den Rahmen gleichsam wie durch ein Fenster in den Bildraum, in die Bild-Wirklichkeit hinein. ${ }^{91}$

Für die vorliegende Fragestellung ist die Schlussfolgerung entscheidend, die Husserl ausgehend von der beschriebenen Erfahrung trifft:

"Die Umgebung ist wirkliche Umgebung, auch das Papier ist wirkliche Gegenwart; das Bild erscheint, aber es streitet mit der wirklichen

Gegenwart, es ist also bloß `Bild<, es ist, wie es erscheint ein Nichts. «92

Da die phänomenologische Deskription daran scheitert, die am Bild vollzogene Erfahrung von Raum mit seiner realräumlichen Erfahrung des Bildträgers zu vereinbaren, wird ihre Beziehung als Widerstreit begriffen. Dieser Widerstreit zwischen Bildraum und Realraum mündet schließlich in der als heuristisch zu verstehenden These, es handle sich beim illusionsräumlichen Bild um eine Negation. So spricht Husserl davon, dass der Widerstreit das Bildobjekt zu einem "Nichtigen " macht, ${ }^{93}$ oder noch drastischer, dass die Bildwahrnehmung die "Eigentlichkeit" einer Wahrnehmung "löscht", indem sie Teile des perzeptiven Wahrnehmungsfelds durch eine "uneigentliche Erscheinung" ersetzt. ${ }^{94}$ Die Beziehung zwischen illusionistischer Bilderscheinung und Bildträger wird also negativ gedacht, weil es der phänomenologischen Einstellung nicht gelingt, das reale, d.h. gegenständlich in der Welt gegebene Bildding mit dem seinerseits reellen, d.h. für ein Bewusstsein gegebenen Bildraum zu verbinden.

Ich argumentiere dafür, dass einerseits das phänomenologische Unvermögen, diese Beziehung anders zu konzipieren denn als Antagonismus zweier ontologischer Modalitäten, sowie andererseits die repräsentationskritische Haltung der Phänomenolo-

91 Ebd., S. 46. Husserls Affinität zum perspektivischen Bildmodell kommt in weiteren seiner Begrifflichkeiten zum Ausdruck, etwa wenn er die intentionale Aufmerksamkeit ausgehend vom Ich als "Strahl« beschreibt. Husserl, Ideen zu einer reinen Phänomenologie und phänomenologischen Philosophie, 1952, S. $105 \mathrm{ff}$.

92 Husserl, Phantasie und Bildbewusstsein, 2006., S. 46.

93 Ebd., S. 48.

94 Ebd., S. 47. 
gie gemeinsam die Wurzel der phänomenologischen Kritik der Perspektive bilden. Wie ich bereits gezeigt habe, werden im zwanzigsten Jahrhundert die Distanzierung von Subjekt und Objekt sowie der illusionistische Charakter des Bildraums zu den wesentlichen Kritikpunkten der Moderne an der Perspektive. Der Antagonismus zweier ontologisch unterschiedlich erlebter Räumlichkeiten (Bildraum versus Realraum), die Husserl noch deskriptiv bestimmt, wird in den Argumentationen Merleau-Pontys und Gottfried Boehms gleichsam zugespitzt. Die ontologischen Modalitäten werden dabei tendenziell zu normativen Momenten, was etwa erkennbar wird, wenn Boehm von der "Negation" des "Eigenwertes" des Bildes spricht und perspektivisch konstruierten Bilder als "schwache Bilder" klassifiziert. ${ }^{95}$ Zugleich wird der formalisierte und distanzierte Charakter des perspektivischen Betrachterstandpunkts als prekäre Subjektivität diskutiert und avanciert zu einem Kernpunkt der Subjektkritik. Die Entwicklung der phänomenologischen Bildtheorie in der Nachfolge Husserls übt dann einen Druck auf die Perspektive aus, der schließlich zu deren Implosion führt, mit der die Differenz zwischen Bildraum und Realraum, Subjekt und Objekt, Repräsentation und Sache zusammenbricht. Die Perspektive, die als Emblem repräsentationaler Epistemologien fungiert, wird in diesem Kontext durch ein topologisches und ontologisches Modell der Welterschließung abgelöst.

Dass sich zeitgleich künstlerische Entwicklungen abzeichnen, mit denen die Modelle der klassischen Repräsentation aus der Sicht der Malerei in Frage gestellt werden, verkompliziert die Angelegenheit. Die antimimetischen Impulse der modernen Malerei, die etwa als mediale Selbstkritik oder Ikonoklasmus verhandelt werden, finden jedoch unter den unterschiedlichsten Voraussetzungen statt und bringen derart vielfältige Phänomene hervor, dass man sie unter keinen Umständen auf einen gemeinsamen Nenner bringen kann. Die Beziehung zwischen dieser Malerei und der phänomenologischen Theoriebildung ist nicht mehr als eine Geschichte einzelner Berührungspunkte. Die Schwierigkeit, diese Berührungspunkte angemessen zu verstehen, resultiert aus ihrer Komplexität, in der sich gestalterische Probleme, theoreti-

95 Boehm, "Zuwachs an Sein. Hermeneutische Reflexion und bildende Kunst“, 1996, S. 101. 
sche Fragen und Historiographie vermischen. Mir scheint, dass weder die Philosophie noch die Kunstgeschichte in der Lage sind, die Komplexität dieser Berührungspunkte, in die sie jeweils involviert ist, adäquat zu reflektieren. Während die Philosophie dazu tendiert, Kunstwerke als Spiegelungen ihrer eigenen und dabei voraussetzungsreichen Überlegungen $\mathrm{zu}$ betrachten, neigt die phänomenologisch orientierte Kunstgeschichte dazu, Narrative der Malereigeschichte zu schreiben, die den bildtheoretischen Interessen des Autors entsprechen. In beiden Fällen wird die kontextuelle Bedingtheit der Kunstwerke deutlich, die den perspektivkritischen Diskurs des zwanzigsten Jahrhunderts tiefgreifend prägen.

\section{Neutralität}

So überzeugend die visuellen Beobachtungen der phänomenologische Bildtheorie sind, so fragwürdig scheinen ihre Schlussfolgerungen. Die berühmte dürersche Übersetzung des Begriffs perspectiva als >Durchsehung im negativen Sinne als eine Nichtung zu interpretieren und zu einem bildtheoretischen Problem zuzuspitzen, erweist sich heute als eine intellektuelle Sackgasse, die auch deshalb besonders frappierend scheint, weil sie ausgerechnet denjenigen Bildtypus als defizitär klassifiziert, der sich global am erfolgreichsten zeigt. Wieso soll die große Mehrheit der produzierten und wahrgenommenen Bilder in der Welt defizitär sein? Nicht dass ihr faktischer Erfolg automatisch ihre Richtigkeit oder gar Universalität beweisen würde, doch ihre normative Bewertung als Nichtungen scheint wenig überzeugend.

Wie aber könnte man dieses Problem lösen? Auf welchem Weg könnte man den Negationsbegriff überwinden, der sich zu einer normativen Wertung piktoraler Qualitäten entwickelt, und dabei die an sich überzeugenden phänomenologischen Deskriptionen des Bildes ernst nehmen?

Eine Antwort findet sich an anderer Stelle in Husserls Werk, nämlich im Text "Zur Lehre von den Anschauungen" und ihrer Modi, der gemäß den Editoren der Meiner-Ausgabe um 1918 entstanden ist. Hier zeichnet sich ein terminologischer Übergang ab, der mir im Hinblick auf die Frage der Wertung perspektivischer 
Bilder vielversprechend scheint. Im Hinblick auf die Bildwahrnehmung schreibt Husserl:

"In einer gewissen inaktuellen (passiven) Weise hat alles da 'Gesehene` den Charakter des Nichtigen, des Durchstrichenen oder besser, nach seiner Wirklichkeit aufgehoben. ${ }^{96}$

Husserl bemerkt selbst, dass die negativen Begrifflichkeiten dem Phänomen nicht gerecht werden, denn es liegt, wie er weiter betont »keine Durchstreichung als tätige Negation " vor. ${ }^{97}$ Auch dürfe der Widerstreit nicht als ständig hin und her schwankende Wechselbeziehung vorgestellt werden, als ob wir "zwischen Wirklichkeit und Schein anschauend abwechseln ${ }^{98}{ }^{98}$ Vielmehr zeichnet das Bildbewusstsein seinen Gegenstand in einem Modus der Suspension, der die existentiale Geltung, d.h. die leibhaftige Anwesenheit des Gegenstandes aussetzt. Dass Husserl schließlich die besondere Qualität der Bilderscheinung doch lieber als eine Suspension der Wirklichkeit versteht haben will denn als eine Nichtung, interpretiere ich als Kennzeichen dafür, dass die Pointe seiner Bildtheorie letztlich nicht in der Negativität des piktoralen Scheins mündet. Dies kommt nicht ganz überraschend, denn eine derartige Weise der Beschreibung, die durchaus offen ist für ein erweitertes Verständnis der perspektivischen Bildgebung, findet sich bereits in den Ideen zu einer reinen Phänomenologie und phänomenologischen Philosophie von 1913, wo das Bildproblem im Zusammenhang mit dem Begriff der `Neutralität` erläutert wird:

"Dieses abbildende Bildobjekt steht weder als seiend noch als nichtseiend, noch in irgendeiner anderen Setzungsmodalität vor uns; oder vielmehr, es ist bewusst als seiend, aber als gleichsam-seiend in der Neutralitätsmodifikation des Seins. ${ }^{99}$

98 Ebd., S. 214.

99 Husserl, Ideen zu einer reinen Phänomenologie und phänomenologischen Philosophie, 1952, S. 226. 
Der fragwürdige ontologische Status der Bilderscheinung ist hier als Neutralität begriffen, was bedeutet, dass eine ontologische Enthaltung der Seinssetzung stattfindet. Diese Schlussfolgerung scheint mir aus mehreren Gründen angemessen. Zum einen der Hintergrund der phänomenologischen Methodik, denn die von Husserl selbst begründete Methode der phänomenologischen Reduktion hat zum Ziel, in einer Weise zu operieren, die den Eigenschaften des Bildbewusstseins nahesteht. Die phänomenologische Eidetik basiert auf einer Neutralisierung des phänomenalen Gegenstandes, für die das Bildbewusstsein gleichsam Modellcharakter hat, leistet es die Enthaltung der Seinssetzung einer Erscheinung doch ab initio und muss nicht allererst durch die Epoché vollzogen werden. Weiter scheint Neutralität auch im Hinblick auf Husserls sensible Beobachtungen und Reflexionen der Bildwahrnehmung mehr Sinn zu machen, ermöglicht sie es doch, den von Husserl beschriebenen Antagonismus, d.h. den Widerstreit von Bildding und Bildobjekt, von Realraum und Bildraum ohne Präjudizierung in seiner jeweiligen Produktivität zu denken. Das in perspectiva enthaltene Präfix per- muss in diesem Zusammenhang nicht ausschließlich im räumlich-transitiven Sinn, sondern zugleich im systemisch-funktionalen Sinn verstanden werden. Der Bildträger ist dabei nicht bloß als dasjenige zu begreifen, durch das hindurch gesehen wird, sondern auch als dasjenige, wodurch etwas gesehen wird. Die besondere Beziehung zwischen Bildfläche und illusionistischem Bildraum und damit die Erfahrung perspektivischer Bilder ist auf diese Weise adäquater beschrieben, als mit dem Konzept einer inneren Negation des Bildes.

Das Konzept einer solchen, genuin bildlichen Neutralität garantiert schließlich die notwendige Offenheit, um ganz unterschiedliche und jeweils im Einzelfall zu bestimmende Verwendungen, Funktionen und Bedeutungen zu untersuchen. Daher kommt Husserl in der Auseinandersetzung mit unterschiedlichen bildlichen Phänomenen zum weitsichtigen Schluss, dass es "sehr verschiedene Gestalten des Neutralitätsbewusstseins« gebe und das Neutralität »in verschiedener Weise « motiviert sein könne. ${ }^{100}$ Ich bin der Meinung, dass eine derartige Neutralität die geeignete

100 Ebd., S. $228 f$. 
heuristische Ausgangslage für eine Analyse der perspektivischen Bildform bietet, die ihren Sinn immer unter jeweils besonderen Bedingungen und innerhalb eines spezifischen Kontexts erhält. ${ }^{101}$

101 Ein Beispiel dieser Abhängigkeit von einem bestimmten historischen und pragmatischen Kontext hat Alexander Perrig in seiner Deutung von Masaccios Trinitätsfresko in der Santa Maria Novella beschrieben. Er argumentiert dafür, dass die geometrische Raumkonstruktion des Wandgemäldes gerade nicht ein Bruch mit der theologischen Ästhetik bedeutet und zu Unrecht als Ausdruck einer "Säkularisationstendenz« interpretiert wird. Man müsse die Perspektive hier als "Vehikel einer neuen Transzendenzdarstellung« verstehen, die ihre Funktion gerade im Kontrast zur historisch maßgebenden Flächenordnung gewinnt. Perrig, "Masaccios >Trinità und der Sinn der Zentralperspektive«, 1986, S. 31f. 


\section{Die Perspektive auf den Kopf stellen}

\section{Perspektivische Depression}

Im Folgenden untersuche ich eine Reihe von Werken, deren formale bzw. strukturelle Anlagen im Zusammenhang mit der Perspektive stehen. In den ausgesuchten Werken, so meine These, kommt eine Kritik der Perspektive zum Tragen, die nicht das Ziel verfolgt, die Perspektive aus der Welt zu schaffen, sondern an und mit ihren Problemen und Möglichkeiten zu operieren. Es geht mir weder darum, eine Geschichte der post-perspektivkritischen künstlerischen Praxis zu schreiben, noch eine umfassende These zu diesen historisch, medial und konzeptionell sehr unterschiedlichen Arbeiten zu formulieren. Die Auswahl der Werke erklärt sich mit dem Fakt, dass sie das Perspektivmodell einer Drehung in die Vertikale unterziehen, mit anderen Worten: Sie stellen die Perspektive auf den Kopf. Die verschiedenen und teilweise komplexen Konsequenzen dieser Drehung sowie deren historische und intellektuelle Voraussetzungen und Referenzen sind der Gegenstand des vorliegenden Kapitels. Ich halte mich dabei mit einer inhaltlichen Interpretation der einzelnen Werke zurück und fokussiere auf die in ihnen angelegte perspektivische Thematik, um deren strukturelle Beziehungen sichtbar zu machen.

Bruce Nauman hat 1976 ein Modell geschaffen (Abb. 1), das als Grundlage für eine größere Arbeit mit landschaftsarchitektonischem Charakter dient. Diese hätte im Kontext der Skulptur Ausstellung in Münster 1977 realisiert werden sollen, was zum damaligen Zeitpunkt jedoch aus verschiedenen Gründen nicht geschehen ist - die Realisierung des Projekts hat schließlich erst im Jahr 2007 stattgefunden. Das dem Projekt zugrunde liegende Objekt trägt den Titel Model for Outdoor Piece:Depression, ist aus Holz und weißem Gips gefertigt und misst 24,8 x 205,7 x 205,7 cm. Das durch den Titel explizit als Modell klassifizierte Objekt stellt eine für den Campus der Universität Münster projektierte, begehbare Außenskulptur im Maßstab 1:12 dar (siehe dazu auch die Skizze in Abb. 2). 


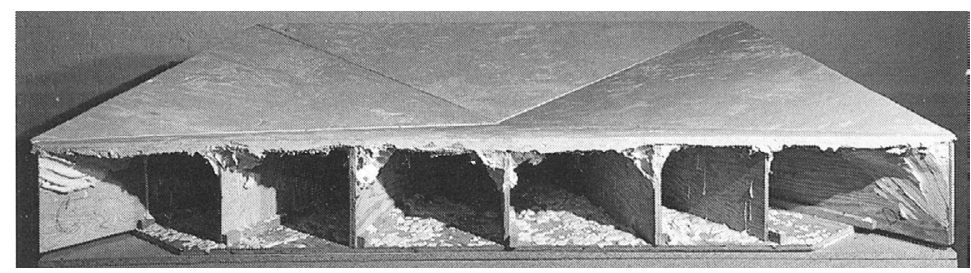

Abb. 1: Bruce Nauman, Model for Outdoor Piece:Depression, 1976, Gips, Sperrholz.

Die quadratische Fläche mit der Seitenlänge achtzig Fuß (24,38 m) ist in vier gleich große dreieckige Segmente geteilt, die mit einem Gefälle von zehn Prozent nach dem exakten geometrischen Zentrum des Quadrates abgesenkt sind und fugenlos in den Boden einbetoniert werden. Der Tiefpunkt, an dem sich alle vier Flächensegmente gleich einer Pyramidenspitze berühren, befindet sich acht Fuß (2,43 m) unter dem Bodenniveau. Einer erwachsenen Person, die sich am oder um den Tiefpunkt des Quadrates bewegt, soll die sie umgebende Außenkante in etwa auf Augenhöhe begegnen. ${ }^{1}$

Die realisierte Arbeit Square Depression verweist in mehrerlei Hinsicht auf das Bildmodell der Perspektive. Da ist zum einen die pyramidale Struktur, die entweder auf die geometrisch konstruierte Sehpyramide im Sinne Albertis verweist, in deren Zentrum die kulminierenden Fugen zusammentreffen und den zentralen Blickpunkt bilden. ${ }^{2}$ Die pyramidale Struktur ist aber auch ein projektives Gegenstück der Sehpyramide, nämlich als perspektivisch konstruierter Tiefenraum mit einem zentralen Fluchtpunkt, der dann exakt am Tiefpunkt der Bodenpyramide liegt und die Form der Sehpyramide gleichsam umstülpt. ${ }^{3}$ In beiden Fällen aber ist

1 Nauman, Catalogue Raisonné, 1994, Werk-Nr. 249, S. 269.

2 Alberti schreibt: "Daher wird ein Gemälde nichts anderes sein, als die Schnittfläche durch die Sehpyramide (piramide visiva), die gemäß einem vorgegebenen Abstand, einem festen Zentralstrahl und mit bestimmter Beleuchtung auf einer gegebenen Fläche mit Linien und Farben kunstgerecht dargestellt ist."Alberti, »De pictura«, 2000, S. 85

3 Die in der Ambivalenz von Square Depression als Seh- oder Raumpyramide angelegte Umstülpung der Form ist ein Verfahren, dass an anderer Stelle in Naumans Werk zum Tragen kommt, etwa in den Venice Fountains (2007) und weniger offensichtlich in Live-Taped Video Corridor 1970. Vgl. dazu Pichler und Neuner, "Das umgestülpte Spiegelbild. Zur plastischen Form von Bruce Naumans Live-Taped Video Corridor«, 2018, S. 88f. 


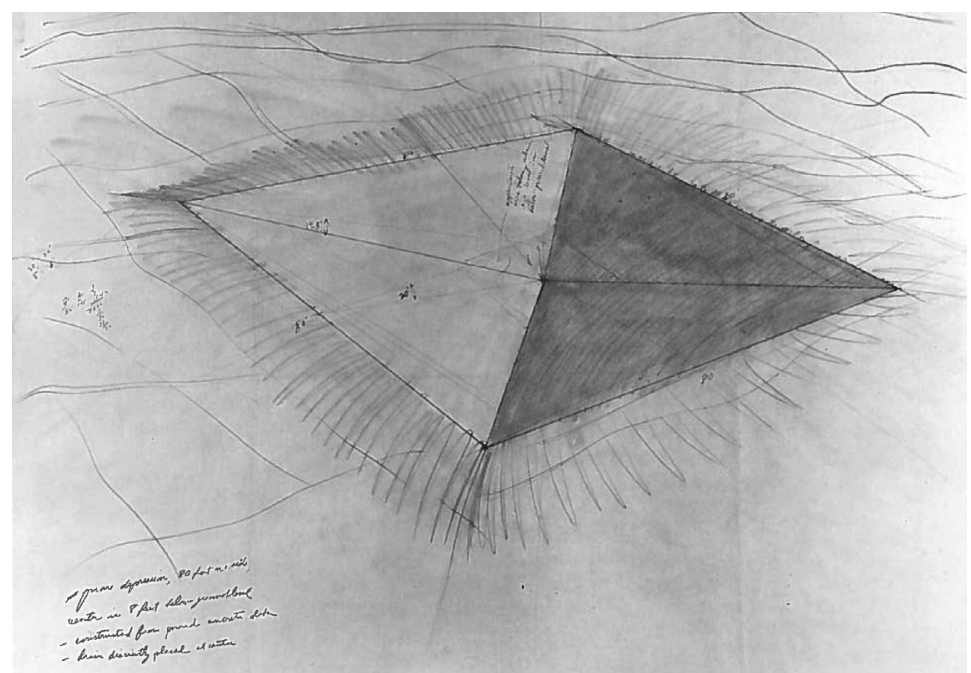

Abb. 2: Bruce Nauman, Studie zu Square Depression, 1976, Bleistift auf Papier.

die gesamte Struktur der perspektivischen Seh- bzw. Raumpyramide um neunzig Grad gedreht und in den Boden eingelassen.

Aber auch im tatsächlichen Erfahrungsvollzug, d.h. beim Begehen der Arbeit, zeigt sich die Bezugnahme auf Perspektive. Denn beim Begehen der Bodenpyramide verschiebt sich durch das Gefälle, die Augenhöhe der Betrachterin und damit ihr faktischer Wahrnehmungshorizont. Im Bereich des Zentrums, also an tiefster Stelle der Pyramide, liegt die Augenhöhe knapp unter dem Bodenniveau. ${ }^{4}$ Es besteht also ein kalkulierter Zusammenhang zwischen dem Flucht- bzw. Blickpunkt der umgekippten Raumbzw. Sehpyramide und dem von dort aus faktisch sichtbaren Horizont - ich werde später darauf zurückkommen.

Abgesehen von diesen nicht zu übersehenden Zusammenhängen mit der Perspektive besitzt Square Depression auch tatsächliche optisch-perspektivische Effekte, die sich im Wahrnehmungs-

4 Dazu heißt es im Catalogue Raisonné: "A person standing at or near the center of the structure would perceive the edge not far above eye level." Nauman, Catalogue Raisonné, 1994, Werk-Nr. 249, S. 269. 
vollzug des Betrachters einstellen. Am Modell sind es die aus der schrägen Aufsicht des Betrachters resultierenden Effekte, durch die das Zentrum des Quadrats als Fluchtpunkt einer illusionsräumlichen Darstellung erscheint. Diese Illusionsräumlichkeit ist auch deshalb von Bedeutung, weil sie sich mit der Bewegung des Betrachters vor dem Modell verändert, was daran liegt, dass sich die Fluchtlinien realräumlich zum Betrachter verhalten, dieses Blickverhältnis zugleich aber das sichtbare Verhältnis der Fluchtlinien zueinander beeinflusst. Siegmar Holsten beschreibt dieselben Effekte an einer verwandten Arbeit Naumans aus dem Jahr

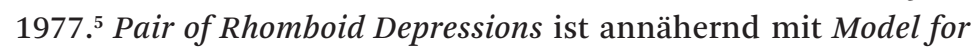
Outdoor Piece:Depression (Abb. 1) identisch, ${ }^{6}$ mit dem Unterschied, dass die Arbeit aus zwei getrennten Objekten besteht, die unmittelbar auf dem Boden im Ausstellungsraum präsentiert werden, also nicht auf einer ca. hüfthohen Basis. ${ }^{7}$ Der Umstand, dass hier zwei an sich identische Objekte aus einer einzigen Blickposition gesehen werden und so unterschiedliche und mitunter gegensätzliche Effekte erzeugen, verweist ebenfalls auf eine perspektivische Problematik, die Siegmar Holsten folgendermaßen beschreibt:

»Betrachtet man jedes der Stücke für sich in flacher Schrägsicht, so wirken die nicht parallelen Außenkanten wie perspektivisch verkürzte Seiten eines Quadrats, die in einem Punkt zusammenlaufen. Bezieht man das zweite Stück vom gleichen Standpunkt aus ein, entlarvt sich der Eindruck als Trug, weil sein Fluchtpunkt abweicht. Durch prüfenden Vergleich aufmerksam geworden, dass an den Gesetzen des perspektivischen Sehens oder am Regelmaß der Körper etwas nicht stimmt, suchen wir wenigstens innerhalb der vier dreieckigen Teilformen jedes der viereckigen Körper nach einer Konstanten. Meint man indes, das Werk aus steiler Aufsicht betrachtend, an einem Teilstück den Halt einer Regel gefunden zu haben, so wird er beim Umschreiten vom abweichenden nächsten wieder entzogen. $\ll^{8}$ 
In Holstens Beschreibung zeigt sich zweierlei: Erstens, dass sich die Funktion der Modelle nicht in ihrer Funktion als skalierte Miniatur des eigentlichen Werks erschöpft. Vielmehr handelt es sich bei ihnen um eigenständige Arbeiten, die eigene Effekte erzeugen. Zweitens werden die mit perspektivischen Mitteln erzeugten Effekte als Irritation der Betrachterin begriffen, eine Irritation, die Holsten erlebt als Infragestellung "unsere[r] von Erwartungen eingeengte[n] Wahrnehmung: “ ${ }^{9}$ Christel Sauer verweist ebenfalls auf die Irritation, wenn sie über dasselbe Werk schreibt:

»Worin der [Aussagewert] liegen kann, zeigt z.B. die Betrachtung der beiden parallel auf dem Boden liegenden vertieften Rhomben, die zu einer völligen Verwirrung der gewohnten Raum-Sicht führt. Die optische Verzerrung der Linienverläufe ohne rechte Winkel [...] überträgt sich auf den umgebenden Raum und hebt jedes 'selbstverständliche` Empfinden für Vertikale und Horizontale auf.«10

Die Perspektive und ihre Effekte werden demnach eingesetzt, um habitualisierte Erwartungen in Frage zu stellen. Dabei ist jedoch unklar, auf welche Erwartungen bzw. welche ihrer Voraussetzungen diese Infragestellung zielt. Wenn Holsten mit seinem Hinweis recht hat, dass die Arbeit darauf verweise, dass an den Gesetzen der Perspektive etwas nicht stimme, wird man sich die Frage stellen müssen, wie diese Kritik der Perspektive genau zu verstehen ist. Wenn die perspektivischen Effekte der Arbeit als solche thematisch werden, indem neben ihrem Gelingen gleichzeitig ihr Scheitern zur Schau gestellt wird, scheint es sich jedenfalls um eine externe Kritik zu handeln. Wie im bereits erläuterten Fall der Anamorphose ist das eine Kritik, die auf einen dem perspektivischen System äußeren Standpunkt verweist, von der aus die Funktionsweisen und Bedingungen der Perspektive in Frage gestellt werden. ${ }^{11}$

9 Ebd.

10 Sauer, Dokumentation 8, 1981, Vorwort, S. 13.

11 Holsten verweist auch auf den anamorphotischen Charakter der Arbeit Pair of Rhomboid Depressions: "Es scheint eher um einen anamorphotischen Prüfstein der Wahrnehmung zu gehen, d.h. um ein Werk, für den die Beziehung von Objekt, Raum und Subjekt maßgebend ist." Holsten, "Verrätseln als Methode«, 1981, S. 34. Zur Kritik der Perspektive durch Anamorphose siehe das Kapitel I der vorliegenden Studie. 
Wenn die Rede von einem äußeren Standpunkt ist, wird damit aber noch nichts darüber gesagt, wohin dieser mögliche Austritt führt. Denn die transzendente Kritik eines Systems ist auf einen Ort angewiesen, der außerhalb dieses Systems liegt und Naumans Perspektivkritik erst ihren eigentlichen Sinn verleiht. Ich möchte dieser Frage nachgehen, indem ich die Aufmerksamkeit von Naumans Modellen zum durch sie intendierten Projekt lenke. Dazu überspringe ich einen Zeitraum von rund drei Jahrzehnten, denn die Realisierung des Projekts hat erst im Jahr 2007 stattgefunden. Den gewissermaßen anachronistischen Charakter, der dem realisierten Projekt durch diese Verzögerung anhaftet, haben die Projektverantwortlichen offenbar ignoriert. Sie realisieren Naumans Entwurf aus den 1970er Jahren nahezu unverändert und betonen dabei, dass das Projekt in den dreißigJahren nicht an Aktualität verloren habe. ${ }^{12}$ Das Resultat, das sich seit 2007 auf dem Campus der Universität Münster in unmittelbarer Nähe zum Institut für Physik befindet, verdeutlicht, was in seinen Modellen nur angelegt war: Nicht die rein visuelle Wahrnehmung des Betrachters steht im Vordergrund, sondern vielmehr die Koppelung dieser Wahrnehmung an eine körperliche Erfahrung, die in unmittelbarem Zusammenhang zu einer konkreten "Erfahrungsarchitektur« steht, wie Felix Thürlemann die Arbeiten Naumans nennt. ${ }^{13}$ Zwar setzen auch hier perspektivische Effekte ein, etwa wenn die Größen- und Distanzverhältnisse von Personen vor dem perspektivisch verzerrten Hintergrund schwer einschätzbar werden (Abb. 3), ${ }^{14}$ doch ist damit das

Ein anamorphotisches Interesse Naumans lässt sich auch in einer anderen Reihe von Arbeiten erkennen, die ebenfalls Mitte der 1970er Jahre entstanden sind. Dazu gehören etwa Forced Perspective I und II aus dem Jahr 1975 sowie die Arbeiten Diamond Mind, Diamond Mind II sowie Enforced Perspective, alle aus dem Jahr 1975.

12 Kurator Kasper König wird im Pressetext vom 5.6.2007 folgendermaßen zitiert: "Als Bruce Nauman 1977 die Arbeit entworfen hat, war er seiner Zeit weit voraus. Die umgekehrte Pyramide hat in den 30 Jahren nicht an Aktualität verloren." Pressemitteilung, "Square Depression« von Bruce Nauman. Eine negative Bühne zu Selbsterfahrung, Skulptur Projekte Münster 07, Westfälisches Landesmuseum für Kunst und Kulturgeschichte, Münster 5.6.2007.

13 Thürlemann, "Gegenräume für Doppelgänger. Bruce Naumans Erfahrungsarchitekturen und ihre Rezipienten«, 1996, S. 118f.

14 Dieter Koepplin spricht diesbezüglich auch von einer "verzerrte[n] Vertiefung" und von einem "verzerrt-zentrierten Werk", Koepplin, Bruce Nauman, 1986, S. 31. 


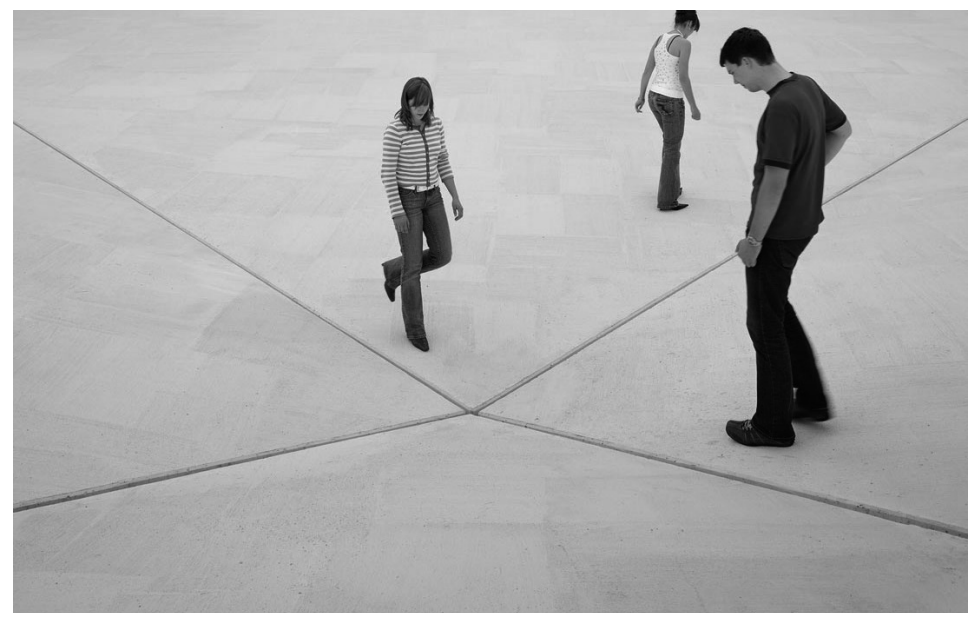

Abb. 3: Bruce Nauman, Square Depression, 2007, Beton.

in diesem Zusammenhang entscheidende Anliegen dieses Werks nicht benannt.

Die zugrunde liegende Operation, die Square Depression an der Perspektive vollzieht, ist deren Vertikalisierung, sprich die Neunzig-Grad-Drehung der Sehpyramide, die sich üblicherweise in seitlich liegender Position befindet und den frontal sichtbaren, perspektivischen Bildhorizont aufspannt. Diese Operation hat nachhaltige Auswirkungen, die nicht mehr nur die visuelle Erfahrung des Werks betreffen, wie es in den Modellen noch der Fall war, sondern auch die Selbsterfahrung des Betrachters als anwesendes, leibliches und bewegtes Subjekt. Die begehbare Arbeit fordert ihn dazu auf, die Bodenpyramide zu durchschreiten, wobei das Gefälle von 10 \% die Erfahrung des Begehens zu einer konstanten Erfahrung der Schwerkraft macht. Die Betrachterin erfährt sich als Masse im Gravitationsfeld der Erde, dem sie durch das starke Gefälle jederzeit spürbar ausgesetzt ist. Die Seitenwände der Pyramide üben durch ihre Neigung eine Kraft auf den Körper aus und zerren ihn bergab in Richtung Mittel- und Tiefpunkt der Pyramide, also jenen Ort, an dem der artifizielle Horizont der Arbeit ungefähr auf Augenhöhe oder tiefer liegt. Dazu äußert sich Nauman folgendermaßen: 
"Ein Gedanke bei der Senkung, den versenkten Dreiecken, war, dass man hineinlaufen kann und so tief darin steht [sic], dass die Augenhöhe unter dem Bodenniveau liegt und dies einen in gewisser Weise isoliert. Alle sind über einem und schauen auf einen herunter. Das war der Ursprung der Idee ${ }^{.15}$

Die Aussage Naumans lässt nur vage auf einen Zusammenhang zur Perspektive schließen. Dass die Augenhöhe am Tiefpunkt deutlich unter dem Bodenniveau liegt, scheint der im Catalogue Raisonné abgedruckten Erläuterung zum Model for Outdoor Piece:Depression zu widersprechen. Dort heißt es: "a person standing at or near the center of the structure would perceive the edge not far above ground level. ${ }^{16}$ Tatsächlich liegt die ab Bodenniveau gemessene Tiefe im Zentrum bei 2,43 Meter (acht Fuß) und liegt damit rund achtzig Zentimeter über der historisch durchschnittlichen Augenhöhe von 1,66 Meter. ${ }^{17}$ Wer sich im Zentrum der Bodenpyramide befindet, sieht also nicht über deren Ränder hinaus. Auf was für eine Kritik der Perspektive aber läuft diese mehr als nur metonymische Beziehung zwischen Square Depression und Perspektive hinaus? Der Projekttext aus dem Jahr 2007 äußert sich folgendermaßen dazu:

"Nauman spielt im Titel auch mit dem Wortsinn von 'Depression<. Depressiv, hilflos, ausgeliefert, so fühlt man sich, wenn man in der Mitte dieser Skulptur steht. Es geht um Raum und den Fluchtpunkt als formale Qualitäten. Gleichzeitig stellt Square Depression die räumliche Konstruktion eines psychischen Zustands unterhalb des Fluchtpunkts dar. Als Skulptur demonstriert Naumans Arbeit, wie sehr Perspektive Zwang ist und inwiefern sie Gewalt antun kann. Eine inszenierte Bedrohung... «18

15 Pressemitteilung, »Square Depression« von Bruce Nauman. Eine negative Bühne zu Selbsterfahrung, Skulptur Projekte Münster 07, Westfälisches Landesmuseum für Kunst und Kulturgeschichte, Münster 5.6.2007.

16 Nauman, Catalogue Raisonné, 1994, Nr. 249, S. 269.

17 Die durchschnittliche Augenhöhe liegt in Deutschland nach Erhebungen der Bundesanstalt für Arbeitsschutz und Arbeitsmedizin auf Faktor 0,93 der Körpergröße und beläuft sich statistisch gemessen auf $166,8 \mathrm{~cm}$. Vgl. Wolfgang Lange/Armin Windel (Hg.), Kleine Ergonomische Datensammlung, 16. aktualisierte Auflage 2017.

18 http://www.skulptur-projekte.de/archiv/07/www.skulptur-projekte.de/ kuenstler/nauman/index_html.html (aufgerufen 24.06.2020) 
Die Projektleiterin Christine Litz scheint demnach davon auszugehen, dass Naumans Werk als radikale, um nicht zu sagen polemische Kritik der Perspektive zu verstehen ist, die seinem Betrachtersubjekt "Zwang « und "Gewalt « antut. Damit greift Litz ein Leitmotiv von Naumans Arbeit auf, der seit den späten sechziger Jahren mit unterschiedlichen Formen der Gewaltausübung auf Körper operiert. ${ }^{19}$

Es zeigt sich also, dass die Projektbeschreibungen der Realisatoren sowie die Äußerungen des Künstlers das Werk als ein Erfahrungsdispositiv beschreiben, das seinem Subjekt eine bestimmte Erfahrung von Gewalt und Unterwerfung aufzwängt. Dabei scheinen drei unterschiedliche Subjektkonzeptionen zusammenzufallen, die ich differenzieren möchte: Erstens das leibliche Subjekt, das sich innerhalb einer geometrisch konfigurierten Umgebung bewegt und der darin wirkenden Schwerkraft auf betonte Weise ausgesetzt ist; zweitens das perspektivische Subjekt, das den Regeln einer geometrisch konstruierten Wahrnehmung unterliegt und dem die Limitierung seines visuellen Horizont vorgeführt wird; und drittens das psychosoziale Subjekt, das die Konsequenzen der ersten beiden als hilflose Unterwerfung und soziale Hierarchie erlebt (»Alle sind über einem und schauen auf einen herunter $\left.\aleph^{20}\right)$.

Dass diese drei Konzeptionen sich im Werk gleichsam überlagern, scheint zwar plausibel, doch ist ihr Zusammenspiel unzureichend geklärt. Was genau hat die psychosoziale Verfassung (`depressiv`, ’hilflos`, ‘ausgeliefert‘, ’bedroht‘, 'gewaltsam` etc.) mit den formalen Qualitäten des perspektivischen Raumes und dem Fluchtpunkt zu tun? Und wie verhält sich dieser Zusammenhang abermals zur bewegten Körperlichkeit des Rezipienten?

Die Verbindung zwischen den dezidiert negativen psychosozialen Qualitäten, dem Subjekt der Perspektive und der Thematik des Leibes sowie der Schwerkraft, lässt sich historisch erläutern. Eine Annäherung an ihre Voraussetzungen erlaubt etwa ein Text Dan Grahams aus dem Jahr 1969, in dem dieser sich u.a. mit Naumans

19 Pichler und Neuner, "Das umgestülpte Spiegelbild. Zur plastischen Form von Bruce Naumans Live-Taped Video Corridor«, 2018, S. 82.

20 Pressemitteilung, "Square Depression" von Bruce Nauman. Eine negative Bühne zu Selbsterfahrung, Skulptur Projekte Münster 07, Westfälisches Landesmuseum für Kunst und Kulturgeschichte, Münster 5.6.2007. 
Schaffen beschäftigt. In der Auseinandersetzung mit einer frühen Bodenarbeit ohne Titel aus dem Jahr 1965-66, bestehend aus Latexgummi, schreibt Graham:

"In place of the rigid notion of Euclidean Geometry (as in 'Minimak sculpture), these 1965-66 works of Bruce Nauman transform the medium (rubber) as it (the medium) acts as a medium conveying its material in-formation. It acts as a record of its material changes of interaction and of its own material nature in yielding to natural forces (its own, the environment's, and the artist's physical presence and procedures in placing it...«11

Die Aussage beinhaltet zentrale Aspekte, die sich im Hinblick auf die oben formulierten Probleme stellen: Zunächst die euklidische Geometrie bzw. deren Rigidität und insbesondere der idealisierte euklidische Raum, der objektive Messbarkeit beansprucht; und weiter die körperliche Präsenz sowie die auf sie einwirkenden natürlichen Kräfte. Die Arbeit Naumans, so Graham, zeichne jene Kräfte auf, die das Material in Abhängigkeit der Materialeigenschaften, der Umgebung und des Körpers Naumans geformt haben, und arbeite damit gegen eine Konzeption des idealisierten Raumes. Die Bedeutung des Zusammenspiels von Körper, Umgebung und Gravitationskraft in Naumans Werk betont Graham auch im Hinblick auf andere Arbeiten, etwa wenn er die Arbeit Bouncing in a Corner bzw. deren vorausgehende Performance beschreibt, die Nauman gemeinsam mit Meredith Monk im Whitney Museum of American Art realisiert hat.

»They [Nauman and Monk] fell back, letting gravity carry them, hitting the walls at about a thirty-five-degree angle of inclination, then rebounding, setting up again, and starting the same procedure over again without stopping.«22

Die Arbeit Bouncing in a Corner ist nicht nur bezeichnend für eine historische Vorstellung des Körpers als künstlerischem Medium, sie weist auch aufschlussreiche Bezüge zu Square Depression auf.

21 Graham, "Subject Matter«, 1993, S. 42.

22 Ebd., S. 48. 
Das 1968 aufgezeichnete Video zeigt, wie Nauman seinen Körper wiederholt in die Ecke des Raumes fallen lässt (Abb. 4). ${ }^{23}$ Die Räumlichkeit der Videoaufnahme ist dabei der Disposition von Square Depression formal verwandt. Die räumliche Tiefe kulminiert in einem Punkt, der ebenfalls die Spitze einer Raumpyramide bildet - auch wenn es sich hier um ein dreiseitige Pyramide handelt. ${ }^{24}$ Das Videobild ist, ähnlich der Sehpyramide in Square Depression, gekippt, denn die Kamera wurde für die Aufzeichnung um $90^{\circ}$ gedreht. Dadurch wird das klare Verhältnis von unten und oben des Videobildes, sowie von Wand und Boden innerhalb des Bildraumes aufgehoben. Die im Videobild dargestellte rhythmische Bewegung des Körpers, fällt dadurch nicht einfach nach unten Richtung Boden, sondern wippt in der pyramidalen Bildtiefe vor- und zurück. Obschon Bouncing in a Corner die physischen Prozesse mit den Mitteln des Videos medial weiterverarbeitet, ${ }^{25}$ ist doch deutlich, dass die Arbeit u. a. auf das Zusammenspiel des Körpers und der Schwerkraft zielt und dazu den pyramidal geformten Raum als gravitationales Kraftfeld inszeniert.

"... falling bodies (Galileo) ... instead of dropping a physical substance outside of the artist's body to be precipitated into an art object, Nauman physically drops himself, instead of then dropping out of the picture, he drops his body into the architectural frame ... it seems important that the performers are not programmed in advance: it is simply their physical reactions in relation to the architecture... $\ll^{26}$

Graham betont die Abwesenheit einer quasi apriorischen Struktur, die hier nicht als euklidische Raumordnung sondern als Planung der Prozesse begriffen ist. Sie sei deshalb abwesend, weil sich die Arbeit aus der bloßen Interaktion des Körpers mit der Umgebung und der darin wirkenden Gravitationskraft ergebe.

23 https://vimeopro.com/user3539702/ubuweb/video/121815710 (aufgerufen 24.06.2020).

24 Dazu ist zu erwähnen, dass Nauman im Jahr 1977 auch ein Model for Triangular Depression geschaffen hat. Siehe: Nauman, Catalogue Raisonné, 1994, Werk-Nr. 255, S. 271.

25 Zur Bedeutung dieser medialen Verarbeitung im Werk Naumans siehe: Egenhofer, »Technik, Rhythmus und Subjektivität in drei Arbeiten von Bruce Nauman«, 2018.

26 Graham, »Subject Matter«, 1993, S. 49. 


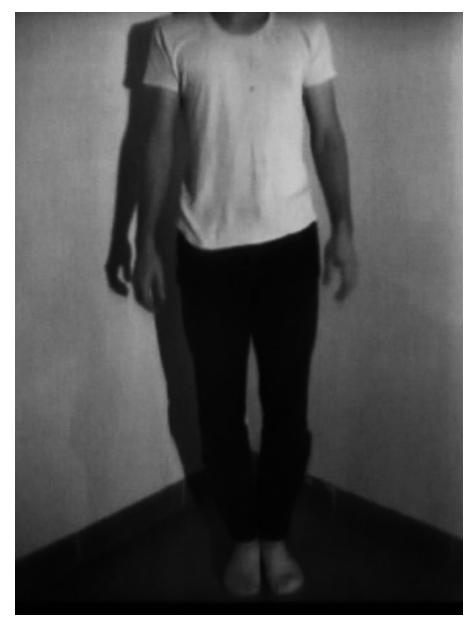

Abb. 4: Filmstill aus: Bruce Nauman, Bouncing in a Corner No. 1, 1968, Einkanal-SW-Video.

Grahams Beschreibung verweist auf einen zentralen Aspekt in Naumans Werk und dessen kritische Haltung zur Perspektive. Die topologischen Paradigmen des Werks, in dem die prozessualen Erfahrungen von Körper, Raum und Schwerkraft im Zentrum steht, ist eine Kritik an der Konzeption des perspektivischen Raumes, dessen weitgehend bedeutungsneutrale Idealität prinzipiell frei von gravitationalen Kräften ist. Die Betrachtererfahrung des linearperspektivisch konstruierten Raumes ist eine geradezu von der Schwerkraft losgelöste Raumerfahrung, die Samuel Edgerton folgendermaßen beschreibt:

"Oddly enough, linear perspective and chiaroscuro, which supply geometric stability to pictures, also allow the viewer a momentary suspension of his dependence on the law of gravity. With a little practice, the viewer can imagine solid volumes floating freely in space as detached components of a device. $\ll^{27}$ 
Die thematisierten Arbeiten Bruce Naumans dagegen sind an einer geradezu entgegengesetzten Adressierung der Betrachterin interessiert. Sie visieren nicht die Aufhebung der Gesetze der Schwerkraft an, sondern nutzen und inszenieren genau diese. In Bouncing in a Cornerwerden sie am Körper des Künstlers durchexerziert und medial vermittelt, in Square Depression werden sie für den partizipierenden Betrachter erfahrbar gemacht und prozessual mit seinem visuellen Wahrnehmungshorizont verkoppelt. Die zugrunde liegende Operation ist in beiden Fällen eine Drehung des Bildes, was zu einer topologischen Umdeutung des Bildfeldes führt. ${ }^{28}$

Mir scheint es aufschlussreich, diese Beobachtungen mit historischen Überlegungen zur Wahrnehmungspsychologie der Nachkriegszeit zu verbinden. Graham leitet seinen Beitrag zu Naumans Arbeiten passenderweise mit einem Zitat von James J. Gibson ein, das einen Teil von deren wissenshistorischen Entstehungsbedingungen widerspiegelt:

"The earth's gravity is a continuous downward force constantly pulling bodies of material downward toward the earth's plane, surface of support. To the body acted upon, the lines of force in the field are stationary, parallel and vertical impressions; all impressions are upon/ from the earth, which is itself, due to the same, but greatly magnified force (formed as) the topological surface area of a sphere. $\aleph^{29}$

Graham zitiert eine Stelle aus Gibsons im Jahr 1950 erschienener Studie, die durchaus beispielhaft für dessen Anliegen ist. Es besteht u. a. darin, die formale Konzeption visueller Wahrnehmung als Korrelat eines abstrakten geometrischen Raumes zu verabschieden, indem er diese durch einen Begriff der Wahrnehmung ersetzt, der die physiologische, intentionale und nicht zuletzt gravitationale Beziehung des wahrnehmenden Subjekts zu seiner Umgebung ins

28 Wolfram Pichler und Stefan Neuner sprechen treffend von der besonderen Bedeutung "topologischer Operationen für Naumans Poetik«, zu denen sie Verfahren wie Verkehrungen, Umstülpungen, Umkehrungen, Vertauschungen von vorne und hinten zählen. Pichler und Neuner, "Das umgestülpte Spiegelbild. Zur plastischen Form von Bruce Naumans Live-Taped Video Corridor", 2018, S. 60.

29 Zitiert nach: Graham, "Subject Matter«, 1993, S. 41. 
Zentrum stellt. ${ }^{30}$ Gibsons Theorie formuliert so die paradigmatischen Grundelemente von Square Depression: Die Erdanziehungskraft, deren vertikale Ordnung, die Erdoberfläche sowie der agierende Körper.

Dieser wissensgeschichtliche Kontext unterstreicht, dass Square Depression an der Modifikation eines Wahrnehmungsmodells arbeitet. Der zentrale Sehstrahl, der im Perspektivmodell das Auge mit dem Fluchtpunkt verbindet, wird um $90^{\circ}$ gekippt und zielt ins Erdinnere - gleich einem Kraftvektor der Erdanziehungskraft. Diese vertikale Richtung bestimmt die gesamte Pyramide, die nicht mehr ein sichtfeld bestimmt, sondern ein begehbares Feld auf der Erdoberfläche. Ihre schiefen Ebenen machen die zum Erdmittelpunkt gerichtete Gravitationskraft jederzeit erlebbar. Sie ist gemäß den Gesetzen Newtons gespalten in die Normalkraft, die als Reibung erfahren wird, und in die Hangabtriebskraft, mit der die Körpermasse in Richtung Tiefpunkt gezerrt wird, der zugleich den Flucht- bzw. Blickpunkt bildet.

Das ideelle perspektivische Bildfeld ist in ein opakes Kraftfeld verwandelt, das Körper und Blick des Betrachters derart vereinnahmt, dass er - angekommen am Blickpunkt des Modells - gleichsam blind ist. Das ihn umgebende Dispositiv schneidet seine Sicht auf die Welt förmlich ab, verschluckt und unterwirft ihn.

Ich enthalte mich an dieser Stelle einer vertieften Interpretation der Erfahrung, die Square Depression vermittelt. Gesellschafts- und technikkritische Aspekte, wie sie der Projekttext andeutet, scheinen evident, aber nicht zwingend. Für die vorliegende Untersuchung ist aber vielmehr von Bedeutung, dass die Perspektive als Modell angewendet wird, um die gewaltsame Unterwerfung des Subjekts künstlerisch zu untersuchen. Naumans Arbeit mit der Perspektive basiert dabei auf einer Operation, deren komplexe Konsequenzen gerade nicht von einer Verabschiedung der Perspektive zeugen, sondern vielmehr von einer vertieften Auseinandersetzung unter bestimmten historischen Voraussetzungen. $\mathrm{Zu}$ diesen gehört nicht nur die oben beispielhaft umrissenen Wahrnehmungstheorien der zunehmend einflussreichen Disziplin der 
Psychologie, auch der Zusammenhang zur Malereigeschichte der Moderne scheint sich in Naumans Werk klar abzuzeichnen. Das Bildfeld ist hier - man mag an Jackson Pollocks Verfahren des Drip Paintings denken - zu einem opaken Graviationsfeld geworden. Es ist ein in der Ebene liegendes Dispositiv einer körperlichen Aktion, deren Prozessualität jedoch nicht vom Künstler eingeschrieben, fixiert und vom Betrachter mimetisch erfahren, sondern von Letzterem jeweils am eigenen Leib durchlebt wird. Dass dieser Leib dabei nicht als emanzipatorisches Moment in Erscheinung tritt, liegt auf der Hand. So gesehen dechiffriert Square Depression nicht einfach die perspektivische Darstellungsform, sondern genauso jene der späten Moderne.

\section{Augenrollen}

Bereits vor der amerikanischen Nachkriegsmoderne werden der Körper des Betrachters und die Schwerkraft zu wichtigen Komponenten der perspektivkritischen Kunstpraxis. Die Arbeit Circuit von Alberto Giacometti aus dem Jahr 1931 (Abb. 5) ist in dieser Hinsicht ein außergewöhnliches Objekt, das thematisch und formal eine Auseinandersetzung mit der Perspektive leistet. Im Folgenden geht es darum zu verstehen, wie diese Auseinandersetzung mit der somatischen Erfahrung des Betrachters in Beziehung gesetzt wird und welche Rolle die Drehung der Perspektive dabei spielt.

Die nahezu quadratische Holztafel ist mit einer ca. fingerdicken Rinne und einer danebenliegenden, lochförmigen Vertiefung versehen, in der eine Kugel liegt. Die naheliegende Bewegung der Kugel in der Rinne, die Materialität und das Format verleihen der Arbeit den Charakter eines Spielbretts. Friedrich Teja Bach hat in zwei kurzen Beiträgen darauf aufmerksam gemacht, wie diese spielbrettartige Arbeit auf das perspektivische Modell des Sehens bezogen werden kann. Er erkennt in Giacomettis Arbeit eine Auseinandersetzung mit einem neuzeitlichen Schaubild aus Mario Bettinis Perspektivtraktat Apiaria universae philosophiae mathematicae aus dem Jahr 1642, das die anamorphotische Projektion eines frontal dargestellten Auges in die Horizontale illustriert (Abb. 6). Giacometti habe die anamorphotische Projektion in eine Plastik umgesetzt, indem er den Augapfel in eine bewegliche Kugel 


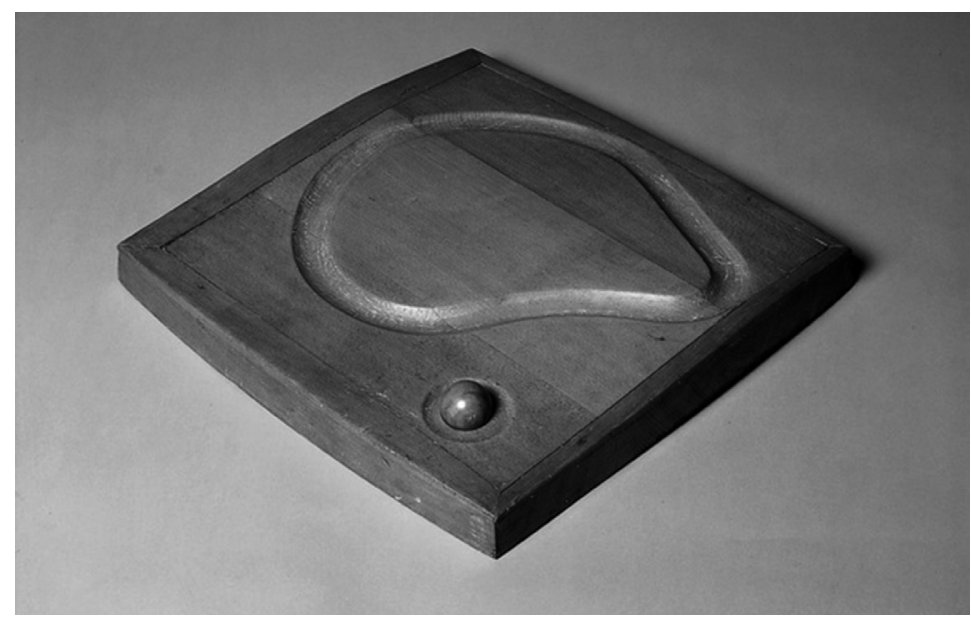

Abb. 5: Alberto Giacometti, Circuit, 1931, Holz.

verwandelt habe, die sich entlang den Grenzen des Auges bewegt. ${ }^{31}$ Bach untermauert seine These mit dem Hinweis auf Giacomettis Auseinandersetzung mit weiteren anamorphotischen Phänomenen - so etwa in der Arbeit Paysage-tête couchée von 1932 - und erkennt in Giacomettis Schaffen ein wiederkehrendes Interesse am Modell der Perspektive. ${ }^{32}$

Bachs These wirft damit die Frage auf, ob und wie Giacomettis Arbeit als Kritik der Perspektive begriffen werden kann und welche Rolle die Drehung der Perspektive dabei spielt. Da ist zunächst das Element der Materialität, das in der massiv hölzernen Arbeit besonders betont wird. Nach Bachs Lesart ist hier nicht nur eine Flächenprojektion zu einem konkreten Objekt geronnen, dieses Objekt stellt zudem das zentrale Element des perspektivischen Verfahrens dar: das Auge. Die transparente Linse, das optische Medium also, das die Lichtstrahlen nach geometrisch bestimmbaren Regeln bündelt und projiziert, ist zu einem flachen und opaken Gegenstand geworden. Das neuzeitliche Moment der Transparenz ist also gleich in doppelter Hinsicht einer opaken Materialität

31 Bach, "Giacomettis Spielbrett- und Platz-Skulpturen«, 2013.

32 Ebd., S. 47. Vgl. zudem: Bach, "Giacometti und das gefallene Auge Gottes«, 2002 . 


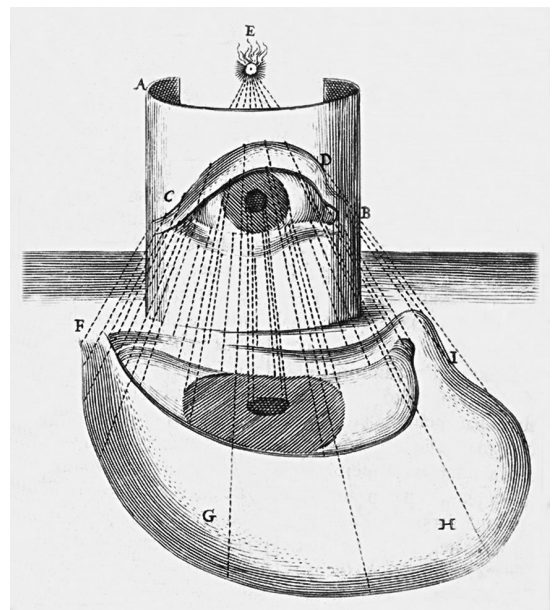

Abb. 6: Mario Bettini, Schaubild aus dem Perspektivtraktat Apiaria universae philosophiae mathematicae, 1642.

gewichen, was Bach dazu veranlasst, von einem wahrhaften "Sturz der Episteme der Repräsentation in die Materialität«zu sprechen. ${ }^{33}$

Diese Materialisierung bringt eine Reihe eigenwilliger Konsequenzen mit sich. Dazu gehört, dass die anamorphotische Darstellung nicht mehr dechiffrierbar ist, da die nötige Disposition zur Auflösung des Zerrbildes abhandengekommen ist. Bach bemerkt zu Recht, dass in Circuit, im Unterschied zu Bettinis Schaubild, die Lesbarkeit "gleichsam abgeschnitten ${ }^{34}$ sei. Giacomettis Arbeit ist in diesem Sinne antirepräsentational. Die Arbeit basiert zwar auf einer projektiven Repräsentation, deren Parameter sind jedoch nicht mehr erkennbar, womit das Bild zu einem kryptischen Objekt mutiert ist. ${ }^{35}$

Auch hier machen sich Materialität und Opazität des Werks als zentrale Charakterelemente bemerkbar, und wie in Square Depression hängen diese zusammen mit einer operativen Arbeit an der Perspektive. Ich möchte den Fokus auch hier auf jenen Aspekt

33 Ebd.

34 Ebd.

35 Die damit verbundene Schwierigkeit der Interpretation dieser Arbeit hat selbst den virtuosen Yves Bonnefoy dazu veranlasst, sie als ein ausgesprochen "dunkles Werk " zu beschreiben. Zitiert nach Bach, "Giacometti und das gefallene Auge Gottes«, 2002. 
legen, den ich im Hinblick auf die Veränderung der perspektivischen Blickachse "Vertikalisierung" nenne, und genauer verstehen, was diese bewirkt. Die Materialisierung der perspektivisch projizierten Augen-Form in der massiven Holztafel erweckt den Eindruck, als sei die Repräsentation zu einem Objekt erstarrt. Dies ist nicht nur auf die Monochromie des Holzblocks zurückzuführen, sondern auch auf dessen horizontale Position im Raum. Das dargestellte Auge liegt flach am Boden, seine mögliche Blickachse bildet eine Senkrechte und korrespondiert so mit der Blickachse der Betrachterin. Das Gesichtsfeld ist so mit dem Gravitationsfeld kurzgeschlossen, der Blick des Betrachters fällt im wörtlichen Sinn auf die Tafel, was durch die auf dem Brett liegende Kugel versinnbildlicht wird. Die bewegliche Kugel weist auf die gravitationale Kraft hin, die das Blickfeld beherrscht, und erzeugt eine eigentümliche Verbindung zwischen dem dargestellten Auge und dem Betrachter. Nicht nur eröffnet sich ihm und seinem Körper ein Handlungsspielraum, indem er die Kugel und damit die Bewegung des Auges bzw. des Blicks anstößt, die Assoziation der Kugel mit dem Augapfel führt zugleich zu einer seltsamen Verbindung von Sehen und Tasten. Da die faktische Größe der Kugel mehr der Augapfelgröße des Betrachters als der des viel größer dargestellten Auges entspricht, stellt sich eine Assoziation zwischen sehendem Auge des Betrachters und der rollenden Kugel ein. Diese Assoziation eines entkörperlichten Auges steht in mehrerlei Hinsicht in Beziehung zum perspektivischen Sehen. Die perspektivische Konstruktion erlaubt etwa die Darstellung von Objekten aus einem frei wählbaren und damit vom Körper losgelösten Blickwinkel. Das entkörperlichte Auge fungiert - etwa in geflügelter Form bei Alberti auch als Symbol des göttlichen Blicks, dessen Allmächtigkeit und Weitsicht keine Grenzen gesetzt sind. ${ }^{36}$ Im Gegensatz zu diesen Vorstellungen eines gleichsam freischwebenden Auges hat in Circuit die Schwerkraft das Sehen erfasst. Während der visuelle Raum der perspektivischen Darstellung keine essenziellen Richtungen aufweist, die ein Oben oder Unten definieren würden - Panofsky

Markus Rath hat darauf hingewiesen, dass Alberti das Emblem des entkörperlichten Auges möglicherweise auch als "Signum einer visuellen Theorie haptisch-optischer Rezeption « verwendet, da seine Ausgestaltung über einen Tastapparat verfüge, der die rein visuelle Wahrnehmung ergänzt. Rath, "Albertis Flug- und Tastauge. Neue Betrachtung eines Emblems visueller Theorie«, 2009. 
spricht daher von der "Richtungs- und Entfernungs-Willkür des modernen Bildraums $«^{37}$-, unterliegt das Auge in Circuit den Gesetzen der Schwerkraft. Die entscheidenden Parameter des Werks sind nicht die Gesetze der geometrischen Optik, sondern jene der Mechanik. Die operationale Grundlage ist dabei die Drehung des Perspektivmodells, die auch hier dazu führt, dass dieses mit Kräften durchsetzt wird, die seinen eigenen Paradigmen fremd sind.

\section{Topologien der Projektion}

Bruce Naumans Square Depression und Alberto Giacomettis Circuit sind nicht die ersten Drehungen der Perspektive im zwanzigsten Jahrhundert, und Alberto Giacometti ist nicht der erste moderne Künstler, der ein Schaubild aus einem Perspektivtraktat als Ausgangslage für seine kritische Arbeit an der Perspektive wählt. Marcel Duchamp hat sich während seiner Tätigkeit in der Bibliothèque Sainte-Geneviève zwischen dem Frühjahr 1913 und dem Sommer 1915 ein beachtliches Wissen über darstellende Geometrie, perspektivische Projektionsverfahren und historische Optik angeeignet. Es ist hinreichend bekannt, dass dieses Wissen sein künstlerisches Schaffen maßgeblich prägt und dass das Material aus der Bibliothèque Sainte-Geneviève Eingang in zahlreiche seiner Objekte findet. ${ }^{38}$ Ich lege den Fokus im Folgenden auf die Arbeit Stéréoscopie à la main aus dem Jahr 1918 (Abb. 7), die ich als ein Schlüsselwerk begreife, um die moderne Konfrontation der Perspektive mit der Thematik der Schwerkraft und Vertikalität zu verstehen. Die stereoskopische Doppelaufnahme der Meeresoberfläche, deren Horizont sich leicht unter der Bildmitte befindet, wurde von Marcel Duchamp manuell bearbeitet. Er fügte in jedes der beiden Bilder eine Zeichnung einer geometrisch pyramidalen Doppelfigur ein, deren Grundfläche mit der Wasseroberfläche koinzidiert. Nicht nur diese rechteckige Fläche, die waagerecht auf dem Meeresspiegel zu liegen scheint, ist perspektivisch auf den

37 Panofsky, "Die Perspektive als `symbolische Form«", 1974, S. 125.

38 Vgl. dazu vor allem: Clair, "Duchamp and the classical perspectivists«, 1978, sowie zuletzt: Peyré und Toussaint, Duchamp à la Bibliothèque Sainte-Geneviève, 2014. 


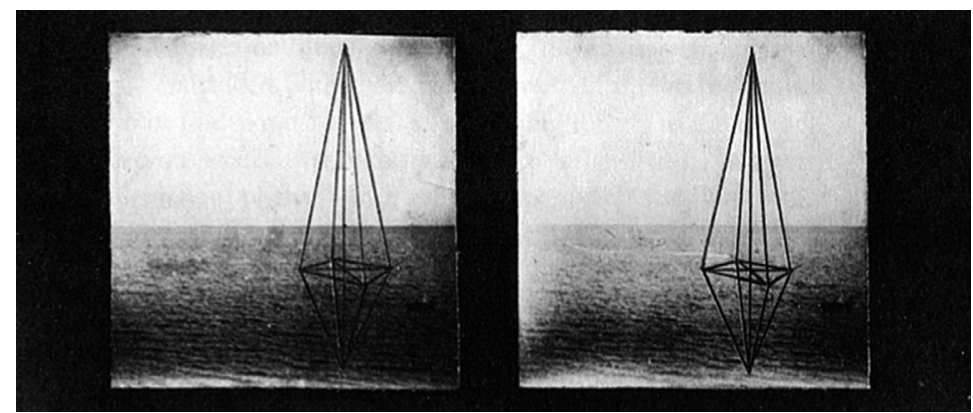

Abb. 7: Marcel Duchamp, Stéréoscopie à la main, 1918-19, Stift auf Gelatine-Silberprints.

Meereshorizont hin konstruiert (siehe Rekonstruktion in Abb. 8), auch in vertikaler Richtung verkürzen sich die Doppelpyramiden, wodurch die scheinbar unter der Wasseroberfläche liegende Pyramidenhälfte deutlich kürzer wirkt.

Dass es sich bei den Figuren um Sehpyramiden handelt, hat Jean Claire überzeugend dargelegt. ${ }^{39}$ Er verweist auf ein Schaubild des Perspektivtraktats La Perspective pratique nécessaire à tous les peintres (1649), das Duchamp aus seiner Zeit an der Bibliothèque Sainte-Geneviève bekannt war (Abb. 9). Unter diesem Gesichtspunkt wird Duchamps Stéréoscopie à la main zu einem komplexen und vielschichtigen Objekt. Der Meereshorizont wird gleichsam zum Emblem perspektivischer Horizonthaftigkeit, der die Grenze der subjektiven Sichtbarkeit mit einer romantischen und dabei malereigeschichtlichen Semantik anreichert. Die Meeresoberfläche als materielle Oberfläche eines transparenten Mediums gewinnt dabei eine Art metaphorische Bedeutung. Als Quasi-Projektionsfläche der Strahlenpyramide wird sie zu einem Gleichnis für die Bildoberfläche, was durch ihren spiegelnden Charakter noch verstärkt wird. ${ }^{40}$

Die Räumlichkeit der Darstellung, die durch eine Kombination aus Fotografie, perspektivischer Zeichnung und Stereoskopie

39 Ebd.

40 In seinem Werk Broken Obelisk aus dem Jahr 1969 wird Barnett Newman das Thema der pyramidalen Vertikalität aufgreifen und ein Multiple der Arbeit wird 1970 in der Wasseroberfläche vor der Rothko Chapel in Houston, Texas installiert. 


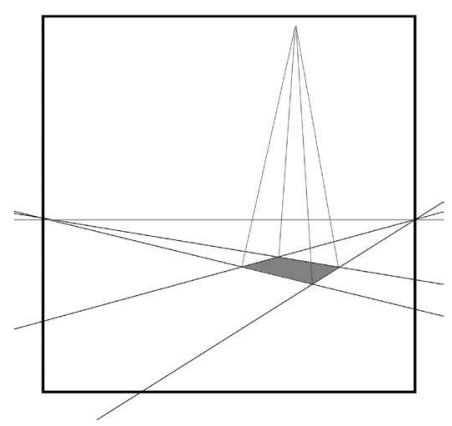

Abb. 8: Schematische Rekonstruktion von: Marcel Duchamp, Stéréoscopie à la main, 1918-19, Stift auf Gelatine-Silberprints.

erzeugt wird, weist dabei eine eigentümliche Ambivalenz auf, die in der Rezeption des Werks Beachtung gefunden hat. So kommt etwa Tim O'Riley zu dem Schluss, dass der stereoskopische Effekt ausschließlich für die fotografische Darstellung des Meeres zustande kommt, nicht aber für die gezeichneten Figuren. Letztere seien nicht aus zwei leicht verschiedenen Perspektiven gezeichnet, was für den stereoskopischen Effekt notwendig ist, sondern links wie rechts identisch und lediglich in der Position seitlich etwas versetzt. O'Riley kommt daher zu dem Schluss, dass die gezeichneten Figuren sich vom illusionistischen Bildraum abheben, flach und erscheinen eher dem realen Raum der Betrachterin und weniger den dargestellten Raum angehören. ${ }^{41}$ Dagegen kommt Jens Schröter zur genau gegenteiligen Einschätzung, nämlich dass der Meereshorizont gerade nicht stereoskopisch erscheinen könne, weil er eine zu große Distanz von den beiden Auge aufweise, als dass der stereoskopische Effekt überhaupt greifen könnte, da der parallaxe Unterschied bei der Ferndistanz annähernd vollständig verlorengeht. Es sei daher die gezeichnete Figur Duchamps, die den räumlichen Effekt erzeuge, denn als "näher gelegene geometrische Figur" sei sie es, die dem durch die Parallaxe bedingten Effekt unterliege. $^{42}$

41 O'Riley, Representing Illusions. Space, Narrative and the Spectator, 1998, S. 61.

42 Schröter, "Das transplane Bild und der Pictorial Turn. Zu Marcel Duchamps Medienästhetik«, 2006, S. 209. 


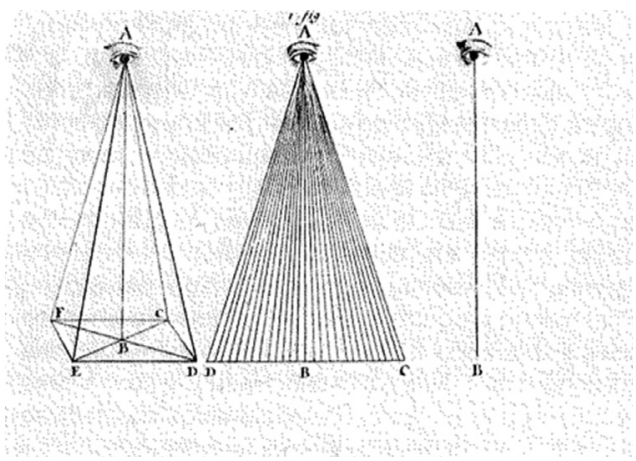

Abb. 9: Schaubild aus: Jean du Breuil, La Perspective pratique nécessaire à tous les peintres, Paris 1649.

Die Ambivalenz, die in diesen gegenläufigen Argumentationen zum Ausdruck kommt, mag für Duchamps Werk bezeichnend sein, sie weist aber auch auf eine Besonderheit von Stéréoscopie à la main hin. Diese resultiert aus der besonderen Kombination verschiedener Weisen der piktoralen Darstellung, die Duchamp hier zusammenbringt: die Fotografie, die eine Vorstellung indexikalischer Repräsentation mit sich bringt; die perspektivische Konstruktion, die, wie der Titel es betont, das Ergebnis eines manuellen und geometrischen Zeichnungsaktes ist; und schließlich die Stereoskopie, eine populäre Rezeptionstechnik des neunzehnten Jahrhunderts, die sich die physiologischen Bedingungen der Wahrnehmung zu eigen macht.

Da das Stereoskop hier als eine Art Rahmenbedingung funktioniert und den anderen Darstellungsformen quasi übergeordnet ist, soll ihr besondere Aufmerksamkeit geschenkt werden. Zunächst ist zu bemerken, dass der Stereoskopie aufgrund ihres vielfachen Gebrauchs zur Betrachtung erotischer bzw. pornografischer Bilder die Konnotation eines voyeuristischen Mediums anhaftet..$^{43}$ Diesen anrüchigen Charakter des Stereoskops könnte man in Beziehung zur komplexen Bedeutung des Begehrens in Duchamps Werk

43 Jonathan Crary verweist in diesem Zusammenhang insbesondere auf das Wheatstone-Stereoskop, das die "Trennung der Seherfahrung von ihrer Ursache besonders deutlich mache. Crary, Techniken des Betrachters, 1996, S. $132 f$. 
setzen, um etwa die Frage aufzuwerfen, was es bedeutet, die Sehpyramide als Emblem des perspektivischen Modells durch einen voyeuristischen Wahrnehmungsapparat sichtbar $\mathrm{zu}$ machen. ${ }^{44}$ Man könnte weiter daraus folgern, dass die Perspektive hier nicht mehr als regelndes Dispositiv der Repräsentation in Erscheinung tritt, sondern als Objekt eines ganz anderen Wahrnehmungsdispositivs, so dass man im Weiteren darüber spekulieren könnte, ob der Perspektive die Rolle eines Objekts des Begehrens zukommt. Doch ich möchte es vermeiden, in die komplexen Spekulationen um die Ökonomie des Begehrens in Duchamps Werk verwickelt zu werden, und mich zunächst auf den physiologischen Charakter der stereoskopischen Wahrnehmung konzentrieren.

Wie Jonathan Crary bekanntlich dargelegt hat, kann die Stereoskopie als Symptom eines Bruchs in der Geschichte der Wahrnehmungstheorie und ihrer Dispositive begriffen werden. Als Apparat, der direkt an den Körper angeschlossen ist, bricht das Stereoskop insbesondere mit dem Paradigma der neuzeitlichen Repräsentation. Der zentrierte Blick wird, wie Crary betont, zugunsten einer Dezentrierung des Betrachters aufgegeben und die lineare Beziehung zwischen Betrachtersubjekt und einheitlichem Bild wird abgelöst durch eine Seherfahrung zweier verschiedener Bilder, die offensichtlich voneinander getrennt sind. ${ }^{45}$

Die Konsequenzen sind gravierend, denn es gibt kaum eine Rezeptionstechnik, mit der die mentale Aktivität der Betrachterin im Wahrnehmungsvorgang stärker betont bzw. erlebbar würde als mit der Stereoskopie. Genau das macht das Stereoskop für Duchamp zu einem faszinierenden Apparat. Es ist so gesehen die anti-retinale Maschine par excellence, denn wie Jean Clair bereits früh bemerkt hat, konzipiert sie die Wahrnehmung von Bildern als einen mentalen Akt, der sich wesentlich im Inneren der Betrachterin abspielt. ${ }^{46}$ Das macht sie für Duchamp insofern besonders attraktiv, als er sie als Gegenmodell zu Verfahren der

Zum Zusammenhang libidinaler Energie und Duchamps Interesse an optischen Phänomenen siehe: Krauss, The Optical Unconscious, 1993, S. $135 \mathrm{ff}$.

45 Crary, Techniken des Betrachters, 1996, $132 \mathrm{ff}$.

46 "The stereoscopic image showed the way to a purely ideal configuration, the intelligible result of a synthesis certainly closer to the brain - and to the working of a cosa mentale - than to the retinal effect."Clair, "Duchamp and the classical perspectivists«, 1978, S. 104. 
modernen Malerei einsetzen kann, die seiner Meinung nach zu stark auf die sinnliche Affektion konzentriert ist, indem sie den Wahrnehmungsvorgang als retinalen Reizprozess begreift, womit die Malerei als eine quasi-physikalische Angelegenheit bestimmt wird. Dagegen möchte sich Duchamp im Medium der Malerei nach eigenen Aussagen mit Ideen beschäftigen, und »die Malerei zurückführen in den Dienst des Geistes ${ }^{4}{ }^{47}$ Die Stereoskopie als Apparat, der die innere Aktivität des Betrachters aufzeigt, bietet demzufolge die Möglichkeit, optisch-visuelle Phänomene mit den geistigen bzw. neurologischen Aktivitäten des Betrachters in Beziehung zu setzen.

Wenn man Duchamps Verwendung des Stereoskops mit Crarys These interpretiert, stellt sich jedoch die Frage, welche Schlüsse sich im Hinblick auf die Perspektive und ihre Bedeutung für die Stéréoscopie à la main ergeben. Man könnte dazu verleitet sein, Duchamps Stéréoscopie à la main als Symptom jener Verabschiedung von Repräsentationsformen $\mathrm{zu}$ interpretieren, die nach Crary auf dem Modell der Renaissanceperspektive basieren. ${ }^{48}$ Dabei muss man jedoch bedenken, dass Duchamp die Perspektive gerade nicht als ein Dispositiv jener tradierten Repräsentationslogik begreift, von der sich die Avantgarde seiner Zeit dezidiert abwendet. Die Tatsache, dass sich Duchamp just in den Jahren dem intensiven Studium von Perspektivtraktaten zuwendet, in welchen die Avantgarde und allen voran der Kubismus das perspektivische Paradigma regelrecht zerbrechen, weist darauf hin, dass Duchamp kein Interesse an einer einseitigen Kritik der Perspektive hat. Vielmehr erkennt er schon früh, dass die Perspektive für seine künstlerische Arbeit besonderes Potential bereit hält, ein Potential, dass sich weder in den gestalterischen noch in den repräsentationalen Funktionen der Perspektive erschöpft, sondern in dem liegt, was bereits Leonardo den geistigen Ursprung der Malerei nannte. ${ }^{49}$ Mit anderen Worten heißt das, die anti-retinale Kraft der Perspektive liegt darin, dass sie die Malerei als Angelegenheit des

47 Duchamp, »Propos«, 2008, S. 167 (Übersetzung des Autors).

48 Crary, Techniken des Betrachters, 1996, S. 92.

49 Leonardos Schriften betonen mehrfach den geistigen Charakter der Malerei, etwa wenn er schreibt: »Und darin besteht die Wissenschaft der Malerei, die im betrachtenden Geist wohnt." Chastel, Leonardo da Vinci. Sämtliche Gemälde und die Schriften zur Malerei, 1990, S. 135. 
Denkens ausweist. Für Duchamp leistet sie dies vor allem dadurch, dass sie als ein ontologisches Modell fungiert, was nur möglich ist, indem er ihren theoretischen Charakter überaus ernst nimmt. Es geht Duchamp nicht darum, das Modell nur zu materialisieren, um etwa seinen metaphysischen Charakter durch schiere Materialität zu kontrastieren. Die theoretische Dimension von Duchamps Perspektivkritik wird erst deutlich, wenn man versteht, dass sich der künstlerische Gehalt seiner Objekte gerade nicht in deren visueller Sichtbarkeit erschöpft, sondern das ermöglicht, was man mit bestem Gewissen Theorie nennen kann.

Die theoretische Dimension wird etwa dann deutlich, wenn man versteht, dass für Duchamp die Intersektion der Sehpyramide, als zweidimensionaler Schnitt durch den dreidimensionalen Raum, ein Modell für eine topologische Ontologie ist, die erweiterbare Formen besitzt:

"Ich dachte nur an die Möglichkeit einer Projektion, einer unsichtbaren, weil mit den Augen nicht erfassbaren vierten Dimension, [...] Ich fand heraus, dass Schatten eines dreidimensionalen Objekts eine zweidimensionale Form konstituieren [...], und schloss daraus, auf analogischem Weg, dass die vierte Dimension ein Objekt mit drei Dimensionen projizieren könne, d.h. dass alle dreidimensionalen Gegenstände, die wir so arglos betrachten, Projektionen von uns unbekannten vierdimensionalen Formen sind. $\aleph^{50}$

Ganz im Sinne der nicht-euklidischen Geometrie kann eine $n$-dimensionale Welt durchschnitten werden von einer $n$-1-dimensionalen Welt. ${ }^{51}$ Diese Vorstellung konzipiert jede Erscheinung als Projektion einer anderen, sie dimensional übersteigenden Erscheinung.

50 Cabanne, Gespräche mit Marcel Duchamp, 1972, S. 56.

51 Diese Vorstellung einer unsichtbaren vierten Dimension entwickelt Duchamp bekanntlich nicht nur in der Auseinandersetzung mit den neuzeitlichen Perspektivtraktaten, sondern auch durch Theorien zum nicht-euklidischen Raum, zu denen etwa die Texte Henri Poincarés zählen. Zentral scheinen dabei vor allem die Texte Poincarés von 1905 und 1908 gewesen sein. Poincaré, Der Wert der Wissenschaft, 2013 sowie Poincaré, Wissenschaft und Methode, 2003. Vgl. dazu auch Dalrymple Henderson, The Fourth Dimension and Non-Euclidean Geometry in Modern Art, 1983, S. $117 \mathrm{ff}$. 


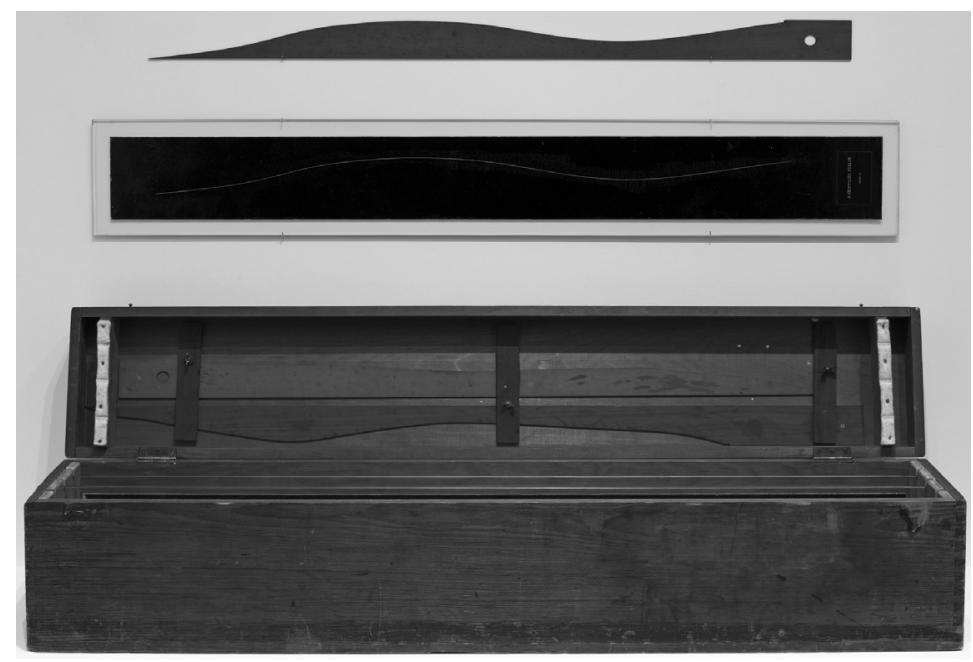

Abb. 10: Marcel Duchamp, 3 Standard Stoppages, 1914, drei Fäden, drei Leinwandstreifen, drei Glasscheiben, drei Holzstäbe, Holzkiste.

Eine Vorstellung davon, wie sich eine unsichtbare vierte Dimension auf die sichtbare Welt projiziert, vermitteln Duchamps Stoppages aus den Jahren 1913-14 (Abb. 10) Er hat in dieser Arbeit bekanntlich die Form zu Boden gefallener Fäden fixiert und präsentiert die Ergebnisse in Form maßstab-artiger Schablonen. Die Konnotationen dieser Arbeit, sind im Kontext der Perspektive unzweideutig: Als den Raum durchkreuzende Sehfäden - eine Vorstellung, die Duchamp durch sein Studium zahlreicher Perspektivtraktate überaus vertraut ist (Abb. 11) - werfen die Stoppages fundamentale Fragen nach den Bedingungen der perspektivischen Raumkonzeption auf und stellen die Arbitrarität normativer Modelle zur Debatte. Wodurch ist die Geradlinigkeit der Sehfäden garantiert? Ist der dreidimensionale Raum tatsächlich ein stabiles und lineares Kontinuum? Und wie stabil sind dessen Maßstäbe und Axiome?

Die Tatsache, dass Duchamp die Schwerkraft einsetzt, um diese Fragen aufzuwerfen, bezeugt den zentralen Zusammenhang von moderner Perspektivkritik und der Vorstellung physischer Kräfte. Jean-François Lyotard schreibt hinsichtlich der Stoppages: 


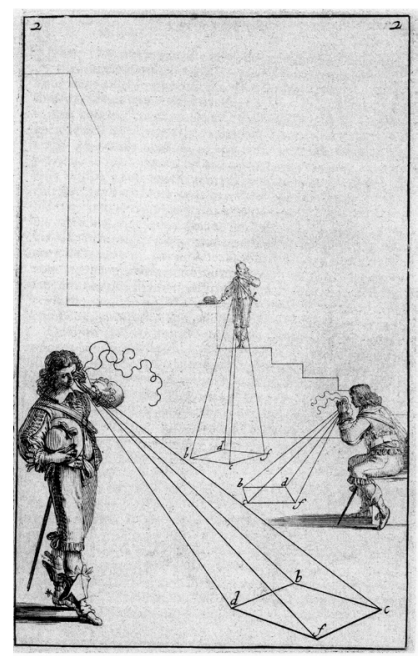

Abb. 11: Schaubild aus: Abraham Bosse, La règle de la pratique de la perspective pour le trait des figures, assiette, d'élévation, de profil et d'ombre ou d'ombrage, 1648.

"Wichtig in diesem Vorgang ist nicht die Aktion, die performance von Monsieur Marcel Duchamp, der seinen Faden fallen lässt; wichtig ist vielmehr die Projektion mittels der Bewegungsenergie der Schwerkraft und dem Zufall als Transformationsdispositiv. $\aleph^{52}$

Die Beziehung zwischen der dreidimensionalen Erscheinung als sichtbarer Projektion und der vierten Dimension ist als eine Wirkung von Kräften begriffen, zu denen die Schwerkraft zählt. Die Stoppages exponieren gewissermaßen die Prozesse, in denen sich diese Wirkung vollzieht, wobei die Perspektive zwar als Modell der Projektion fungiert, dabei aber auch einer Kritik unterliegt. Die an den Fäden vollzogenen Prozesse sind zwar, wie das perspektivische Projektionsverfahren, entpersonalisiert, finden jedoch in der raumzeitlichen Realität statt. Anders als in der idealen perspektivischen Raumkonstruktion wirken Schwerkraft, Reibung usw. auf die gleichsam materialisierten Sehfäden ein. ${ }^{53}$ Im Gegensatz zum

52 Lyotard, Die TRANSformatoren DUCHAMP, 1987, S. 27.

53 Linda Dalrymple Henderson betont den Zusammenhang zwischen Duchamps Interesse an Gravitationskraft und der vierten Dimension und verweist auf die 
perspektivischen Verfahren sind diese Prozesse also weder vollständig durch Regeln determiniert, noch sind sie identisch wiederholbar. Es sind singuläre Ereignisse und als solche einmalig.

Wenn Hans Belting die Stéréoscopie à la main mit Duchamps Schiffsreise nach Buenos Aires im Jahr 1918 in Verbindung bringt, wird der historische Erfahrungscharakter von derartig singulären Prozessen deutlich. Belting verweist auf Duchamps Seekrankheit und insbesondere auf seine Reisenotizen, in denen die Gravitation als zentrales Thema auftaucht:

"Physisch ist das Auge das Sinnesorgan der Perspektive, aber diese ähnelt der Farbe darin, dass sie genauso wenig durch den Tastsinn kontrolliert werden kann. Schwerkraft lässt sich mit keinem der gewöhnlichen Sinne kontrollieren. Die Erfahrung der Schwerkraft (gravitation) ist eine Selbsterfahrung, die wir, ob imaginär oder real, im Magen fühlen. ${ }^{54}$

Ich argumentiere dafür, dass Duchamps schwimmende Sehpyramiden in Stéréoscopie à la main eine Vertikalisierung der Perspektive vornehmen, die in den Stoppages bereits angelegt war. Sie vollzieht dabei jene idealtypische Verbindung von gravitationalen Kräften, die Duchamp bei der Schiffsfahrt am eigenen Leib erfährt, und der idealen piktoralen Darstellung. Dabei liegt Duchamps besondere Leistung darin, dass er die Perspektive modellhaft als Projektionsverfahren versteht, mit dem er die analoge Erweiterung von der dritten in eine vierte Dimension theoretisch entwickelt. Diese unterbestimmte, weil unsichtbare vierte Dimension bestimmt er als denjenigen Ort, an dem jene Kräfte wirken, deren Effekte uns als dreidimensionale Erscheinungen begegnen. Das Perspektivmodell ist so mit den ihm wesensfremden Kräften, Prozessen und Dynamiken systematisch verknüpft, womit es Duchamp gelingt, die Perspektive, wie Hans Belting es treffend formuliert, "gegen ihren Sinn fortzusetzen«. ${ }^{55}$

Texte Hintons und Bouchers. Dalrymple Henderson, The Fourth Dimension and Non-Euclidean Geometry in Modern Art, 1983, S. 159.

54 Zitiert nach: Belting, Der Blick hinter Duchamps Tür, 2009, S. 28.

55 Ebd., S. 9. 
Damit wird deutlich, dass die Vertikalisierung der Perspektive hier auf eine sehr besondere und komplexe Weise vollzogen wird. Sie ist keine systemexterne Kritik an den Parametern der perspektivischen Darstellungsverfahren, sondern sie entsteht aus einer theoretischen Erweiterung der Perspektive selbst, die zum Modell der intradimensionalen Projektionen wird. Die Stéréoscopie à la main ist in diesem Sinn das Emblem dieser theoretischen Erweiterung, denn sie setzt die vektorielle Richtung der Gravitationskraft der Erde mit der Projektions- und Blickrichtung der Sehpyramide gleich und stellt die unsichtbaren Kräfte der postulierten vierten Dimension als quasi-perspektivische Projektion vor. Idealtypisch ist dieses Vorgehen, weil es einen zentralen Ansatzpunkt der Perspektivkritik des zwanzigsten Jahrhunderts bildet, die den perspektivischen Bildraum nicht einfach negiert, sondern einer engagierten Kritik unterwirft.

Die operationale Vertikalisierung der Perspektive hat also vielfältige Facetten, doch scheint ihr ein zentrales Interesse zugrunde zu liegen: Die Kontaminierung, Kollision bzw. Verbindung der Perspektive, ihres neutralisierten und idealisierten Raumkontinuums, mit dynamisierenden gravitationalen Kräften. Man mag zu Recht einwenden, dass eine Dynamisierung der Perspektive nicht zwingend mit einer Vertikalisierung des perspektivischen Systems einhergehen muss, sondern auch durch andere Mittel vollzogen werden kann. Paul Klees Zimmerperspektive rot/grün aus dem Jahr 1921 (Abb. 12) wäre nur eines von vielen Beispielen, wie eine im Grundsatz perspektivische Raumordnung etwa durch Farbgebung in ein energetisiertes Feld verwandelt werden kann. ${ }^{56}$ Von einer derartigen Verwandlung durch Farbe, die einen grundsätzlichen Wechsel des malerischen Registers bedeutet, unterscheidet sich die Vertikalisierung dahingehend, dass sie keine Zusammenführung des Modells mit einem anderen Modell - etwa jenem des Kolorismus - ist, sondern eine Modifikation desselben Modells

56 Klee spricht in seinem Aufsatz "Wege des Naturstudiums" selbst von der »irdischen Gebundenheit«. Zitiert nach Flügge u.a., Raum. Orte der Kunst, 2007, S. 222. 


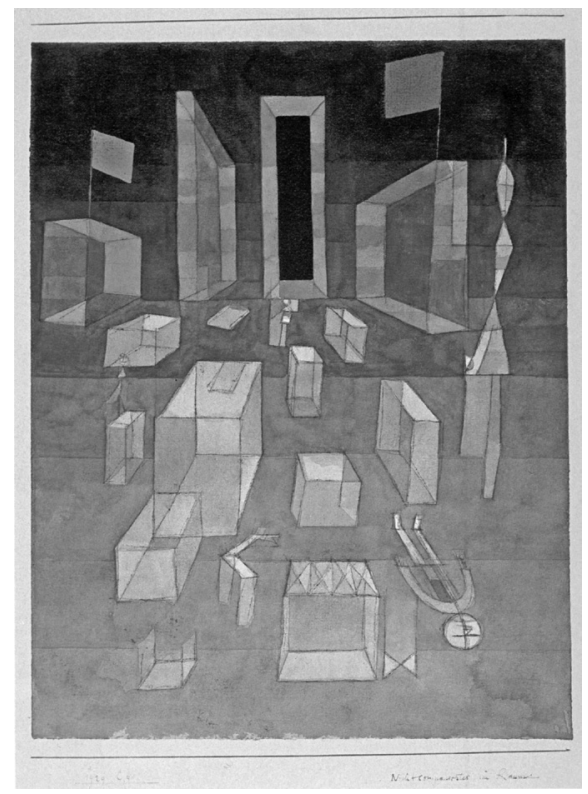

Abb. 12: Paul Klee, Möbelrücken, 1929, Aquarell, Tusche auf Papier.

betreibt. Die Perspektive auf den Kopf zu stellen heißt, die Funktionen und Bedeutungen der sonst horizontal konzipierten Blickachse zu mutieren. Freilich kommt man dabei zu verschiedenen Resultaten, aus denen wiederum unterschiedliche Schlüsse zur Kritik der Perspektive gezogen werden müssen. Naumans Square Depression, eine Arbeit, mit der das Perspektivmodell regelrecht geerdet wird, scheint in dieser Hinsicht einer Bändigung des metaphysischen Abgrundes gleichzukommen. Die am eigenen Leib erfahrenen Kräfte - eine Thematik, die Naumans gesamtes Werk durchzieht - binden das Betrachtersubjekt an den Boden zurück, ein Boden, der zugleich eine Metapher für das in der Moderne opak gewordene Bildfeld der Malerei bildet.

Diese implizite Metaphysikkritik bestimmt auch Giacomettis Circuit, indem das Projektionsfeld zu einem materiellen, opaken und brachliegenden Objekt geronnen ist, das nicht mehr als materieller Träger einer perspektivischen Raumprojektion funktioniert, sondern als Träger eines der Gravitation unterliegenden 
Auges. Auch hier wird die somatische Erfahrung als Entgrenzung des klassischen Perspektivdispositivs eingesetzt. Mir scheint evident, dass diese Entgrenzung das ästhetische Subjekt nicht einfach in eine postmetaphysische Freiheit entlässt, sondern es Spannungen aussetzt, die sich aus den historischen und epistemologischen Verschiebungen der Moderne ergeben. Die am Körper zerrenden Kräfte sind in diesem Sinn als Effekte von Dispositiven zu verstehen, die das Subjekt gerade auch somatisch adressieren. Entscheidend ist dabei, dass diese Adressierungen des Körpers mit denjenigen der Perspektive gezielt verkoppelt sind. Die vertikalen Topologien der Gravitationskräfte sind dann nicht die prinzipiellen Antagonisten der Perspektive, sondern werden vielmehr mit der Perspektive entwickelt. 



\section{Inversionen der Kritik}

\section{View from Inner to Outer Compartment}

Walid Raad nutzt in seinem seit 2007 entstandenen Werkkomplex Scratching on Things I Could Disavow perspektivische Gestaltung als kritisches Element, um sie gezielt mit einer politischen Thematik zu verknüpfen. Das aus verschiedenen Teilen, Objekten und Medien bestehende Projekt beinhaltet eine Werkgruppe die als Section 88 bezeichnet ist und den Titel View from Inner to Outer Compartment trägt. Die zumeist nicht datierten Arbeiten wurden 2010 erstmals ausgestellt - meine Beobachtungen beruhen auf der Ausstellung an der Art Basel Unlimited aus dem Jahr 2013. Es handelt sich um eine Kombination verschiedenartiger Objekte: Ein-KanalVideos, die auf im Raum hängende Leinwände projiziert sind und leere Innenräume zeigen, die an klassische Museumsarchitektur des neunzehnten Jahrhunderts erinnern (Abb. 1); bühnenbildartige Objekten, die im abgedunkelten Raum aufgestellt sind und von Scheinwerfern beleuchtet werden (Abb. 2 bis 4); Wandobjekte, die teilweise Reliefcharakter aufweisen, teilweise an Holzeinlegearbeiten erinnern (Abb. 5 bis 7). Gemeinsam ist ihnen allen, dass sie in der ein oder anderen Weise perspektivische Effekte einsetzen.

Die bühnenbildartigen Objekte (Abb. 2 bis 4) stellen auf ihrer Vorderseite das klassizistische Holzwerk einer Innenarchitektur ungefähr in Echtgröße dar, dessen räumlicher Illusionismus durch die perspektivischen Fluchten und die fein gearbeitete Reliefstruktur erzeugt wird. Alle Wand- und Bodenbereiche sind aus der Darstellung ausgespart, so dass die Struktur des Holzwerks gleichsam als leeres Skelett erscheint. Die Beleuchtung von mehreren Seiten erzeugt dabei auffällige Schattenwürfe, die sich sowohl hinter als auch vor dem Objekt abzeichnen. Die damit erzeugte Wahrnehmung des umgebenden Raumes und die Tatsache, dass die Struktur selbst frei im Raum steht, betont deren Objektcharakter und lädt die Betrachterin dazu ein, um das Bühnenbild herumzugehen.

Die Wandreliefs (Abb. 5) weisen ähnliche materielle und phänomenale Qualitäten auf, mit dem Unterschied, dass sie kleiner sind, 

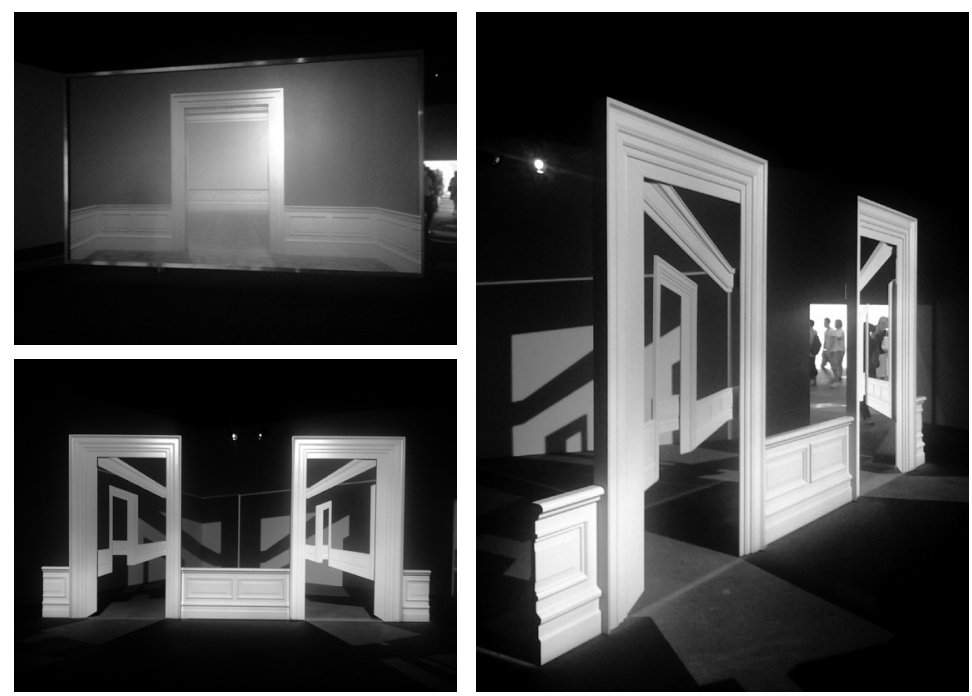

Abb. 1-3: Ausstellungsansichten: Walid Raad, Scratching on Things I Could Disavow, View from Inner to Outer Compartment, 2014.

ihre Perspektivität noch überzeichneter ist und sie unmittelbar an der Wand angebracht sind. Auch ihr Objektcharakter wird durch den teilweise scharfen Schlagschatten unterstrichen, was in ausgeprägtem Kontrast zu ihrem hohen Grad an Illusionismus steht.

Bei einer weiteren Gruppe von Wandarbeiten (Abb. 6 und 7) handelt es sich um flache Imitationen von fluchtenden Parkettböden, deren architektonische Begrenzung fehlt und die daher wie ausgeschnittene Bildelemente aus den Wandreliefs wirken sie scheinen diesen aber nicht exakt zu entsprechen und sind in diesem Sinn nicht als unmittelbare Gegenstücke zu verstehen. Auch diesen Wandarbeiten ist ein auffälliger Kontrast eigen, der sich zwischen überzeichnetem Illusionismus und gleichzeitigem Objektcharakter, mithin zwischen perspektivischer Raumtiefe und materieller Flächigkeit auftut. Ihre hölzerne Materialität und die hohe Präzision ihrer Verarbeitung erinnert an die perspektivischen Holzeinlegearbeiten der Renaissance, einer Handwerkskunst, die zu den Königsdisziplinen der perspektivischen Gestaltung gehörte (Abb. 8), aber auch an die geometrisch organisierten Böden der frühneuzeitlichen Perspektivkonstruktionen. Der kunsthandwerkliche Charakter und die damit verbundene Materialsemantik wird 


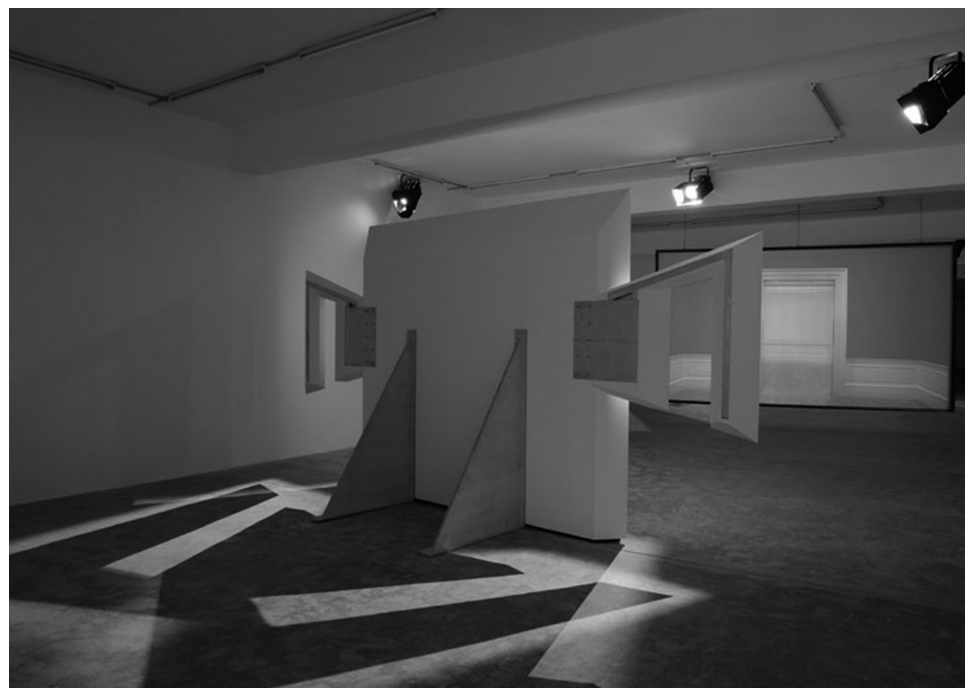

Abb. 4: Ausstellungsansichten: Walid Raad, Scratching on Things I Could Disavow, View from Inner to Outer Compartment, 2014.

wiederum vom besonderen Bildformat kontrastiert, das im Zusammenspiel mit der als weißem Grund erscheinenden Wand an die shaped canvas der Nachkriegsmalerei erinnert.

Die Kontraste zwischen Illusionismus und Objekthaftigkeit, Bildraum und Realraum, Tiefe und Fläche, kunsthandwerklicher Raffinesse und spätmodernistischer Ästhetik ist auch deshalb bemerkenswert, weil mit ihnen das orthodoxe Zusammenspiel von Perspektive und materiellem Träger verändert wird. Die perspektivische Projektion bestimmt etwa bei den Parkettboden-Arbeiten nicht nur die im perspektivischen Raum dargestellte Ebene, den geometrisch organisierten Boden, sondern auch das Format des materiellen Trägers, auf den die Projektionsebene gleich einer Schablone aufgelegt ist. Diese Weise der Formatierung des Bildträgers weicht die üblicherweise nach dem Fensterprinzip meist klar organisierte Grenze zwischen dem illusionistischen Bildraum und dem Realraum auf - ein Effekt, den etwa John Baldessari in den 1980er Jahren eingesetzt hat (Abb. 9). Indem die perspektivische Figuration nicht innerhalb eines klar abgegrenzten ästhetischen Bereichs zum Tragen kommt, sondern auf ein Objekt im realen Raum ausgreift, wird die Grenze und Beziehung der beiden 


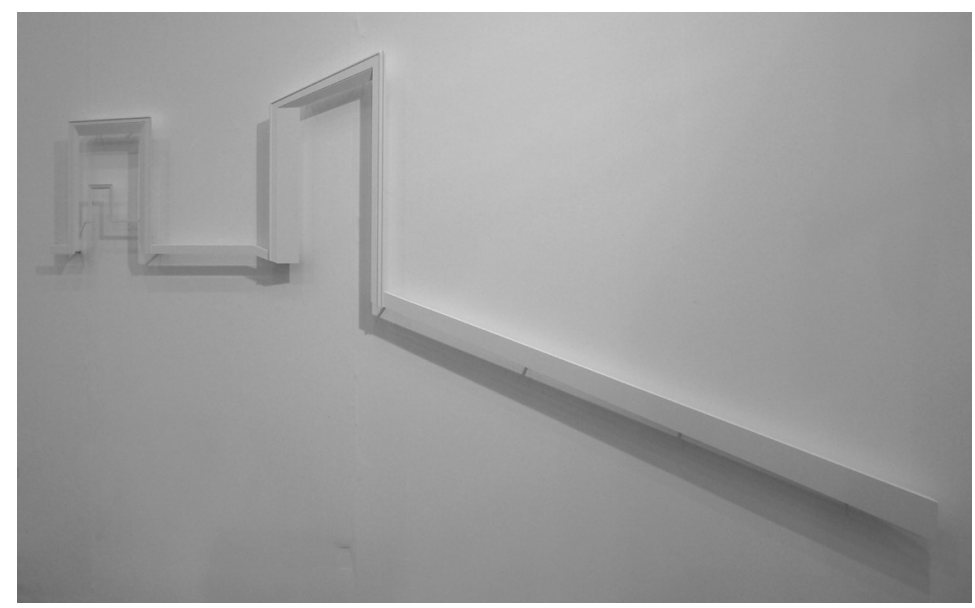

Abb. 5: Ausstellungsansichten: Walid Raad, Scratching on Things I Could Disavow, View from Inner to Outer Compartment, 2014.

prekarisiert. Das Ergebnis ist ein Illusionismus, der mit seinen eigenen Mitteln gebrochen ist, denn die Entgrenzung der perspektivischen Figuration führt dazu, dass nicht nur der artifizielle Charakter der perspektivischen Sichtbarkeit sondern, auch die schiere Materialität ihres Trägers betont werden. Raads Arbeit operiert so gesehen mit der Prekarität der Randzonen der perspektivischen Projektion, also den Übergangszonen von Flächenprojektion und der realen Umgebung. Dabei handelt es sich um Zonen, die schon immer die ausgesprochen heiklen Orte des perspektivischen Bildes waren, was etwa in der Quattrocentomalerei und ihren komplexen Beziehungen zur architektonischen Umgebung der Bilder zum Ausdruck kommt, ${ }^{1}$ oder bereits in Brunelleschis Experiment angelegt ist, das den Übergang der perspektivischen Darstellung. zur realen Welt mit Hilfe einer spiegelnden Silberfolie zu glätten versucht. ${ }^{2}$

Diese Verwendung der perspektivischen Darstellung bezieht also die Mittel der Illusionsbildung von Raum so direkt auf deren

1 Dazu: Grave, Architekturen des Sehens. Bauten in Bildern des Quattrocento, 2015.

2 Dazu: Bach, "Filippo Brunelleschi und der dicke Holzschnitzer. Perspektive als anthropologisches Experiment und das Paradigma des Bildes als Einlegearbeit«, 2009, S. 73. (Siehe dazu auch Kapitel VI der vorliegenden Studie). 


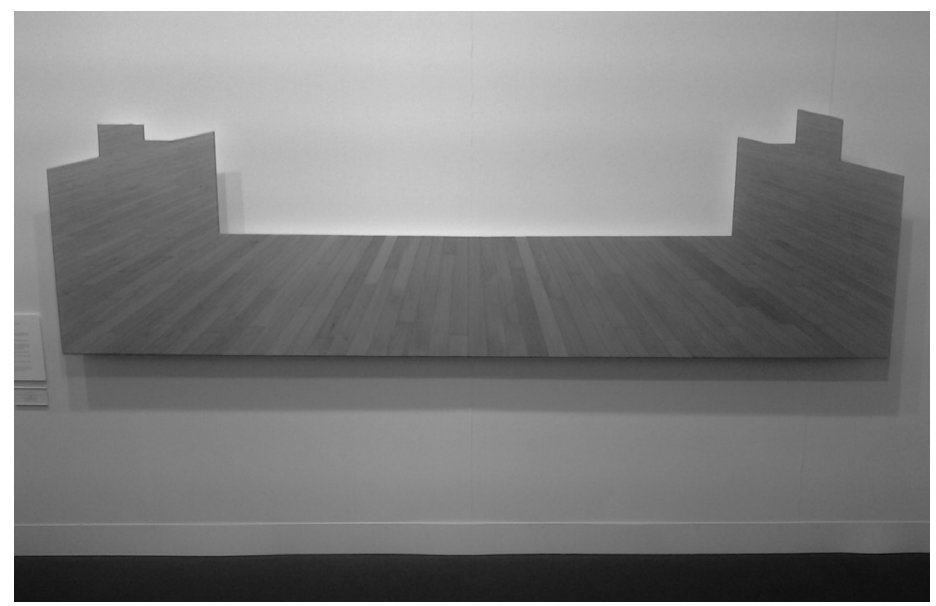

Abb. 6: Ausstellungsansichten: Walid Raad, Scratching on Things I Could Disavow, View from Inner to Outer Compartment, 2014.

materiellen Träger und sein Format, dass die Artifizialität der Darstellung geradezu hervorgehoben wird. Die darin enthaltene Reflexivität der Darstellung bleibt aber nicht auf der formalen Ebene stehen. Es geht Raad nicht bloß um die Disposition von Betrachterstandpunkt, Bildraum und Bildträger und deren zugespitztes Verhältnis zum realen Raum. Vielmehr sind diese Teile eines fiktionalen Narrativs, das in den verschiedenen Werkgruppen von Scratching on Things I Could Disavow erzählt wird und das mit den besprochenen formalen Qualitäten in Beziehung gesetzt wird. Dieses Narrativ wird von Walid Raad selbst im Rahmen eines performativen Ausstellungsrundgangs vermittelt, ist aber auch als Audiorundgang sowie in Form eines Saalblatts verfügbar. ${ }^{3}$ Der Werkgruppe Views from Inner to Outer Compartments ist dabei der folgende Abschnitt zugeordnet:

"At the opening of a new museum of modern and/or contemporary art in an Arab city, a proud local resident rushes the entrance only to find that he is unable to proceed.

3 Es wird ein Saalblatt in englischer und deutscher Sprache zur Verfügung gestellt, zudem sind die Audio- und Textdateien online verfügbar: www.scratchingonthings.com (aufgerufen: 25.8.2018). 


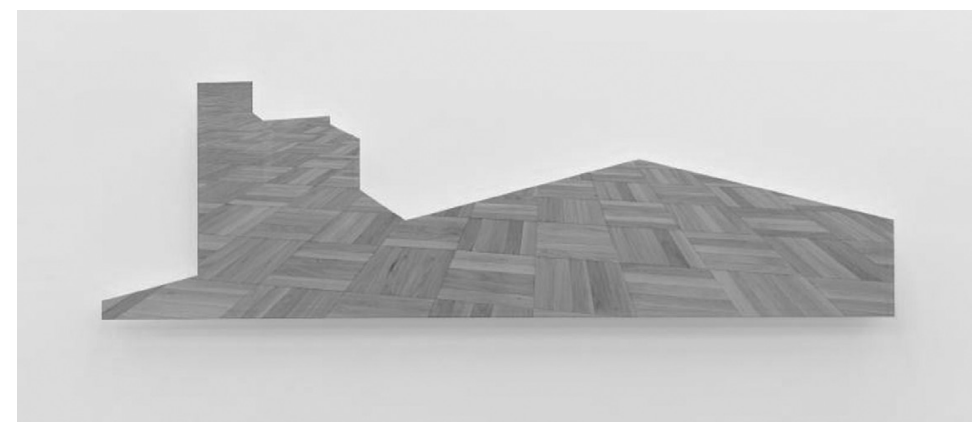

Abb. 7: Walid Raad, Scratching on Things I Could Disavow, View from Inner to Outer Compartment, 2014.

Was it his casual wear at an event announced as a black-tie affair? No. Was it the thugs that shielded the ruling dynasty attending the event en masse to showcase their benevolence and refined sensibilities, pubescent-future-rulers in tow that prevent his access? No.

He simply feels that were he to walk in, he will certainly hit a wall. On the spot, he turns to face the rushing crowd and screams: Stop. Don't go in. Be careful.

Within seconds, he is removed from the site, severely beaten and sent to a psychiatric facility.

These events will take place sometime between 2014 and 2024. We will certainly read in newspapers the following day the headline: Demented Man Disturbs Opening - Claims World is Flat.«4

Die kafkaesk anmutende Erzählung verknüpft reale Entwicklungen und Bedingungen im Nahen Osten mit einem fiktiven Protagonisten und dessen Geschichte, die zum Schluss des Abschnitts als kritische Zukunftsprojektion deklariert wird. Diese Erzählung wirkt sich unmittelbar auf die Rezeption der Arbeit aus, denn die dargestellten Architekturen geben sich nun als jene traditionellerweise europäischen Ausstellungsdispositive zu erkennen, die in den letzten Jahren an gutzahlende Monarchien im Nahen Osten ausgelagert wurden und von denen die Erzählung handelt. Neben

4 Zitiert nach dem Saalblatt zur Ausstellung an der Art Basel Unlimited 2013. Publiziert durch die dOCUMENTA (13). 


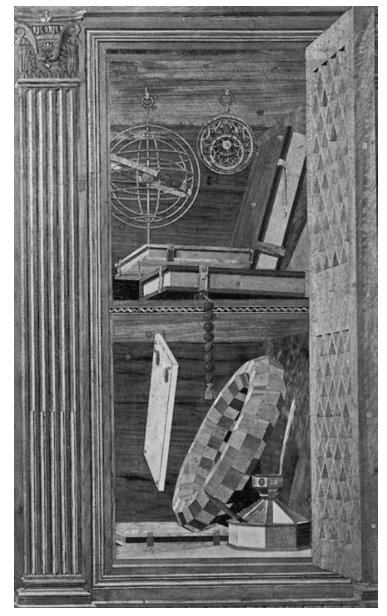

Abb. 8: Francesco di Giorgio Martini, Intarsien im Studiolo des Herzogs von Urbino, 15. Jh., Urbino: Palazzo Ducale.

dieser Semantisierung des Dargestellten erhalten aber auch die formalen Aspekte der Darstellung eine Bedeutung. Die räumlichen Perspektiven werden mit den geschilderten Erlebnissen des Protagonisten assoziiert, womit der formalperspektivische Betrachterstandpunkt mit dem Standpunkt des Protagonisten identifiziert wird.

Gemeinsam mit der Erzählung wird die perspektivische Darstellung also eingesetzt, um eine ästhetische Erfahrung mit einer politischen Thematik zu verknüpfen. Diese Verknüpfung lässt sich am besten mit der kanonischen Kritik der Apparatus-Theoretiker an der Perspektive beschreiben, die in den späten 1960er Jahren im Kontext marxistischer Technikkritik und psychoanalytischer Auseinandersetzungen mit dem Kino entstanden ist. Der formale Charakter des Blickpunkts ermöglicht eine, mit JeanLouis Baudry gesprochen, »doppelte Identifikation « $:^{5}$ eine primäre Identifikation mit dem perspektivischen Blick sowie eine weitere Identifikation mit dem Protagonisten einer fiktionalen Erzählung. Dabei setzt Raads Arbeit eine für die perspektiv-illusionistische

5 Baudry, »Ideologische Effekte erzeugt vom Basisapparat«, 1993, S. 41. 


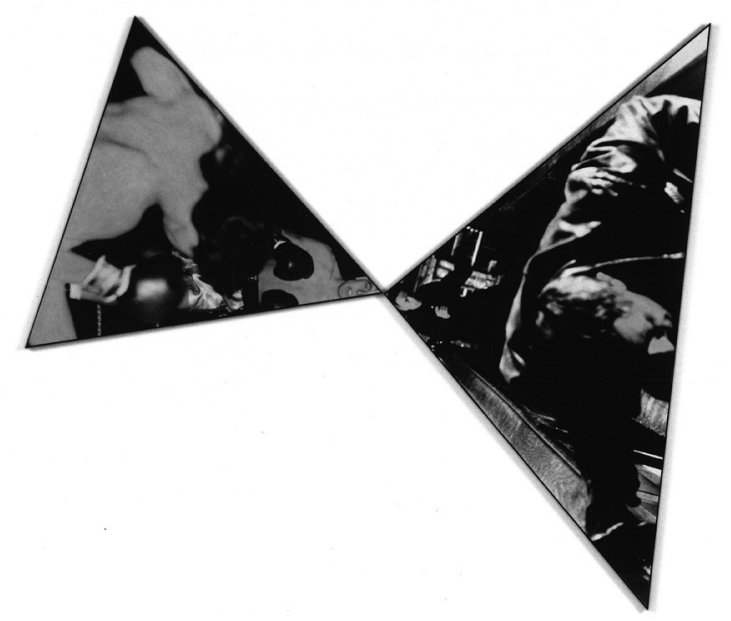

Abb. 9: John Baldessari, A Bow to the Flesh:(Far to Near), 1984, Zwei SW-Fotografien, Ölfarbe.

Darstellung charakteristische Beziehung zum Betrachter so ein, dass sie mit der Erzählung in Resonanz tritt. Der Betrachter der perspektivischen Projektionen erfährt in Form des mit ihm korrespondierenden Fluchtpunkts eine Weise der Präsenz im Bildraum, eine Präsenz, die aufgrund ihres formalisierten Charakters aber zugleich seine Absenz bedeutet. Es handelt sich um eine Präsenz als Absenz, die Hubert Damisch als »Elision" des Subjekts beschreibt und damit den Fluchtpunkt als Signum des aus dem Raum ausgeschlossenen Betrachters interpretiert. ${ }^{6}$ Ein Symptom dieser Elision des Subjekts erkenne ich in den Schattenwürfen der Besucher von View from Inner to Outer Compartment, die auf die Leinwände der Videoprojektionen fallen (Abb. 10 und 11). Die körperlosen Schlagschatten brechen nicht nur die kontinuierliche Integrität der projizierten Bildräume, sie haften zudem an jener unüberwindbaren 'Mauer', auf die der Protagonist von Raads Narrativ zu stoßen glaubt, würde er versuchen in die Museumsräume zu gelangen.

6 Damisch, Der Ursprung der Perspektive, 2010, S. 68. (Siehe dazu auch das Kapitel II der vorliegenden Studie). 

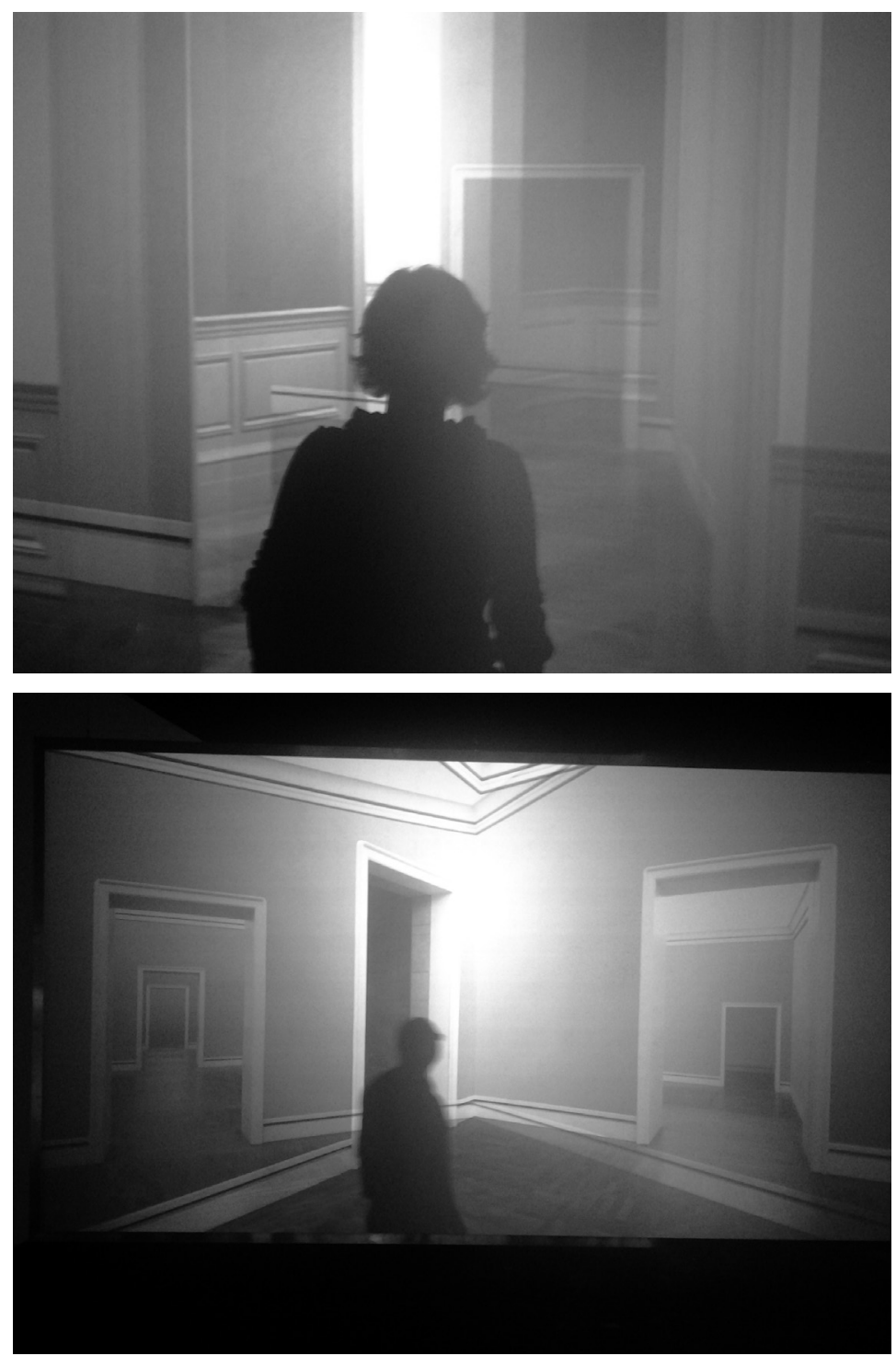

Abb. 10, 11: Ausstellungsansicht mit Schattenwürfen der BesucherInnen: Walid Raad, Scratching on Things I Could Disavow, View from Inner to Outer Compartment, Art Basel 2014. 
Während die Perspektive in der Diskussion der ApparatusTheoretiker als Modell einer ideologischen Subjektivierung verhandelt wird, welche die bruchlose Kontinuität einer illusionären Erfahrung gewährleistet, exponiert Walid Raads Arbeit mittels perspektivischer Effekte gerade die problematischen politischen Bedingungen seiner Zeit. Die Perspektive und ihre Erfahrungsqualitäten sind explizit bezogen auf die gesellschaftlichen Verhältnisse gewisser Regionen des Nahen Ostens, deren Herrscher in den vergangenen Jahren teilweise enorme Summen in scheinbar liberale Kunst- und Kulturprojekte investiert haben, ohne dabei die realen politischen Verhältnisse zu reformieren. ${ }^{7}$

Raads Arbeit setzt den besonderen Charakter der perspektivischen Subjektivierung gezielt ein, um ein Erfahrungsäquivalent einer politischen Situation zu schaffen. ${ }^{8}$ Die Erfahrung einer artifiziellen ästhetischen Inszenierung, verbunden mit dem falschen Versprechen auf Partizipation. Die für Baudry noch sideologischen Effekte des perspektivischen Codes sind damit in ideologiekritische Effekte verwandelt. Zunächst ermöglicht die doppelte Identifikation mit einem Blickpunkt eine Alteritätserfahrung. Raads Perspektivismus ist daher nicht radikal im Sinne einer einschränkenden und unüberwindbaren Sicht, sondern gewinnbringend, weil er es dem Betrachter erlaubt, die Perspektive eines anderen einzunehmen. ${ }^{9}$ Weiter ermöglicht der Elisionscharakter des perspektivischen Fluchtpunkts, die suggestive Partizipation des Subjekts im Raum der (politischen) Repräsentation zu erleben. Und schließlich ist die Artifizialität dieser konstruierten Repräsenta-

7 Beispielhaft dafür sind etwa die Großprojekte Sa'adiyat in Abu Dhabi (es beinhaltet einen Ableger des Louvre sowie des Guggenheim Museums) sowie Khor Dubai, ein mittlerweile gescheitertes Großprojekt, das diverse Museen, Theater, Kunstgalerien und Bibliotheken hätte versammeln sollen.

8 Antonia von Schöning etwa interpretiert die Perspektiven der Arbeiten als Metaphern für die notwendigerweise immer verzerrten historischen Perspektiven. Raad mache deutlich, "dass jede Geschichte durch einen bestimmten Standpunkt, durch eine bestimmte Optik bedingt ist." Er kritisiere, so von Schöning, dass die gegenwärtige Aneignung von Kunst im Nahen Osten, dieser historisch bedingten Perspektivität entbehrt und sie als Errungenschaft einer quasi universalistischen Entwicklungslogik einsetzt, die letztlich bloß den eigenen Interessen dienen. Von Schöning, "Archäologie der Zukunft. Zum Entwurf von Geschichtlichkeit in Walid Raads Scratching on Things I Could Disavow - A History of Art in the Arab World«, 2015, S. 113.

9 Vgl. dazu Schmetkamp, "Narrative Empathie und der ethische Wert der Perspektiveinnahme«, 2019. 
tion selbst exponiert. Die Tragweite der Perspektive in View from Inner to Outer Compartment liegt also vereinfacht gesprochen in ihrer Transzendenz sowie ihrer Reflexion und demonstriert daher, wie Kritik an der Perspektive in eine Kritik mit der Perspektive verwandelt werden kann.

\section{Bedroom Ensemble}

Dass die Apparatus-Theoretiker mit ihrer Kritik sozusagen unfreiwillig auf das kritische Potential der Perspektive aufmerksam machen, wird nicht erst mit Waalid Raads Arbeit deutlich. Bereits früher, noch vor der Blütezeit der französischen Ideologiekritik, entstehen Werke, mit denen die Beziehungen von Perspektive, Kritik und Ideologie neu verhandelt werden. Claes Oldenburgs Bedroom Ensemble aus dem Jahr 1963 ist ein solches Werk, und es dient mir im Weiteren als Gegenstand, um jene Verhandlung zu untersuchen (Abb. 12).

Oldenburgs Werk, das zwischen Oktober und Dezember 1963 an der US-amerikanischen Westküste bei Los Angeles entsteht und im Januar 1964 erstmals in der Sidney Janis Gallery in New York ausgestellt wird, bildet einen Höhepunkt der kritisch-reflexiven Praxis mittels Perspektive in der Moderne. ${ }^{10}$ Das Werk ist als Objektensemble aufgebaut, das u. a. aus Holz und Vinyl hergestellt ist und als nicht betretbare Installation in den Ausstellungsraum eingebaut wird. Es stellt ein Schlafzimmerinterieur dar, das aus Möbelimitaten besteht, deren rhomboide Formen und scharfkantige Umrisse sie als geometrische Körper eines fluchtenden Raumes erscheinen lassen. Tatsächlich folgt die räumliche Logik des Ensembles einer perspektivgeometrischen Ordnung, die den Objekten und ihrem Raum eine eigentümliche Verzerrung auferlegt und über die Oldenburg explizit sagt: "Geometry, abstraction, rationality - these are the themes that are expressed formally in Bedroom. «11 Die zentrale Thematik der Perspektive und der Logik

10 Oldenburg wird nach 1969 mehrere Repliken von Bedroom Ensemble anfertigen u. a. für das Los Angeles County Museum sowie für die Hayward Gallery in London.

11 Rose, Claes Oldenburg. Museum of Modern Art New York, 1969, S. 193. 


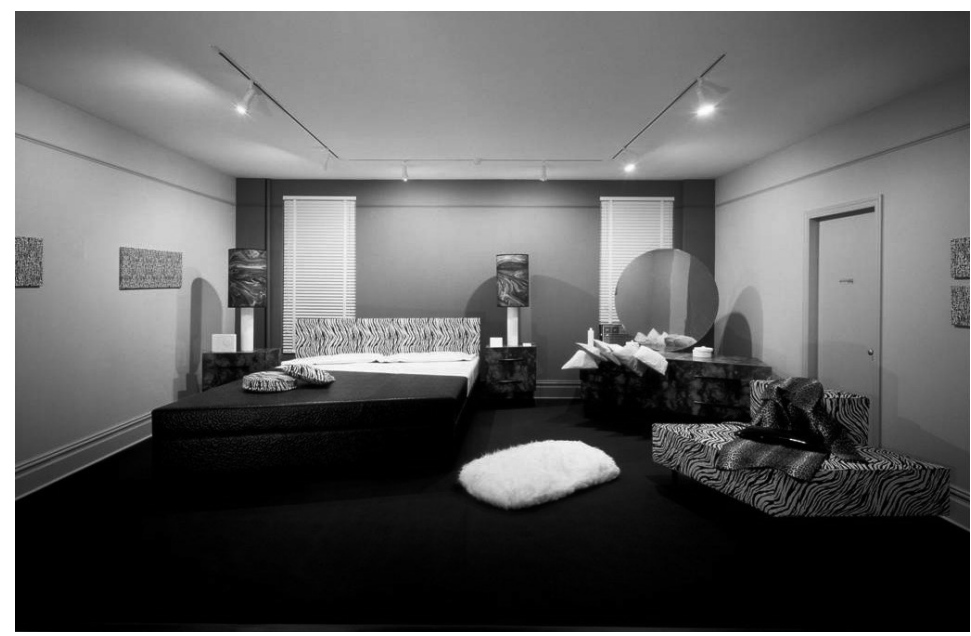

Abb. 12: Claes Oldenburgs, Bedroom Ensemble (Replica I), 1969, Resopal, Vinyl, Holz, Metall, Pelzimitat und Dekorationsstoff.

des disegno kommt auch in der farblichen Reduktion des Werks zum Tragen, das sich abgesehen von den drei blauen Möbelstücken auf Schwarz, Weiß und Goldbrauntöne beschränkt.

Die geometrische Figuration, die betont harten Oberflächen und die damit verbundene artifizielle Kälte stehen in Kontrast zum dargestellten Ort, dem Schlafzimmer als einem Raum, der nicht nur der körperlichen Regeneration dient, sondern auch Stätte des Schlafs und des Träumens ist. ${ }^{12}$ Oldenburg betont diese Polarität zwischen formalen und semantischen Aspekten des Werks selbst, wenn er sagt: "The Bedroom as rational tomb, pharaoh's or Plato's bedroom ${ }^{13}$

Dieser augenfällige Kontrast und die damit verbundene Disfunktionalität von Bedroom - beides Aspekte, die in Oldenburgs Kunst präsent sind - werden von weiteren Irritationsmomenten begleitet. So steht auch der repräsentative Charakter der perspek-

12 Oldenburg erwähnt die in seinem Werk nicht unwichtige Thematik des Schlafs selbst: "There was this obsession with sleep - it was the same in London, like the ancient laws of the bears going to sleep for the winter - as if the whole exhibition had sleep as the dominant metaphor. First the Bedroom, and then the Light Switches you could turn on and off«. Ebd., S. 144.

13 Ebd., S. 193. 
tivischen Darstellung in gegenteiliger Beziehung zur Intimität des Schlafzimmers, das in der modernen Gesellschaft die Bedeutung eines privaten Rückzugsorts besitzt. Mit ausreichend Phantasie und ohne Angst vor Anachronismen könnte man ausgehend von Oldenburg die Bildtradition perspektivisch konstruierter Schlafzimmer zurückverfolgen, die bis ins Quattrocento und den Anfängen der Perspektive führen würde, wo Mariä Verkündigung oft in einem schlafzimmerähnlichen und perspektivisch konstruierten Innenraum stattfindet.

Anders als die Gemächer der heiligen Jungfrau besitzt Oldenburgs Bedroom Ensemble mit seinen auffälligen Oberflächen - der glatten Härte der Möbel einerseits und der textilen Weichheit der Kissen und Kunstpelze andererseits - auch einen betont fetischisierten Charakter, der unmittelbar mit den Objekten und deren Qualität zusammenhängt, weshalb Oldenburg selbst von einer 'Objektpornografie` spricht: "'object pornography is in a way a model of the >objective expressionism< I practice. ${ }^{14}$ In dieser Entblößung der Objekte zeigt sich vor allem deren faktische Eigenschaft als industriell hergestellte Waren. Oldenburg weiß die artifizielle und betont vulgäre Oberflächenästhetik einzusetzen, um die industrielle Fertigung und damit die `Depersonalisierung` des Werks zu betonen.

»The Home works made of fabric or wood required plans and templates, partly because I lacked the skill for sewing and facilities for fine woodworking; partly out of a desire to depersonalize the work and involve others in its manufacture. $\aleph^{15}$

»The style I am concerned with in these works from Los Angeles is the style of manufacturing and production [...] a rehearsal of machine style, affecting not only the image or object produced but the method of producing it. Involving others, involving technicians, visits to industries, having parts made. The style of manufacturing abstracted into production of art. «16 
Sein Interesse an industrieller Massenproduktion und deren Oberflächen muss dabei auch im Kontext der Malereigeschichte und besonders des abstrakten Expressionismus begriffen werden. Die Suggestion von Subjektivität und Lebendigkeit, die der Oberflächenfaktur der Nachkriegsmalerei oftmals zugeschrieben wird, möchte Oldenburg durch entsubjektivierte, weil industriell erzeugte Oberflächen ablösen: "Texture becomes photographed texture in the surface of the formica. Nothing reak or $`$ human $`$ « ${ }^{17}$ Der Höhepunkt dieses Antivitalismus findet sich in den Bildern, die an den Seitenwänden des Schlafzimmers hängen (Abb. 13) und als Persiflage von Pollocks Drip Painting die Beziehung zur amerikanischen Malereigeschichte explizit machen:

"What ever else this act suggests, I intended at the time to use Pollock as a symbol of life and his reproduction, removal by counterfeit and photography, as the symbol of Death ${ }^{118}$.

In diesem Zitat aus dem Jahr 1967 kehrt nicht nur die Thematik des Todes wieder, die bereits in Oldenburgs Bezeichnung des Bedroom Ensemble als platonischem Grab zum Ausdruck kommt, auch wird hier die bereits historische sowie kulturelle Distanz Oldenburgs zur amerikanischen Malereiavantgarde und deren Zentrum New York City deutlich, das Oldenburg im September 1963 bewusst verlässt. Bedroom Ensemble entsteht in Venice bei Los Angeles, also fernab jenes New Yorker Kunstbetriebs, als dessen Ikonen Pollocks Drip Paintings bereits fungieren. Die Umgebung von Los Angeles ist dabei in einem doppelten Sinn für das Werk von Bedeutung: Erstens ist laut Oldenburg ein Motel bei Malibu das Vorbild für Bedroom Ensemble; ${ }^{19}$ zweitens hat Los Angeles für Oldenburg die Bedeutung eines Ortes der Industrie und Konsumkultur:

17 Ebd., S. 193.

18 Ebd., S. 135-136.

19 "To complete the story I should mention that the Bedroom is based on a famous motel along the shore road to Malibu, 'Las Tunas Isles $>$ in which (when I visited it in 1947) each suite was decorated in the skin of a particular animal, i.e. tiger, leopard, zebra.« Ebd., S. 193. 


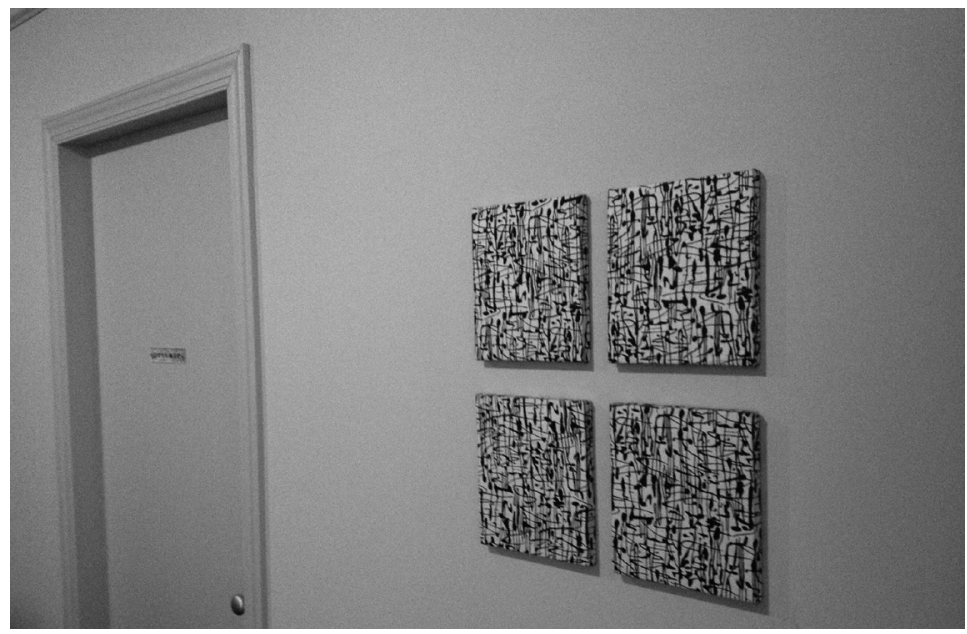

Abb. 13: Detail aus: Claes Oldenburg, Bedroom Ensemble (Replica I), 1969, Resopal, Vinyl, Holz, Metall, Pelzimitat und Dekorationsstoff.

"LA is many things and many things to many people. To me it is the paradise of industrialism. LA has the atmosphere (my selected part of it) of the consumer, of the home, the elegant neat result, like the frankfurter in its nonremembered distance from the slaughterhouse. «20

Der historische Kontext zeigt eindeutig, dass man Bedroom Ensemble nicht gerecht wird, wenn man den pornografischen Charakter der Arbeit auf die Konnotationen des Schlafzimmers als Ort sexueller Befriedigung reduziert. Oldenburgs Objektpornografie zielt wesentlich auf die Entblößung des schieren Warencharakters seiner Objekte, und er tut dies vor allem mit formalen Mitteln, in denen er auch die eigentliche und dauerhafte Qualität des Werks erkennt. In Bezug auf Bedroom Ensemble sagt er etwa:

"Subject matter is not necessarily an obstacle to seeing spure form and color. Since I am committed to openness, my works are constructed to perform in as many ways as anyone wants them to. As time 
goes on and the things they represent vanish from daily use, their purely formal character will be more evident: Time will undress them. Meanwhile they are sticky with associations, and that is presumably why my Bedroom, my little gray geometric home in the West is twostepping with Edward Hopper. «¹

Für den hier verfolgten Zusammenhang ist entscheidend, dass die formalen Mittel den pornografischen Charakter nicht nur erzeugen, sondern auch reflektieren - und dabei nimmt die Perspektive eine Schlüsselrolle ein. Die Perspektivierung des gesamten Arrangements führt eine Metaebene ein, indem sie auf den konsumistischen Blick zurückverweist. Die Entblößung der Objekte basiert wesentlich auf der perspektivischen Form, in der sich der begehrende Blick gleichsam kristallisiert und dadurch thematisch wird. ${ }^{22}$ Umgekehrt kann man konstatieren, dass die perspektivische Form ihre Bedeutung - in diesem Fall als Dispositiv des Begehrens - durch die Objekte erhält, mit denen sie korreliert. Die Perspektive ist hier gleichsam aus dem mathematischen Idealraum ausgebrochen und in den realen historischen Raum eingebrochen, wo sie sich an einer historisch verfassten Dinglichkeit aktualisiert, deren spezifische Ontologie - es sind industriell erzeugte Objekte des konsumbasierten Kapitalismus - mit ihr sichtbar gemacht werden. Anders als in den Rezeptionswünschen seiner minimalistischen Zeitgenossen, die ebenfalls industriell hergestellte Objekte und geometrische Gestalt im Realraum verwenden, um die alltägliche Weltwahrnehmung zu transzendieren, sind Repräsentation und historische Semantik für Bedroom Ensemble also zentral. ${ }^{23}$ Die mit der Perspektive ermöglichte Erfahrungsqualität zeigt diese Objekte nicht als bloß formale oder spezifische Objekte einer neutralen Wahrnehmungserfahrung, sondern im Licht ihrer ontologischen und dabei historischen Verfassung, die dem begehrenden Blick eines Konsumenten ausgesetzt sind.

21 Ebd., 193

22 Die auffälligen Oberflächenmusterungen der Lampenschirme, der Wandbilder sowie des Sofas und Bettkopfteils unterstützen den visuellen Verzerrungscharakter, indem sie formal an anamorphotische Störungen erinnern.

23 Donald Judd bespricht Oldenburgs erste Ausstellung von Bedroom Ensemble wohlwollend. Judd, »In the Galleries. Claes Oldenburg“, 1975, S. 133. Vgl dazu auch: Shiff, »Judd through Oldenburg«, 2004. 
Die Perspektive gewinnt hier ihre Bedeutung also im Zusammenspiel mit den industriell erzeugten Objekten einer historischen Lebenswelt. So tritt die prinzipiell unendliche Reproduzierbarkeit perspektivischer Konstruktionen mit der prinzipiell unendlichen Reproduzierbarkeit der Massenware in Beziehung. Kapitalistische Rationalität als historischer Prozess ist mit ästhetischer Rationalität als formgenetischem Konstruktionsprinzip kurzgeschlossen. Der perspektivische Subjektbezug zentriert diese doppelte Rationalität in einem Fluchtpunkt, der als formales Korrelat des Betrachters ein Subjekt-Objektverhältnis expliziert, das nicht auf den idealen mathematischen Raum und dessen exakte Beziehungen von Punkten reduziert bleibt, wie es noch Erwin Panofsky beschreibt. ${ }^{24}$ Vielmehr zeigt sich hier gerade der gegebene Raum als rational und konstruktiv erzeugt. Perspektivierung fungiert als Signum der Artifizialität einer sichtbaren Welt, die für ein sehendes Subjekt nicht einfach da ist, sondern produziert wird.

\section{Die Dialektik der Autonomie}

Eine Deutung von Oldenburgs Bedroom Ensemble, die im Hinblick auf die kritische Dimension der Perspektive von Interesse ist, stammt aus der französischen Philosophie der frühen 1970er Jahre. Oldenburgs künstlerische Kritik der Perspektive setzt sich gewissermaßen in Lyotards 1973 publiziertem Text »Die Malerei als Libido-Dispositiv« fort. ${ }^{25}$ Weil die darin formulierten Überlegungen jedoch direkt an Lyotards 1971 erschienene Dissertation Discours, figure $^{26}$ anschließen, wo Lyotard bereits die Grundbegriffe seiner Auseinandersetzung mit der Perspektive entwickelt, beginne ich mit der Untersuchung dieses Textes.

Die im Titel Discours, figure formulierten Begriffe bilden gleichsam die beiden polaren Bereiche ab, an und zwischen denen sich

24 Panofsky, "Die Perspektive als 'symbolische Form«", 1974, S. 101.

25 Erschienen ist der Text ursprünglich in der Aufsatzsammlung, Lyotard, Des dispositifs pulsionnels, 1973. Ich beziehe mich im Folgenden auf die deutsche Übersetzung: Lyotard, »Die Malerei als Libido-Dispositiv«, 1982.

26 Lyotard, Discours, figure, 1974. Eine deutsche Übersetzung liegt bisher lediglich für ein Kapitel des Buches vor: Lyotard, "Veduta auf ein Fragment der Geschichte des Begehrens«, 2011. 
Lyotards seine Perspektivtheorie ausarbeitet. Lyotard versteht unter dem Figuralen einen genuin sinnlichen Raum, der heterogene, asymmetrische und atemporale Qualität aufweist und ausschließlich durch Wahrnehmungsprozesse erscheint. Dieser sinnlich-heterogene Raum des Figuralen weist Differenzen auf, die als solche sichtbar (und nur sichtbar) sind. Diese figuralen Differenzen (Lyotard nennt sie auch "wahre Differenzen«) stellt Lyotard einer anderen Logik der Differenz gegenüber, die den Raum des Diskursivem bestimmen, einen Raum der symbolischen Ordnung, in den das Figurale gleichsam überführt wird. Mit dieser strukturalistisch gedachten Transkription findet jeweils eine kulturelle Formierung des Figuralen in der Ordnung des Diskursiven statt, die eine textförmige Ordnung ist. Diese ist bestimmt von Differenzen, die als Oppositionen, d.h. als bestimmte Negationen begriffen sind und nicht der sinnlichen Logik der figuralen Differenz folgen. Dies bringt mit sich, dass eine Überführung des Figuralen ins Diskursive nie vollständig gelingen kann, da das Diskursive nicht in der Lage ist, das ausreichend zu repräsentieren. Den dabei sich vollziehenden Verlust diskutiert Lyotard unter psychoanalytischen Vorzeichen, nämlich als Verdrängung des Figuralen. Die sinnlichen Dimensionen des Figuralen werden vom Diskurs gleichsam unterdrückt, um sich dann im Modus eines Begehrens bemerkbar zu machen.

Das Figurale befindet sich zwar außerhalb des Diskurses, aber es ist nicht bloß ex negativo das Andere des Diskurses, sondern es meldet sich im Diskurs laufend wieder. Die Intensität sowie die Art und Weise dieser Meldungen hängt vom jeweiligen Diskurs bzw. von dem ab, was Lyotard die `Position` nennet. Lyotard unterscheidet grundsätzlich zwischen zwei Positionen des Diskurses: erstens den epistemischen Diskurs, dessen Schrift als textförmig bestimmt ist, und zweitens den figuralen Diskurs, dessen Schrift figuralen Charakter aufweist. Die Position des Diskurses bezeichnet damit seine Beziehung zum Figuralen, denn je nach Position vermag der Diskurs das Figurale mehr oder weniger anzuschreiben, seine sichtbaren Differenzen in sich aufzunehmen und damit die Bereiche des Figuralen und des Diskursiven in ein Gleichgewicht zu bringen. Lyotards Beispiel für eine derartige Balance zwischen figuralem Bereich und textförmigem Bereich ist etwa die mittelalterliche Buchmalerei, in der Bild und Text in eine quasi-harmonische, weil sich gegenseitig befruchtende Beziehung gestellt sind. 
Unter diesen Voraussetzungen kann Lyotard seine These zur Perspektive formulieren, die der eigentliche Gegenstand des Kapitels ist. Bei der Perspektive handle es sich um einen besonderen Diskurs, denn er übertrage die diskursive, d.h. textförmige Differenz auf das Sichtbare selbst. Durch die Konstruktion nach Gesetzen der projektiven Geometrie diskursiviert die perspektivische Darstellungsweise also das Sichtbare nach festen Regeln. In diesem Sinn vollzieht sich in der Theorie und Praxis der Malerei in der frühen Neuzeit ein Gleichgewichtsverlust der mittelalterlichen Bild-Text-Balance, welcher freilich zugunsten des Diskursiven ausgeht (nicht das Diskursive wird versinnlicht, sondern das Sinnliche wird diskursiviert). In diesem Sinn erkennt Lyotard in der Evidenz der perspektivischen Konstruktion und der damit verbundenen Auffassung der Malerei als einer "causa mentale« eine "unmögliche Sublimierung « des verlorenen Figuralen.

Die innige Verwandtschaft des textförmigen Diskurses mit der perspektivischen Repräsentationsweise zeigt sich nach Lyotard etwa in der Arbitrarität ihrer Methode, d.h. des Regelsatzes, den er als Konvention begreift. Diese Konventionalität sei eine Folge der Übertragung des Diskursiven, d.h. eines arbiträren Zeichensystems, auf das in Wahrheit heterogene und mannigfaltige Feld des Sichtbaren. Während das mittelalterliche Text-Bild noch eine "Veräußerlichung des Geschriebenen« sei, handle es sich bei der perspektivischen Repräsentation um eine »Verschriftlichung des Außen ${ }^{27}{ }^{27}$

Eine entscheidende Rolle bei dieser Verschriftlichung spielt der materielle Träger und seine Funktionsweise in der perspektivischen Repräsentation. Denn im Gegensatz zum mittelalterlichen Schrift-Bild mache die Repräsentation ihren materiellen Träger transparent, um jenen virtuellen Raum zu entwerfen, der als Bühne für die dargestellten Figuren dient. Lyotard erkennt in dieser Beziehung eine partielle Ablösung der dargestellten Figuren vom materiellen Träger, welche er als kennzeichnend für die neuartige Weise des Diskurses in der frühen Neuzeit begreift. Die Verschriftlichung des Außen ist nicht nur eine Frage der geregelten Ordnung innerhalb des Sichtbaren, sie ist auch mit dem 
semiotischen Problem der Referentialität von Zeichen verbunden. Die Durchlässigkeit des Signifikanten auf sein Signifikat hallt in der Transparenz des Bildes gleichsam nach, indem dessen materielle Fläche eine transitive Funktion übernimmt.

Dennoch ist dieser Diskurs nicht vollkommen bereinigt von figuralen Elementen, denn die im illusionistischen Raum sichtbaren Objekte besitzen nichtsdestotrotz figurale Eigenschaften wie Umrisse, Oberflächen, Farben, kurzum: eine Gestalt, die wesentlich auf figuralen Differenzen basiert und ausschließlich mittels opaker Elemente des Bildes erzeugt werden kann. Für Lyotard leistet die perspektivische Repräsentation daher eine eigentümliche Synthese: Sie nimmt den figuralen Raum sowie den diskursiven Raum in sich auf, indem sie eine Neutralisierung der Bildfläche als Ort der materiellen Einschreibung sowie des Bildraumes als Ort der dargestellten Figuren vollzieht. Die perspektivische Repräsentation, so Lyotard, "behandelt den Träger sowohl als sichtbarmachende Transparenz als auch als lesbarmachende Opazität. «²8 Das Jenseits des Trägers muss paradoxerweise auf dem Träger selbst »bezeichnet" sein, folglich handle es sich um eine "transparente, aber nicht minder undurchdringliche Fläche«, weshalb Lyotard zu dem Schluss kommt, die perspektivische Repräsentation erzeuge eine "Präsenz einer Absenz«, die sich, anders als bei Hubert Damisch, nicht auf die Betrachterin, sondern auf die Einschreibung auf einer Fläche bezieht. ${ }^{29}$ Obschon für den Autor die Perspektive letztlich dem Regime der Diskursivität angehört, hat das Figurale seinen Ort innerhalb der Repräsentation. Die perspektivische Transparenz wird als eine Weise der Neutralisierung der Fläche und ihrer Einschreibungen verstanden werden, die letztlich ein fruchtbares Wechselspiel zwischen Transparenz und Opazität ermöglicht.

In seinem Text "Die Malerei als Libido-Dispositiv" (1973) entwickelt Lyotard die Polarität von Discours, figure weiter. Ein zentrales Element dieser Weiterentwicklung bildet dabei der Begriff der 'Energie‘. Lyotard macht sich den weiten Bedeutungshof des Begriffs zu eigen, wobei zwei zentrale Referenzen wichtig sind. Einerseits verweist der Begriff auf den psychoanalytischen Topos 
des Begehrens und zwar nicht als negative Kraft, die aus einem Mangel oder Entzug entwächst, sondern als positiv bestimmte, libidinöse Energie, die als prozesshaft, dynamisch und verwandelbar begriffen wird und in Objekten gespeichert, potenziert und wiederum freigesetzt werden kann. Lyotard setzt diese polymorphe Energie in Beziehung zu marxistischen Begriffen der Arbeitskraft, in denen er dieselbe Logik der Umwandlung, Speicherung und Abrufung von Energie erkennt.

"Der Kapitalismus stellt seine Probleme in Kategorien von Energie und Energieumwandlung: Umwandlung von Rohstoffen, Umwandlung von Apparaten, Produktion von Apparaten, manuelle, intellektuelle Arbeitskraft, Produktion, Umwandlung dieser Arbeitskraft, Geld ... schlicht Energie, die zirkuliert, ausgetauscht wird, d. h. die sich umsetzt. «30

Andererseits begreift Lyotard das Begehren auch als "arbeitende Energie «, ${ }^{31}$ deren wichtigste Eigenschaft ihre Wandelbarkeit ist. Dadurch ist es möglich, von einer "Libido-Ökonomie « ${ }^{32} \mathrm{zu}$ sprechen, die der Autor in unmittelbare Beziehung zu einer politischen Ökonomie setzt, deren Logik er im Prinzip des kapitalistischen Wertgesetzes als Matrix der Umwandlung und Konstanz erkennt. Das Diskursive sowie das Figurale fungieren dann als unterschiedliche Organisationsweisen von Energie: das Diskursive als Dispositiv bzw. System, das eine geregelte Ordnung der prozessualen Energie und deren Umwandlung leistet. Das Figurale hingegen als eine Entregelung, Störung und Unordnung. Es handelt sich in diesem Sinn um ein "Nicht-Regime «, ${ }^{33}$ das sich von jeder im weitesten Sinn diskursiv-sprachlichen Logik her nur negativ beschreiben lässt.

Im Hinblick auf diese Organisationen von Energie nehmen Kunstwerke und insbesondere Malerei in mehrerlei Hinsicht eine privilegierte Stellung ein. Malerei ist für Lyotard ein Umwandlungsdispositiv par excellence, es verwandelt nicht zuletzt körperliche Energie, d.h. Gebärden in Farbaufträge, die im Werk als

30 Lyotard, »Die Malerei als Libido-Dispositiv«, 1982, S. 51.

31 Ebd., S. 48.

32 Ebd.

33 Ebd. 
potentielle Energie gespeichert und in der Betrachtung freigesetzt wird. (Diese Verwandlung, Konservierung und Freisetzung libidinöser Energie möchte Lyotard nicht im subjektiv-psychologischen Sinn verstanden wissen. Es geht gerade nicht darum, Malerei als Dispositiv der Intentionen oder desUnbewussten eines malenden Subjekts zu verstehen. Beides fällt für Lyotard in den Bereich einer problematischen, weil ideologischen "Pseudo-Autonomie «. ${ }^{34}$ ) Die besondere Leistung der Malerei liegt vor allem darin, dass in ihr die beiden Regime der Energie, namentlich das Figurale und das Diskursive, zusammenfinden. Denn Malerei ist Ordnung und zugleich Unordnung, sie regelt, besetzt Positionen und steuert energetische Prozesse, sie kann aber zugleich auch Ordnung auflösen und Kräfte freisetzen. Es ist diese doppelte und paradoxe Funktion der Malerei zwischen Regulierung und De-Regulierung, auf die Lyotards Konzeption des Libido-Dispositivs abzielt.

Für die Frage nach der Bedeutung der Perspektive muss dann geklärt werden, ob die Perspektive mit einer besonderen Organisationsweise von Energie verbunden ist und wie sich diese gegenüber anderen Darstellungsformen unterscheidet. Wie bereits in Discours, figure behandelt Lyotard die Perspektive hier als ein regelndes Dispositiv, dessen Eigenart wesentlich in der besonderen Modifikation der Einschreibungen auf dem Bildträger beruht. Die Überlegungen zur perspektivischen Herstellung von Transparenz werden nun auf die ideologiekritische These hin zugespitzt, dass die perspektivische organisierte Einschreibung auf dem Bildträger "sich selbst verschleiert « ${ }^{35}$ Damit wird die Perspektive, wie schon bei Baudry, ins Register ideologischer Dispositive überführt, denn sie schafft eine artifizielle Repräsentation, um im selben Zug die Herstellung ebendieser unsichtbar zu machen.

Im Hinblick auf die im Text zentrale Frage nach der Ökonomie von Energie kommt Lyotard zu dem Schluss, dass die sich selbst auslöschende Einschreibung des perspektivischen Dispositivs das Einfangen und Abfließen von libidinöser Energie bedeute, womit die perspektivische Neutralisierung von Fläche und Faktur gleichgesetzt wird mit der Neutralisierung der energetischen Kraft. Die 
Arbeit der Malerin, mit der Energie auf das Bild übertragen wurde, ist gleichsam von der perspektivischen Regelung absorbiert worden.

Lyotard treibt seine politische Interpretation der Perspektive noch weiter, indem er die Frage nach der Beziehung dieses repräsentationalen Dispositivs der Malerei zu den historischen Bedingungen politischer Macht stellt. Er setzt die perspektivische Regelung von Kraft mit der politischen Regelung von Macht im italienischen Stadtstaat in Beziehung. Dem Modell der griechischen Polis verwandt, finde im frühneuzeitlichen Stadtstaat eine bestimmte Regulierung der politischen Kräfte statt, welche Lyotard in Analogie zur Regulierung von Energie durch die perspektivische Repräsentation setzt. Es handle sich bei beiden um Kanalisierungen und Filterungen von Kraft bzw. Macht, aber auch um die Konstitution von Sichtbarkeit auf einer eigens dafür geschaffenen Bühne, die auf eine Gruppe von Zuschauern ausgerichtet ist. Wie bei der perspektivischen Repräsentation sei die Herstellung dieser politischen Bühne und der auf ihr stattfindenden Darbietungen ausgeblendet, insofern die komplexen Mechanismen der Einflussnahme auf die politische Macht, wie Geld, Beziehungen und Lobbying, verborgen blieben.

Lyotard bezeichnet diese Beziehung zwischen der Form der malerischen Darstellung und der politischen Organisationsform von Macht als Isomorphie und erkennt sogleich ihre Fortsetzung in der modernen Malerei. Mit Verweis auf Werke von Paul Cézanne, Robert Delaunay und Paul Klee konstatiert er einen radikalen Wandel in der malerischen Organisation von Energie, die er vor allem als Auflösung des tradierten perspektivischen Dispositivs beschreibt. Seine weitgehend formalen Beobachtungen konstatieren erstens eine Dekonstruktion der räumlich-linearen Bildlogik, die den Bildraum sowie die Betrachterposition bestimmt und sich zugunsten einer Verflüssigung der Energie in Form von Farbe entwickelt; zweitens erkennt er in der modernen Gestaltungsweise eine Enthüllung der Einschreibungen, d.h. das Sichtbarmachen von Pinselstrich, Leinwand etc.; drittens beschreibt er die Überwindung der repräsentationalen Funktion der Werke, die dadurch autonome Objekte werde. Lyotard betont emphatisch, dass all dies ausschließlich dazu diene, die Objekte der Malerei zu autonomen Depots libidinöser Energie zu machen, d.h. zu chromatischen Speichern von Energie, die anders als in der perspektivischen 
Malerei nicht nach Gesetzen geregelt und neutralisiert wird, sondern als Potenz in den Werken eingefangen bleibt, um sich im Akt der Betrachtung freisetzen zu können.

Diese Funktion der modernen Malerei als gespeicherte und abrufbare Energie, die sich in Leinwand und Farbe objektförmig manifestiert, erstarrt und akkumuliert, verbindet Lyotard dann nicht etwa mit der Idee von Autonomie und Freiheit, sondern mit der Funktionsweise der Ware innerhalb der kapitalistischen Ökonomie. Die in beliebige Objekte verwandelbare und akkumulierbare Energie entspricht so gesehen der bereits erwähnten Logik des Wertgesetzes, das eine prinzipielle Verwandlung des Kapitals nach einer Wertäquivalenz bedeutet. Hierin wird nun das Doppelregime der Malerei zwischen Diskurs und Figur eigentlich deutlich. Malerei regelt die Segmentierung, Akkumulation und Verwandlung von Arbeitskraft in figuraler Form, d.h. als Gebärde, Farbe, Affekt etc. Während das perspektivische Dispositiv diese Energie filtriert, neutralisiert und damit verdrängt hat, findet durch das Dispositiv der modernen Malerei eine Freisetzung der Energie statt, die dann nach den Prinzipien einer kapitalistischen Ökonomie zirkuliert.

Lyotard formuliert seine Thesen zur Malerei als Libido-Dispositiv zwar mit einer nicht zu übersehenden Sympathie für die moderne Malerei, ich möchte aber dafür argumentieren, dass man diese Überlegungen zur Malerei zugleich als kritische Befragung modernistischer Paradigmen interpretieren muss. Denn die Isomorphie, die der Autor zwischen malerischer und politischer Ökonomie skizziert, koppelt die Freisetzung von Energie in der modernen Malerei unmittelbar an die zweischneidige Freiheit der modernen Lebensbedingungen. Die Autonomie des Werks ist dialektisch auf dessen ideologische Konstitution verwiesen, einen gesellschaftlichen, d.h. ökonomischen Zusammenhang, der die Idee der Freiheit von Kunst zwar nicht komplett zerstört, ihren Sinn jedoch relativiert und damit ihre Absolutheit aufhebt. Die Deregulierung der perspektivischen Bildordnung entspricht so gesehen der Deregulierung ökonomischer Beziehungen, deren Freiheit keine absolute ist, da sie letztlich den Gesetzen des Marktes unterworfen bleiben.

Unklar bleibt dabei, ob und wie die Werke der modernen Malerei in der Lage sind, diese ideologische Konstitution zu adressieren und oder gar zu kritisieren. Lyotard sagt zwar, dass die Einschreibungen und damit der Träger und die Farbe in der modernen Male- 
rei nicht mehr verborgen sind, doch zugleich gibt er zu bedenken, dass die libidinöse Energie selbst verschleiert bleibe - was mithin die Voraussetzung für die vielfältigen theoretischen Diskurse über die modernistische Malerei sei. So gesehen wäre es verfehlt, der modernen Malerei, als einer reflexiven Praxis der Oberflächeneinschreibung, eine per se ideologiekritische Funktion zuzuschreiben, nur weil mit ihr die manuelle Arbeit des Malers sichtbar wird.

An dieser Stelle kommt nun die Perspektive und ihre Rolle innerhalb des Zusammenhangs von Repräsentation und moderner Ökonomie ins Spiel. Denn nebst ihrer historischen Bedeutung als einem diskursiven und neutralisierenden Dispositiv von Energie, vor dessen Hintergrund sich die Freisetzung und damit die Zirkulation von Energie überhaupt beschreiben lässt, stellt sich die Frage nach der möglichen Bedeutung der Perspektive innerhalb des Horizonts der modernen Bildökonomie. Oldenburgs Bedroom Ensemble mit seiner eigenwilligen Reaktivierung der Perspektive expliziert eine mögliche Beziehung der Perspektive zur modernen Ökonomie, welche Lyotard folgendermaßen beschreibt:

"Sie betreten ein 'wirkliches` Serienschlafzimmer; Sie bemerken jedoch Anspielungen auf das Faktum der Repräsentation; in einem solchen Schlafzimmer ist z.B. das große Bett mit Perspektiveffekten versehen, es ist ein dreidimensionales, also `reales` Objekt, aber es verengt sich hin zum entferntesten Punkt. Ein Verfahren, um die Repräsentation zu kritisieren, aber ein umgekehrtes, und es bedeutet nicht mehr: die Repräsentation, das ist die Ware, sondern: die Ware, das ist immer die Repräsentation, das ist immer der Fetischismus. « ${ }^{36}$

Dass Lyotard in Bedroom Ensemble die Umkehrung von Repräsentation und Ware erkennt, ist den Effekten der Perspektive zu verdanken, die nicht als Verschleierung einer malerischen Flächeneinschreibung zum Einsatz kommt, sondern als reflexives Dispositiv, dass auf die neuartige Ontologie des konsumbasierten Kapitalismus aufmerksam macht. Wenn die moderne Malerei die repräsentationalen Funktionen aufgibt, um autonome Gemälde zu schaffen, mit denen Energie akkumuliert wird und zirkuliert, dann sind 
diese Werke zu Objekten eines ökonomischen Systems mutiert, eines Systems, das selbst repräsentationalen Charakter hat. Die Problematik dieser anti-repräsentationalen und ästhetisch autonomen Gemälde liegt dann darin, dass sie zwar ihre materielle Produktion, d.h. die Verfahren der Flächeneinschreibung nicht mehr verschleiern - hierin liegt aus marxistischer Sicht ein Teil ihres ideologiekritischen Gehalts -, doch ist nun die ökonomische Organisation der in ihnen deponierten Energie verborgen. Die repräsentationale Disposition hat sich gleichsam aus dem einzelnen Werk in ein die Werke übergreifendes Dispositiv verschoben. Mit dieser Verschiebung, die mit dem Verlust der repräsentationalen Funktion der Werke und deren verstärkter Selbstbezüglichkeit als bemalte oder sonst wie gestaltete Flächen bzw. Objekte einhergeht, scheinen zugleich die Möglichkeiten einer reflexiven Adressierung der Seinsweise durch die Werke selbst zu schwinden.

Mit Lyotard kann man zu dem Schluss gelangen, dass Oldenburg diesem Problem begegnet, indem er die Perspektive in den Raum externalisiert, womit die Auslagerung der repräsentationalen Funktion aus den Werken der Malerei hin zu einem sie übergreifenden Repräsentationssystem thematisch wird. Die bereits erwähnten Anspielungen im Bedroom Ensemble auf die spätmodernistische Malerei sind daher kein Zufall. Durch die Perspektivierung wird die Fetischisierung der modernistischen Malerei mit der Fetischisierung der konsumierbaren Waren gleichsam kurzgeschlossen - wobei der interessanteste Effekt dieses Kurzschlusses in der damit erzeugten Problematisierung der ästhetischen Autonomie der Werke liegt. Autonomie scheint hier bestenfalls als dialektische fortzubestehen, nämlich als Autonomie, die immer in einer Abhängigkeitsbeziehung zu werkexternen Verhältnissen steht. Diese Verhältnisse lassen sich mit Lyotard als kapitalistische Ökonomie bestimmen oder, nüchterner, als historische Diskurse um Authentizität, Freiheit und Lebendigkeit der Malerei.

Man muss weder Lyotards psychoanalytisch informiertem Vitalismus noch dessen Verknüpfung mit dem Marxismus bzw. dem Strukturalismus folgen, um zu erkennen, dass Ideologiekritik auf vielfältige Weise mit der Perspektive verknüpft werden kann. Wenn ich in diesem Kapitel die Perspektivkritik der ApparatusTheoretiker mit den Arbeiten Waalid Raads und Claes Oldenburgs kontrastiere, geht es mir darum zu zeigen, dass die Beziehungen 
von Perspektive, Kritik und Ideologie in der Moderne keineswegs festgeschrieben ist. Der ideologische Code, den die ApparatusTheoretiker in der Perspektive erkennen, wird zur selben Zeit als ideologiekritisches Moment zur Befragung politischer bzw. ökonomischer Voraussetzungen eingesetzt. Die Subjektivierung durch Perspektive, die für den Marxisten Baudry eine idealistische und daher ideologische ist, kann unter anderen Bedingungen in eine Reflexion auf die historische Konstitution der Wahrnehmung und ihrer Objekte umschlagen. 



\section{Perspektive und Bewusstsein}

\section{"Bis jemand kommt und mir sagt, wer ich bin"}

Der Topos der perspektivischen Subjektivität ist komplex. Dass es sich bei der Perspektive um ein Dispositiv handelt, das seine Betrachterin nötigt, ihre Position, ihre Verfassung und nicht zuletzt ihre Grenzen zu hinterfragen, ist hinreichend deutlich. In diesem Kapitel geht es darum, diese Fragen und Probleme der Subjektivität auf zwei Aspekte hin zu befragen. Erstens nach dem Verhältnis zwischen Subjekt und dem perspektivischen Dispositiv, d.h. genauer genommen nach dessen Wirkungsweise im Subjekt. Es wird darum gehen, die Tragweite dieser Wirkung zu diskutieren und auf die Frage nach dem Bewusstsein zuzuspitzen. In diesem Zusammenhang frage ich nach den Konsequenzen der Beziehung zwischen Perspektive und Bewusstsein für die Bedeutung der Perspektive in der künstlerischen Moderne und zwar innerhalb eines ideologiekritischen Horizonts. Zwei ideologiekritische Ansätze stehen im Zentrum: Friedrich Teja Bachs Überlegungen zur Perspektive als einem anthropologischen Experiment und Sebastian Egenhofers Thesen zur Perspektive als einem Modell der Kritik. Beide erlauben auf je unterschiedliche Weise, ein bildgeschichtliches Narrativ der Perspektive zu denken, welches deren frühneuzeitlichen Ursprung mit der ästhetischen Moderne und ihren Paradigmen der Kritik in Verbindung setzt.

Man kann mit guten Gründen annehmen, dass das Experiment Brunelleschis, der Spiegelkreislauf des Blicks, der 1425 auf dem Domplatz von Florenz erstmals stattgefunden haben soll, den Ursprung der Perspektive, so wie wir sie kennen, darstellt. ${ }^{1}$ Dass derselbe Urheber auch Akteur eines anderen Experiments ist, das ebenfalls in Florenz stattfand, wissen wir dank Antonio Manetti. Der Autor, dem wir die Vita Filippo Brunelleschis und damit auch

1 Neben Hubert Damisch ist auch James Elkins der Meinung, dass Brunelleschis Apparat den experimentellen Ursprung der Perspektive bildet. Elkins, Poetics of Perspective, 1994, S. $6 \mathrm{ff}$. 
die Beschreibung des Apparats verdanken- dieser ist zum Leidwesen der Historiker nicht erhalten geblieben -, verfasst in der ersten Hälfte des fünfzehnten Jahrhunderts eine Novelle, die den Titel "La Novella del Grasso Legnaiolo« (Die Novelle vom dicken Holzschnitzer) trägt. ${ }^{2}$ Sie beschreibt in kunstvoller Erzählform ein Ereignis im Jahr 1409, das Brunelleschi verantwortet haben soll und dessen Opfer ein gewisser Manetto gewesen sei, seinerseits ein berühmter Florentiner Holzschnitzer. Die Erzählung beginnt mit der Beschreibung Manettos, den man seiner Statur wegen auch den Dicken (il grasso) nennt und der eines Abends dem Umtrunk seines Florentiner Freundeskreises ohne Abmeldung fernbleibt. An diesem Abend beschließen die Anwesenden unter Federführung des jungen Brunelleschi, dem Dicken einen Streich zu spielen. Er solle glauben, so schlägt Brunelleschi vor, er habe sich in einen anderen verwandelt, wozu eine raffinierte Inszenierung ausgetüftelt wird. Als der Holzschnitzer am folgenden Abend in sein Haus gehen will, findet er die Tür verriegelt vor. Eine aus dem Haus dringende Stimme spricht ihn mit »Ach, Matteo" an. ${ }^{3}$ Der Holzschnitzer ist nicht nur darüber verwirrt, dass er als Matteo angesprochen wird, sondern auch dass Stimme und Manier wie seine eigene klingen. Er sagt zu sich: »Mich dünkt, als ob der, welcher oben im Haus ist, ich wäre. «4 Seine Verwirrung wird noch größer, als ihn im Vorbeigehen Donatello mit den Worten »Guten Abend, Matteo, suchst du den Dicken? Der ist gerade vorhin ins Haus gegangen $\aleph^{5}$ begrüßt. In seiner Verwirrung beschließt der Dicke, auf die Piazza San Giovanni zu laufen, und er sagt bei sich: "Jetzt bleibe ich so lange hier stehen, bis jemand kommt und mir sagt, wer ich bin«, wobei ihn die Angst überkommt, dass er »so schnell« ein anderer geworden ist, »ohne es zu merken « ${ }^{6}{ }^{6}$

Als er kurz darauf von der Obrigkeit des Handelsgerichts verhaftet wird, mit dem Vorwurf, er schulde einem Mann Geld, wehrt er sich gegen die Verhaftung, die er sich nur als Verwechslung erklären kann. Der Holzschnitzer wird von den eingeweihten Beamten jedoch weiterhin als Matteo angesprochen und verbringt

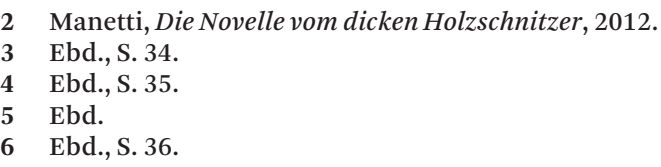


unfreiwillig eine Nacht im Gefängnis, wo er am folgenden Tag von den verärgerten Brüdern Matteos abgeholt wird. Auch sie behandeln ihn wie Matteo, begleichen seine Schulden und nehmen ihn zu sich nach Hause mit. Bereits im Gefängnis, und erst recht im Haus der Brüder, beginnt der Dicke nach und nach den Umstand zu akzeptieren, dass er auf mysteriöse Weise von Manetto, dem dicken Holzschnitzer, zu Matteo geworden ist. Ein Schlaftrunk, der ihm in der folgenden Nacht ohne sein Wissen verabreicht wird, versetzt ihn in einen tiefen Schlaf, wodurch es möglich wird, ihn unbemerkt in sein Haus zurückzubringen. Dort wacht er am kommenden Morgen erleichtert auf, um sich wieder als Manetto, den dicken Holzschnitzer, in seinem eigenen Bett zu wiederzufinden.

Dass Brunelleschis Inszenierung den Holzschnitzer im Glauben lässt, er wäre tatsächlich während zwei Tagen ein anderer gewesen, ist bedenkenswert. Die nachhaltige Wirkung des Streichs zeigt sich etwa darin, dass Manetto der Dicke mit der Vorstellung weiterlebt, er sei vorübergehend ein anderer geworden. Im Folgenden werde ich über die Beziehung von Manettis Novelle bzw. dem darin beschriebenen Experiment von 1409 und der perspektivischen Bildkonstruktion bzw. Brunelleschis Bildexperiment im Jahr 1425 nachdenken. Friedrich Teja Bach, dem ich die Kenntnis dieses Textes verdanke, hat sich in einem klug angelegten Text der Frage nach diesen Zusammenhängen gewidmet. Der Titel seines knappen und zugleich dichten Beitrags formuliert die Hypothesen Bachs vorweg: "Filippo Brunelleschi und der dicke Holzschnitzer: Perspektive als anthropologisches Experiment und das Paradigma des Bildes als Einlegearbeit ${ }^{7}{ }^{7}$ Bach sieht in beiden Experimenten die für die Perspektive grundlegenden Momente angelegt. Er beruft sich dabei in mehrfacher Hinsicht auf Panofsky, dessen Charakterisierung und philosophische Interpretation der Perspektive er in beiden Experimenten wiedererkennt. Dazu gehören die »Objektivierung des Subjektiven", die Konzeption der Perspektive als »Triumph des distanzierenden und objektivierenden

7 Bach, "Filippo Brunelleschi und der dicke Holzschnitzer. Perspektive als anthropologisches Experiment und das Paradigma des Bildes als Einlegearbeit«, 2009. 


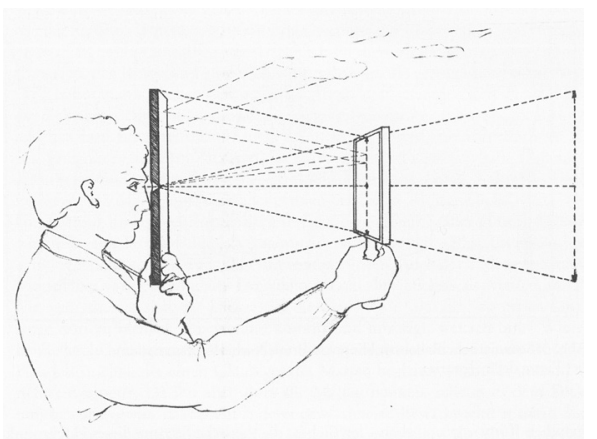

Abb. 1: Schematische Rekonstruktion des von Brunelleschi durchgeführten Experiments auf dem Domplatz von Florenz (nach Friedrich Teja Bach).

Wirklichkeitssinns" sowie ihre Bedeutung als "ein Triumph des distanzverneinenden menschlichen Machtstrebens « ${ }^{8}$

Allerdings gewinnt der Begriff der 'Macht bei Bach eine völlig neue Dimension, und zwar indem er eine Reihe von Analogien zwischen dem ersten, sozialen Experiment und dem zweiten, visuellen Experiment aufstellt. Während der materielle Apparat mit Guckloch, Spiegel und Bildtafel ein Experiment mit der Darstellung von Wirklichkeit sei (Abb. 1), handle es sich beim ersten Experiment um ein Experiment mit der sozialen Wirklichkeit. ${ }^{9}$ Der Florentiner Domplatz nimmt in beiden Experimenten eine zentrale Rolle ein: in Brunelleschis visuellem Experiment als Bühne des Wahrnehmungsgegenstands - dem Baptisterium -, in seinem sozialen Experiment als Bühne, auf die der verwirrte Holzschnitzer flüchtet, um, wie es in der Novelle heißt, zu warten, bis jemand kommt und ihm sagt, wer er ist. Das Experiment Brunelleschis weise auf die Funktion des kommunalen Symbolraums hin, in dessen Zentrum nicht zufällig das Baptisterium, also die Taufkirche stehe, ein Ort der rituellen Namensgebung, d.h. der sozialen Identitätskonstitution.

Tatsächlich ist es gerade diese Identitätskonstitution, welcher der Holzschnitzer ausgeliefert ist, und so kann Bach beide Experimente als Experimente mit und an der Identität behandeln. Die

8 Ebd., S. 65.

9 Ebd., S. 66 sowie S. 76. 


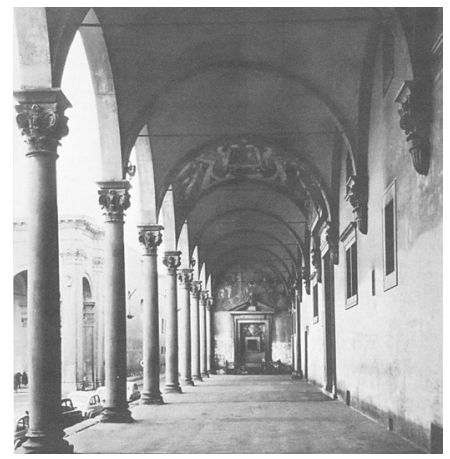

Abb. 2: Filippo Brunelleschi, Loggia des Ospedale degli Innocenti in Florenz.

Identität betrifft einmal den Namen (Matteo bzw. Manetto) und einmal den visuellen Fluchtpunkt in der Darstellung, in beiden Fällen aber ein Moment, das innerhalb eines konstruierten Netzes situiert ist, das sich einmal als Netz sozialer Ereignisse, einmal als Netz visuell organisierter Linien zeigt. ${ }^{10}$ Um diese Analogie zwischen Namen und perspektivischem Fluchtpunkt zu untermauern, verweist Bach u. a. auf das von Brunelleschi erbaute Ospedale degli Innocenti, dessen Portikus über eine Drehlade (Torno) verfügt, durch die anonyme Neugeborene ins Innere des Findelhauses abgegeben werden konnten (Abb. 2). Den Umstand, dass dieser Portikus am Ende einer langen Arkadenreihe liegt und damit den Fluchtpunkt der architektonischen Perspektive einnimmt, deutet Bach als Hinweis auf die "anthropologische[n] Implikationen" der Perspektive. ${ }^{11}$ Der Fluchtpunkt, so Bach, bildet dabei den Ort eines Übergangs zwischen Anonymität und sozialer Identität, ein Übergang, der einem Körper widerfährt, der durch die Drehlade ins Innere der Institution gelangt, die dem Kind seinen Platz in der Gesellschaft geben wird.

10 Bach spricht davon, dass Brunelleschi »ein darauf fein abgestimmtes Netz von Ereignissen« auslege, um den Dicken zu täuschen, und dass sich das Subjekt »dem leeren Netz des Raumes ausgesetzt sieht." Ebd., S. 67 bzw. S. 87. Die philosophische Grundlage dieser Konstruktion erkennt Bach in Platons Dialog Kratylos, der das sprachphilosophische Problem der Kontingenz der Namensgebung formuliert, ein Problem, das Bach in Brunelleschis Experimenten wiedererkennt. Ebd., S. 80f.

11 Ebd., S. 76. 
Bachs geschickte Analogiebildung zwischen den beiden perspektivischen Experimenten ist letztlich eine Homologie der Form, die sich zwischen der "Form des Tafelbilds" und der "Handlung in der Wirklichkeit « zeigt. ${ }^{12}$ Diese Form ist weiter als simulative begriffen, denn der Streich sowie das Tafelbild operieren beide als Simulation der sozialen bzw. visuellen Wirklichkeit. ${ }^{13}$ Das prekäre Moment beider Simulationen liege dabei nicht nur auf der destabilisierten Identität, d. h. dem Namen bzw. Punkt, der im Zentrum des jeweiligen Netzes steht, sondern auch an den Rändern, d.h. den Zonen, an denen die Simulation an die überdeckte Realität grenzt. Beide Simulationen, so Bach, seien darum bemüht, ihre Grenzen unkenntlich zu machen, indem sie diese dissimulieren. ${ }^{14}$ Dies geschehe dadurch, dass die Grenzen der Simulationen nicht als harte Grenzen gestaltet sind, sondern als gleichsam verschwimmende Übergänge hin zur Realität. Es sind Zonen, an denen die Simulationen auf die Realität hin durchsichtig werden und diese kalkuliert in sich aufnehmen. Beim ersten Experiment seien es die uneingeweihten Passanten, die als unfreiwillige Statisten in Brunelleschis Inszenierung mitwirken. Im zweiten Experiment sei es der Himmel, der sich in der Silberfolie spiegelt, die Brunelleschi in seiner Darstellung des Baptisteriums angebracht hat.

Bach behandelt beide Experimente als perspektivische, die jeweils eine »simulierte Realität« herstellen, deren Ränder gleichsam in die Realität eingetaucht sind. Die unkontrollierbaren Agenten dieser Realität umspülen das Simulakrum wie Wellen, mit der ständigen Gefahr, dass seine Grenzen und damit die Täuschung sichtbar werden. Diese Konzeption der Perspektive und die mit ihr verbundene Subjektivierungsweise setzen dabei voraus, dass bereits eine Realität vorhanden ist, die von der simulierenden Darstellung überdeckt wird. Die Perspektive wird hier als anthropologische Funktion begriffen, insofern sie als artifizielle Konstruktion den "natürlichen Code « durch einen »künstliche[n] « Code ersetzt. ${ }^{15}$ Sie wird verwendet, um eine "simulierte Realität in den Raum einer realen Realität einzupassen $«{ }^{16}$ Diese Beobachtung bringt Bach zu 
der Schlussfolgerung, es handle sich bei der Perspektive modellhaft um eine Intarsie, eine »Einlegearbeit in die Wirklichkeit « ${ }^{17}$ eine These, die sich nicht nur die Tatsache zunutze macht, dass die Perspektive im fünfzehnten Jahrhundert eine herausragende Rolle in der Intarsienarbeit gespielt hat, ${ }^{18}$ sondern auch, dass Manetto, der Holzschnitzer in der Novelle Manettis, als begnadeter Intarsienleger beschrieben wird.

Wenn die Perspektive aber ein künstlicher Code sein soll, der eine natürliche Ordnung verdeckt, um sich selbst als solche zu geben, dann stellen sich gewisse Fragen, die den Status der Darstellung sowie der Subjektivität betreffen. Wessen Wirklichkeit soll jene 'Realität`sein, die sich jenseits der ssimulierten Realität abzeichnet? Und bezeichnen die Prädikate ssimuliert bzw. sreak tatsächlich die Beziehung zwischen diesen Realitäten auf adäquate Weise?

Die Frage steht und fällt mit der Tragweite, die man der subjektgenetischen Funktion der Perspektive zugesteht. Manettis Novelle enthält zumindest Hinweise dafür, dass der Effekt der Subjektivierung des Experiments nicht im Begriff der 'Simulation`aufgeht, und stellt den Realismus Bachs in Frage. Denn die Erzählung zeichnet einen deutlichen Wandel im Bewusstsein des Dicken nach. Dieser wird zunächst als bloß verstört beschrieben, dann heißt es, er sei »beinah sicher, dass er nun ein anderer sei«, und schließlich: "jetzt zweifelte er nicht mehr daran, dass er wirklich Matteo war « ${ }^{19}$ Demnach affirmiert der Dicke seine neue Identität nicht nur performativ nach außen, wenn er etwa auf die Frage des Richters: "Wer ist denn Matteo?«, antwortet: »Der bin ich, mein Herr», oder wenn er später auf die Anrede des Pfarrers "Guten Abend, Matteo« einwilligend antwortet "Guten Abend «. ${ }^{20}$ Neben dieser sozialen und performativen Anerkennung, die unweigerlich an Konzepte der Performanz und der Anrufung erinnert, scheint der Dicke die Effekte des ihn umgebenden Netzes vor allem innerlich zu affirmieren und zu reproduzieren. Dieser psychische Prozess, den wir durch die Innensicht der Erzählung zu verfolgen imstande sind,

17 Ebd., S. 71.

18 Bach erwähnt selbst den in diesem Zusammenhang zentralen Studiolo des Palazzo Ducale in Urbino, ebd., S. 88.

19 Ebd., S. 37f. bzw. S. 47.

20 Ebd., S. 50 bzw. S. 55. 
weist Anzeichen dessen auf, was man - freilich unter ganz anderen Bedingungen - als 'Subjektivation` bezeichnet, denn das perspektivische Experiment scheint das Subjekt in seinem seelischen Zustand zu treffen. Zeigt sich in Manettis Schilderungen zum Innenleben des dicken Holzschnitzers nicht gerade, dass das Subjekt, mit Michel Foucault gesprochen, bis in sein Innerstes "Effekt und Instrument" einer Macht ist, die es "ständig produziert«? ${ }^{21}$

Wenn die Macht von Brunelleschis Konstruktion über das Subjekt aber derart profund ist, wenn sie eine psychische Dimension hat, die das Bewusstsein verändert, wie angebracht ist es dann noch, diese als simulierende zu begreifen und sie von der vermeintlichen Realität zu unterscheiden? Bachs Hinweis auf Austins Theorie des Sprechakts sowie der Terminus der 'Simulation< und des ${ }^{2}$ Codes $^{22}$ liebäugeln zwar mit einem Konstruktivismus, doch wird dieser durch seine Unterscheidung von Simulation und der damit einhergehenden Aufrechterhaltung einer zugrunde liegenden Realität letztlich nicht eingelöst.

Der Begriff der 'Simulation ' wirft aber auch im Hinblick auf das zweite Experiment Fragen auf, allerdings aus ganz entgegengesetzter Richtung. Ist es überzeugend, die bildförmige perspektivische Darstellung als Simulation zu beschreiben? Es scheint zweifelhaft, ob Brunelleschi seinen Apparat mit der Intention anfertigt, den Betrachter glauben zu lassen, er sehe das wahre Baptisterium, und es ist unklar, ob er selbst oder irgendein anderer Betrachter, der sein Gesicht an die Rückseite der Bildtafel legt, um mit einem Auge die Darstellung des Baptisteriums zu sehen, dieses für das echte Gebäude hält. Hierin liegt möglicherweise ein zentraler Unterschied zwischen der sozialen und der bildförmigen perspektivischen Inszenierung. Materialisierte Bildformen scheinen die Inszenierung als solche zu reflektieren, indem sie ihre Artifizialität zu jedem Zeitpunkt exponieren. Selbst jener postmoderne Theoretiker, der den Simulationsbegriff wie kein anderer behandelt hat, thematisiert im Hinblick auf materialisierte Bilder diese Weise der Reflexion. Jean Baudrillard schreibt, dass Kunstwerke als solche

21 Foucault, Überwachen und Strafen. Die Geburt des Gefängnisses, 1994, S. 41f.

22 Bach, "Filippo Brunelleschi und der dicke Holzschnitzer. Perspektive als anthropologisches Experiment und das Paradigma des Bildes als Einlegearbeit«, 2009, S. 84. 
»durchschaubar" sind, dass man ihre Darstellung nicht mit ihrem Motiv verwechselt und ihr Reiz gerade darin liege, dass man stets um die Artifizialität des Sichtbaren wisse. ${ }^{23}$

Wenn ich den historischen Anachronismus ausblende, der in dieser gesamten Problematik zum Tragen kommt, dann um ein theoretisches Problem zu behandeln, das sich am Begriff der 'Simulation und im Hinblick auf Bachs Analogie bemerkbar macht. Im Falle des ersten Experiments scheint das Konzept der 'Simulation` der Wirkung der perspektivischen Inszenierung nicht gerecht zu werden, weil es deren psychische Virulenz nicht angemessen zu beschreiben scheint. Im Falle der perspektivischen Inszenierung des Baptisteriums hingegen scheint der Begriff der reflexiven Dimension der Bildförmigkeit nicht zu entsprechen. Der Begriff der Simulation ist also entweder zu schwach oder aber zu stark, um den Sachverhalt angemessen zu beschreiben. Vor diesem Hintergrund scheint es fraglich, ob die beiden Experimente sich der raffinierten Analogie Bachs widerstandslos fügen. Die Hypothese, es handle sich bei beiden um eine Einlegearbeit in die Wirklichkeit, zeigt, dass der Autor die Perspektive letztlich als trügerisch begreift. Sie verstellt die Realität, auf die sie undurchlässig ist, weshalb die Randzonen der perspektivischen Inszenierungen verunklärt werden müssen, um den Anschein eines homogenen Wahrnehmungskontinuums zu erwecken. Die Tragweite ihrer subjektkonstituierenden Funktion ist dann genauso ein Täuschung:smanöver wie ihre visuelle Darstellung des Baptisteriums von Florenz. Der Begriff des >Anthropologischen`, der in der Hypothese von der Perspektive als anthropologischem Experiment angezeigt wird, ist in diesem Sinn nicht eindeutig geklärt. Zwar heißt es in Bachs Text:

"Kunstwerke tragen zur Konditionierung von Wahrnehmung und sozialen Verhaltensweisen bei, soziale Wirklichkeiten strukturieren aber auch die künstlerischen und intellektuellen Dispositive. ${ }^{24}$

23 Baudrillard, "Die Simulation«, 1988, S. 161.

24 Bach, "Filippo Brunelleschi und der dicke Holzschnitzer. Perspektive als anthropologisches Experiment und das Paradigma des Bildes als Einlegearbeit«, 2009, S. 83. 
Doch wenn die Auswirkung der perspektivischen Dispositive auf bloße Täuschungen begrenzt ist, bleibt die im Text ohnehin bloß angedeutete Reziprozität zwischen Kunst und sozialer Realität unterbestimmt.

\section{Der blinde Fleck}

Ich habe oben die Frage aufgeworfen, was jene 'Realität sein könnte, die von der perspektivischen Simulation verdeckt wird und gleichsam deren ontologische Antithese bilden soll. Diese Frage führt mich zum modernistischen Charakter von Friedrich Teja Bachs Interpretation der Perspektive. Dieser zeigt sich u.a. darin, dass Bach jene Realität in einer profunden Widerständigkeit des Leibs verortet, die ich kurz darlegen will. Die Konzeption der leiblichen Widerständigkeit und das darin angelegte ideologiekritische Potential sind idealtypisch für das moderne Verständnis der Perspektive. Der menschliche Körper und seine Realität vermögen sich danach der Konstruktion zu entziehen und in diesem Entzug mache sich die begrenzte Macht der Perspektive, ihr »blinder Fleck«, wie Bach sagt, bemerkbar. Bach argumentiert dafür, dass der Leib und seine Selbstwahrnehmung als irreduzible Momente fungieren, die sich den perspektivischen Inszenierungen widersetzen. ${ }^{25}$ Das erste Experiment sei zwar ein Experiment mit dem Körper, jedoch werde dieser letztlich zu wenig ernst genommen. ${ }^{26}$ Bach ist der Auffassung, der dicke Holzschnitzer hätte im Moment seiner tiefen Verunsicherung über seine Identität bloß seinen eigenen Leib anfassen müssen, um zu merken, dass es der Leib des Dicken ist. Der Leib und seine eigene Reflexivität werden hier als widerständiges Element begriffen, das die perspektivische Konstruktion und ihre Subjektivierung nicht einzuholen vermag. ${ }^{27}$ Wenn der menschliche Körper aber der Garant einer stabilen Identität bildet, dann stellt sich die Frage, warum die konstruierte Inszenierung, die Manettis Novelle beschreibt, trotzdem gelingt. Es scheint

27 Vgl. dazu auch meine Ausführungen zu Merleau-Pontys Chiasmus in Kapitel II der vorliegenden Studie. 
doch zweifelhaft, dass man der Macht des sozialen Lebens und seiner psychischen Virulenz dadurch entgehen kann, dass man sich selbst an der Hand fasst, um sich so seiner vermeintlich stabilen Identität zu versichern.

Bach macht die `Überlistung des Körpers a auch im Hinblick auf das zweite Experiment Brunelleschis zum Thema. Der Leib sei hier das Moment einer Verdrängung, die der perspektivischen Konstruktion als einer »falschen Konstruktion« innewohne. ${ }^{28}$ Die anthropologische Bedeutung der Perspektive zeigt sich vor diesem Hintergrund als eine Art Dualismus zwischen Kultur und Natur. Die Vergesellschaftung leiblich fundierter Subjekte ist eine verhüllte und ideologische Disziplinierung, die den Körper in ihre Netze einfängt - allerdings ohne diesen restlos bändigen zu können. ${ }^{29}$

Ausgehend von diesem Antagonismus zwischen einer von der Perspektive betrogenen und letztlich doch unkontrollierbaren Körperlichkeit skizziert Bach auf den letzten Seiten seines Aufsatzes andeutungsweise ein bild- bzw. kunstgeschichtliches Narrativ der modernen Kunst. Es ist die Geschichte eines aus der Verdrängung sich meldenden Leibes, der sich, einem Wiederholungszwang gleich, immer wieder und unter jeweils anderen Bedingungen in der Kunst bemerkbar macht. Bach konstatiert, dass das im Netz der perspektivischen Konstruktionen gefangene Subjekt zur Melancholie neigt, wobei ihm eine Darstellung der Melancholia aus dem Jahr 1561, die eine massige, scheinbar im perspektivischen Raum eingeschlossene Frauenfigur zeigt, ebenso als Symptom dieser Wiederkehr des Verdrängten gilt, wie ein Filmstill Cindy Shermans aus dem Jahr 1978 (Abb. 3 bzw. Abb. 4).

Bachs Text zeigt sich letztlich als kritische Untersuchung perspektivischer Subjektivität und kommt zu einem beinahe widersprüchlichen Ergebnis. Vor dem Hintergrund einer präjudizierenden Konzeption des Leiblichen wird die perspektivische Konstruktion

28 Bach, "Filippo Brunelleschi und der dicke Holzschnitzer. Perspektive als anthropologisches Experiment und das Paradigma des Bildes als Einlegearbeit«", 2009, S. 80.

29 Der Natur-Kultur-Dualismus wird etwa deutlich, wenn Bach schreibt: "Auch die Novella figuriert die Neubegründung des Subjekts als doppeltes Geschehen, auf kultureller und auf natürlicher Ebene, als Perspektivierung auf einen neuen Namen hin und als Trennung von der natürlichen Herkunft...«. Ebd., S. 84 . 


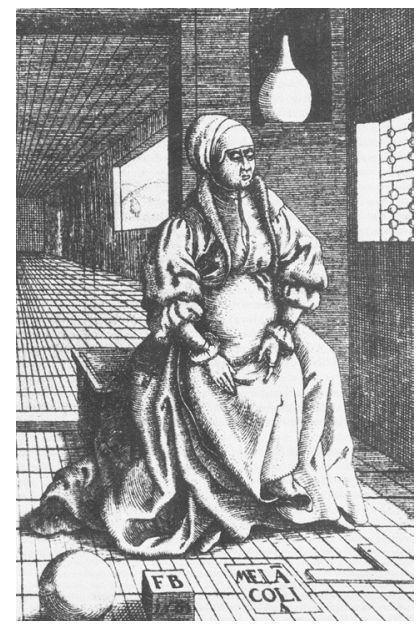

Abb. 3: Monogrammist F.B., Melancholia, 1561, Radierung.

der Identität als dezidiert ‘falsche`Konstruktion begriffen. Das Gelingen dieser perspektivischen Identifikation bezahle den Preis, einer sie begleitenden Verdrängung, die sich als Unbehagen bzw. Melancholie bemerkbar mache.

Das Motiv einer verdrängten Körperlichkeit als der »dunklen, wilden anderen Seite ${ }^{30}$ von der die lineare Konstruktion als Agent der Vergesellschaftung des Subjekts begleitet wird, entpuppt sich bei genauerem Hinsehen als bezeichnendes Signum der Moderne. Deutlich wird dies, wenn Bach, in aller Kürze, von den konstruktiven Linien in Mondrians Werk spricht. Er erzeugt zunächst eine Analogie zwischen dem perspektivisch-räumlichen Gitternetz und den geometrischen Liniengerüsten Mondrians, um schließlich das sunfassbare Flimmern an den Rändern dieser Linien als positiv gewendete Wiederkehr einer verdrängten Körperlichkeit zu beschreiben (Abb. 5).

Auch hier weise ich nicht auf den Anachronismus der Argumentation hin, sondern auf den modernen Charakter von Bachs malereigeschichtlichem Narrativ. Darin deutet sich ein Bild der Moderne an, die einerseits das historische Erbe der Perspektive 


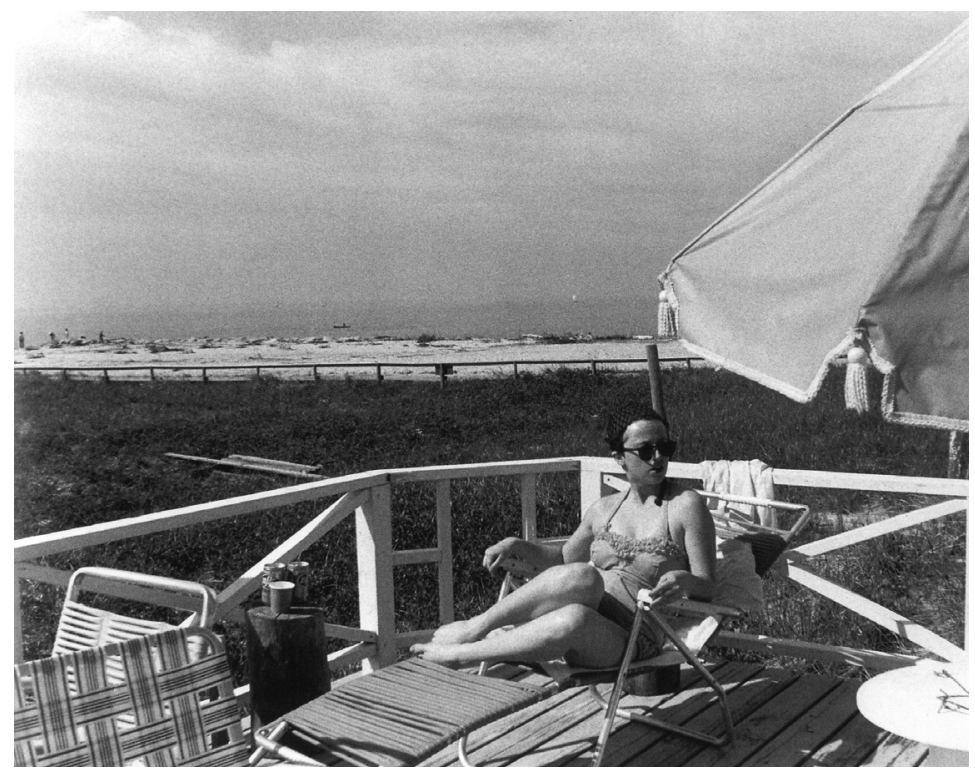

Abb. 4: Cindy Sherman, Untitled Film Still, 1978, SW-Fotografie.

in sich trägt - in Form des geometrischen Liniengerüsts - und andererseits diesen disziplinierenden Linearismus mit den pulsierenden Farbfeldern zu überwinden sucht. Es scheint dann, als sei die Bedeutung der modernistischen Malerei eine therapeutische. Denn der Text vermittelt den Eindruck, dass die verdrängte Körperlichkeit in der künstlerischen Moderne jenen Raum zurückerhält, der ihr von der perspektivischen Konstruktion angeblich entzogen wurde. Die unterdrückte Körperlichkeit erhält in der Moderne die Möglichkeit, aus der Verdrängung hochzusteigen, um an der Oberfläche des Bildes bemerkbar zu werden.

Dabei ist nicht ohne weiteres einleuchtend, was Mondrians Konstruktionen mit den perspektivischen Konstruktionen der Neuzeit zu tun haben. Die konstruierten Liniennetze der Perspektive sind ideelle Ebenen im virtuellen Bildraum, während Mondrians Liniengerüste spätestens ab 1918 komplett planar erscheinen (Abb. 5). Letztere sind also flächige Linien oder Raster, deren Materialität scheinbar wenig mit der Linie als 'principium`zu tun hat, als deren folgenreichste Erscheinungsform die Perspektive 


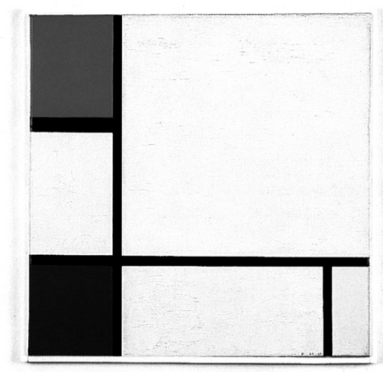

Abb. 5: Piet Mondrian, Komposition No. IV, mit Rot, Blau, und Gelb, 1929, Öl auf Leinwand.

zu Beginn des Textes beschrieben wird. ${ }^{31}$ Und sollte man sich auf gewisse technische Instrumente wie das Velum berufen wollen, welche bei der Übertragung eines Wahrnehmungsausschnitts in ein Bild geholfen haben, dann muss man eingestehen, dass diese Raster von anderer Art und Funktion sind als Mondrians Liniengerüste. Rosalind Krauss hat in ihrer Untersuchung des Rasters darauf hingewiesen, dass die moderne Rasterung des Bildfeldes weder mit einer derartigen Übertragungsfunktion noch mit den perspektivischen Linienkonstruktionen zu tun hat und ihre Assoziation irreführend sei. ${ }^{32}$ Wenn Bach in Mondrians Werk also die "positiv gewendet[e]« Wiederkehr einer durch das Bildmodell der Perspektive verdrängten Leiblichkeit erkennt, wird damit klar, dass Bach die Perspektive mit den Augen eines Modernisten interpretiert und nicht etwa den Modernismus mit den Augen eines Perspektivisten. Die tradierte Dichotomie der Kategorien von Linearismus versus Kolorismus und ihre implizite Bewertung fungiert als Hintergrundschema, das mehr mit den Voraussetzungen der Moderne zu tun hat, als mit den Gegebenheiten des frühneuzeitlichen Perspektivismus. ${ }^{33}$

31 Ebd., S. 63.

32 Rosalind Krauss, "Grids«, 1979, S. 52.

33 Nebenher kann man fragen, ob nicht auch die Farbe, genauso wie die Linie, der Agent einer Konstruktion sein kann. Warum der Farbe also nicht eine Funktion zukommen kann, die analog der Perspektive, zur Disziplinierung und Kontrolle des Subjekts beiträgt? Schließlich hat Isaac Newton mit seinem Traktat zur Optik bereits 1730 den entscheidenden Grundstein für die physikalische Systematisierung der Farbe gelegt und man kann sich fragen, 
Bachs moderne Interpretation der Perspektive und sein Postulat einer Inkommensurabilität der leiblichen Selbstwahrnehmung traut dem Körper möglicherweise zu viel zu. Die kulturelle Konstruktion, die im sozialen Experiment Brunelleschis zum Tragen kommt, übt ihre Kraft auf der Basis einer machtvollen psychischen Virulenz aus, gegen die sich kein Körper wehren kann. Wenn man Manettis Novelle ernsthaft zum Anlass nimmt, um über Prozesse der perspektivischen Subjektivierung nachzudenken, kommt man nicht umhin, die darin geschilderte psychische Verfassung des Dicken ernst zu nehmen. Sie wird in der Introspektion während seines Gefängnisaufenthalts mehr als deutlich, wenn er in Gedanken zu sich selbst spricht: »Was soll ich tun, wenn ich wirklich Matteo geworden bin? «34 Das eigentliche Gefängnis dieses Leibs scheint weniger äußerlich als vielmehr innerlich zu sein: »Die Seele: Gefängnis des Körpers«, schreibt Foucault, »ein Stück der Herrschaft [...], welche die Macht über den Körper ausübt« ${ }^{35}$

\section{Bewusstseinskritik}

Die Wirkung von Brunelleschis sozialem Experiment ist, wie ich gezeigt habe, eine profunde, denn sie wirkt im Bewusstsein des Subjekts. Dass dieses Experiment im weitesten Sinn perspektivisch ist, insofern es mit einer kalkulierten Inszenierung vollzogen wird, die auf ein Subjekt hin ausgerichtet ist, erklärt aber noch nicht, ob und warum die Perspektive im engeren Sinn mit dem Bewusstsein in Beziehung steht. Wie eng kann man die soziale und kulturelle Konstruktion der Realität mit der linearperspektivischen Bildraumkonstruktion zusammenführen, ohne den Begriff der Perspektive ins Nichtssagende zu metaphorisieren? Und wenn es tatsächlich einen plausiblen Zusammenhang zwischen der Konstruktion von gesellschaftlicher und linearperspektivischer Subjektivität gibt, wie ist dann die moderne Kritik an der Perspektive genau zu verstehen, wenn man sie nicht bloß als therapeutische

ob die zunehmend differenzierten Farbsysteme, die daraus hervorgegangen sind, nicht als Dispositive einer anderen Weise der disziplinierenden Konstruktion funktionieren.

34 Manetti, Die Novelle vom dicken Holzschnitzer, 2012, S. 38.

35 Foucault, Überwachen und Strafen. Die Geburt des Gefängnisses, 1994, S. 41. 
Regeneration der Leiblichkeit begreifen will? Es geht also darum, die Dimension und Tragweite der Perspektive jenseits der gestalterischen Formgenese mit den Anliegen der Ideologiekritik zu verbinden. Sebastian Egenhofer ist diesem Unterfangen in einem knappen und zugleich komplexen Text mit dem Titel » $\mathrm{Zu}$ einer Topik der Bildkritik « nachgegangen. ${ }^{36} /$ Kritik bildet den zentralen Begriff des Textes, der ausgehend von Immanuel Kants kritischer Philosophie entwickelt wird, um dann mit dem Begriff des Bildes verbunden zu werden. Der Begriff `Kritik`meint dabei wesentlich "genetische Kritik«, d.h. Kritik am Gewordensein des Bildes. ${ }^{37}$ Die Art und Weise der Genese ist dabei abhängig von der Art und Weise des Bildes, denn der Begriff »Bild« besitzt im Rahmen dieser Überlegungen zwei grundlegende Bedeutungen: Zum einen bezeichnet Bild die allgemeine Form der Erscheinungen für ein Bewusstsein, d.h. die phänomenale Welt des Subjekts; zum anderen bezeichnet Bild (im Folgenden als Bild' markiert) ein materielles Artefakt, sprich ein als Ding erscheinendes Objekt. Das Bild' hat zur ihm umgebenden Welt eine besondere Beziehung, denn es vermag diese dingliche Welt durch den ihm eigenen (bildlichen) Schein zu transzendieren. Diese Transzendenz ist nicht bloß eine phänomenale, insofern das Bild' eine darstellende Leistung vollzieht, sprich in einem materiellen Objekt eine selbst immaterielle und nur sichtbare Erscheinung erzeugt, vielmehr weist der an Adornos Ästhetik angelehnte Begriff des `Scheins` darauf hin, dass das Bild' als Werk der bildenden Kunst begriffen ist. Der Schein, so die implizite Prämisse von Egenhofers Text, ist auch ästhetischer Schein und er konstituiert das Bild', insofern es seine positivistisch bestimmbare Dinglichkeit in einem ganz bestimmten Sinn transzendiert, nämlich als Kunst. Dies verleiht dem Bild' die Fähigkeit in einer ästhetischen und daher von der Realität suspendierten Erscheinungsmodalität jene Genese zu wiederholen, die beim Bild immer schon vollzogen ist, insofern Letzteres die unhintergehbar erscheinende Realität bezeichnet - d.h. das Produkt der subjektiven Erkenntniskräfte (für Egenhofer ist das primär eine kantisch konzipierte Einbildungskraft).

36 Egenhofer, »Zu einer Topik der Bildkritik«, 2011.

37 Ebd., S. $147 \mathrm{ff}$. 
Der Begriff der 'genetischen Kritik` hängt also unmittelbar mit dem transzendenten Charakter des Bildes zusammen, weil das kritische Potential des ästhetischen Bildes gewissermaßen in der damit ermöglichten Wiederholung liegt. Diese ermöglicht es, die Genese von Erscheinung als solcher erfahrbar zu machen, eine Genese, die in der menschlichen Weltwahrnehmung (dem bloßen Bild) notwendigerweise entzogen bleibt.

"Da sie [Bilder'] den Schein des natürlichen Bewusstseins - eines Bewusstseins, das nie allzu natürlich, sondern von den medialen Dispositiven und der symbolischen Ordnung einer Gesellschaft gestützt und informiert ist - duplizieren, können sie die Latenz dessen aufbrechen lassen, dessen Verdrängung der Schein seine Konsistenz verdankt. $\ll^{38}$

Als innerweltlich situierte Subjekte tragen wir den Horizont als Grenze unserer endlichen Anschauung immer mit uns, so dass dieser nie als Objekt der Anschauung, sprich in der Welt selbst erscheinen kann. Im Unterschied zu diesem unhintergehbaren Bild der Welt, dessen Konstitution sich dem Subjekt vollständig entzieht, kann das Bild' die Bedingungen seines Erscheinens kritisch reflektieren, denn seine Ränder sind gerade nicht die absolute Grenze der Welt, sondern selbst Teil der Welt.

'Kritik` ist also (erstens) 'Bildkritik`, weil sie vom Bild' selbst vollzogen wird, und sie ist (zweitens) 'Ideologiekritik`, weil sie am Bild' quasi stellvertretend die verborgene Konstitution des Bildes (als Produkt einer gesellschaftlichen Realität) aufdeckt. Dies ist etwa deshalb möglich, weil sich die Konstitution des Bildes' in dessen Sichtbarkeit einschreibt. In der formalen Perspektivierung der Darstellung sedimentiert sich also nicht nur deren Subjektbezug, sondern auch deren Gewordensein bzw. die Bedingungen ihrer Existenz als bildliche Erscheinung. Wenn sich im Bild' aber immer die Bedingungen seiner Genese zeigen, eine Genese, die im marxistischen Sinn als Produktion verstanden wird und immer einen geschichtlichen Ort hat, wird damit auch die Historizität des Bildes' thematisch. Das Bild' wird so zu einem geradezu ausgezeichneten 
Ort der Ideologiekritik, indem es jene Konstitution der Sichtbarkeit expliziert, von welcher der Mensch in seiner Weltwahrnehmung radikal getrennt ist.

Verkompliziert wird dieses Verhältnis von Bild und Bild' durch die komplexen Beziehungen der Bildgeschichte zur Philosophiegeschichte, die Egenhofers Text mitbestimmen. Denn das Bild' als ideologiekritischer Agent erscheint in seinen Überlegungen auch als ein eigentümliches Korrelat einer Ideengeschichte - ein Sachverhalt, in dem das Bildmodell der Linearperspektive eine zentrale Rolle spielt. Um die Bedeutung der Perspektive in diesem Zusammenhang zu begreifen, muss man zunächst bedenken, worin ihre fundamentale und gewissermaßen methodische Funktion für Egenhofers Überlegungen liegt: Entwickelt im frühen fünfzehnten Jahrhundert, setzt die Linearperspektive jene bildtheoretische Voraussetzung, die für die vom Autor konzipierte ‘Bildkritik`fundamental ist: Das mittels des perspektivischen Verfahrens hergestellte Bild' ist als Analogon des Sehbildes konzipiert und ermöglicht es so, die (selbst-)kritischen Kapazitäten von Bild' mit dem Bild in eine systematische Beziehung zu setzen. Ohne dieses analogische Verhältnis bliebe die Bedeutung und Tragweite der im Bild' möglichen Selbstkritik weitgehend unbestimmt, da ihre Beziehung zur Realität des Subjekts unklar oder nicht vorhanden wäre.

Doch wenn das Perspektivbild gleichsam Ursprung und Modell des selbstkritischen Bildes' ist, dann stellt sich die Frage, auf welche Konstitution seine Kritik verweist. Oder um es in materialistischen Termini zu formulieren: Welche historischen Produktionsverhältnisse kann oder konnte das Perspektivbild der Renaissance aufdecken?

Diese im Grunde anachronistische Frage beantwortet Egenhofer, in dem er das Bild' mit der Geschichte der Metaphysik in Verbindung bringt. Er setzt den mathematisch-konstruktiven Charakter des perspektivisch hergestellten Bildes in Beziehung zur neuzeitlichen Philosophie des Rationalismus, und zwar zur Philosophie Descartes'. Dessen skeptizistische Gegenüberstellung der Selbstgewissheit des Bewusstseins, d.h. des Cogito als einer sich selbst denkenden Immanenz auf der einen Seite und dem ungewissen Charakter seiner endlichen, weil sinnlichen Erfahrungen auf der anderen Seite, sieht Egenhofer gewissermaßen in der Linearperspektive angelegt. Diese reflektiert als Bild' die Endlichkeit der 
subjektiven Wahrnehmung, indem es deren Perspektivierung formal exponiert. Der Fluchtpunkt als Korrelat des subjektiven Blickpunktes fungiert dabei als projektives Pendant des cartesischen Cogito, indem er dessen qualitäts- und ausdehnungslose Eigenschaft unter geometrischen Voraussetzungen darstellt. Die auf diesen Punkt bezogene Sichtbarkeit (das Bild') entspricht dann der Erscheinungswelt des kognitiven Bewusstseins (dem Bild) und ist daher in der Lage, das zu leisten, was der Autor als »bildkritische Funktion « bezeichnet. ${ }^{39}$

Dem Element der Zeichnung kommt dabei eine zentrale Rolle $\mathrm{zu}$, denn sie ist einerseits ein Operator im mathematischen Raum und konvergiert daher mit den deduktiven Verfahren rationalistischer Philosophie, d.h. ihre Bestimmung ist metaphysisch. Andererseits vollzieht sich im perspektivischen Disegno aber auch die Wendung der unendlichen räumlichen Idealität hin zur endlichen Subjektivität. Indem seine Linien in einem einzelnen Punkt kulminieren, wird der Raum auf einen subjektiven Standpunkt hin gebrochen, womit sich in seine ideale Transparenz die Insignien der Endlichkeit einschreiben. Die Endlichkeit des Subjekts ist letztlich also der Unendlichkeit einer metaphysischen Realität gegenübergestellt, die sich jedoch immer nur unter subjektiven und daher perspektivischen Bedingungen anzudeuten vermag und in der liminalen Funktion des perspektivischen Horizonts zum Ausdruck kommt.

Egenhofers metaphysische Interpretation hat offensichtlich eine Konzeption der Perspektive als reinem Punktprojektionsverfahren im Auge, sprich der formalisiertesten Spielart der perspektivischen Darstellungstechniken. Für ihn ist die Renaissanceperspektive geradezu der Inbegriff eines deduktiv operierenden Rationalismus. Dem könnte man entgegenhalten, dass der quantitative Charakter der Perspektive auf einer vorhergehenden Induktion basiert, also wesentlich auf empirischen Erkenntnissen der antiken und mittelalterlichen Optik. Aufgrund dieser empirisch fundierten Genese der Perspektive möchte ich einige weitere Aspekte in Erinnerung rufen, die den metaphysischen Charakter in Frage stellen. Denn die Perspektive hat nicht nur einen wissen- 
schaftshistorisch untersuchten empirischen Ursprung ${ }^{40}$ sondern kann in ihrer systematischen Funktion auch als Modell empirischen Denkens verstanden werden.

Wie Manettis Schilderung von Brunelleschis Experiment verdeutlicht, vergleicht das Subjekt der Perspektive das perspektivisch konstruierte Bild mit seinem Wahrnehmungsbild. Darin liegt denn überhaupt der Sinn, eine handliche und damit mobile Tafel zu konstruieren, die Brunelleschi auf den Domplatz hat mitnehmen können, um dort und nur dort das Bild der Wirklichkeit mit der wahrgenommenen Wirklichkeit zu vergleichen. Das in diesem Sinn naturwissenschaftlich durchgeführte Experiment überprüft also diese mögliche Deckungsgleichheit anhand einer durch vorhergehende Induktion entstandenen Theorie, indem sie diese mit der Wirklichkeit abgleicht. ${ }^{41}$ Das Subjekt dieses Experiments ist aber - anders als Descartes' Cogito - nicht ein denkendes, sondern ein sehendes. So betrachtet erscheint es fraglich, ob die genetische Kritik der frühneuzeitlichen Perspektive die metaphysischen Existenzbedingungen des Subjekts reflektiert. Eine der Perspektive inhärente genetische Kritik würde doch genauso auf die Geschichte der mittelalterlichen bzw. antiken Optik verweisen, d. h. einer wissenschaftlichen Praxis, die zwar nicht mit den exakten Naturwissenschaften gleichgesetzt werden kann, jedoch als experimentell und empirisch angesehen werden muss.

Weiter könnte man in Zweifel ziehen, ob Egenhofers Identifizierung des Bewusstseins als reine Apperzeption mit dem anschauungsbezogenen Bewusstsein überzeugend ist, bzw. ob die linearperspektivische Darstellungsweise tatsächlich die radikale Immanenz des Cogito transzendiert und mit seiner Außenwelt zusammenführt. Denn wenn man eine Verbindung zwischen dem Cogito und dem Betrachtersubjekt von Bildern proklamiert und sich auf die Metaphysik als Grundlage der Genese ebendieser Bilder beruft, dann stellt sich die Frage, ob diese These durch andere Bildmodelle nicht besser repräsentiert würde. Ein Bewusstsein als denkende Immanenz ist als solches schließlich nicht auf dieselbe Weise perspektivisch verfasst wie ein anschauungsbezogenes

40 Vgl. Simon, Archéologie de la vision. L'optique, le corps, la peinture, 2003.

41 Vgl. dazu auch: Horn, "Das Experiment der Zentralperspektive. Filippo Brunelleschi und Réne Descartes«, 2000. 
Bewusstsein, denn Letzteres ist vor allem deshalb perspektivisch, weil es in einen Leib inkarniert ist, dessen in der Welt situierte Wahrnehmung perspektivisch funktioniert. Dagegen scheint der metaphysische Referenzraum eines reinen Bewusstseins ein Raum ohne Verzerrungen zu sein, ein im strengsten Sinn mathematischer Raum, der "nur gedacht werden kann«, wie Egenhofer es ausdrückt. ${ }^{42}$ Aber käme dieser Art von Raum nicht die axonometrische Darstellungsweise deutlich näher? Wäre nicht sie die Darstellungsweise, mit der ein Raum sichtbar wird, dessen Verhältnis zur Betrachterin so geartet ist, dass sich die Vorstellung eines ungebundenen Auges zumindest andeutet? ${ }^{43}$

Für die Tragweite von Sebastian Egenhofers Perspektivtheorie ist letztlich weniger entscheidend, ob der ursprüngliche Charakter der Perspektive tatsächlich ein metaphysischer ist, sondern vielmehr, dass die perspektivische Bildform auf transzendentale Fragen hinweist und mit einer Ideengeschichte verbunden werden kann. Das bedeutet, dass die Perspektive als potentielles Objekt zweier Gegenstandsbereiche funktioniert: Einerseits gehört sie zu den Anlagen materieller Bilder, wo sie als raumbildendes Mittel einer jeweils konkreten Darstellung fungiert; andererseits gehört sie dem Bereich der Philosophie an, wo sie mit fundamentalen Fragen des Bewusstseins, der Subjektivität und der Welterschließung verbunden ist. Die Beziehung dieser beiden Gegenstandsbereiche ist von Egenhofer als Homologie konzipiert, die sich ausgehend von der frühen Neuzeit historisch fortsetzt.

Auf der ideengeschichtlichen Seite zieht der Autor eine Linie vom neuzeitlichen Rationalismus, der die inkommensurable Rückseite der Erscheinungswelt metaphysisch bestimmt, hin zur kantischen Philosophie, wo das präsynthetische Konstituens der erscheinenden Welt noch als Noumenon oder Ding-an-sich postuliert wird. ${ }^{44}$ Schließlich wird dieses Präsynthetische, so Egenhofer, im neunzehnten und zwanzigsten Jahrhundert zunehmend als energetische Kraft begriffen, die den rezeptiven Körper affiziert.

42 Egenhofer, "Zu einer Topik der Bildkritik", 2011, S. 149.

43 Vgl. dazu auch: Scolari, Oblique Drawing. A History of Anti-Perspective, 2012. (Insbesondere seine Bemerkungen zu Plotin auf S. 16f.)

44 Egenhofer, "Zu einer Topik der Bildkritik«, 2011, S. 143 f. 
"Seit und mit dem neunzehnten Jahrhundert wird das, was Kant als die transzendentale Konstitution der Gegenständlichkeit aus dem 'Gewühl der Sinnesdaten begreift, dezidiert in szientifischen, biologischen und physikalischen Begriffen gedacht. Es ist die Zeit und die Arbeit der Nerven, die aus den weder hellen noch dunklen Schwingungen des `Lichts`, die das Auge affizieren, erst die Sichtbarkeit der Welt konstituiert. « ${ }^{45}$

Dieser physiologische Perspektivismus - zu seinen prominenten Vertretern im neunzehnten Jahrhundert gehört etwa Hermann von Helmholtz - findet nach Egenhofer in der Malerei der Moderne seine Entsprechung. Während die linearperspektivische Bildkritik den "genetische[n] Grund des Bildes und des Bildbewusstseins « ${ }^{46}$ als metaphysischen Grund vorstelle, sei dieser im Impressionismus als Energie konzipiert, die in Form von Schwingungen den menschlichen Nervenapparat affiziert. Die Fraktalisierung des Lichts in seine Spektralfarben, die der Impressionismus als bildnerisches Mittel einsetzt, sei in diesem Sinn eine Reflexion auf das präsynthetische Konstituens subjektiver Welterscheinung und müsse daher als historische Ausformung in einer Geschichte der genetischen Kritik des Bildes verortet werden. Diese setzt sich im zwanzigsten Jahrhundert fort, um in der modernistischen Malerei unter je unterschiedlichen historischen Bedingungen das Gewordensein des Bildes zu exponieren - etwa in Mondrians flächigen Kompositionen der drei Primärfarben, als essentielle Grundlagen jeder malerischer Darstellung (Abb. 5), oder in Pollocks Drip Paintings, die ihren gestisch und materiellen Herstellungsprozess ausstellen (Abb. 6). Auf diese Weise gelingt es Egenhofer, die "moderne Selbstreflexion des Mediums ${ }^{47}$ als Symptomatik einer geschichtlich sich transformierenden genetischen Kritik zu lesen, die ihren Ursprung in der Linearperspektive der Renaissance hat. Diese bildet gleichsam die Matrix einer Subjektivität - oder besser, von Subjektivität schlechthin -, deren perspektivisch verfasster Weltzugang die Prämisse einer sich in der Kunst historisch fortsetzenden Subjekt- und Ideologiekritik ist. 


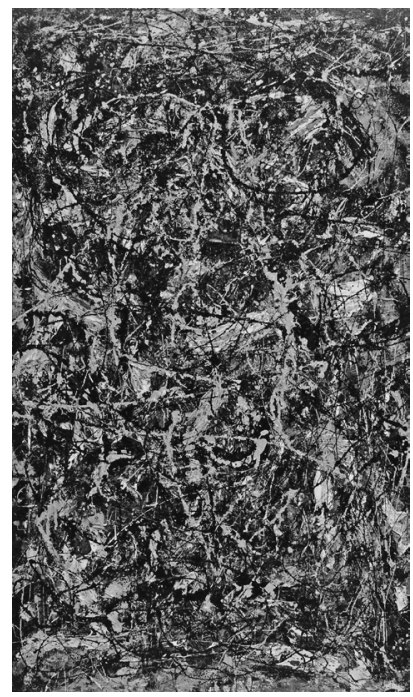

Abb. 6: Jackson Pollock, Full Fathom Five, 1947, Öl auf Leinwand mit Nägeln, Heftklammern, Knöpfen, Schlüssel, Münzen, Zigaretten, Streichhölzern.

Eine größere Tragweite und damit auch Bedeutung für die ästhetische Moderne kann man der Perspektive kaum zuschreiben. Die Perspektive, das legt die Lektüre dieses dichten Textes nahe, ist nicht nur das Modell eines Dispositivs mit subjektivierenden Effekten, sie ist auch das Modell einer reflexiven Kritik derselben Effekte, deren vielschichtige Dimensionen (Bildkritik, Subjektkritik, Ideologiekritik etc.) in der Moderne an Brisanz gewinnen und nicht etwa verlieren. Damit zeichnet sich ein ungewohntes Bild der Beziehung zwischen Perspektive und Moderne ab, zumal der Perspektive hier, anders als bei Bach, nicht eine dezidiert negative Rolle zukommt. Ihre Bedeutung erschöpft sich nicht darin, ein aus der frühen Neuzeit stammendes raumbildendes Mittel zu sein, dessen Funktionsweisen in der Moderne überwunden werden. Vielmehr dient sie als historisch gewachsenes Modell einer fundamentalen Selbstkritik des Bildes sowie des Subjekts, einer Selbstkritik, die wir für gewöhnlich als genuine Errungenschaft des neunzehnten und zwanzigsten Jahrhunderts begreifen. Die kritischen Kapazitäten der Perspektive sind so gesehen nicht bloß eine von der 
Moderne verschmähte Spielart der Selbstkritik, ${ }^{48}$ vielmehr ist die Perspektive die tieferliegende Grundlage der modernistischen Selbstkritik. Der Vorschlag, die Perspektive als Modell einer Bildund Subjektkritik zu verstehen, wirft dann ein neues Licht auf die Beziehung zwischen der Perspektive und der Moderne. Es reichte nicht mehr aus, sie als Objekt der Kritik zu begreifen, denn die Kritik wäre selbst ein Effekt der Perspektive. 


\section{Appositionen der Perspektive}

\section{Die Perspektive als...}

Angesichts der unzähligen Ausformungen und singulären Effekte der perspektivischen Darstellungsform sowie ihrer vielfältigen theoretischen Interpretationen stellt sich die Frage, ob eine aussagekräftige und zugleich adäquate Bestimmung der Perspektive überhaupt möglich ist. Da ein einheitlicher Begriff der Perspektive stets Gefahr läuft, den zahlreichen künstlerischen und theoretischen Funktionsweisen der Perspektive nicht gerecht zu werden, möchte ich im Folgenden eine Konzeption der Perspektive formulieren, welche gerade auf die Vielseitigkeit perspektivischer Phänomene in Praxis und Theorie zielt. Meine Ausgangslage bildet dabei die Konjunktion "als", mit der Panofsky die Perspektive im Titel seines berühmten Aufsatzes verbindet. Ich begreife diese Apposition im Titel der folgenreichsten modernen Perspektivtheorie als symptomatisches Phänomen für die Bedeutung der Perspektive in der Moderne. Die Funktionsweise der Perspektive, so meine These, muss appositional gedacht werden, d.h. durch einen Zusatz, der ihre jeweilige Bedeutung genauer bestimmt. Dieser appositionale Charakter der Perspektive ist ein Resultat ihrer Anschlussfähigkeit an ästhetische Praktiken und theoretische Diskurse. Es soll folglich nicht darum gehen, der Perspektive eine weitere Apposition hinzuzufügen, vielmehr möchte ich sie als ein Objekt denken, das in Kunst und Theorie auf unterschiedliche Weisen in Anspruch genommen, verhandelt und transformiert wird. Der moderne Charakter dieser Aneignungen und ihrer Dynamiken zeigt sich in deren Kritikalität, denn man wird der appositionalen Funktionsweise der Perspektive im Kontext der Moderne nicht gerecht, wenn man die Perspektive bloß als statisches Schema etwa für eine bestimmte Vorstellung von Subjektivität oder eines rationalen Raumbegriffs versteht. Die appositionale und dabei kritische Funktionsweise der Perspektive in der Moderne geht über eine 
derartige, wie James Elkins sagt, »fossilisierende« Stilllegung der Perspektive hinaus. ${ }^{1}$

Ein besonderes Merkmal der modernen Beanspruchungen der Perspektive liegt in deren Fähigkeit, die Grenzen von Gegenstandsbereichen zu überqueren. Seit den frühen Anfängen operiert die Perspektive etwa zwischen den Disziplinen der Malerei, der Architektur, der Geometrie sowie der Optik. Rekonstruiert man die appositionalen Funktionsweisen der Perspektive bloß innerhalb einer Disziplin, läuft man folglich Gefahr, eine ihrer bedeutendsten Eigenschaften aus dem Auge zu verlieren. Es gehört abermals zu Panofskys Leistung, dass er die grenzüberschreitenden Funktionen der Perspektive erkannt hat, und sein Vorschlag, die Perspektive als "symbolische Form« im Sinne Cassirers zu verstehen, hat gerade durch seine philosophisch unpräzise Darstellung den appositionalen Charakter der Perspektive in der Moderne noch hervorgehoben. ${ }^{2}$ Auch wenn ihr Charakter als Objekt von Übersetzungen zwischen verschiedenen Gegenstandsbereichen bereits in ihrer frühen Geschichte sichtbar wird, verstärkt er sich in der Moderne zusätzlich. Dass die Perspektive in diesen Übersetzungen oft nicht visualisiert wird und damit unsichtbar bleibt, ist ein Grund, warum ihre Bedeutung in der Moderne allzuoft unterschätzt wird.

Ein Grund, weshalb die Perspektive - in sichtbarer oder unsichtbarer Weise - immer wieder Eingang in theoretische und künstlerische Diskurse findet und diese Felder unter verschiedenen historischen, sozialen und intellektuellen Bedingungen miteinander in Beziehung setzt, liegt in ihrem formalisierten Charakter. Einem System von Punkten und Linien fällt es leicht, besetzbare Stellen zu schaffen und daher anschlussfähig zu sein für die gestalterische und theoretische Arbeit. Dazu kommt die Modalität der perspektivischen Bildillusion, mit der die ontologische Bestimmung der Bilderscheinung gleichsam neutralisiert wird. ${ }^{3}$ Diese fiktionale Modalität der Sichtbarkeit kann in unterschiedlichen Kontexten verschieden eingesetzt werden und schafft so breite Verwendungs-

1 Elkins, Poetics of Perspective, 1994, Kap. 6, S. 215-261.

2 Siehe etwa Iversen, "The Discourse of Perspective in the Twentieth Century. Panofsky, Damisch, Lacan«, 2005. Sowie den Sammelband: Schweizer u.a., Raum-Perspektive-Medium II, Wahrnehmung im Blick, 2010.

3 Siehe dazu meine Erläuterungen zur Neutralitätsmodifikation des Bildes bei Husserl in Kapitel II der vorliegenden Studie. 
sowie Interpretationsmöglichkeiten der perspektivischen Projektion. Dass starke Formalisierung von Beginn an zu den zentralen Qualitäten des perspektivischen Darstellungssystems gehört, wird etwa an der Tatsache deutlich, dass Albertis Perspektivtraktat sich zur Frage der Emissions- bzw. Intromissionstheorie indifferent verhält. ${ }^{4}$ Der Zentralstrahl, der die Spitze der Sehpyramide mit dem Zentrum ihrer Grundfläche verbindet, ist für Alberti zwar noch in der Tradition der Optik ein Strahl (radius), jedoch besitzt dieser keine eindeutige Bewegungs- oder Ausbreitungsrichtung. Während die Antike Optik des Aristoteles bzw. Euklids noch die Theorie einer Emission der Sehstrahlen vertrat und die Optik Alhazens eine Intromission derselben, beschreibt Alberti die Verbindung von Auge zum sichtbaren Objekt als bloß lineare Beziehung, die scheinbar nichts anderem dient als der geometrischen Regelhaftigkeit, auf der die perspektivische Darstellungsweise fußt. Sehstrahlen sind für ihn denn auch keine energetischen oder beseelten Extensionen des Betrachters, sondern bloß relationale, geometrisch kalkulierbare und an sich qualitätslose Beziehungen.

Dieser radikal formalisierte Charakter der Perspektive mutet dem Historiker schließlich größere Probleme zu, denn die mathematische Idealität, die sich mit diesem formalen System manifestiert, lässt sich nicht ohne weiteres auf überzeugende Weise historisieren. Dem Problem aus dem Weg zu gehen, indem man die Perspektive als bloße Konvention behandelt, scheint im Hinblick auf die mathematische Evidenz der perspektivischen Konstruktion eine unbefriedigende oder zumindest verkürzte Lösung. Inwiefern hat die Perspektive eine Geschichte? Und ist sie ausreichend begriffen als ein Objekt der Geschichte?

Das vorliegende Kapitel erarbeitet eine Konzeption der Perspektive, mit der die Aspekte der grenzüberquerenden Übersetzungen, der Formalisierung und der Historizität berücksichtigt werden. Diese drei Aspekte, die den appositionalen Charakter der Perspektive ausmachen, untersuche ich anhand des heuristischen Begriffs des »Modells«. In diesem Zusammenhang werde ich Hubert Damischs These von der Perspektive als Modell ernst nehmen,

4 Dazu: Simon, Archéologie de la vision. L'optique, le corps, la peinture, 2002, S. $167 f$. 
kritisieren und systematisch erweitern, um damit das Fortleben der Perspektive in der Moderne besser bestimmen zu können.

\section{Das Modell »Perspektive»}

Panofskys Beitrag zu einer modernen Theorie der Perspektive kann kaum überschätzt werden, denn indem er die Perspektive als "symbolische Form $\aleph^{5}$ diskutiert, befreit er sie von einer Lesart, die sich auf ihre bloß technischen, formalen oder stilistischen Errungenschaften konzentriert, um sie im größeren Zusammenhang - nicht nur historisch, sondern auch theoretisch - zu begreifen. Mit der Thematisierung der epistemologischen, ontologischen sowie kosmologischen Implikationen der Perspektive hat der Text schließlich mehr Fragen aufgeworfen als beantwortet, und er hat damit sozusagen die Grundlage dessen geschaffen, was man zu Recht als moderne Perspektivtheorie bezeichnen kann und weit über die Grenzen der Kunstgeschichte hinaus seine Wirkung bewiesen hat. Wenn Panofsky die Konjunktion "als" verwendet, um seine These von der Perspektive als einer symbolischen Form vorzustellen, dann zeigt sich darin nicht nur, dass er sich der Schwierigkeit einer eindeutigen Bestimmung der Perspektive bewusst war, sondern er formuliert mit diesem Titel implizit auch die fundamentale Frage, die jeder perspektivtheoretischen Unternehmung zugrunde liegt: Was ist die Perspektive?

Aus vielen Gründen lässt sich diese Frage nicht leicht beantworten. Die Probleme beginnen etwa mit dem eigentümlichen Status der Perspektive zwischen Idealität und Anschauung, d. h. zwischen der Allgemeinheit ihrer Gesetze und der Singularität der durch sie hergestellten Bildern. Die Perspektive scheint eine klare Trennung dieser beiden aus philosophischer Sicht dichotomen Bereiche in Frage zu stellen. Die Perspektive operiert unter mathematischen Prinzipien und generiert eine Evidenz, deren Kalkül ganz offensichtlich auf deduktiven Verfahren basiert. Zugleich produziert sie Bilder, sprich anschauungsbezogene Objekte, die unsere Sinnlichkeit und unsere ästhetische Empfindung adressieren. Diese 
Dichotomie zwischen dem Unsichtbaren und dem Sichtbaren, die der Wissenschaftshistoriker Ivins als "rationalization of sight" beschrieb, ${ }^{6}$ hängt mit einem weiteren Problem zusammen: dem genetischen Charakter der Perspektive. Die sichtbaren Produkte, die wir als perspektivische Darstellungen erkennen, sind Erzeugnisse eines Verfahrens, für das die Perspektive als solche steht. Damit macht sich eine Unterscheidung bemerkbar zwischen der Perspektive als genetischem Prozess und ihren singulären Ausformungen, d.h. den perspektivischen Bildern. ${ }^{7}$

Hubert Damisch hat vorgeschlagen, dieser Problematik mit dem Begriff des "Modells" zu begegnen. ${ }^{8}$ Ich werde im Folgenden den Modellcharakter der Perspektive genauer herausarbeiten und die Tragweite von Damischs Modellbegriff untersuchen. In letzter Instanz ziele ich dabei auf die Frage ab, ob die Konzeption der Perspektive als Modell helfen kann, ihr Fortleben in der Moderne und Gegenwart besser zu verstehen.

Damisch entwickelt seine Konzeption der Perspektive als Modell zunächst in einer linguistischen Tradition, die sich auf Ferdinand de Saussure beruft. Er bringt die Perspektive mit einem linguistischen "Äußerungsdispositiv" in Verbindung, das nach grammatischen Regeln verschiedene Elemente zu einer netzartigen und dabei subjektbezogenen Ordnung verbindet. ${ }^{9}$ Die syntaktische Ordnung der Sprache als einem syntagmatischen und paradigmatischen Äußerungsdispositiv setzt Damisch in Analogie zum perspektivischen Dispositiv. Als formaler Apparat organisiere die Perspektive analog der Sprache eine Aussage mittels Deklinationen und Konjugationen sowie durch die Positionierung eines Subjektes relativ zur Darstellung bzw. dem Dargestellten. Die deklinatorische Funktion der Perspektive erkennt Damisch in der Perspektivierung der dargestellten Figuren auf eine formalisierte Position hin, die im perspektivischen Bild als Punkt auftritt. Die

6 Ivins, On the Rationalization of Sight, 1973.

7 Dazu auch: Boehm, »Vom Medium zum Bild«, 1999.

8 Damisch, Der Ursprung der Perspektive, 2010, S. $18 \mathrm{ff}$.

9 Siehe dazu auch Kapitel II der vorliegenden Studie. 
perspektivisch geregelte Brechung der visuellen Erscheinung entspreche so gesehen der Flexion deklinierter Wörter. Die Gruppierung und Ordnung dargestellter Objekte "auf der Ebene " hingegen bringt Damisch mit der Konjugation sprachlicher Systeme in Verbindung, einer lateral organisierten Verbindung durch Flexion der Teilelemente.

Aus dieser - nicht detailliert ausgearbeiteten - Analogie folgert Damisch keineswegs, dass es sich bei der Perspektive im Grunde um ein Zeichensystem handelt, das im Medium der Sprache erklärbar ist, noch dass die Wahrnehmung perspektivischer Bilder in irgendeiner Weise als sprachliche Aktivität verstanden werden muss. Die Analogie bezieht sich vielmehr auf die dispositionale und strukturelle Ordnung einer Aussage, die sich im einen Fall sprachlich und im anderen Fall visuell ausdrückt - in beiden Fällen jedoch auf ein relationales, zur Aussage positioniertes Subjekt bezogen ist. Der Begriff des Paradigmas muss in diesem Sinn synonym und zugleich ergänzend zum Begriff des 'Modells`verstanden werden. Denn die 'paradigmatische Funktion der Perspektive meint einerseits deren im grammatischen Sinn begriffene Funktion, mittels Flexion von Bestandteilen eine Aussage zu bilden hier ist sie ein linguistisches Modell.

Andererseits bezieht sich Damisch auf die ideengeschichtliche Bedeutung des Begriffs Paradigma. In Berufung auf Thomas Kuhns Studie The Structure of Scientific Revolutions spricht Damisch vom Paradigma als einem »Modell wissenschaftlicher Praxis «, ${ }^{10}$ das sich am Beginn einer sich fortschreibenden Tradition manifestiert und damit die Axiome eines sich weiterentwickelnden epistemischen Systems bildet. Die Perspektive, so Damisch, sei in diesem Sinn als "Modell für das Denken ${ }^{111}$ zu verstehen und als solches ein Objekt, dass zwar einen historisch bestimmbaren Anfang hat - einen Anfang, der mit praktischen Fragen und Problemen der Darstellbarkeit von Raum auf einer Fläche zusammenhängt -, sich aber nicht in dieser anfänglichen Bedeutung erschöpft. Zum Modell geworden, wird es selbst zu einer Quelle von Theorie, die ihren anfänglich praktischen Gegenstandsbereich transzendiert. In einem Interview aus dem Jahr 1998 spricht Damisch davon, dass 
uns diejenigen Objekte auf eine besondere Weise in Anspruch nehmen, die er theoretisch`nennt: Das Modell wirft Fragen auf, die uns dazu nötigen, Theorie zu betreiben, und wenn wir uns auf diesen Anspruch des Modells einlassen, wird es theoretische "Effekte produzieren «. ${ }^{12}$ Das Modell tritt hier nicht nur als Paradigma bzw. Dispositiv auf, es ist auch ein theoretisches Objekt. Als solches generiert es nicht bloß Bilder, es provoziert auch Theorie, was Damisch dazu veranlasst zu konstatieren, man könne »in der Malerei denken «. ${ }^{13}$

Diese theoretische Dimension der Perspektive hängt nach Damisch vor allem mit ihrer Fähigkeit zusammen, ihre eigenen Funktionen zu reflektieren. Denn bei der Perspektive handle es sich um ein Dispositiv, das in der Lage sei, seine eigenen Funktionen, d.h. die paradigmatischen, syntagmatischen sowie subjektivierenden Effekte, als solche zu exponieren und damit ihrer Betrachterin eine Reflexion besonderer Art zu ermöglichen. ${ }^{\mathbf{1 4}}$

An dieser Stelle könnte der Eindruck entstehen, Damischs Perspektivtheorie sei letztlich ein dem Idealismus verpflichtetes Unternehmen, dass an einer tradierten Konzeption von Subjektivität und Reflexion festhält und die Perspektive als quasi-bürgerliche Form bestimmt, wie es die Theoretiker althusserscher Prägung schon vor einem halben Jahrhundert kritisiert haben. Jean-Louis Baudry erkannte in der Perspektive schließlich jene ideologische Codierung und Subjektivierungsweise, die sich in der Fotografie sowie dem Kino fortsetze. ${ }^{15}$ Damisch konzipiert die Perspektive dagegen als ein reflexives Dispositiv, das nicht einfach eine Affirmation von Subjektivität bedeutet, sondern vielmehr eine Subjektkritik mit formalen Mitteln leistet. ${ }^{16}$ In diesem Sinn liegt Christopher Wood falsch, wenn er Damischs Grundthese als kantisch beschreibt, denn Damischs Konzeption der Reflexion zielt gerade nicht auf eine Affirmation der subjektiven Erkenntnisvermögen

12 Bois u. a., "A Conversation with Hubert Damisch", 1998, S. 8.

13 Damisch, Der Ursprung der Perspektive, 2010, S. 440.

14 Ebd., S. 439ff. Zur Reflexivität von Bildern im Quattrocento vgl. zudem: Marin, Das Opake der Malerei. Zur Repräsentation im Quattrocento, 2004, S. 20f. sowie Kapitel III der vorliegenden Studie.

15 Baudry, "Ideological Effects of the Basic Cinematographic Apparatus", 1986, S. 41. Siehe dazu Kapitel VI der vorliegenden Studie.

16 Dazu siehe Kapitel II der vorliegenden Studie. 
durch Reflexion. ${ }^{17}$ Die Perspektive als Modell ist für den französischen Kunsthistoriker ausdrücklich ein "formaler Apparat", der eben nicht dem Humanismus verpflichtet ist. ${ }^{18}$

Die These, dass die Perspektive ein theoretisches Objekt ist, und die damit verbundene Idee eines Denkens in der Malerei wurde auch kritisiert, etwa von Isabelle Graw, die in Damischs Theorie eine Pseudoverlebendigung des Mediums Malerei erkennt. ${ }^{19}$ Sie kritisiert die "Stilisierung von Malerei zu einem Quasi-Subjekt«, weil damit jener »Wertbildungsprozess" begünstigt werde, mit der Malerei zum scheinbar belebten Objekt werde und damit ihre Warenförmigkeit verhülle. ${ }^{20}$ Dieser Kritik kann entgegnet werden, dass Damischs Konzeption eines Denkens in Malerei im Zusammenhang mit der Perspektive auf der Vorstellung beruht, dass es sich bei dieser um ein Modell, d.h. um einen idealen Gegenstand handelt. Einmal zum Modell geworden, ist die Perspektive weder identisch mit den durch sie konstruierten Bildern, noch beseelt sie diese gleich einem Fetisch. Man kann hinzufügen, dass ideale Objekte sich gerade dadurch auszeichnen, dass sie kein privates Eigentum sein können und sich folglich als Objekt des ökonomischen Handels sowie Besitzverhältnissen grundsätzlich entziehen.

Im Weiteren möchte ich zunächst den Versuch unternehmen, den Modellcharakter der Perspektive präziser zu erklären. Dazu beziehe ich mich auf die Überlegungen Bernd Mahrs, der die Voraussetzungen und Zusammenhänge von Modellen in einer allgemeinen Modelltheorie systematisiert und damit eine hervorragende Basis geschaffen hat, um über die Modellfunktionen der Perspektive nachzudenken. Mahr entwickelt seine Überlegungen ausgehend von der Beobachtung, dass Modellsein unmöglich auf Merkmale eines Objekts zurückgeführt werden kann, sondern allein durch Zuschreibung stattfindet.

17 Wood, "The Origin of Perspective by Hubert Damisch; Le Jugement de Pâris by Hubert Damisch«, 1995, S. 678.

18 Dazu etwa: Damisch, Der Ursprung der Perspektive, 2010, S. 71. bzw. S. 440.

19 Graw und Geimer, Über Malerei. Eine Diskussion, 2012. S. 34ff. und zuletzt: Graw, Die Liebe zur Malerei, 2017.

20 Graw und Geimer, Über Malerei. Eine Diskussion, 2012, S. 36. 
»Im Hinblick auf diese Erklärung [...] wird in jedem einzelnen Fall eines Modells der betrachtete Gegenstand durch das Urteil des Modellseins einer Konzeptualisierung unterworfen, die sein Modellsein bestimmt und beurteilt. « ${ }^{21}$

Modellsein heißt demnach als Modell aufgefasst werden, d.h. ein beliebiges Objekt kann als Modell in Anspruch genommen werden. Grundlegend an dieser Weise der Auffassung ist laut Mahr eine Kontextualisierung des Modells:

"Durch die Auffassung eines Gegenstandes als Modell steht dieser Gegenstand in einem Kontext, durch den er bestimmte Beziehungen zu anderen realen oder gedachten Entitäten hat, die seine Identität als Modell bestimmen. ${ }^{22}$

Dieser Kontext, der durch Intention dem modellgewordenen Objekt zugeordnet wird, bestehe allgemein aus einer »doppelten Orientierung«: Das Modell ist einerseits ein Modell von etwas und es ist andererseits ein Modell für etwas. Diese beiden Orientierungsrichtungen werden von Mahr weiter spezifiziert. Zum einen beschreibt er diese als Induktion, d.h. es werden Anforderungen an das Modell herangetragen, die aus den beobachteten Eigenschaften dessen, wovon es ein Modell ist, resultieren. Zum anderen spricht er von Deduktion zwischen dem Modell und jenem, wofür es ein Modell ist. Die gelingende Anwendung eines Modells sei in erster Linie abhängig vom Transport, mit welchem "etwas von dem, wovon es ein Modell ist, zu dem, wofür es ein Modell ist«, überträgt. ${ }^{23}$ Diese Übertragung kann aber Störungen unterliegen und so das Funktionieren des Modells beeinträchtigen, etwa wenn das Modell dem Gegenstandsbereich seiner Anwendung - also der Deduktion - als nicht angemessen beurteilt wird. ${ }^{24}$

Fasst man vor diesem Hintergrund die Perspektive ins Auge, erkennt man schnell die Evidenz von Mahrs Modellkonzeption. Die erste Richtung, das wovon, scheint im Hinblick auf die Perspektive

21 Mahr, "Ein Modell des Modellseins. Ein Beitrag zur Aufklärung des Modellbegriffs «, 2008, S. 199.

22 Ebd., S. 201.

23 Ebd., S. 211.

24 Ebd., S. 212. 
offensichtlich und vielseitig diskutiert. Erwin Panofsky hat pointiert davon gesprochen, dass die Perspektive als »adäquate Wiedergabe unseres Sehbildes" gelten möchte. Er hat aber auch die dabei "stillschweigend " gemachten Voraussetzungen problematisiert und auf die Bedingungen des Modells verwiesen: die »überaus kühne Abstraktion von der Wirklichkeit«, vom "tatsächlichen, subjektiven Seheindruck", die zur Homogenität und Unendlichkeit des perspektivisch konstruierten Raumes sowie dessen Monokularität führen..$^{25}$

Die Perspektive ist demnach ein Modell von der subjektiven visuellen Wahrnehmung, deren strukturelle Bedingungen sie unter gewissen (modellimpliziten) Voraussetzungen und in abstrahierter Weise aufnimmt. Auch wenn die Perspektive weder ein buchstäbliches Äquivalent des menschlichen Wahrnehmungsvorgangs ist noch alleinigen Anspruch auf Geltung verlangen kann, zeigt sich doch, dass sie als Modell auf gewisse Bedingungen der subjektiven Wahrnehmung rekurriert. ${ }^{26}$ Die Stärke der Modellkonzeption liegt u.a. darin, dass man mit ihr die Perspektive weder als eine entdeckte Wahrheit noch als eine bloße Konvention denken muss, sondern als eine modellhafte, d.h. durch Intention zugeschriebene, systematische Abstraktion und Idealisierung der Bedingungen menschlicher Wahrnehmung. Ob die Entstehung dieses Modells aus dem Glauben resultierte, es sei möglich, die menschliche Wahrnehmung exakt und vollständig zu systematisieren, ist zweifelhaft. Das bereits für die Quattrocento-Perspektivisten belegte Bewusstsein um die Grenzen und Probleme der perspektivischen Konstruktion spricht genauso dagegen ${ }^{27}$ wie die zahlreichen Abweichungen vom perspektivischen Verfahren in ihren Bildern. ${ }^{28}$

Damit berühre ich aber bereits einen anderen Aspekt des Modells, denn während ausreichend klar wurde, dass die Perspektive ein Modell von der visuellen Wahrnehmung ist, scheint dessen andere Richtung, das wofür, weniger eindeutig festzustehen.

25 Panofsky, "Die Perspektive als 'symbolische Form«", 1974, S. 101.

26 Vgl. Kemp, The Science of Art. Optical Themes in Western Art from Brunelleschi to Seurat, 1990, S. 337.

27 Chastel, Leonardo da Vinci, Sämtliche Gemälde und die Schriften zur Malerei, 1990, S. 241ff.

28 Dazu: Elkins, Poetics of Perspective, 1994, S. $220 \mathrm{ff}$. 
Zunächst liegt es nahe, die Perspektive aus ihrem ursprünglichen Fragehorizont zu begreifen, der nichts anderes betrifft als die Möglichkeit der Darstellung von Raum auf einer Fläche. Das Modell, das auf Bedingungen der subjektiven Wahrnehmung basiert, bietet vor allem einen systematisch strukturierten Möglichkeitshorizont für eine geregelte visuelle Darstellung. Sybille Krämer formuliert dies so: "Die Gesetze, wie wir Objekte sehen, werden also umgebildet zu Regeln, wie wir Objekte darzustellen haben. ${ }^{29}$ Richtig verstanden bedeutet das nicht, dass perspektivische Bilder Modelle sind, sondern sie sind das Ergebnis eines regelhaften Darstellungsverfahrens, das wir Perspektive nennen. Das Perspektivmodell ist selbst keine Darstellung, sondern ein System, das Darstellung auf gewisse Weise und unter gewissen Bedingungen ermöglicht. ${ }^{30}$ Diese Weisen und Bedingungen der Darstellung basieren nicht ausschließlich auf vorhandenen Strukturen und Formen des Dargestellten, sondern werden wesentlich vom Modell erzeugt. Diese generative Funktion verweist auf die Vorrangstellung des Perspektivmodells gegenüber der singulären perspektivischen Darstellung. Die Perspektive als Modell ist selbst ein ideales Objekt, das aber unmittelbaren Einfluss auf die singuläre Gestalt des perspektivisch Dargestellten ausübt und folglich als Modell für die bildliche Formgenese fungiert.

Dass der Transferfunktion der Perspektive einerseits als Modell von der visuellen Wahrnehmung und andererseits - was nicht das gleiche ist - als Modell für die bildliche Formgenese in unterschiedlichen Kontexten und je nach Intentionen der Anwendung andere Bedeutung zukommen kann, zeigen etwa wissenschaftshistorische Überlegungen. Bruno Latour betont ausdrücklich den Transportcharakter der Perspektive und folgt William Ivins darin, dass die Perspektive die Möglichkeit bietet, die stabilen Eigenschaften eines Objekts zu erhalten und zugleich so zu transformieren, dass es von verschiedenen Blickwinkeln aus sichtbar werden kann. ${ }^{31}$ Zum Erfolg der Perspektive beigetragen hat nach Latour der Umstand, dass die zweidimensionale Fixierung dieser Transformation eine weitere Bewegung im Raum ermöglicht, denn die

29 Krämer, »Vom Trugbild zum Topos. Über fiktive Realitäten«, 1995, S. 131.

30 Vgl. dazu auch: Boehm, »Vom Medium zum Bild«, 1999, S. 171f.

31 Bruno Latour, »Visualisation and Cognition, Drawing Things Together«, 1986. 
perspektivische Inskription auf einem flachen Träger ist als solche ein mobiles Objekt, das im Raum bewegt werden und damit abwesende Objekte repräsentieren und operativ zur Disposition stellen kann. Entgegen der verbreiteten modernen Rede von der Statik und Stilllegung perspektivischer Darstellungen zeigt sich in diesem Zusammenhang, dass Bewegung auf mehreren Ebenen ein wichtiges Moment der Perspektive ist. ${ }^{32}$ Die Bewegung eines dargestellten Objekts in jede beliebige Lage einerseits sowie die Bewegung dieser Darstellung im geografischen, kulturellen oder politischen Raum müssen im weitesten Sinn zu den Übertragungsleistungen des Modells Perspektive gezählt werden. Gerade im Hinblick auf den globalen Erfolg der Perspektive im nicht-künstlerischen Kontext scheinen diese Übertragungsleistungen eine zentrale Rolle zu spielen. Man denke etwa an die Bedeutung des dreidimensionalen Renderns in der Computersimulation. ${ }^{33}$ Bedenkt man zudem die Rolle der Fotografie, die mehrheitlich perspektivische Bilder generiert, ${ }^{34}$ scheinen technologische Faktoren ausschlaggebend für ihre weltweite Verbreitung: ${ }^{35}$

In der künstlerischen Bildgebung sind weitere Umstände mitentscheidend für den Erfolg der Perspektive. Der generative Charakter, ich habe es bereits erwähnt, ermöglicht es, nahezu jede erdenkliche Form und jeden vorstellbaren Gegenstand mit den Mitteln der Perspektive zu konstruieren und darzustellen. Ich sage

32 Etwa Gottfried Boehm betont den stillstellenden Charakter perspektivischer Darstellungen: »Das Perspektivbild tendiert dahin, sie [die Zeithaftigkeit] im doppelten Sinne des Wortes saufzuheben projektiven Aktes formt es eine Welt, in der die Koordinaten des Horizontes und der senkrecht aufstrebenden Bildfläche stets rektangulär miteinander verknüpft erscheinen, das heißt aber, zum Stehen kommen. Eine gefestigtere und das heißt zeitenthobenere Konstellation als die rechtwinklige gibt es unter Anschauungsbedingungen nicht." Boehm, "Die Wiedergewinnung der ikonischen Zeit«, 2007, S. 101.

33 Dazu: Hinterwaldner, Das systemische Bild. Ikonizität im Rahmen computerbasierter Echtzeitsimulationen, 2010.

34 Dazu: Valaouris, Perspektive in der Fotografie. Studien zur Naturalisierung des Kamerabildes, 2018.

35 Eine durch Technologie verbreitete Verwendung der Perspektive schließt deren kulturimperialistische Rolle weder aus, noch muss sie zwingend mit ihr zusammenhängen. Massimo Scolari beschreibt, wie die jesuitische Missionierung in China seit dem sechzehnten Jahrhundert versuchte, perspektivische Darstellungen einzusetzen, diese von der lokalen Bevölkerung jedoch als durchwegs »falsch"empfunden wurden und sich daher nicht durchsetzen konnten. Scolari, Oblique Drawing. A History of Anti-Perspective, 2012. 
bewusst `mit den Mitteln der Perspektive`, um nicht den Eindruck zu erwecken, die Perspektive bringe selbst, gleichsam einer Imaginationskraft, Objekte oder gar Vorstellungen hervor. Vielmehr sind es ihre Regeln, die in einer jeweils spezifischen Anwendung und unter bestimmten Bedingungen bedeutsame Formen schaffen. Nur weil diese Regeln einem Modell entspringen, das seinerseits von der visuellen Wahrnehmung handelt, bedeutet das nicht, dass ihre formgenetische Funktion auf bloße Wahrnehmungsobjekte beschränkt bleibt. Man kann also jede erdenkliche Form und jeden vorstellbaren Körper im Raum perspektivisch konstruieren. Mit anderen Worten, man kann mittels eines Modells, das seinem Ursprung nach ganz der visuellen Wahrnehmung verpflichtet ist, nie gesehene Gegenstände darstellen.

Genauso wenig, wie die Formgenesen mittels des Perspektivmodells auf Objekte der Wahrnehmung beschränkt sind, beschränken ihre Regeln die künstlerische Bildproduktion im streng normativen Sinn. Auch wenn das perspektivische Darstellungsverfahren auf klaren Regeln basiert, spielen diese für die künstlerische Anwendung letztlich nicht mehr als eine regulative Rolle. Die Implementierung des Modells in der Praxis erlaubt Abweichungen, Fluktuationen und Modifikationen. So ist es denn nicht erstaunlich, dass James Elkins in seinen überzeugenden Analysen der Quattrocentomalerei zu dem Schluss kommt, dass sich dort kaum ein durchgängig korrekt nach perspektivischen Regeln konstruiertes Bild finden lässt. Von Beginn an war die künstlerische Praxis stärker an den Möglichkeiten der Variabilität und Modifikation, also an einer Pluralität der Perspektive interessiert als an deren Einheit. ${ }^{36}$ Eine Einheitlichkeit der Perspektive, so Elkins, sei erst in der Moderne, also retrospektiv, proklamiert worden und habe zu einer verkürzten und statischen Vorstellung der Perspektive geführt - eine »Fossilisierung“, mit dem selbstdefinitorischen Ziel der modernen Zerschlagung der Perspektive. ${ }^{37}$

Die Komplexität des Sachverhalts ist mit der Beschreibung der Perspektive als Modell von der Wahrnehmung und zugleich als Modell für die bildliche Formgenese jedoch noch nicht erfasst.

37 Elkins, Poetics of Perspective, 1996, Kap. 3, S. $81 \mathrm{ff}$. 
Denn die Übertragungsleistung eines Modells wie der Perspektive, liegt nicht bloß in der einseitigen Bewegung von einem Gegenstandsbereich (Wahrnehmung) hin zu einem anderen Gegenstandsbereich (Bildproduktion). Die Perspektive zeigt sich in dieser Hinsicht als komplizierter Fall eines Modells, denn sie impliziert zugleich eine Übertragungsleistung, die sich in die entgegenlaufende Richtung bewegt. Denn genauso wie die Perspektive die Wahrnehmung zur Ausgangslage ihrer Bildtheorie nimmt, macht sie das Bild zur Ausgangslage ihrer Theorie der Wahrnehmung. Joel Snyder hat darauf hingewiesen, dass erst im Zusammenhang mit der Perspektive die Idee eines bildförmigen Sehens entstanden ist und erst damit die Vorstellung einer Äquivalenz zwischen wahrgenommenem und artifiziellem Bild möglich wurde. ${ }^{38}$ Daraus folgt, dass man die induktiv-deduktive Richtung des Modells als eine reziproke Beziehung zwischen dem Sehen und dem Bild verstehen muss, denn die Perspektive ist auch ein Modell von der bildlichen Formgenese für die visuelle Wahrnehmung.

Es zeigt sich, dass Praktiken, Institutionen und ihre Akteure konstitutiv sind für das Funktionieren der Perspektive als Modell. Damit wird klar, dass die jeweilige Intention, mit der sie mit einem Gegenstandsbereich auf induktive bzw. deduktive Weise verknüpft wird, unter bestimmten historischen Bedingungen und Vorzeichen stattfindet. Dass ihre Bedeutung als Modell von der Wahrnehmung seit dem neunzehnten Jahrhundert zunehmend in Frage gestellt wird und heute einen historischen Charakter hat, liegt auf der Hand. Es gibt jedoch mindestens drei Gründe, warum der Perspektive in der Moderne mehr als nur eine historische Bedeutung zukommt. Erstens kann man annehmen, dass ihre Rolle als Objekt der Kritik ein wichtiger Katalysator für die modernen Innovationen der Bildpraxis war. Zweitens erlaubt die Inanspruchnahme des Perspektivmodells, wie bereits erwähnt, Modifikationen und Erweiterungen - elaborierte künstlerische Arbeit ist dann Arbeit am Modell selbst. ${ }^{39}$ Drittens ist ein potentes Modell wie die Perspektive in der

39 Siehe dazu Kapitel V der vorliegenden Studie. 
Lage, seine präskriptive Richtung (Modell für) auf verschiedene Gebiete auszuweiten, womit sich ihre Bedeutung für die Moderne nicht in der bildgenetischen Funktion erschöpft. ${ }^{40}$ Letzteres ist von besonderem Interesse, weil die Funktion der Perspektive als einem theoretischen Objekt wesentlich mit dieser Übertragbarkeit verbunden ist. Die Tatsache, dass ihre Modellfunktion nicht auf die Wahrnehmung und Bildgestaltung beschränkt bleibt, sondern dass sie diese beiden Gegenstandsbereiche mit philosophischen Fragen verbindet, beschert der Perspektive ihr besonderes Schicksal in der Moderne. Panofskys Text macht dies besonders deutlich, formuliert er seine philosophische Wertschätzung der Perspektive doch zu einem Zeitpunkt, in dem die Perspektive in der avancierten künstlerischen Praxis als Gestaltungsmittel schon seit geraumer Zeit nicht mehr dieselbe Rolle spielt wie noch in der Malerei vor dem neunzehnten Jahrhundert. Dass Panofsky ausgerechnet zu diesem historischen Zeitpunkt die Perspektive als Modell der Weltanschauung, der subjektiven Wahrnehmung sowie der transzendentalphilosophischen Disposition von Subjekt und Objekt diskutiert, ${ }^{41}$ zeigt nicht nur die Modellfunktion der Perspektive für die Philosophie, sondern auch die Bedeutung der Perspektive in der Moderne als einem theoretischen Objekt. Bekanntlich wird sich in der Nachfolge von Panofskys Aufsatz die Perspektive als beliebter Gegenstand der philosophischen Auseinandersetzung bewähren und Autoren verschiedenster Provenienz beschäftigen, zu denen Heidegger, Merleau-Ponty, Jean-François Lyotard, Jacques Lacan oder Michel Foucault zählen. Das Charakteristikum dieser perspektivtheoretischen Auseinandersetzungen des zwanzigsten Jahrhunderts liegt in ihrer ausgesprochen kritischen Haltung gegenüber Perspektivität, und genau das ist es, was sie von den Perspektivisten der Neuzeit unterscheidet. Für Leibniz etwa ist der Perspektivismus weder mit Problemen des Relativismus noch mit einer Distanzierung und Isolation des Gesichtspunktes verbunden. Dies wird deutlich an seiner Verwendung der Perspektive als Modell für die Monade, wo er deren monistische Konzeption veranschaulicht:

40 Mahr betont die Wichtigkeit dieser Übertragbarkeit und nennt sie Überbrückung von "Businessgrenzen«. Mahr, "Ein Modell des Modellseins. Ein Beitrag zur Aufklärung des Modellbegriffs«, 2008, S. $212 f$.

41 Siehe dazu auch Kapitel I der vorliegenden Studie. 
"Und wie die selbe Stadt von unterschiedlichen Seiten betrachtet als eine andere erscheint und wie perspektivisch vervielfältigt ist, so geschieht es auch durch die unendliche Vielheit der einfachen Substanzen, dass es ebenso viele unterschiedliche Universen gibt, die gleichwohl nur die Perspektiven eines einzigen sind, je nach verschiedenen Gesichtspunkten [points de veüe] jeder Monade.«42

Die Monade als eine »einfache Substanz« besitzt keine Teile, beinhaltet jedoch eine unendliche Vielheit, die perspektivisch gedacht wird. Da Leibniz' monistische Konzeption der Monade und ihrer Perspektivität die Dichotomien der traditionellen Metaphysik wie Substanz versus Akzidenz, res extensa versus res cogitans, aber auch Subjekt versus Objekt weitgehend auflöst, stellen sich ihm die modernen Probleme einer in unzählige subjektive Perspektiven zerfallenden Welt genauso wenig wie das Problem einer korrekten Vermittlung zwischen Subjekt und Welt. ${ }^{43}$

Dass die Krise der Perspektive ein Phänomen des modernen Denkens ist, hat in den letzten Jahren neben James Elkins auch James Conant behandelt. ${ }^{44}$ Während sich Elkins vor allem mit den historischen und technischen Variationen der perspektivischen Projektionsverfahren beschäftigt, widmet sich Conant ihrer philosophischen Bedeutung. Er ist der Auffassung, die zentralen Merkmale der Perspektive in der Renaissance seien im neunzehnten und zwanzigsten Jahrhundert geradezu negiert worden, und er erläutert dies anhand von fünf Momenten: War man (1.) in der Renaissance der Auffassung, die perspektivische Ansicht einer Sache könne problemlos geändert werden, ist sie in der Moderne nicht ohne weiteres veränderbar, womit sich eine subjektive Beschränkung der Perspektive abzeichnet. In der Frühen Neuzeit ist man (2.) davon ausgegangen, dass die Perspektive die Sicht auf eine Sache ermöglicht - sie ist gleichsam durchlässig auf die Welt. Dagegen erkennt die moderne Auffassung in der Perspektive ein Diktum, das die Sache unüberwindbar verstellt. Weiter steht in der anfänglichen Konzeption (3.) jeder perspektivische Standpunkt in

42 Leibniz, Monadologie, 2002, S. 135.

43 Siehe dazu auch die $\S 7$ und $\S 13$ von Leibniz' Monadologie, ebd., S. 111f. bzw. S. 115. Vgl. dazu auch: Deleuze, Die Falte. Leibniz und der Barock, 2000, S. 37.

44 Elkins, Poetics of Perspective, 1996, bzw. Conant, Friedrich Nietzsche. Perfektionismus \& Perspektivismus, 2014. 
systematischer und kongruenter Weise zu allen anderen Standpunkten, während diese Beziehungen in der Moderne gekappt werden, wodurch jeder Standpunkt im epistemischen Sinn isoliert wird. Zugleich wird in der Moderne (4.) die Identität des in der Vielheit von Perspektiven erscheinenden Gegenstands in Frage gestellt und (5.) wird der Pluralität von Perspektiven ihre systematische, d.h. zusammenhängende Erkenntnisfunktion abgesprochen, wodurch jeder perspektivische Standpunkt gleichsam gegen andere abgeriegelt und totalisiert wird. ${ }^{45}$

Conant bezeichnet diese zunehmend kritische Auffassung der Perspektive als modische Ausprägung und wirft schließlich die Frage auf, wie es zu dieser Neuauslegung der Perspektive kommen konnte. ${ }^{46}$ Seine Antwort liegt darin zu sagen, dass der Begriff der Perspektive eine Erweiterung erfahren hat, mit der er Stück für Stück auf andere, seiner ursprünglichen Bedeutung fremden Zusammenhänge vergrößert wurde. Diese Erweiterung greift zunächst auf Aspekte der Erscheinungsweise von Dingen aus, die im anfänglichen Sinn nicht abhängig von der Perspektive waren. Conant zeigt auf, dass die Perspektive einst nur die Bedingungen der räumlichen Erscheinungsweisen betraf, was dann auf andere Aspekte wie Farbe, aber auch nicht-visuelle Qualitäten ausgedehnt wurde. In einem zweiten Schritt sei der Begriff schließlich aus dem Bereich der Wahrnehmung entgrenzt worden und auf die im weitesten Sinne kognitive Welterschließung erweitert worden. Eine Perspektive einnehmen bedeutet jetzt nicht mehr zwingend ein Objekt wahrnehmen, sondern kann auch das Nachdenken über einen Sachverhalt meinen. Conant beschreibt eine weitere, dritte Erweiterung des Begriffs, mit der dieser mit den Bedingungen subjektiver Welterschließung schlechthin verbunden wird. Die Perspektive wird hier zur Begrenzung der subjektiven Beziehung zur Erscheinungswelt und dem damit verbundenen Denken, was Conant dazu veranlasst, hier von einem »Pseudokantianismus« zu sprechen ${ }^{47}$ Perspektivität wird damit zum Signum eines Subjektivismus, der eine an-sich-seiende Welt bloß noch postulieren kann. Die vierte und nach Conant letzte Erweiterung der Perspektive 
beschreibt dann lediglich noch eine Zuspitzung dieses Subjektivismus in quasi neukantianischer Weise, denn sie gibt das Postulat einer jenseits der perspektivischen Erscheinung seienden Welt auf, womit die subjektphilosophische Bedeutung der Perspektive gleichsam ihren Höhepunkt erreicht.

Conants scharfsinnige Analyse der modernen Mutationsgeschichte der Perspektive wirft jedoch auch Fragen auf. Erstens ist nicht ohne weiteres einsichtig, dass es sich bei den vier von Conant beschriebenen Schritten jeweils um Erweiterungen handelt. Die Stadien drei und vier scheinen vielmehr eine Verengung des Begriffs anzudeuten, wird dessen Bedeutung dabei doch schrittweise von der sehr allgemeinen zweiten Auslegung - Conant verhandelt sie als Realismus der verborgenen Welt $\star^{48}$ - auf eine jeweils spezifische subjektphilosophische Ausformung eingeengt. In diesem Sinne scheint es mir angebracht, von einer Übertragung oder Verschiebung der Bedeutung des Begriffs "Perspektive« zu sprechen und weniger von einer `Ausdehnung: bzw. 'Erweiterung: wie Conant. Die Begrifflichkeiten der 'Ausdehnung und 'Erweiterung« mögen zwar die philosophische Tragweite der jeweiligen Konzeption von Perspektivismus beschreiben - die vierte, aus subjektphilosophischer Sicht radikalste Position nennt Conant deshalb auch "antirealistischen Perspektivismus" -, mir scheint jedoch, dass diese aus philosophischer Sicht schwerwiegenden Konsequenzen nicht notwendigerweise mit einer allgemeinen Ausdehnung des Wortes "Perspektive" einhergehen. Die philosophische Tragweite müsste vielmehr noch deutlicher von der semantischen Tragweite unterschieden werden, zumal Conant explizit die "Erweiterung des Begriffs" diskutiert. ${ }^{49}$

Damit komme ich zu meinem eigentlichen Punkt: Obschon Conant die philosophischen Probleme des Perspektivismus präzise analysiert, verhandelt er die Erweiterungen der Perspektive letztlich als eine Metaphorisierung. ${ }^{50}$ Ich zweifle jedoch daran, ob das Konzept der Metapher geeignet ist, die beschriebene Erweiterung und philosophische Verwendung angemessen zu erfassen, 
erschöpft sich diese doch nicht bloß in einerveränderten Semantik. Conant schreibt an einer Stelle:

"Was wir hier vor uns haben, ist ein Wort [Perspektive] auf der Suche nach einer Bedeutung - ein Wort, das in einer Reihe von Äußerungen eines Sprechers vorkommt, der das Wort 'Perspektive weiterhin benutzen möchte, obwohl alle Verbindungen mit seiner ursprünglichen Grammatik nacheinander und allmählich gekappt worden sind. $\aleph^{51}$

Ist die Frage nach der Bedeutung der Perspektive lediglich die Frage nach der Bedeutung eines Wortes? Conant setzt den Fokus letztlich auf die Inkongruenzen, die sich in den Erweiterungen der Perspektive abzeichnen. Diese Betonung der Brüche tendiert dazu, die kontinuierlichen, gleichsam axiomatischen Strukturen der Perspektive aus den Augen zu verlieren. Denn bei der von Conant beschriebenen Übertragungen der Perspektive handelt es sich doch auch um eine in weiten Teilen gelingende Übertragung formalisierter Strukturen von der visuellen Wahrnehmung in den Bereich der Philosophie. Diese Übertragung wirft zwar auch semantische Fragen auf, im Kern betrifft sie jedoch das, was ich ihre Modellfunktion nenne: eine Übertragung von Eigenschaften eines Gegenstandsbereichs in einen anderen Gegenstandsbereich. Das bedeutet nichts anderes, als die visuelle Wahrnehmung, wovon die Perspektive ein Modell ist, mit dem philosophischen Denken, wofür sie ein Modell ist, in Beziehung zu setzen.

Die Modellleistung der Perspektive für die Philosophie liegt also darin, dass sie das Denken mit den Gegenstandsbereichen der visuellen Wahrnehmung sowie der bildlichen Formgenese verbindet, womit sich eine Gruppe von Beziehungen abzeichnet, die sich als Dreieck darstellen lässt und gleichsam die Konstellation beschreibt, innerhalb der die Kritik der Perspektive stattfindet. Ich habe bereits erwähnt, dass die vom Perspektivmodell ermöglichten Beziehungen zwischen diesen Gebieten reziprok funktionieren, insofern sie sich wechselseitig beeinflussen. Dass 
diese Übertragung jeweils mit bestimmten Intentionen und unter bestimmten Bedingungen geschieht, ist genauso deutlich geworden wie der Umstand, dass sich erst mit ihr die jeweilige Bedeutung des Modells ausbildet, eine Bedeutung, die vom ursprünglichen Sinn innerhalb des vorherigen Gegenstandsbereichs abweichen kann, ohne diesen vollständig zu kappen, wie Conant es formuliert. So gesehen scheint es fraglich, ob die Begriffe ,Übertragung', 'Transfer oder `Transport` die Modellfunktion angemessen beschreiben . Auch wissenschaftshistorische Projekte wie Robert Brains Studie zur Bedeutung der physiologischen Techniken und Visualisierungen für die moderne Kunst beschreiben den Austausch zwischen Kunst und Wissenschaft als "Transfer.$^{52}$ Das scheint mir deshalb problematisch, weil der Begriff erstens eine unidirektionale Richtung nahelegt und damit der tatsächlichen Wechselwirkung nicht gerecht wird, und zweitens eine gleichsam neutrale Übertragung suggeriert, womit er den kritischen Wesenszug der Übertragungen ignoriert. Daher halte ich es für angemessen, von einer kritischen Übersetzungsleistung zwischen verschiedenen Gegenstandsbereichen zu sprechen. Diese findet beispielsweise dann statt, wenn Duchamp die Perspektive als Modell für seine topologische Ontologie von der vierten Dimension einsetzt, oder Claes Oldenburg die Perspektive gegen ihren anfänglichen Sinn verwendet, um die realräumlichen Objekte seines Bedroom Ensemble zu perspektivieren..$^{53}$ Aber auch in umgekehrter Richtung, d.h. vom Bereich der Kunst hin zum Bereich der Philosophie, leistet das Perspektivmodell eine kritische und transformatorische Übersetzung, die etwa deutlich wird an Jean-François Lyotards Interpretation des Bedroom Ensemble als Modell einer kapitalistischen Ontologie oder an Jean Baudrys Auslegung der Perspektive als Modell einer ideologischen Subjektivierung. ${ }^{54}$

Die Untersuchung und Erweiterung des Modellbegriffs im Anschluss an Damisch hat gezeigt, dass die Konzeption der Perspektive als einem Modell geeignet ist, um ihren (oben angesprochenen) appositionalen Charakter genauer zu beschreiben. Die Gründe dafür lassen sich folgendermaßen zusammenfassen: In

52 Brain, The Pulse of Modernism, 2015, S. XVI, S. XXVII sowie S. XXX.

53 Siehe dazu auch Kapitel IV bzw. V der vorliegenden Studie.

54 Siehe dazu auch Kapitel V der vorliegenden Studie. 
der Modellkonzeption kann die Perspektive (1.) als ideale Größe verstanden werden, wobei zugleich ihre formgenetische Funktion in der Bildgestaltung erklärbar ist. Als Modell muss die Perspektive nicht identisch sein mit den singulären Darstellungen, die mit ihr erzeugt werden. Das Modell ist vielmehr ein generisches System, das Darstellung auf eine gewisse Weise und unter gewissen Bedingungen ermöglicht. Das Perspektivmodell ist so gesehen ein intelligibles Objekt, das zwar einen immanenten Gegenstandsbezug aufweist - sie ist ein Modell für die bildliche Formgenese von Objekten -, selbst aber nicht zur Anschauung kommt. Die Modellkonzeption erfasst (2.) weiter nicht nur den Doppelcharakter der Perspektive als Objekt der theoretischen und gestalterischen bzw. künstlerischen Auseinandersetzung, sie ist darüber hinaus in der Lage, die Rolle der Perspektive als bilaterale und zugleich transformative Übersetzerin zwischen diesen Bereichen zu erklären. Damit verbunden kann (3.) ihre Kritik und Neuverhandlung erklärt werden. Zum einen ist ihre Rolle in der gestalterischen Formgenese regulativ und erlaubt Abweichungen, Fluktuationen und Modifikationen. Zum anderen erschöpft sich ihre Bedeutung für die künstlerische Arbeit nicht in der bloßen Applikation des Modells als dessen bloße Aktualisierung. Elaborierte künstlerische Arbeit kann vielmehr als Arbeit mit und am Modell ausgewiesen und untersucht werden. Letztlich zeigt die Modellkonzeption der Perspektive (4.) die kontextuellen Bedingungen ihrer Bedeutungszuschreibung, denn es bedarf Akteuren, Praktiken und Rezipienten, oder, formaler gesprochen, intentionaler Bezugnahmen, mit denen die Appositionen und damit die Bedeutungen der Perspektive konstituiert werden. Diese Kontextualität sehe ich im Zusammenhang mit der zuvor erläuterten Neutralität, die Husserl in Hinblick auf bildlicher Darstellung beschreibt. ${ }^{55}$ Die Perspektive als Modell zu begreifen vereinfacht es (5.) zugleich, sie mit einer Pluralität von Modellen in Beziehung zu setzen. Ihr Modellcharakter impliziert, dass sie ein Modell unter vielen ist, und vereinfacht die wertneutrale Untersuchung und Differenzierung. 


\section{Zur Geschichtlichkeit der Perspektive}

Die Moderne schreibt die Geschichte der Perspektive in der Regel als eine Geschichte vom Untergang bzw. von Brüchen. Von der holländischen Malerei des siebzehnten Jahrhunderts, in der sich ein erster sanfter Bruch abzeichnet, ${ }^{56}$ über den Barock mit seiner zur Desorientierung tendierenden Raumordnung bis zur Physiologie des neunzehnten Jahrhunderts ${ }^{57}$ und der Malerei der klassischen Moderne ${ }^{58}$ kann man die Diskontinuitäten in der Bildraumgestaltung nachzeichnen. Eine derartige Geschichte suggeriert zwar in erster Linie einen zunehmenden Bedeutungsverlust der Perspektive; indem sie diese aber zum zentralen Gegenstand nimmt, affirmiert sie zugleich die axiomatische Bedeutung der Perspektive. Das Narrativ vom Ende der Perspektive festigt paradoxerweise ihre Wirksamkeit, denn in ihr manifestiert sich zugleich die kontinuierliche Virulenz des vermeintlich Negierten.

Wer eine Geschichte der Perspektive als eine Geschichte von Bildern schreibt, wird aber auch der Schwierigkeit begegnen, dass er oder sie die perspektivischen Erzeugnisse auf sinnvolle Weise mit dem ihnen zugrunde liegenden Modell in Verbindung bringen muss. Was kann die lange Reihe an perspektivisch hergestellten Produkten aussagen über das Verfahren und das Modell, das sie hervorgebracht haben, zumal eine emanatistische und in diesem Sinn metaphysische Bestimmung den Historiker nicht zu befriedigen vermag?

Auf der anderen Seite haben die philosophischen Interpreten der Perspektive ein anderes Problem, wenn sie deren epistemologische bzw. kosmologische Tragfähigkeit unterstreichen und sie damit als Teil der Philosophiegeschichte behandeln. Wenn die Perspektive eine Philosophie impliziert, die das Denken nachhaltig verändert hat, auf welche Weise kann sie dann historisiert werden? Anders formuliert: Kann ein Objekt in der Geschichte verordnet werden, wenn es eben diese Geschichte selbst mitschreibt? Dieser symptomatischen Problematik unterliegt etwa Panofskys

Alpers, Kunst als Beschreibung. Holländische Malerei des 17. Jahrhunderts, 1985.

57 Dazu: Crary, Techniken des Betrachters. Sehen und Moderne im 19. Jahrhundert, 1996.

58 Exemplarisch dafür: Novotny, Cézanne und das Ende der wissenschaftlichen Perspektive, 1938. 
wegbereitender Aufsatz "Die Perspektive als 'symbolische Form" ", der die Perspektive zugleich als Gegenstand sowie als epistemologisches Modell seiner Überlegung verwendet. ${ }^{59}$

Die historiografische Problematik liegt also auf der Hand, und da ich mich verpflichtet habe, in diesem Kapitel nach dem appositionalen Charakter der Perspektive zu fragen, möchte ich unter diesen Vorzeichen auch über die Geschichte der Perspektive nachdenken. Die Appositionen der Perspektive, ich habe es oben erläutert, verweisen auf die kontextuellen Bedingungen, d.h. die Konstitution und damit die Genese ihrer Bedeutung. Die zentrale Frage, die sich im Zusammenhang mit ihrer theoretischen Bedeutung stellt, ist daher eine Frage nach der historischen Genese von Theorie. Wie bezieht sich ein Subjekt auf Theorie? Hubert Damisch hat vorgeschlagen, diese Frage auf husserlianischem Weg zu lösen, und er beruft sich dabei auf einen Text, der für die philosophiegeschichtlichen Entwicklungen des zwanzigsten Jahrhunderts eine Schlüsselrolle einnimmt. Edmund Husserls Untersuchungen zum Ursprung der Geometrie haben entscheidend zur Wissenschaftsund Metaphysikkritik des modernen Denkens beigetragen und Grundlagen der philosophischen Dekonstruktion - das Konzept der Écriture - mitgeschaffen. ${ }^{60}$ Ich werde im Folgenden Husserls Überlegungen zur Geometrie erläutern und Damischs Vorschlag rekonstruieren, der die Perspektive auf dieser Basis interpretiert.

Husserls späte Auseinandersetzung mit der Geometrie setzt ein zentrales Anliegen seiner gesamten Phänomenologie in Beziehung zu einem neuen Problem. Die Idealität mathematischer Wahrheiten, die Husserl in den Logischen Untersuchungen noch als überzeitliches und übersubjektives Moment behandelt, ${ }^{61}$ erfährt hier eine Wende, die sie mit der Frage von Historizität kollidieren lässt. Während er die Konstitution von Idealität vorher weitgehend als Korrelat des Bewusstseins und seines logischen Überschusses diskutiert, wird in den Schriften zur Krisis die Lebenswelt mit ihren praktischen, sozialen und historischen Dimensionen zentrales Element für die intentional konstituierte Idealität. Die mathe-

59 Dazu Kapitel I der vorliegenden Studie.

60 Derrida, Husserls Weg in die Geschichte am Leitfaden der Geometrie. Ein Kommentar zur Beilage III der »Krisis", 2001.

61 Husserl, Logische Untersuchungen. Untersuchungen zur Phänomenologie und Theorie der Erkenntnis, 1980. 
matische Wahrheit ist nicht mehr getrennt zu verstehen von der Lebenswelt als einem Horizont konkreter Praktiken, die nicht nur geteilt, sondern auch historisch tradiert werden. Mathematische Wahrheit, so Husserl, muss mit der Geschichte dieser Lebenswelt in eine sinnvolle Beziehung gesetzt werden. Das bedeutet jedoch nicht, dass ideale Gegenstände der Mathematik, Geometrie und anderer Wissenschaften als beliebige Gegenstände der Geschichte zu verstehen sind, vielmehr verfügen sie über eine eigene Weise der Geschichtlichkeit. Ideale Gegenstände haben für Husserl einen lebensweltlichen, d.h. praktischen Ursprung, der im Zusammenhang mit der Lösung konkreter Probleme steht, jedoch bleiben sie in diesem Ursprung und seinem historischen Ort nicht stehen. Denn ihre Eigenschaften, d.h. ihre Strukturen und Gesetze werden nicht nur passiv übernommen bzw. rezipiert, sondern fortlaufend im Bewusstsein "aktiv« erzeugt. Husserl beschreibt diese Aktivität folgendermaßen:

"Ein passiv (ev. erinnerungsmäßig) auftauchender oder im Hören passiv verstandener Satz wird zunächst in passiver Ichbeteiligung bloß rezipiert, als geltend aufgenommen, und in dieser Gestalt ist er schon unsere Meinung. Davon unterscheiden wir die eigenartige und wichtige Aktivität der Verdeutlichung unserer Meinung. ${ }^{62}$

Ein Besonderes ist nun, wie gesagt, die Intention auf Explikation und die Aktivität, welche das Gelesene (oder einen interessanten Satz daraus) Sinnglied für Sinnglied in Sonderheit aus dem vagen passiv einheitlich Rezipierten heraus artikuliert und in neuer Weise die Gesamtgeltung aufgrund der Einzelgeltungen zum aktiven Vollzug bringt. Aus einer passiven Sinngestalt ist nun eine in aktiver Erzeugung sich bildende geworden. So ist denn diese Aktivität eine - eigenartige - Evidenz, das in ihr entspringende Gebilde in dem Modus originärer Erzeugtheit. « ${ }^{63}$

Die auf Explikation und Aktivität gerichtete Intention rezipiert also nicht bloß, sondern reaktiviert die Evidenz einer Aussage. Die Evidenz wird damit vorübergehend lebendig und kann z. B. durch Deduktion ergänzt und verkompliziert werden. Die Eigenschaften

62 Husserl, »Der Ursprung der Geometrie«, 1987, S. 216.

63 Ebd., S. 216. 
des idealen Gegenstands werden damit fortgeschrieben zu einem größeren Komplex. Da die so entstehende Länge und Komplexität der "Evidenzkette« die endliche Kapazität des Denkens überfordert, kommt es zu einer Idealisierung des Objekts:

\begin{abstract}
"Danach scheint es, dass sich von den Urevidenzen aus die Ursprungsechtheit fortpflanzen muss durch die noch so lange Kette der logischen Folgerungen. Indessen, bedenken wir die offenbare Endlichkeit des individuellen wie gemeinschaftlichen Vermögens, die logischen Ketten von Jahrhunderten wirklich in der Einheit eines Vollzuges in ursprungsechte Evidenzketten zu verwandeln, so merken wir, dass das Gesetz eine Idealisierung in sich birgt: nämlich die Entschränkung, und in gewisser Weise die Verunendlichung unseres Vermögens. «64
\end{abstract}

Weil etwa der Geometer nicht in der Lage ist, in jeder seiner Operationen die ihr zugrunde liegende Evidenzkette bis zurück zur »Urprämisse« zu reaktivieren, ${ }^{65}$ beruft er sich auf Gesetze, für die er allgemeine Gültigkeit in Anspruch nimmt. Damit findet eine Idealisierung statt, die das Ergebnis einer idealisierenden geistigen Tätigkeit ist und aus dem ursprünglich lebensweltlichen Verfahren und seinem Material eine »ideale Gegenständlichkeit " erzeugt. ${ }^{66}$

Ideale Objekte haben so gesehen einen empirischen Boden, sie nehmen ihren Anfang in einer konkreten Praxis, die sie durch eine lange Kette von Abstraktionen, Formalisierungen und Weiterentwicklungen jedoch transzendieren. Dabei findet eine Tradierung statt, die sich im historischen Horizont vollzieht. Sie wird intentional, d.h. durch das Bewusstsein geleistet und basiert auf mehreren Voraussetzungen. Die historische Zeit muss in irgendeiner Weise eine apriorische Struktur aufweisen, die eine kontinuierliche Fortschreibung und Tradierung der Gesetze ermöglicht. Historizität bedarf also quasi einer intelligiblen Gleichförmigkeit, damit die Reaktivierung der Evidenz gelingen kann. Da historische Zeiträume aber nicht mit einem gleichsam intelligiblen Äther gefüllt sind, muss eine andere stabile Instanz diese Gleichförmigkeit 
leisten. Man könnte sich zu diesem Zweck auf das Cogito berufen, das als Noesis den identischen Pol aller intentionaler Vollzüge bildet, die im Strom der historischen Zeit stattfinden, doch wenn das Cogito als endliches Vermögen die apriorische Voraussetzung der intentionalhistorischen Vollzüge ist, wie kann dann eine überpersonale und historische Tradierung stattfinden? Die externe, d.h. dem Bewusstsein äußerliche Bedingung, die Husserl dafür in Anschlag bringt, ist die schriftliche Fixierung. Erstens ermöglicht sie intersubjektive Beziehung von nicht zeitgleich anwesenden Subjekten, indem sie als Medium auf virtuelle Weise Sinn vermittelt und damit vergemeinschaftet:

"Es ist die wichtige Funktion des schriftlichen, des dokumentierenden sprachlichen Ausdrucks, dass er Mitteilungen ohne unmittelbare oder mittelbare persönliche Ansprache ermöglicht, sozusagen virtuell gewordene Mitteilung ist. Dadurch wird auch die Vergemeinschaftung der Menschheit auf eine neue Stufe erhoben. Schriftzeichen sind, rein körperlich betrachtet, schlicht sinnlich erfahrbar und in ständiger Möglichkeit, intersubjektiv in Gemeinsamkeit erfahrbar zu sein. «67

Zweitens ist die schriftliche Fixierung die Bedingung von Tradierbarkeit, mit der die Reaktivierung und Präsentwerdung von Evidenzen über größere historische Zeitverläufe möglich werden:

"Es müsste eine Kontinuität von Person zu Person, von Zeiten zu Zeiten durchführbar gewesen sein. Es ist klar, dass die Methode der Erzeugung der ursprünglichen Idealitäten aus den vorwissenschaftlichen Gegebenheiten der Kulturwelt vor dem Dasein der Geometrie niedergeschrieben und fixiert sein müsste in festen Sätzen; dass ferner das Vermögen, diese Sätze aus dem vagen sprachlichen Verstehen in die Klarheit der Reaktivierung ihres evidenten Sinnes überzuführen, in seiner Weise tradiert und beständig tradierbar sein müsste. « ${ }^{68}$

Es ist dieses genealogische Muster, das Damisch auf die Perspektive überträgt, um die ihr eigene Weise der Geschichtlichkeit zu begreifen. Seine These vom »Ursprung der Perspektive« beschreibt weder 
die Entdeckung einer absoluten Wahrheit der Wahrnehmung bzw. Darstellung von Raum noch die Erfindung einer konventionalisierten Formel. `Ursprung meint vielmehr die besondere Historizität idealer Gegenständlichkeit, die durch intentionale Tradierung ein intelligibles Objekt erzeugt, das damit zu einem "Modell« wird, wie Derrida in Bezug auf Husserl sagt. ${ }^{69}$ Wie jedes geometrische Gesetz hat die Perspektive ihren Anfang in einer lebensweltlichen und materiellen Praxis, die darin bestand, Raum auf einer Fläche darzustellen. Die daraus generierten Verfahren werden zu idealen Gesetzen formalisiert, die schließlich in die Bildgestaltung als Linear- oder Fluchtpunktperspektive und in der projektiven Geometrie als Satz von Desargues eingegangen sind.

Welche Konsequenzen ergeben sich nun für die Bedeutung und Entwicklung der Perspektive in der Moderne und Gegenwart, wenn man sie als ein theoretisches Objekt im Sinne Husserls begreift? Zunächst ist Damischs Vorschlag einer intentional-historischen Untersuchung der Perspektive geeignet, um die Transformationsprozesse zwischen den drei Bereichen zu präzisieren, die das Feld der modernen Kritik der Perspektive darstellen. Die Modellkonzeption der Perspektive hat gezeigt, dass diese zwischen visueller Wahrnehmung, bildlicher Formgenese und Philosophie vermittelt, und zwar durch intentionale Zuschreibung, die den Kern dessen ausmacht, was ich den appositionalen Charakters der Perspektive nenne. Mit Husserl kann man zeigen, dass die Transformationen, die mit dieser Vermittlung langfristige Prozesse der Tradierung und Formalisierung sind, eine historische Dimension besitzen. Weiter wird verdeutlicht, dass diese Prozesse der Transformation auf fixierte, d.h. materialisierte Einschreibungen angewiesen sind, die selbst jedoch nicht ausreichen, um die Bedeutung und Effekte des Modells zu verstehen. Die besondere Weise der Geschichtlichkeit theoretischer Objekte ist wesentlich eine intentionale, d. h. eine Geschichte des Bewusstseins. Im Hinblick auf die moderne Kritik der Perspektive lässt sich nun die Frage aufwerfen, 
weshalb diese Geschichte plötzlich zu einem Ende kommen soll. Wenn der ideale Gegenstand einer fortlaufenden Reaktivierung, Verkomplizierung und Weiterentwicklung unterliegt, wieso soll er dann zu einem gewissen Zeitpunkt seine Bedeutung verlieren? Die zahlreichen Diskurse und Debatten um die Perspektive, ihre philosophische und überhaupt ihre theoretische Aneignung, müssen in diesem Sinn als Teil jener besonderen Geschichtlichkeit begriffen werden, die ihr als Modell eigen sind. Man mag zwar eine Unterscheidung treffen wollen zwischen ihrer Bedeutung als Gegenstand der Theorie einerseits und der künstlerischen Praxis andererseits, doch welchen Sinn macht diese Unterscheidung im Horizont der modernen Kunst, die - denken wir etwa an Marcel Duchamp - eine Trennung von Theorie und Kunst, von Denken und Gestalten weitgehend aufgibt?

Will man mit Hilfe von Husserls Konzeption eines >Ursprungs der Geometrie das Schicksal der Perspektive in der Moderne verstehen, kommt man nicht umhin, den Kontext seiner Überlegungen ins Auge zu fassen. Denn als dritte Beilage der sogenannten "Krisis-Schriften« kommt Husserls Auseinandersetzung mit der Geometrie eine besondere Rolle zu. Die in den dreißiger Jahren des zwanzigsten Jahrhunderts entstandenen, aber erstmals 1954 im Rahmen der Husserliana publizierten Schriften Die Krisis der europäischen Wissenschaften und die transzendentale Phänomenologie ${ }^{70}$ skizzieren in der Auseinandersetzung mit Geometrie ein genuin modernes Problem. Die zunehmende Entfremdung der Wissenschaften vom menschlichen Dasein und seiner Lebenswelt bildet das Hauptthema dieser späten Schriften Husserls und er führt diese vor allem auf die Abspaltung, Formalisierung und Abstraktion der exakten Wissenschaften von der Philosophie zurück. Die Geschichte der Geometrie nimmt in diesem Zusammenhang eine zentrale Rolle ein, denn sie ist nicht nur das früheste Beispiel einer exakten Wissenschaft, sondern bildet einen methodischen Grundpfeiler der Mathematisierung der Wissenschaften. Die euklidische Geometrie ist in diesem Sinn zwar bereits systematische Abstraktion der Lebenswelt und ihrer ursprünglichen Anschaulichkeit, sie ist für Husserl jedoch noch ausreichend mit dieser Anschau- 
lichkeit verbunden.$^{71}$ Die Beziehung zwischen ihren formalisierten Axiomen und dem lebensweltlichen Boden, auf dem sie ausgehend von konkreten Praktiken entstanden sind, sei noch intakt, d.h. nachvollziehbar. In den neuzeitlichen Weiterentwicklungen der euklidischen Geometrie, sprich in der analytischen Geometrie, die sich ausgehend von René Descartes entwickelt, erkennt Husserl jedoch eine zunehmende Abspaltung und Entfernung jener Anschaulichkeit. ${ }^{72}$ Die radikale Formalisierung ihrer Sprache, Verfahren und Gesetze entbehrt jeder Möglichkeit der Übertragung auf die sinnliche Anschauung womit eine Rückübersetzung zur Lebenswelt verunmöglicht ist. Diese Geometrie ist demnach eine ideale Sprache, deren Zeichen jede außersprachliche Realität verloren haben:

"Man operiert mit Buchstaben, Verbindungs- und Beziehungszeichen $(+, \times,=$ usw.) und nach Spielregeln ihrer Zusammenordnung, in der Tat im Wesentlichen nicht anders wie im Karten- oder Schachspiel. Das ursprüngliche Denken, das diesem technischen Verfahren eigentlich Sinn und den regelrechten Ergebnissen Wahrheit gibt [...], ist hier ausgeschaltet. $\ll^{73}$

Der am Beispiel der algebraischen Sprache dargestellte Verlust aller lebensweltlichen Bezüge bildet für Husserl den Wesenszug der modernen Wissenschaften und verschuldet jene Krisis, um die es ihm geht.

Mit Husserls intentionalgeschichtlicher Analyse die Perspektive zu interpretieren, scheint so verführerisch wie heikel. Nicht nur dass die von Husserl beschriebene Krisis mit der modernen Kritik der Perspektive verquickt ist, auch auf der systematischen Ebene der Interpretation treten Probleme auf. Zwar kann Damisch, indem er die Perspektive in überzeugender Weise als idealen Gegenstand analog der Geometrie konzipiert, jene genealogischen Probleme lösen, die sich um den Streit drehen, ob die Perspektive erfunden oder entdeckt wurde. Auch relativiert die Genealogie der Perspektive die Kritik der Apparatus-Theoretiker, die in der Perspektive 
die bürgerliche Ideologie einer transzendentalen Subjektivität erkennen. Während sich die Apparatus-Theoretiker auf einen in ihren Augen idealistischen Husserl berufen und entsprechend aus seinen Cartesianischen Meditationen zitieren, ${ }^{74}$ wählt Damisch eine Schrift, die wie keine andere die Frage der Geschichtlichkeit stellt. Das ist deshalb entscheidend, weil das 'Ego', das sich im perspektivischen Dispositiv gespiegelt sieht, hier nicht mehr als ein transzendentales Subjekt auftritt, sondern in Beziehung steht zu einer Lebenswelt sowie deren Praktiken und materielle Einschreibungen. Das 'Ich`, das im Zusammenhang mit der Perspektive zum Tragen kommt, ist damit keine von der Geschichte isolierte Instanz, keine Apperzeption, sondern in seinem Ursprung ein lebendes und handelndes Bewusstsein. Genau darin aber zeigt sich ein Problem in Damischs husserlianischer Interpretation der Perspektive. Denn wenn die Perspektive als theoretisches Objekt das Ergebnis einer Idealisierung ist, die durch intentionale Tradierung des Bewusstseins, d.h. des Subjekts stattfindet, dann muss das Bewusstsein vorgängig sein, als ein Apriori, das die Konstitution des idealen Gegenstandes leistet. Wie aber kann dasselbe Bewusstsein dann ein Effekt der Perspektive als einem in der historischen Welt fundierten Dispositiv sein $?^{75}$ Husserl hat die genealogische Paradoxie zwischen Subjektivität und ihrer historischen Welt im dritten Teil der Krisis-Schriften selbst benannt:

"Wie soll ein Teilbestand der Welt, ihre menschliche Subjektivität, die ganze Welt konstituieren, nämlich konstituieren als ihr intentionales Gebilde? - Welt, ein immer schon gewordenes und fortwerdendes Gebilde des universalen Konnexes der intentionalen leistenden Subjektivität - wobei sie, die im Miteinander leistenden Subjekte, selbst nur Teilgebilde der totalen Leistung sein sollen?

Der Subjektbestand der Welt verschlingt sozusagen die gesamte Welt und damit sich selbst. Welch ein Widersinn. $\ll^{76}$

74 Baudry, »Ideologische Effekte erzeugt vom Basisapparat«, 1993, S. 40.

75 Jean-Louis Déotte hat bereits auf dieses Problem hingewiesen und er erkennt darin letztlich ein ontologisches Problem. Déotte, Video und Cogito, 2006, S. $19 \mathrm{ff}$.

76 Husserl, Die Krisis der europäischen Wissenschaften und die transzendentale Phänomenologie, 2012, S. 165. 
Damischs Interpretation der Perspektive basiert letztlich auf dem oben von Husserl beschriebenen Problem. Die Perspektive als theoretisches Objekt lässt sich nicht in die gewöhnliche Geschichte einreihen, weil sie die Verfassung derjenigen Subjekte mitverantwortet, die diese Geschichte zu schreiben bemüht sind. ${ }^{77}$

77 Damisch geht davon aus, dass das Subjekt zugleich der Effekt und Träger des Dispositivs ist und folgt damit Michel Foucault. Damisch, Der Ursprung der Perspektive, 2010, S, 440f. Dabei bleibt zweifelhaft, ob diese Konzeption der perspektivischen Subjektivierung mit Husserls Philosophie in Einklang gebracht werden kann. Husserls Begriff des "historischen Aprioris" entspricht jedenfalls nicht Foucaults Konzeption desselben. Dazu etwa: Goris, "Das historische Apriori bei Husserl und Foucault. Zur philosophischen Relevanz eines Leitbegriffs der historischen Epistemologie«, 2013. 



\section{Schluss}

Wenn die vorliegende Studie etwas klar macht, dann dass die Kritik der Perspektive nicht abschließend auf einen Punkt gebracht werden kann. Ihre Effekte sind zu vielfältig und voraussetzungsreich, als dass sie gleichsam in einem Fluchtpunkt gebündelt werden könnten. Wenn ich hier also einen Schluss ziehe, dann weder mit dem Anspruch einer endgültigen Sicherung noch einer vollständigen Bestandsaufnahme der Thematik. Ich habe im Grunde lediglich einige der Umstände hervorgehoben, unter denen die Perspektive in der Moderne kritisch verhandelt wird. Es hat sich dabei gezeigt, dass Probleme und Fragen der Richtigkeit, sprich der Übereinstimmung zwischen Sehen und Darstellen, für die Rolle der Perspektive in der Moderne eine geringfügige Rolle spielen. Natürlich haben die Paradigmenwechsel der Wahrnehmungstheorien etwa durch die Physiologie des neunzehnten Jahrhunderts die Perspektive aus wissenschaftlicher Sicht in Bedrängnis gebracht, doch es hat sich gezeigt, dass diese Kritik erst der Startschuss ihres Werdegangs als Objekt der Auseinandersetzung in der Moderne gewesen ist.

Offensichtlich geworden ist der Umstand, dass die Perspektive in unterschiedlichen Gegenstandsbereichen bzw. Disziplinen wirksam ist und diese miteinander in Beziehung setzt. Das Element, durch das sie diese Grenzen passiert, ist dabei die Form. Als ein Modell beschreibt und konturiert die Perspektive die Form der visuellen Wahrnehmung, setzt sie in Verbindung mit den Formen der piktoralen Darstellung sowie den Formen des Denkens. Die Konzeption der Perspektive als Modell, die ich ausgehend von Hubert Damisch vorschlage, kann diese formalen Übertragungen zwischen den unterschiedlichen Inanspruchnahmen erklären, welche als Transformationen zu begreifen sind. Wer in der Moderne das Ende der Perspektive erkennt, übersieht diese vielseitigen Funktionen und Bedeutungen.

Wie jedes Modell hat die Perspektive in Abhängigkeit von Zeit, Ort und Interessen gewisse Stärken und Schwächen. Aus historischer Sicht liegt ihre besondere Qualität u. a. in ihrer rigiden Regelhaftigkeit, etwa im Unterschied zur Luft oder Farbperspektive, aber auch in der unzweideutigen räumlichen Stabilität, die, im Gegen- 

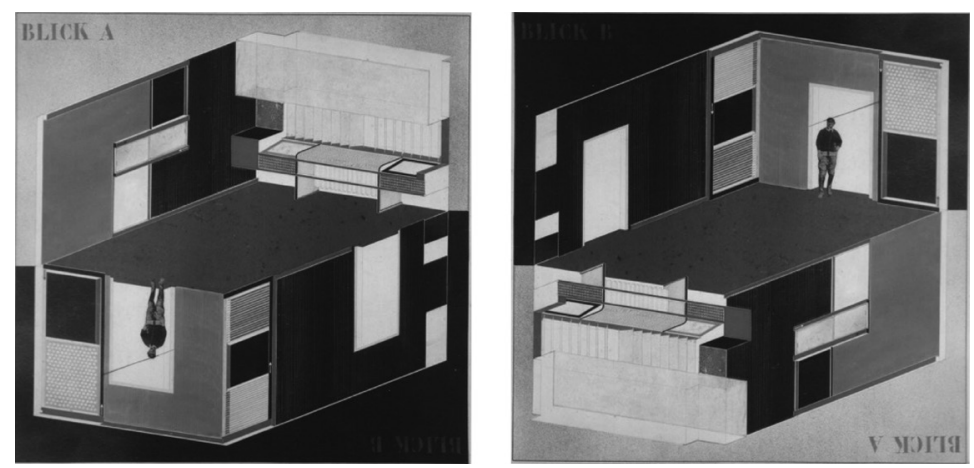

Abb. 1: El Lissitzky, Entwurf zum Kabinett der Abstrakten, 1927/28.

satz zu axonometrischen Konstruktionen, räumliche Ambiguität und eigentümliche Kippeffekte verhindert (Abb. 1). ${ }^{1}$

Diese mathematische Präzision und räumliche Unzweideutigkeit können kontextabhängig große Vorteile bedeuten, sie korrelieren jedoch nicht zwingend mit der menschlichen Wahrnehmungsweise. Dass die Idee einer möglichen Übereinstimmung von Wahrnehmung und Darstellung selbst eine historische Konzeption ist, die im Zusammenhang mit der Perspektive entsteht, rückt die Kritik an der Richtigkeit jedoch in ein anderes Licht. Ohnehin ist die Frage nach der korrekten Wiedergabe der Welt für die ästhetische Moderne nicht von großer Bedeutung. Dass die gestalterisch-raumbildende Funktion der Perspektive in der modernen Kunst zunehmend in den Hintergrund tritt, zeigt lediglich eine Verschiebung ihrer Bedeutung an, die sich in ihrer zunehmend theoretischen Bedeutung und Tragweite ausdrückt. Entgegen James Elkins und James Conant scheint mir diese theoretische Bedeutung mit dem Begriff der Metapher unzureichend bestimmt, weshalb ich mich auf die systematische Modelltheorie Bernd Mahrs beziehe, um die Übertragungen und Transformationen der Perspektive besser zu verstehen.

Die Kritik der Perspektive in der Moderne muss unter diesen Voraussetzungen begriffen werden, d.h. sie muss als Kritik eines

1 Ich verdanke den Hinweis auf El Lissitzkys Entwurf Adam Jasper. 
theoretischen Objekts gedacht werden, mit dem transformative Funktionen zwischen unterschiedlichen Gegenstandsbereichen vollzogen werden. Die Kritik der Perspektive, die im Wechselspiel dieser Gegenstandsbereiche stattfindet, ist eine engagierte Kritik, die in der Auseinandersetzung mit ihrem Objekt immer wieder neue und produktive Effekte erzeugt. Die Kritik der Perspektive ist nicht bloß eine Kritik an der Perspektive, sie ist vor allem eine Kritik mit der Perspektive.

Wie ich gezeigt habe, ist dieser Sachverhalt dort besonders komplex, wo sich die Geschichte der Kritik der Perspektive mit der Geschichte der modernistischen Kritik kreuzt. An diesen Kreuzungspunkten zeigen sich denn auch die symptomatischen Probleme der Moderne selbst. So etwa, wenn sie die Perspektive als historisch gewordene Norm aufdeckt und ihre hegemoniale Bedeutung kritisiert, im selben Zug jedoch die Normen der Perspektive durch andere kontingente Normen ersetzt. Ich denke etwa an die Logik der Flächeneinschreibung in der modernistischen Malerei, die anstelle der perspektivischen Bildraumtiefe bestimmend wird. Verbunden ist dieser Paradigmenwechsel auch mit einer Idee von authentischer Singularität. Perspektivkritik zielt dabei etwa auf die prinzipielle Reproduzierbarkeit, die im Perspektivsystem angelegt ist. Wie die Fotografie erlaubt die perspektivische Darstellungsweise eine beliebige Anzahl von Wiederholungen der identischen räumlichen Konstruktion - worin William Ivins einen zentralen Grund für ihren Erfolg in der visuellen Kultur erkennt. ${ }^{2}$ Die durch strenge Regeln ermöglichte Wiederholbarkeit steht dabei modernen Vorstellungen künstlerischer Einmaligkeit und ästhetischer Autonomie des Bildes entgegen.

William Ivins deutet das Bedürfnis nach nicht-perspektivischen Bildern in der Moderne als einen dialektischen Effekt, der durch die Sättigung perspektivischer Bildwahrnehmung entsteht und mit der modernen Inflation fotografischer Bilder zusammenhängt. ${ }^{3}$ Dabei ignoriert er jedoch die dem Modernismus eigenen Theorien und Logiken. Zu den einflussreichsten dieser Theorien gehört Clement Greenbergs Konzeption eines selbstkritischen Modernismus, welche die Perspektive aus dem Register reflexiver

2 Ivins: On the Rationalization of Sight, 1973, S. $7 \mathrm{ff}$.

3 Ebd., S. 12. 


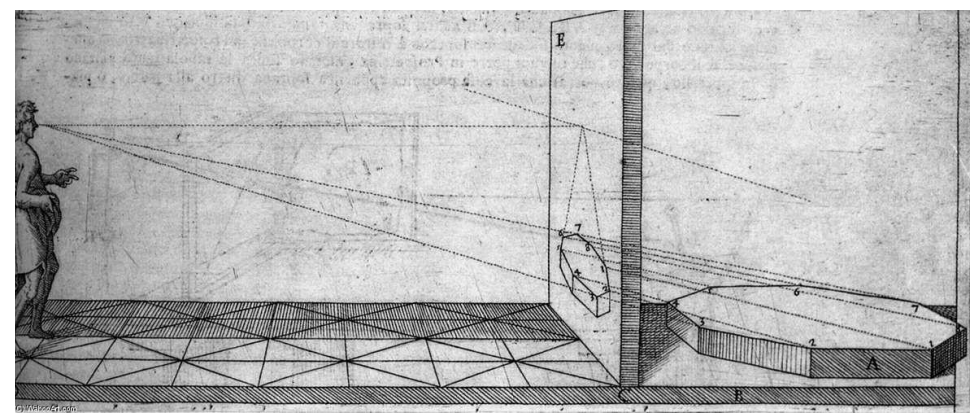

Abb. 2: Schaubild aus: Giacomo Barozzi da Vignola, Le due regole della prospettiva practica, Rom 1583.

Bildgebungsverfahren ausschließt, obschon es sich bei der Perspektive um ein Dispositiv und Gestaltungsmittel handelt, das durchaus in der Lage ist, sich mit seinen eigenen Mitteln kritisch zu befragen.

Während Sebastian Egenhofer mit der reizvollen These antritt, es handle sich bei der Perspektive um das Modell der modernistischen Selbstkritik schlechthin, scheint es mir naheliegender, von einer teilweisen Übereinstimmung der Perspektive und dem modernistischen Paradigma der Selbstkritik auszugehen. Perspektivische Gestaltungsverfahren sind durchaus in der Lage, sich selbst mittels ihrer eigenen Methoden zu kritisieren und diese Kritik zu exponieren. Bereits die Schaubilder aus den Perspektivtrakten des 17. Jahrhunderts erklären die Funktionsweisen und Voraussetzungen der Perspektive mit nichts anderem als der perspektivischen Konstruktion selbst (Abb. 2). Es war und ist also möglich, mit einem perspektivisch konstruierten Bild die Prinzipien und Voraussetzungen der perspektivischen Konstruktion selbst darzustellen. Diese Form der Selbstreferenzialität gelingt dabei, ohne dass Darstellung und Dargestelltes in jenes tautologische Verhältnis geraten, mit dem deren repräsentationale Distanz kollabiert und welches zu einem Leitthema der spätmodernistischen Malerei geworden ist. ${ }^{4}$

4 Bezeichnend für dieses tautologische Verhältnis ist bis heute Frank Stellas berühmte Aussage im Radio-Interview mit Bruce Glaser von 1964: „What 
Ich habe gezeigt, dass die antiperspektivischen Impulse der modernen Malerei in der Philosophie des zwanzigsten Jahrhunderts Verbündete finden. Etwa die Phänomenologie Maurice Merleau-Pontys formuliert ihre perspektivkritischen Überlegungen explizit in Beziehung zur modernen Malerei. Der Kern dieser Kritik ist, wie ich gezeigt habe, eine ontologische Argumentation, die sich gegen eine epistemische Kultur richtet, als deren Emblem die Perspektive verhandelt wird. Diese epistemische Kultur umfasst nicht nur die neuzeitliche Tradition der Metaphysik und des Rationalismus - an dieser Stelle kreuzen sich Metaphysikkritik und Perspektivkritik -, sondern auch die modernen Naturwissenschaften und die damit verbundenen Techniken. Ihr mathematischer Charakter macht die Perspektive in den Augen dieser Denker genauso verdächtig wie das distanzierte Verhältnis, das sie zwischen Subjekt und Objekt der Repräsentation herstellt. Die phänomenologischen bzw. hermeneutischen Ansätze von Maurice Merleau-Ponty, Hans-Georg Gadamer oder Martin Heidegger betonen die untrennbaren Verflechtungen des Selbst mit der Welt, um damit die ursprünglichen und teilweise ontologischen Bedingungen menschlicher Existenz zu untersuchen. Maurice Merleau-Pontys Konzept des Weltleibes bildet einen Höhepunkt dieser monistischen Verflechtungen, der im Hinblick auf die Perspektive und ihre distanzierende Disposition als Implosion beschrieben werden kann.

Die Allianz dieser Philosophie mit den antiperspektivischen Diskursen des Modernismus ist dann partiell als zweckhafte Komplizenschaft zu verstehen, denn die philosophische Kritik der Perspektive beruht auf anderen Gründen als jene der Kunst, auch wenn beide möglicherweise ähnlichen Bedürfnissen entspringen, nämlich dem Wunsch nach einer Authentizität und Ursprünglichkeit, denen das moderne Leben entsagt. Die Kritik der Perspektive ist unter diesen Umständen also auch auf das Versagen des Idealismus zurückzuführen, der etwa noch in Erwin Panofskys Aufsatz zum Tragen kommt. Für Panofsky bleibt die Perspektive, trotz seiner Kritik, letztlich doch eine geglückte Verbindung, ein Gleichgewicht zwischen Subjektivität und Objektivität, das den geglückten

you see is what you see«, in: Battcock, Minimal Art. A Critical Anthology, 1995, S. 158. 
epistemologischen Weltzugang sichert. Dieses Gleichgewicht, das die idealistische Interpretation der Perspektive erkennt, gerät im Laufe des zwanzigsten Jahrhunderts jedoch aus den Fugen.

Ich habe in meinen Überlegungen gezeigt, dass der Leib nicht nur in der phänomenologischen Auseinandersetzung mit der Perspektive eine zentrale Rolle spielt, sondern auch einen vielschichtigen Grund der modernen Kritik der Perspektive bildet. Während die phänomenologischen Konzeptionen des Leibes zumeist von einer primordialen und somatischen Ordnung des menschlichen Körpers im Raum ausgehen, durch welche die Selbst- und Welterfahrung ursprünglich orientiert ist, ${ }^{5}$ führen die Entwicklungen der Physiologie bereits im neunzehnten Jahrhundert zu einer andersartigen Bedeutung des menschlichen Körpers und seiner Wahrnehmung. Dies hat die Entstehung eines ganzen Arsenals neuartiger Apparate zur Folge - an prominenter Stelle das Stereoskop -, die als neue Wahrnehmungsdispositive die Perspektive grundsätzlich in Frage stellen. ${ }^{6}$

Diese physiologische Erforschung des Körpers sowie seine damit zusammenhängende Disziplinierung steht mindestens teilweise in Widerspruch zur phänomenologischen Vorstellung einer primordialen somatischen Ordnung und ihrer ursprünglichen Valenzen. Zugleich bilden beide Konzeptionen des menschlichen Körpers eine Kritik der Perspektive und ihrer Paradigmen. Der Leib als holistisch somatische Ordnung bzw. als zusammenhängendes neurologisches Funktionssystem stellt die wahrnehmungstheoretischen Voraussetzungen der Perspektive fundamental in Frage. Der Leib fungiert in der modernen Kritik der Perspektive nicht selten als widerständiges Moment, das sich der Implementierung in das Perspektivsystem versperrt. Im Hinblick auf Manettis Novelle vom dicken Holzschnitzer habe ich gezeigt, dass perspektivische Konstruktionen, im sozialen oder visuellen Sinn, eine profunde Macht auf das Bewusstsein ausüben, gegen die der Leib wenig bis nichts ausrichten kann. Ich schlage deshalb vor, die Berufung auf eine widerständige Leiblichkeit als moderne Essentialisierung des

5 Siehe etwa: Husserl, Ideen zu einer reinen Phänomenologie und phänomenologischen Philosophie, 2002, S. $158 \mathrm{ff}$.

6 Vgl. Crary, Techniken des Betrachters. Sehen und Moderne im 19. Jahrhundert, 1996. 
Körpers zu begreifen, die der subjektivierenden Virulenz perspektivischer Phänomene nicht genügend Rechnung trägt.

Andererseits wird diese Virulenz von der modernen Kritik der Perspektive auch emphatisch betont. So etwa die ideologiekritischen Interpretationen, welche in der Perspektive eine hegemoniale Macht erkennen, die mit der Suggestion von Natürlichkeit operiere und damit ihren artifiziellen und instrumentellen Charakter verdecke. Meine Untersuchungen des dafür exemplarischen Textes von Jean Baudry hat ergeben, dass der perspektivische Weltbezug im Zeichen der Ideologiekritik marxistischer Prägung einseitig umgedeutet wird zu einer Unterwerfung und Disziplinierung des Subjekts.

Hierin zeichnet sich abermals der Verlust eines Gleichgewichts $a b$, nämlich zwischen der Autonomie und der Abhängigkeit des perspektivischen Subjekts. Wie bereits erwähnt, kann man in Panofskys Aufsatz dieses Gleichgewicht noch erkennen, denn er beschriebt die Perspektive also eine überaus "ambivalente Methode «, ${ }^{7}$ die das Subjekt anerkennt und stabilisiert, zugleich aber auch seine Abhängigkeit in einem normativen System markiert. Die unterkomplexe Interpretation der Perspektive kippt dieses Gleichgewicht. Sie erkennt in der perspektivischen Subjektivität eine einseitige Implementierung und Unterwerfung des Subjekts. Die Perspektive wird in dieser Sichtweise vollumfänglich zum Objekt der Kritik und ihre kritisch-reflexiven Effekte werden konsequent übergangen.

Eine komplexe ideologiekritische Interpretation der Perspektive, wie sie Claes Oldenburg oder R. H. Quaytman auf künstlerische Weise, Jean-François Lyotard oder Sebastian Egenhofer auf theoretische Weise formulieren, nutzt dagegen gerade die Bedingungen und Eigenschaften der perspektivischen Bildform und der damit einhergehenden Subjektivität, um eine Weise der genuin perspektivischen Reflexion und Kritik zu entwickeln. Obwohl auch sie von einer exogenen Subjektgenese ausgehen, erkennen sie in der Perspektive ein kritisches Potential, das dazu eingesetzt werden kann, spezifische ideologische Verhältnisse von Macht zu 
reflektieren. Ihr unverhohlen artifizieller Charakter verschleiert nicht, sondern exponiert geradezu die Konstruktion des Sichtbaren und damit die Genese und Abhängigkeit von Subjektivität bzw. Objektivität. Damit ist sie nicht bloß Mittel, sondern ein Modell ästhetischer Kritik überhaupt.

Ich habe darauf hingewiesen, dass auch diese Interpretationen der Perspektive nicht unproblematisch sind. Die profunde Reflexion durch die Perspektive, die etwa Hubert Damisch ausgehend von Brunelleschis Experiment untersucht, vermag das Subjekt an einem empfindlichen Punkt zu treffen. Wenn das Schicksal moderner Subjektivität in der Aufrechterhaltung des Gleichgewichts zwischen Abhängigkeit und Autonomie liegt, kann die Spiegelung der Genese des Selbst, die Damisch in der Perspektive erkennt, jedoch zu einer prekären Angelegenheit für das Subjekt werden. Die Kritik der Perspektive als Subjektkritik bedroht dann das Subjekt in seiner innersten Verfassung, der im Anblick ihrer eigenen Konstitution die Möglichkeit der Illusion von Autonomie abhanden kommt.

In meinen Werkanalysen des OEuvres von R. H. Quaytman haben ich die ästhetischen Konsequenzen dieser kritischen Reflexion nachgezeichnet und den nihilistischen Charakter der mit ihr verbundenen Erfahrung beschrieben. Die destabilisierte Autonomie des Subjekts hat sich dabei als Korrelat einer destabilisierten ästhetischen Autonomie des einzelnen Gemäldes erwiesen. Die Perspektive hat im Kontext dieser Malerei zwar eine selbstkritische Funktion, insofern sie die Gemälde von einer suggestiven Immanenz und mystifizierten Autorschaft befreit und deren Abhängigkeit vom Kontext betont. Ihre Reflexionsstrategie, mit der die Perspektive als Modell für eine radikale Selbstkritik genutzt wird, läuft jedoch Gefahr, den prekären Status der abhängigen und konstruierten Subjektivität so unverhohlen zu exponieren, dass ihre Erfahrung einer emanzipatorischen Resonanz im Subjekt entbehrt.

Dass die künstlerische Kritik der Perspektive in der Moderne vielfältig ausfallen kann und von den jeweiligen Interessen abhängt, habe ich u. a. durch die Untersuchung der Vertikalisierung der Perspektive gezeigt. Die ausgesuchten Werke zeigen, dass die künstlerische Praxis seit Beginn des zwanzigsten Jahrhunderts eine engagierte Kritik der Perspektive leistet, die am Modell der Perspektive und an dessen epistemischen, ästhetischen und theoretischen Dimensionen interessiert ist. Es hat sich auch dabei gezeigt, 
dass die anspruchsvolle Kritik der Perspektive eine Kritik mit der Perspektive ist, auch wenn deren Unterscheidung von einer nichtanspruchsvollen Kritik an der Perspektive nicht immer trennscharf vollzogen werden kann.

Eine andere und schwierigere Frage ist jene nach den politischen Implikationen dieser Kritik. Ein großer Teil der untersuchten künstlerischen Kritik der Perspektive scheint eine tendenziell als progressiv zu bezeichnende Stoßrichtung zu verfolgen. Dies wird etwa deutlich an Claes Oldenburgs kritischer Befragung des konsumbasierten Kapitalismus und seiner spezifischen Warenästhetik der 1960er Jahre, an Walid Raads postkolonialer Befragung der Distribution und Rezeption von Kunst im Nahen Osten sowie an Rebecca Quaytmans institutionskritischem Dekonstruktivismus. Obschon diese künstlerischen Praktiken alle auf der potentiellen Reflexivität der perspektivischen Bildgestaltung beruhen, ist ihre Politizität von den jeweiligen historischen, sozialen und kulturellen Kontexten abhängig, in denen sie stattfinden. Es scheint mir, gerade auch im Hinblick auf die erläuterten Überlegungen Husserls zur Modifikation der illusionistischen Bilderscheinung, angemessen, von einer ontologischen sowie politischen Neutralität der Perspektive auszugehen.

Dass sich politischer Sinn und Bedeutung perspektivischer Phänomene wandeln kann, zeigt sich etwa an Bruce Naumans Projekt Square Depression. Das in den 1970er Jahren entworfene Projekt, betreibt eine Weise der Perspektivkritik, die zum Zeitpunkt seiner Realisierung im Jahre 2007 längst historisch geworden ist. Anders als den Projektverantwortlichen der Manifesta, scheint es mir fragwürdig, dass die Verwandlung der Perspektive in ein topografisches Feld mit Gravitationskräften im Hinblick auf eine damit assoziierte soziale Topografie eine gesellschaftliche Kritik formuliert, die im Kontext der Lebensbedingungen des 21. Jahrhunderts noch aussagekräftig ist.

Dass die politische Bedeutung der Perspektive primär von der Inanspruchnahme ihrer Kritikerinnen und Kritiker sowie deren Intentionen abhängt, zeigt sich weiter auch in ihrer theoretischen Kritik. Wie ich deutlich gemacht habe, taucht die Perspektive nicht nur als Element der marxistisch geprägten Ideologiekritik auf, sondern etwa auch in der Philosophie Martin Heideggers. Seine Auffassung ist jener der marxistischen Ideologiekritiker zunächst 
zwar verwandt, denn auch Heidegger erkennt im perspektivischen Paradigma den Agenten der Metaphysik sowie einer schlechten Subjektivität. Zudem ist Perspektivität für Heidegger auch mit den exakten bzw. experimentellen Wissenschaften sowie der modernen Technik verwandt, deren gewaltsame Welterschließung er aus philosophischen Gründen dezidiert ablehnt. Der Unterschied zwischen der progressiven und der konservativen Kritik der Perspektive liegt jedoch u.a. darin, dass sich Heidegger auf einen jenseits jeder perspektivischen Weltsicht fundierten Seins-Grund beruft, dessen ontologischer Charakter und Wahrheitsanspruch letztlich nicht verhandelbar ist. ${ }^{8}$ Folglich sagt die Problematisierung idealistischer Subjektivität zunächst wenig bis nichts über die jeweilige politische Orientierung der Kritik aus. Kritik der Perspektive ist also genauso wenig mit einer eindeutigen politischen Erklärung verbunden wie die perspektivische Raum- und Subjektkonstitution selbst.

Wollte man dennoch eine Politik der Perspektive konstatieren, würde es sich freilich um eine abstrakte Homologie handeln, deren Bedeutung abermals von der Interpretation abhängt. Die Perspektive kann etwa als Modell eines formalen Kontraktualismus begriffen werden, der politische Subjekte in formalisierter Weise adressiert. Diese Formalisierung garantiert eine prinzipielle Gleichheit aller Subjekte innerhalb eines homogenen Systems, ungeachtet ihrer partikularen Verfasstheit. Der inklusive Aspekt einer derartigen Formalisierung hat natürlich eine Kehrseite, die auf politischer Ebene von identitätspolitischen Bewegungen zu Recht kritisiert wird: Formalisierung von Subjekten macht blind für die partikularen Bedingungen ihrer jeweiligen Existenz. Dafür ermöglicht sie eine für die demokratische Politik notwendige Voraussetzung: die Bildung von Allianzen über die Grenzen partikularer Verfasstheit hinweg. Natürlich steht und fällt eine mögliche Politik der Perspektive mit der zugrunde liegenden philosophischen Konzeption von Perspektivität. Bedeutet eine Perspektive einzunehmen, einer unüberwindbaren Sicht auf die Welt verhaftet zu sein? Sind Perspektiven undurchlässig und führen sie zu einer Pluralisierung der Weltbilder, die nicht miteinander vereinbar sind? 
Fest steht, dass eine derartige Vervielfältigung und Egozentrierung von Weltanschauungen und der damit einhergehenden Identitäten nicht dem Prinzip der Linearperspektive entsprechen. Abgesehen von der bereits erläuterten Reflexivität und Selbstkritik impliziert sie erstens, dass jede wahrgenommene Perspektive auf die Welt eine unzählige Menge an alternativen Perspektiven beinhaltet, was bedeutet, dass keine Ansicht in Immanenz verhaftet bleibt, sondern immer schon transzendenten Charakter aufweist. Zweitens steht jede dieser perspektivischen Ansichten in systematischer Verbindung mit jeder anderen auch nur denkbaren Ansicht, womit ein grundsätzlicher Konnex zwischen allen Ansichten gegeben ist.

Natürlich ist der Preis für diese Transzendenz und Verbindung pluraler Ansichten ein formales, rationales und homogenes System, an dessen Universalität heute niemand mehr zu glauben vermag. Doch hier ist nicht der Ort, um die Frage aufzuwerfen, ob die Systematik der Perspektive im Kontext einer zunehmend globalisierten Welt die nötige Dynamik und Flexibilität aufweist, um der kulturellen und sozialen Heterogenität gerecht zu werden, oder ob sie einem genuin europäischen Systemdenken verpflichtet ist, dessen falsche Universalität im Kontext einer postkolonialen und postmigrantischen Welt nichts mehr zu sagen hat.

Abschließend möchte ich einige Gedanken zur besonderen Art und Weise des Fortlebens der Perspektive in der Moderne formulieren. Die Infragestellungen, die aus den Wissenschaften, den Künsten und der Philosophie an die Perspektive herangetragen werden, könnten auf den ersten Blick ihr auswegloses Ende nahelegen. Während sie den exakten Wissenschaften wie der Physiologie oder der Physik als überholt gilt, erscheint sie paradoxerweise den Künstlern und Philosophen des zwanzigsten Jahrhunderts als zu »wissenschaftlich «. ${ }^{9}$ Die vorliegende Untersuchung hat jedoch

9 Fritz Novotnys Studie aus dem Jahr 1938 mit dem bezeichnenden Titel "Cézanne und das Ende der wissenschaftlichen Perspektive« ist bezeichnender Ausdruck dieser ästhetischen Krise der Perspektive. Novotny, Cézanne und das Ende der wissenschaftlichen Perspektive, 1938. 
gezeigt, dass diese vermeintliche Pattsituation weder den Tod noch die Versteinerung der Perspektive besiegelt hat. Es ist hinreichend klar geworden, dass unzählige kritische Weiterverarbeitungen des angeblich erstarrten Schemas stattfinden. Wenn die Kunst- und Wissenschaftsgeschichte diese Fortsetzungen nicht zu greifen vermögen, dann weil sie sich in erster Linie auf historische Momente des Wandels konzentrieren, wie ihn etwa Jonathan Crary im neunzehnten Jahrhundert verortet. Zweifellos hat es diese und andere tiefgreifende Wandlungen gegeben und natürlich hatten sie massive Auswirkungen auf die Bedeutung der Perspektive. Sie haben jedoch, entgegen der populären Annahme, nicht zum Verschwinden oder zur Bedeutungslosigkeit der Perspektive geführt. Wenn ich mit der vorliegenden Untersuchung die bleibende Virulenz der Perspektive punktuell nachgezeichnet habe, eine Virulenz, die sich in Form einer engagierten Kritik der Perspektive ausdrückt, geht es mir u.a. darum zu zeigen, dass der vermeintliche historische Bruch, den man der Moderne im Hinblick auf die Perspektive zuschreibt, in Wahrheit nicht so scharf und tiefgreifend war, wie das gewisse Narrative suggerieren.

Wenn ich vorschlage, die Perspektive als Modell zu begreifen, dann also auch um damit zwei Aspekte zu bedenken, die für ihr Fortleben in der Moderne wesentlich sind: Ihr Modellcharakter impliziert erstens, dass sie Teil einer Vielzahl von Modellen ist. Während ein Narrativ von Brüchen und Paradigmenwechseln dazu tendiert, diese Pluralität auszublenden, weisen künstlerische Phänomene oftmals auf die gleichzeitige Wirkung mehrerer Modelle hin. Die besprochene Vertikalisierung der Perspektive in den Werken von Bruce Nauman, Alberto Giacometti und Marcel Duchamp haben diese Gleichzeitigkeit deutlich gemacht. Etwa Duchamps Stéréoscopie à la main zeigt auf beispielhafte Weise, wie unterschiedliche Modelle, zu denen die Perspektive, die Fotografie, die Stereoskopie und die Gravitationslehre gehören, in ein und demselben Werk zusammen treffen und gemeinsam neue Effekte erzielen. ${ }^{10}$

Dass die Kombination verschiedener und teilweise widersprüchlicher Modelle nicht nur in der künstlerischen Moderne von Bedeutung sind, zeigt sich etwa an den raumgeometrischen Farbmodellen. Der LMS-Farbraum verbindet Axiome der physikalischen Optik, der Physiologie des Auges sowie der euklidischen Geometrie zu einem praktikablen Modell der Farbmischung. 
Die Modellkonzeption der Perspektive hat weiter gezeigt, dass sie dem Gestalten, Denken und Wahrnehmen ausgezeichnete formale Dispositionen zur Verfügung stellt. Es handelt sich um Dispositionen, die einem jeweils historischen Bewusstsein gewisse Möglichkeiten bieten. Wesentlich für das Perspektivmodell ist seine Möglichkeit der Selbsttransformation und damit die Veränderung und Weiterentwicklung seiner Bedingungen. Es ist richtig, dass die Perspektive nach gewissen Regeln eine formale Ordnung erzeugt, aber es ist auch richtig, dass die Vektoren dieser Ordnung in der Lage sind, dem orthodoxen Modell widersprechende Effekte zu erzeugen. Die moderne Kritik der Perspektive ist in ihrem Objekt also bereits enthalten, sie ist ein teilweise immanenter Prozess und zeigt sich darin, dass die Perspektive kritisch auf sich selbst bezogen werden kann. Die Kritik der Perspektive fußt in erster Linie auf diesen reflexiven Kapazitäten und erst in zweiter Linie auf der dialektisch-historischen Infragestellung der modernen Konzeption malerischer Flächeneinschreibung.

Die Kritik der Perspektive generiert also unter verschiedenen historischen, politischen und intellektuellen Bedingungen der Moderne sehr unterschiedliche Effekte, die belegen, dass die Moderne keine generelle Absage an die Perspektive ist. Entgegen James Elkins' Einschätzung, dass die moderne Kritik der Perspektive diese zu einem monolithischen Block fossilisiert, erkenne ich vielmehr eine Verflüssigung derselben. In verflüssigter Form wird sie von Kunst und Theorie absorbiert und sickert gleichsam in das Denken der Moderne ein. Diese Verflüssigung macht die Perspektive zwar zu einem zunehmend unsichtbaren Objekt, doch geht mit diesem Verlust von Sichtbarkeit nicht automatisch ein Verlust ihrer Bedeutung einher. Wer noch immer am Narrativ vom Ende der Perspektive festhalten möchte, übersieht diese Virulenz und verkennt, dass die Perspektive sich selbst zur Disposition stellt. 



\section{Anhang}

\section{Abbildungsverzeichnis}

\section{Einleitung}

1 David Hockney, The Perspective Lesson, 1984, Lithographie auf Papier, $76 \times 56 \mathrm{~cm}$, London: Tate Modern, Foto: https://www.tate.org.uk/art/artworks/hockney-the-perspective-lesson-p20104 [aufgerufen 25.8.2018]

2 Cerith Wyn Evans, Think of this as a Window, 2005, Neonschrift, $13 \times$ $14,7 \times 5 \mathrm{~cm}$, Foto: Cerith Wyn Evans, ...in which something happens all over again fort the very first time. (Kat.), Musée d'Art moderne de la Ville de Paris, June 9-September 17, 2006, Berlin 2007, S. 148.

\section{Kapitel I}

1 Guido Hauck nach Panofsky, Pfeilerhalle, konstruiert gemäß der subjektiven (Kurven-)Perspektive (links) und der schematischen (Plan-) Perspektive (rechts), 1927, Foto: Erwin Panofsky, "Die Perspektive als 'symbolische Form «(1927), in: Ders., Aufsätze zu Grundfragen der Kunstwissenschaft, Berlin 1974, S. 103.

2 Jean François Niceron, Bildtafel aus La perspective curieuse ou magie artificielle des effets merveilleux, 1638, Bildtafel 25, Foto: Bibliothèque nationale de France.

3 Grundrissschemata perspektivischer Darstellungen (Dominique Laleg). A entspricht dem Augpunkt der Projektion, F entspricht der linearen Richtung des Fluchtpunkts, die Gerade AF bildet die zentrale Blickachse, $\mathrm{P}$ bildet die systemische Projektionsfläche, B die materielle Bildfläche. Die Winkeldifferenz $\alpha$ ergibt sich aus der Rotation der Projektionsfläche relativ zur Bildfläche (WP-WB), während sich die Winkeldifferenz $\beta$ aus der Rotation der zweiten Projektionsfläche relativ zur ersten Projektionsfläche ergibt (WP1-WP2).

4 Rebecca H. Quaytman, The Sun, Chapter 1, 2001, 50,8 $\times 81,2 \mathrm{cmm}$, Siebdruck, Gesso auf Holz, Foto: Rebecca H. Quaytman, Spine, Berlin 2011, S. 30 . 
5 Rebecca H. Quaytman, The Sun, Chapter 1, 2001, 50,8 $\times 81,2 \mathrm{~cm}$, Siebdruck, Gesso auf Holz, Foto: Rebecca H. Quaytman, Spine, Berlin 2011, S. 22.

\section{Kapitel II}

1 Rebecca H. Quaytman, Ausstellungsansicht Cherchez Holopherne Chapter 21, 2011, Köln: Galerie Buchholz, Foto: http://www.galeriebuchholz.de/exhibitions/r-h-quaytman/ [aufgerufen 25.8.2018]

2 Rebecca H. Quaytman, Point de Gaze - Chapter 23, 2012, Öl, Siebdruck, Gesso auf Holz, $133 \times 82,2 \mathrm{~cm}$, Brüssel: Gladstone Gallery, Foto: Dominique Laleg.

3 Rebecca H. Quaytman, Ausstellungsansicht, Point de Gaze-Chapter 23, 2012, Brüssel: Gladstone Gallery, Foto: Dominique Laleg.

4 Rebecca H. Quaytman, Point de Gaze - Chapter 23, 2012, $51 \times 51 \mathrm{~cm}$, Brüssel: Gladstone Gallery, Foto: Dominique Laleg.

5 Rebecca H. Quaytman, Cherchez Holopherne - Chapter 21, 2011, Siebdruck, Gesso auf Holz, $133 \times 82,2$ cm, Brüssel: Galerie Buchholz Köln, Foto: Rebecca H. Quaytman, Spine, Berlin 2011, S. 22.

6 Rebecca H. Quaytman, Ausstellungsansicht, Distracting Distance Chapter 16, 2010, New York: Whitney Biennial - Whitney Museum of American Art, Foto: http://www.contemporaryartdaily.com/2010/03/ whitney-biennial-r-h-quaytman/ [aufgerufen 25.8.2018].

7 Rebecca H. Quaytman, Distracting Distance - Chapter 16, 2010, Öl, Siebdruck, Gesso auf Holz, $133 \times 82,2 \mathrm{~cm}$, New York: Whitney Biennial-Whitney Museum of American Art, Foto: http://www.contemporaryartdaily. com/2010/03/whitney-biennial-r-h-quaytman/ [aufgerufen 25.8.2018].

8 Rebecca H. Quaytman, Distracting Distance - Chapter 16, 2010, Öl auf Holz, $51 \times 31,5$ mm, New York: Whitney Biennial - Whitney Museum of American Art, Foto: http://www.contemporaryartdaily.com/2010/03/ whitney-biennial-r-h-quaytman/ [aufgerufen 25.8.2018].

9 Rebecca H. Quaytman, Ausstellungsansicht, Distracting Distance Chapter 16, 2010, New York: Whitney Biennial - Whitney Museum of American Art, Foto: Parkett, 90 (2012), S. 188.

10 Rebecca H. Quaytman, Distracting Distance - Chapter 16, 2010, Siebdruck, Gesso auf Holz, $51 \times 51 \mathrm{~cm}$, New York: Whitney Biennial - Whitney Museum of American Art, Foto: http://www.contemporaryartdaily. com/2010/03/whitney-biennial-r-h-quaytman/ [aufgerufen 25.8.2018]. 


\section{Kapitel III}

1 William Turner, Schneesturm, 1842, Öl auf Leinwand, $91 \times 122 \mathrm{~cm}$, London: National Gallery, Foto: William Turner. Maler der Elemente (Kat.), Inés Richter-Musso/Ortrud Westheider (Hg.), München 2011, S. 233.

2 Edouard Manet, Die Barke, 1874, Öl auf Leinwand, 82,7 × $105 \mathrm{~cm}$, München: Bayrische Staatsgemäldesammlung, Foto: James H. Rubin, Manet. Initial M, Hand And Eye, Paris 2010, S. 295.

3 Claude Oscar Monet, Kathedrale von Rouen, 1894, Öl auf Leinwand, $100,1 \times 65,8$ cm, Washington: National Gallery, Foto: Diathek des Kunsthistorischen Seminars der Universität Basel, ID 6540.

\section{Kapitel IV}

1 Bruce Nauman, Model for Outdoor Piece: Depression, 1976, Gips, Sperrholz, 24,8 × 205,7 × 205,7 cm, Stuttgart: Staatsgalerie, Foto: Bruce Nauman, Catalogue Raisonné, Werk-Nr. 249, S. 269.

2 Bruce Nauman, Studie zu Square Depression, 1976, Bleistift auf Papier, $89 \times 114$ cm, Zürich: Kunsthaus, Foto: Ursula Perucchi-Petri (Hg.), Amerikanische Zeichnungen und Graphik. Von Sol LeWitt bis Bruce Nauman. Aus den Beständen der Graphischen Sammlung des Kunsthauses Zürich, Sammlungsheft Nr. 19, Zürich 1994, S 101.

3 Bruce Nauman, Square Depression, 2007, Beton, $2438 \times 2438$ cm, Münster: Campus der Westfälischen Wilhelms-Universität Münster, Foto: http://www.landezine.com/index.php/2009/07/square-depression/ [aufgerufen 25.8.2018].

4 Filmstill aus: Bruce Nauman, Bouncing in a Corner No. 1, 1968, EinkanalSW-Video, 60 Minuten, Chicago: Video Data Bank, Foto: https://vimeopro.com/user3539702/ubuweb/video/121815710 [aufgerufen 25.8.2018].

5 Alberto Giacometti, Circuit, 1931, Holz. 4,8 $\times 47 \times 47 \mathrm{~cm}$, Paris: Collection Henriette Gomès, Foto: https:/www.centrepompidou.fr/cpv/resource/ cGeBgp/r4bA5b7 [aufgerufen 25.8.2018].

6 Mario Bettini, Schaubild aus dem Perspektivtraktat Apiaria universae philosophiae mathematicae, 1642, III. S. 7, Foto: Bibliothèque nationale de France.

7 Marcel Duchamp, Stéréoscopie à la main, 1918-19, Stift aufGelatine-Silberprints, $6,8 \times 17,2 \mathrm{~cm}$, New York: The Museum of Modern Art, Foto: https:// giovannifredi.bandcamp.com/track/marcel-duchamp-handmade-stereopticon-slides-1918-litography-8-x-16-cm [aufgerufen 25.8.2018]. 
8 Schematische Rekonstruktion von: Marcel Duchamp, Stéréoscopie à la main, 1918-19, Stift auf Gelatine-Silberprints, 6,8 × 17,2 cm (Dominique Laleg).

9 Schaubild aus: Jean du Breuil, La Perspective pratique nécessaire à tous les peintres, Paris 1649, Foto: Artforum, 16/7 (March 1978), S. 49.

10 Marcel Duchamp, 3 Standard Stoppages, 1914, drei Fäden $(100 \mathrm{~cm})$, drei Leinwandstreifen $(13,3 \times 120 \mathrm{~cm})$, drei Glasscheiben $(18,4 \times 125,4 \times$ $0,6 \mathrm{~cm})$, drei Holzstäbe $(6,2 \times 109,2 \times 0,2 \mathrm{cmm})$, Holzkiste $(28,2 \times 129,2 \times$ 22,7 cm), New York: Museum of Modern Art, Foto: https://www.moma. org/collection/works/78990 [aufgerufen 25.8.2018].

11 Schaubild aus: Abraham Bosse, La règle de la pratique de la perspective pour le trait des figures, assiette, d'élévation, de profil et d'ombre ou d'ombrage, 1648, Paris, S. 85, Foto: Bibliothèque nationale de France.

12 Paul Klee, Möbelrücken, 1929, Aquarell, Tusche auf Papier, 31,7 × 24,5 cm, Foto: Catalogue raisonné, Bd. 5, Bern 2001, S. 312.

\section{Kapitel V}

1-6 Ausstellungsansichten: Walid Raad, Scratching on Things I Could Disavow, View from Inner to Outer Compartment, Basel: Art Basel 2014, Foto: Dominique Laleg.

7 Walid Raad, Scratching on Things I Could Disavow, View from Inner to Outer Compartment, Basel: Art Basel 2014, Foto: https://www.zerodeux. fr/guests/walid-raad-inside-information/ [aufgerufen 25.8.2018].

8 Francesco di Giorgio Martini, Intarsien im Studiolo des Herzogs von Urbino, 15. Jh., Urbino: Palazzo Ducale, Foto: Norbert Schneider, Stillleben. Realität und Symbolik der Dinge. Die Stilleben der frühen Neuzeit, Köln 1994, S. 10.

9 John Baldessari, A Bow to the Flesh: (Far to Near), 1984, Zwei SW-Fotografien, Ölfarbe, $235 \times 240 \mathrm{~cm}$, Belgien: Paolo Vedovi, Foto: John Baldessari, Catalogue Raisonné, Bd. 2, 1975-1986, Yale 2014, S. 260.

10-11 Ausstellungsansicht mit Schattenwürfen der BesucherInnen: Walid Raad, Scratching on Things I Could Disavow, View from Inner to Outer Compartment, Basel: Art Basel 2014, Foto: Dominique Laleg.

12 Claes Oldenburg, Bedroom Ensemble (Replica I), 1969, Resopal, Vinyl, Holz, Metall, Pelzimitat und Dekorationsstoff $303 \times 512 \times 648 \mathrm{~cm}$, Frankfurt am Main: Museum für Moderne Kunst, Foto: Dominique Laleg. 
13 Detail aus: Claes Oldenburg, Bedroom Ensemble (Replica I), 1969, Resopal, Vinyl, Holz, Metall, Pelzimitat und Dekorationsstoff $303 \times 512 \times$ $648 \mathrm{~cm}$, Frankfurt am Main: Museum für Moderne Kunst, Foto: Dominique Laleg.

\section{Kapitel VI}

1 Schematische Rekonstruktion des von Brunelleschi durchgeführten Experiments auf dem Domplatz von Florenz (nach Friedrich Teja Bach), Foto: Friedrich Teja Bach/Wolfgang Pichler (Hg.), Öffnungen. Zur Theorie und Geschichte der Zeichnung, München 2009, S. 65.

2 Filippo Brunelleschi, Loggia des Ospedale degli Innocenti in Florenz, Foto: Friedrich Teja Bach/Wolfgang Pichler (Hg.), Öffnungen. Zur Theorie und Geschichte der Zeichnung, München 2009, S. 78.

3 Monogrammist F.B., Melancholia, 1561, Radierung, 7,3 $\times 5 \mathrm{~cm}$, Foto: Friedrich Teja Bach/Wolfgang Pichler (Hg.), Öffnungen. Zur Theorie und Geschichte der Zeichnung, München 2009, S. 86.

4 Cindy Sherman, Untitled Film Still, 1978, SW-Fotografie, $21 \times 26 \mathrm{~cm}$, Foto: Cindy Sherman, The Complete Untitled Film Stills, München 2003, S. 51.

5 Piet Mondrian, Komposition No. IV, mit Rot, Blau, und Gelb, 1929, Öl auf Leinwand, $52 \times 51,5 \mathrm{~cm}$, Amsterdam: Stedelijk Museum, Foto: Joop M. Joosten, Piet Mondrian. Catalogue raisonné of the Work of 1911-1944, Bd. II, Leiden/Toronto 1998, S. 66.

6 Jackson Pollock, Full Fathom Five, 1947, Öl auf Leinwand mit Nägeln, Heftklammern, Knöpfen, Schlüssel, Münzen, Zigaretten, Streichhölzern, 29,2 × 76,5 cm, New York: Museum of Modern Art, Foto: Kirk Varnedoe, Jackson Pollock, (Kat.) Museum of Modern Art New York, 1.11.1998-2.2.1999, S. 221

\section{Schluss}

1 El Lissitzky, Entwurf zum Kabinett der Abstrakten, 1927/28 Hannover: Landesgalerie, Foto: http://www.getidan.de/kritik/hj_tast/75996/el-lissitzky-kabinett-der-abstrakten [25.8.2018].

2 Schaubild aus: Giacomo Barozzi da Vignola, Le due regole della prospettiva practica, Rom 1583, S. 55, Foto: Bibliothèque nationale de France. 



\section{Literaturverzeichnis}

Adorno, Theodor W.: Ästhetische Theorie, Frankfurt a. M. 1973.

Alberti, Leon Battista: »De pictura«, in: Bätschmann, Oskar und Schäublin, Christoph (Hg.): Leon Battista Alberti. Das Standbild. Die Malkunst. Grundlagen der Malerei, Darmstadt 2000, S. 194-335.

Alloa, Emmanuel: »Ist die Perspektive eine symbolische Form?«, in: Koch, Gertrud (Hg.): Perspektive. Die Spaltung der Standpunkte, München 2010, S. 13-27.

Alloa, Emmanuel: Das durchscheinende Bild, Zürich, Berlin 2011.

Bach, Friedrich Teja: »Filippo Brunelleschi und der dicke Holzschnitzer. Perspektive als anthropologisches Experiment und das Paradigma des Bildes als Einlegearbeit«, in: Ders. und Pichler, Wolfgang (Hg.): Öffnungen. Zur Theorie und Geschichte der Zeichnung, München 2009, S. 63-91.

Bach, Friedrich Teja: »Giacometti und das gefallene Auge Gottes«, in: Neue Zürcher Zeitung, 16.2.2002.

Bach, Friedrich Teja: "Giacomettis Spielbrett- und Platz-Skulpturen", in: Gassner, Hubertus und Görgen, Annabelle (Hg.): Giacometti. Die Spielfelder, Hamburger Kunsthalle, Hamburg 2013, S. 46-54. (Kat. Ausst.).

Baltrušaitis, Jurgis: Les perspectives depravées - anamorphoses ou thaumaturgus, Paris 1955.

Battcock, Gregory (Hg.): Minimal Art. A Critical Anthology, Berkeley u.a. 1995. Baudrillard, Jean: "Die Simulation«, in: Welsch, Wolfgang (Hg.): Wege aus der Moderne. Schlüsseltexte der Postmoderne-Diskussion, Weinheim 1988, S. 153-162.

Baudry, Jean-Louis: "Ideological Effects of the Basic Cinematographic Apparatus", in: Rosen, Philip (Hg.): Narrative, Apparatus, Ideology. A Film Theory Reader, New York 1986, S. 286-298.

Baudry, Jean-Louis: "Ideologische Effekte erzeugt vom Basisapparat", in: EIKON. Internationale Zeitschrift für Photographie \& Medienkunst, 5 (1993), S. 36-43.

Belting, Hans: Der Blick hinter Duchamps Tür. Kunst und Perspektive bei Duchamp, Sugimoto, Jeff Wall, Köln 2009.

Boehm Gottfried: »Ikonische Differenz«, in: Rheinsprung 11, 1 (2011), S. 170176.

Boehm, Gottfried: "Der Grund. Über das ikonische Kontinuum", in: Boehm, Gottfried und Burioni, Matteo (Hg.): Der Grund. Das Feld des Sichtbaren, München 2012, S. 29-92. 
Boehm, Gottfried: "Die Bilderfrage«, in: Ders. (Hg.), Was ist ein Bild?, München 1994, S. 325-343.

Boehm, Gottfried: »Die Wiedergewinnung der ikonischen Zeit«, in: Schweidler, Walter (Hg.): Weltbild Bildwelt. Ergebnisse und Beiträge des Internationalen Symposiums der Hermann und Marianne Straniak-Stiftung, St. Augustin 2007, S. 97-123.

Boehm, Gottfried: ״Vom Medium zum Bild«, in: Spielmann, Yvonne und Winter, Gundolf (Hg.): Bild, Medium Kunst, München 1999, S. 165-177.

Boehm, Gottfried: "Zuwachs an Sein. Hermeneutische Reflexion und bildende Kunst «, in: Klüser, Bernd (Hg.):Hans-GeorgGadamer.Die Moderne und die Grenze der Vergegenständlichung, München 1996, S. 95-125.

Boehm, Gottfried: Studien zur Perspektivität, Heidelberg 1969.

Bois, Yve-Alain u. a.: "A Conversation with Hubert Damisch«, in: October, 85 (Summer 1998), S. 3-17.

Bois, Yve-Alain: "Of Wasps and Orchids and Books and Paintings«, in: Quaytman, Rebecca: Morning. Chapter 30, München u.a. 2016.

Bourdieu, Pierre: Die männliche Herrschaft, Berlin 2012.

Brain, Robert: The Pulse of Modernism. Physiological Aesthetics in Fin-deSiècle Europe, Seattle und London 2015.

Cabanne, Pierre: Gespräche mit Marcel Duchamp, Köln 1972.

Cassirer, Ernst: Philosophie der symbolischen Formen. Die Sprache (1923), Hamburg 2010.

Chastel, André (Hg.): Leonardo da Vinci. Sämtliche Gemälde und die Schriften zur Malerei, München 1990.

Clair, Jean: "Duchamp and the Classical Perspectivists«, in: Artforum, 16/7 (März 1978), S. 40-49.

Conant, James: Friedrich Nietzsche. Perfektionismus \& Perspektivismus, Konstanz 2014.

Crary, Jonathan: Techniken des Betrachters. Sehen und Moderne im 19. Jahrhundert (1990), Dresden und Basel 1996.

Dalrymple Henderson, Linda: The Fourth Dimension and Non-Euclidean Geometry in Modern Art, Princeton 1983.

Damisch, Hubert: Der Ursprung der Perspektive (1987), Zürich 2010.

Deleuze, Gilles: Die Falte. Leibniz und der Barock (1988), Frankfurt a. M. 2000.

Déotte, Jean-Louis: Video und Cogito, Zürich, Berlin 2006

Derrida, Jacques: Husserls Weg in die Geschichte am Leitfaden der Geometrie. Ein Kommentar zur Beilage III der »Krisis« (1962), München 2001.

Duchamp, Marcel: »Propos« (1946), in: Sanoullet, Michel und Matisse, Paul (Hg.): Duchamp du signe, Suivi de notes, Paris 2008, S. 165-169. 
Edgerton, Samuel: »The Renaissance artist as a quantifier«, in: Hagen, Margaret (Hg.): The Perception of Pictures, Bd. I, New York 1980.

Edgerton, Samuel: Die Entdeckung der Perspektive, München 2002.

Egenhofer, Sebastian: "Zu einer Topik der Bildkritik«, in: Zeitschrift für Ästhetik und Allgemeine Kunstwissenschaft, 56/1 (2011), S. 143-151.

Elkins, James: Poetics of Perspective, Ithaca 1994.

Flügge, Matthias u. a. (Hg.): Raum. Orte der Kunst, Nürnberg 2007.

Foucault, Michel: Die Ordnung der Dinge (1971), Frankfurt a. M. 1974.

Foucault, Michel: Überwachen und Strafen. Die Geburt des Gefängnisses (1975), Frankfurt a. M. 1994.

Foucault, Michel: "Das Subjekt und die Macht", in: Dreyfus, Hubert und Rabinow, Paul: Michel Foucault. Jenseits von Strukturalismus und Hermeneutik, Frankfurt a. M. 1982, S. 243-264.

Fraser, Andrea: »Was ist Institutionskritik?«, in: Texte zur Kunst, 59 (2005), S. 87-89.

Fried, Michael: »Shape as Form. Frank Stella’s Irregular Polygons"(1966), in: Ders.: Art and Objecthood, Chicago und London 1998, S. 77-99.

Gadamer, Hans-Georg: Philosophische Lehrjahre (1977), Frankfurt a. M. 1995. Gadamer, Hans-Georg: Wahrheit und Methode (1960), in: Ders.: Gesammelte Werke, Bd. 3, Tübingen 1999.

Gibson, James: The Perception of the Visual World, Cambridge 1950.

Gombrich, Ernst H.: Art and Illusion (1959), Princeton 1984.

Goodman, Nelson: Sprachen der Kunst. Entwurf einer Symboltheorie (1968), Frankfurt a. M. 1997.

Goris, Wouter: »Das historische Apriori bei Husserl und Foucault. Zur philosophischen Relevanz eines Leitbegriffs der historischen Epistemologie«, Quaestio 12 (2013), 291-342.

Graham, Dan: »Subject Matter« (1969), in: Ders. und Brian Wallis: Rock My Religion, Cambridge 1993, S. 38-51.

Grave, Johannes: Architekturen des Sehens. Bauten in Bildern des Quattrocento, Paderborn 2015.

Graw, Isabelle und Geimer, Peter: Über Malerei. Eine Diskussion, Berlin 2012. Graw, Isabelle: Die Liebe zur Malerei, Zürich 2017.

Greenberg, Clement: "Avantgarde und Kitsch« (1939), in: Ders.: Die Essenz der Moderne. Ausgewählte Essays und Kritiken, Hamburg 2009, S. 29-55.

Greenberg, Clement: "Modernistische Malerei«(1960), in: Ders.:Die Essenz der Moderne. Ausgewählte Essays und Kritiken, Hamburg 2009, S 265-278.

Greenberg, Clement: "Zu einem neuen Laokoon«(1940), in: Ders.: Die Essenz der Moderne. Ausgewählte Essays und Kritiken, Hamburg 2009, S. 56-81. 
Hauck, Guido: Die subjektive Perspektive und die horizontalen Curvaturen des dorischen Styls, Stuttgart 1879.

Heidegger, Martin und Cassirer Ernst: "Davoser Disputationen zwischen Ernst Cassirer und Martin Heidegger" in: von Herrmann, FriedrichWillhelm (Hg.): Martin Heidegger. Kant und das Problem der Metaphysik, Gesamtausgabe Band 3, Frankfurt a. M. 1998, S. 27-296.

Heidegger, Martin: "Der Ursprung des Kunstwerks«, in, Ders.: Holzwege, S. 1-74.

Heidegger, Martin: "Die Frage nach der Technik«, in: Ders.: Vorträge und Aufsätze, Stuttgart 2004, S. 9-40.

Heidegger, Martin: "Die Zeit des Weltbildes" (1938), in: von Herrmann, Friedrich-Willhelm (Hg.): Gesamtausgabe, Bd. 5, Frankfurt a. M. 2003, S. 75-113.

Heidegger, Martin: Sein und Zeit (1927), Tübingen 2006.

Hinterwaldner, Inge: Das systemische Bild. Ikonizität im Rahmen computerbasierter Echtzeitsimulationen, München 2010.

Holsten, Siegmar: „Verrätseln als Methode«, in: Bruce Nauman, 1972-1981, Rijksmuseum und Staatliche Kunsthalle Baden-Baden, Amsterdam und Baden-Baden 1981, S. 33-41. (Kat. Ausst.)

Horn, Angelica: »Das Experiment der Zentralperspektive. Filippo Brunelleschi und René Descartes«, in: Niebel, Wilhelm Friedrich (Hg.): Descartes im Diskurs der Neuzeit, Frankfurt a. M. 2000, S. 9-32.

Husserl, Edmund: "Der Ursprung der Geometrie« (1936), in: Jacques Derrida: Husserls Weg in die Geschichte am Leitfaden der Geometrie, München 1987, S. 204-232.

Husserl, Edmund: Ideen zu einer reinen Phänomenologie und phänomenologischen Philosophie, Erstes Buch (1913), Tübingen 2002.

Husserl, Edmund:Ideen zu einer reinen Phänomenologie und phänomenologischen Philosophie, Zweites Buch (1913), Tübingen 1952.

Husserl, Edmund: Logische Untersuchungen. Untersuchungen zur Phänomenologie und Theorie der Erkenntnis (1901), Tübingen 1980.

Husserl, Edmund: Phantasie und Bildbewusstsein (1898-1925), Hamburg 2006.

Iversen, Margaret: »The Discourse of Perspective in the Twentieth Century. Panofsky, Damisch, Lacan«, in: Oxford Art Journal, 28/2 (2005), S. 191202.

Ivins, William: On the Rationalization of Sight, New York 1973.

Jay, Martin: "Scopic Regimes of Modernity«, in: Vision and Visuality, Seattle 1988, S. 3-27. 
Jay, Martin: Downcast Eyes. The Denigration of Vision in Twentieth-Century French Thought, Berkeley u.a. 1994.

Joselit, David: »Painting beside Itself«, in: October, 130 (2009), S. 125-134.

Judd, Donald: »In the Galleries: Claes Oldenburg«(1964), in: Ders.: Complete Writings 1959-1975, Halifax 1975, S. 133.

Kacunko, Slavko und Leach, Dawn (Hg.): Image_Problem? Medienkunst und Performance im Kontext der Bilddiskussion, Berlin 2006, S. 197-216.

Kahnweiler, Daniel Henry: "Der Kubismus«, in: Die Weissen Blätter, 3 (1916), S. 209-222.

Kant, Immanuel: Kritik der Urteilskraft (1790), Hamburg 2006.

Kant, Immanuel: Reflexionen zur Logik, Band 16 der Akademieausgabe, Berlin 1902.

Kemp, Martin: The Science of Art. Optical Themes in Western Art from Brunelleschi to Seurat, New Haven und London 1990.

Kemp, Wolfgang: "Masaccios Trinität im Kontext«, in: Marburger Jahrbuch für Kunstwissenschaft, 21 (1986), S. 44-72.

Kemp, Wolfgang: Die Räume der Maler. Zur Bilderzählung seit Giotto, München 1996.

Koepplin, Dieter, in: Bruce Nauman. Zeichnungen 1965-1986, Museum für Gegenwartskunst Basel, Basel 1986. (Kat. Ausst.).

Koschorke, Albrecht: Die Geschichte des Horizonts. Grenze und Grenzüberschreitung in literarischen Landschaftsbildern, Frankfurt a. M. 1990.

Krämer, Sybille: "Vom Trugbild zum Topos. Über fiktive Realitäten«, in: Iglhaut, Stefan u.a. (Hg.): Illusion und Simulation. Begegnung mit der Realität, Ostfildern 1995, S. 130-137.

Krauss, Rosalind: »Grids«, in: October, 9 (Summer 1979), S. 50-64.

Krauss, Rosalind: The Optical Unconscious, Cambridge 1993.

Latour, Bruno: "Visualisation and Cognition, Drawing Things Together", in: Kuklick, H. (Hg.): Knowledge and Society Studies in the Sociology of Culture Past and Present, 6 (1986), S. 1-40.

Leibniz, Gottfried Wilhelm: "Monadologie«, in: Ders.: Monadologie und andere metaphysische Schriften, Hamburg 2002, S. 110-151.

Lyotard, Jean-François: Des dispositifs pulsionnels, Paris 1973.

Lyotard, Jean-François: "Die Malerei als Libido-Dispositiv« (1972), in: Ders.: Essays zu einer affirmativen Ästhetik, Berlin 1982, S. 45-94.

Lyotard, Jean-François: »Veduta auf ein Fragment der Geschichte des Begehrens", in: Alloa, Emmanuel (Hg.): Bildtheorie aus Frankreich. Eine Anthologie, München 2011, S. 136-201. 
Lyotard, Jean-François: Die TRANSformatoren. DUCHAMP (1977), Stuttgart 1987.

Lyotard, Jean-François: Discours, figure, Paris 1974.

Mahr, Bernd: "Ein Modell des Modellseins. Ein Beitrag zur Aufklärung des Modellbegriffs«, in: Dirks, Ulrich und Knobloch, Eberhard (Hg.): Modelle, Frankfurt a. M. 2008, S. 187-218.

Manetti, Antonio: Die Novelle vom dicken Holzschnitzer (1480), Berlin 2012.

Marin, Louis: Das Opake der Malerei. Zur Repräsentation im Quattrocento (1989), Berlin und Zürich 2004.

Marx, Karl: »Einleitung zur Kritik der politischen Ökonomie«, in: Ders. und Friedrich Engels: Werke, Band 13, Berlin 1974.

Maynard, Patrick: Drawing Distinctions. The Varieties of Graphic Expression, Ithaca u. a. 2005.

Merleau-Ponty, Maurice: »Das Auge und der Geist«, in: Ders.: Das Auge und der Geist, Hamburg 1984, S. 275-318.

Merleau-Ponty, Maurice: "L'œil et l'esprit« (1961), in: Ders.: L'œil et l'esprit, Paris 1964.

Merleau-Ponty. "Das indirekte Sprechen und die Stimmen des Schweigens", in: Ders.: Das Auge und der Geist, Hamburg 1984, S. 53-116.

Mersch, Dieter: »Abbild und Zerrbild. Zur Konstruktion von Rationalität und Irrationalität in frühneuzeitlichen Darstellungsweisen«, in: Schramm, u. a. (Hg.): Theatrum Scientiarum, Bd. 2, Berlin, New York 2006, S. 22-39.

Mülder-Bach, Inka: »The point where the death comes in. Perspektivik und Blendung in James 'The Ambassadors «, in: Amerikastudien und American Studies, No. 42 (1997), S. 239-253.

Nauman, Bruce: Catalogue Raisonné, hg. von Simon, Joan u.a., Minneapolis 1994.

Nauman, Bruce: Zeichnungen 1965-1986, Museum für Gegenwartskunst Basel, Basel 1986.

Nicéron, Jean François: La perspective curieuse ou magie artificielle des effets merveilleux, Paris 1638.

Novotny, Fritz: Cézanne und das Ende der wissenschaftlichen Perspektive, Wien und München 1938.

O'Riley, Tim: Representing Illusions. Space, Narrative and the Spectator, Milton Keynes 1998.

Panofsky, Erwin: »Die Perspektive als 'symbolische Form« (1927), in: Ders.: Aufsätze zu Grundfragen der Kunstwissenschaft, Berlin 1974, S. 99-167.

Perrig, Alexander: "Masaccios `Trinità und der Sinn der Zentralperspektive«, in: Marburger Jahrbuch für Kunstgeschichte, 21 (1986), S. 11-44. 
Peyré, Yves und Toussaint, Evelyne: Duchamp à la Bibliothèque Sainte-Geneviève, Paris 2014.

Pichler, Wolfram und Neuner, Stefan: "Das umgestülpte Spiegelbild. Zur plastischen Form von Bruce Naumans Live-Taped Video Corridor«, in: Eva Ehninger u.a. (Hg.): Bruce Nauman. A Contemporary, Schaulager Münchenstein, Münchenstein 2018, S. 59-92. (Kat. Ausst.)

Pichler, Wolfram und Ubl, Ralph: Bildtheorie zur Einführung, Hamburg 2014.

Poincaré, Henri: Der Wert der Wissenschaft (1905), Heidelberg 2013.

Poincaré, Henri: Wissenschaft und Methode (1908), Berlin 2003.

Quaytman, Rebecca H.: Allegorical Decoys, Gent 2008.

Quaytman, Rebecca H.: New Work, New York 2010.

Quaytman, Rebecca H.: Spine, Berlin 2011.

Rebentisch Juliane: "Reflections and Refractions. Notes on R. H. Quaytman“, in: Quaytman, Rebecca: Morning. Chapter 30, München u.a. 2016, S. 100-136.

Rehm, Robin: »Die 'Einsicht des Blickes‘. Das Perspektivschema in der Wissenschaft des 19. Jahrhunderts und das Sich-Zeigen des Raumes«, in: Boehm, Gottfried u.a. (Hg.): Zeigen. Die Rhetorik des Sichtbaren, München 2010, S. 232-255.

Rose, Barbara: Claes Oldenburg, Museum of Modern Art New York, New York 1969. (Kat. Ausst.)

Rotman, Brian: Die Null und das Nichts. Eine Semiotik des Nullpunkts, Berlin 2000.

Saalman, Howard (Hg.): Antonio Manetti. The Life of Brunelleschi, University Park 1970.

Sauer, Cristel: »Vorwort«, in: Dokumentation 8, Halle für Internationale Neue Kunst, Zürich 1981, S. 10-13.

Schlenzkam, Jenny: »Augen auf!«, in: Monopol, 8 (2011), S. 56-65.

Schmetkamp, Susanne: »Narrative Empathie und der ethische Wert der Perspektiveinnahme«, in, Zeitschrift für Ästhetik und Allgemeine Kunstwissenschaft, 63/1 (2019), 73-92.

Schröter, Jens: "Das transplane Bild und der Pictorial Turn. Zu Marcel Duchamps Medienästhetik", in: Schweizer, Yvonne u.a. (Hg.): Raum. Perspektive. Medium, Bd. II, Tübingen 2010.

Scolari, Massimo: Oblique Drawing. A History of Anti-Perspective, Cambridge und London, 2012.

Shiff, Richard: "Judd through Oldenburg«, in: Tate Papers, No. 2 (Autumn 2004) https://www.tate.org.uk/research/publications/tate-papers/02/ judd-through-oldenburg (aufgerufen: 25.8.2018). 
Simon, Gérard: Archéologie de la vision. L'optique. le corps. la peinture, Paris 2003.

Simon, Gérard: Le Regard, l'être et l'apparance dans l'optique de l'Antiquité, Paris 1988.

Snyder, Joel: »Picturing Vision«, in: Critical Inquiry, 6/3 (Spring 1980), S. 499526.

Stillman Steel: »Interview with Rebecca H. Quaytman«, in: Art in America, 6 (2010), S. 87-95.

Thürlemann, Felix: „Gegenräume für Doppelgänger. Bruce Naumans Erfahrungsarchitekturen und ihre Rezipienten", in: Kemp, Wolfgang (Hg.): Zeitgenössische Kunst und ihre Betrachter, Köln 1996, S. 111-120.

Tugendhat, Ernst: Der Wahrheitsbegriff bei Husserl und Heidegger, Berlin 1967.

Valaouris, Michalis: Perspektive in der Fotografie. Studien zur Naturalisierung des Kamerabildes, Berlin 2018.

Villinger, Rahel: "Form und Mimesis. Elemente frühromantischer Kunsttheorie bei Husserl, Benjamin und Adorno«, in: Zeitschrift für Ästhetik und Allgemeine Kunstwissenschaft, 60/2 (2015), S. 277-298.

von Schöning, Antonia: »Archäologie der Zukunft. Zum Entwurf von Geschichtlichkeit in Walid Raads Scratching on Things I Could Disavow A History of Art in the Arab World «, in: Kernbauer, Eva (Hg.): Kunstgeschichtlichkeit. Historizität und Anachronie in der Gegenwartskunst, München 2015, S. 99-114.

Waldenfels, Bernhard: "Das Rätsel der Sichtbarkeit. Kunstphänomenologische Betrachtungen im Hinblick auf den Status moderner Malerei«, in: Ders.: Der Stachel des Fremden, Frankfurt a. M. 1990, S. 204-224.

Wiesing, Lambert: "Phänomenologie des Bildes nach Edmund Husserl und Jean-Paul Sartre«, in: Ders.: Phänomene im Bild, München 2000, S. 43-60.

Wiesing, Lambert: Sehen lassen. Die Praxis des Zeigens, Berlin 2013.

Wood, Christopher: »The Origin of Perspective by Hubert Damisch; Le Jugement de Pâris by Hubert Damisch", in: The Art Bulletin, 77/4 (Dezember 1995), S. 677-682. 

